University of Louisville

ThinkIR: The University of Louisville's Institutional Repository

Electronic Theses and Dissertations

\title{
$5-2011$
}

\section{Historiography, disciplinarity, and the future(s) of composition.}

Lisa R. Arnold

University of Louisville

Follow this and additional works at: https://ir.library.louisville.edu/etd

\section{Recommended Citation}

Arnold, Lisa R., "Historiography, disciplinarity, and the future(s) of composition." (2011). Electronic Theses and Dissertations. Paper 48.

https://doi.org/10.18297/etd/48

This Doctoral Dissertation is brought to you for free and open access by ThinkIR: The University of Louisville's Institutional Repository. It has been accepted for inclusion in Electronic Theses and Dissertations by an authorized administrator of ThinkIR: The University of Louisville's Institutional Repository. This title appears here courtesy of the author, who has retained all other copyrights. For more information, please contact thinkir@louisville.edu. 


\title{
HISTORIOGRAPHY, DISCIPLINARITY, AND THE FUTURE(S) OF COMPOSITION
}

\author{
By \\ Lisa R. Arnold \\ Bachelor of Arts, Saint Louis University, 1997 \\ Master of Fine Arts, George Mason University, 2005
}

\begin{abstract}
A Dissertation
Submitted to the Faculty of the

College of Arts and Sciences of the University of Louisville in Partial Fulfillment of the Requirements

for the Degree of
\end{abstract}

Doctor of Philosophy

Department of English

University of Louisville

Louisville, Kentucky

May 2011 
Copyright 2011 Lisa R. Arnold

All rights reserved 


\title{
HISTORIOGRAPHY, DISCIPLINARITY, AND THE FUTURE(S) OF COMPOSITION
}

\author{
By
}

\author{
Lisa R. Arnold \\ Bachelor of Arts, Saint Louis University, 1997 \\ Master of Fine Arts, George Mason University, 2005 \\ A Dissertation Approved on
}

April 11, 2011

By the following Dissertation Committee:

Karen Kopelson, Dissertation Director

Carol Mattingly

Bruce Horner

Susan Ryan

John Schilb 


\section{DEDICATION}

To my Aunt Mary, with love. 


\section{ACKNOWLEDGEMENTS}

I would like to thank my advisor, mentor, and friend, Karen Kopelson, for valuing not only this project but my potential as a scholar. Your support and critique pushes me to pursue this life. And to the other members of my committee - Carol Mattingly, Bruce Horner, Susan Ryan, and John Schilb - thank you for reading my work closely enough to challenge my habits of thinking and writing. To Samantha NeCamp and Vanessa Kraemer Sohan, my best scholar-friends, for reading every word of this project and so much more.

My gratitude extends to the other good friends and burgeoning scholars I've come to know and love these last few years: Nancy Bou Ayyash, Carrie Kilfoil, Brice Nordquist, and Caroline Wilkinson. And to Lisa Ampleman, Christina Campbell, Kimberly Cherry, Michelle Finley, Katie Giles, Abby Nordquist, Sarah Oppland, and Lisa Pepper - for giving me something other than school to talk about.

Finally, to my family: Mom, Dad, Andrew, Jason and Mark. Many thanks for always believing in me. 


\begin{abstract}
HISTORIOGRAPHY, DISCIPLINARITY, AND THE FUTURE(S)

OF COMPOSITION

Lisa R. Arnold
\end{abstract}

April 11, 2011

This dissertation analyzes and critiques the historiography of more than 150 texts documenting the history of writing instruction in the United States. In examining the rhetoric of disciplinary historiography, I demonstrate how the historicization of composition has worked, rhetorically and politically, to highlight and complicate some of the central concerns of the field while also raising questions about and prompting proposals for the future of the discipline. To carry out this analysis, I engage in a process I call metahistorical critique, with which I trace three disciplinary narratives: the role of first-year composition, the discipline's legacy of current-traditional rhetoric and pedagogy, and composition's relationship to other disciplines. I argue that metahistorical critique can reveal many of the discipline's primary values and practices, which today create important possibilities and limitations in the ways composition scholars construct the past, present, and future of the field.

I introduce the dissertation by laying the theoretical groundwork for my reading of disciplinary historiography using Michel Foucault, Hayden White, and Dominick LaCapra. In Chapter 2, I focus on how historians have used current-traditional rhetoric and pedagogy (CTRP) problematically as a trope, neglecting actual historical phenomena. 
In Chapter 3, I argue that composition historians' persistent focus on first-year composition (FYC) and the debate surrounding its viability as a required academic course allows the discipline tends to think of and define "work," "writing," and "writing instruction" as a problematically abstract, monolingual, institutionalized, pedagogically produced and reader-oriented practice relevant only to Americans. Chapter 4 explores how the relationship between composition and other disciplines has (or has not) been historicized in order to argue that the discipline should be rehistoricized as an interdiscipline. I conclude that if we are to allow for other questions and narratives about the discipline to emerge, and if we intend to promote ethical ways of engaging with teachers, students, and the world, we must continually interrogate the prevailing narratives that shape the field, as well as our habits of thinking, reading, and writing about the history of writing instruction in the United States and elsewhere. 


\section{TABLE OF CONTENTS}

\section{PAGE}

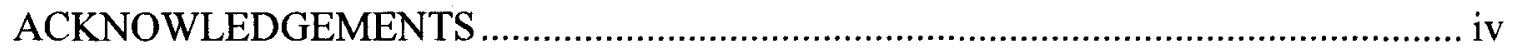

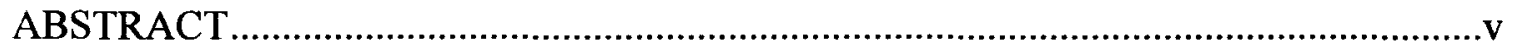

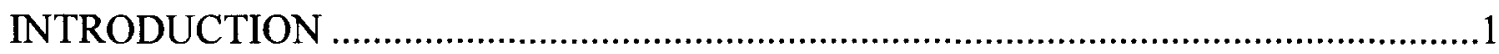

Rationale: Historiography, Disciplinarity, and the Future(s) of Composition ........4

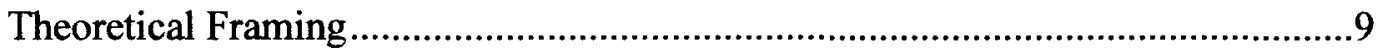

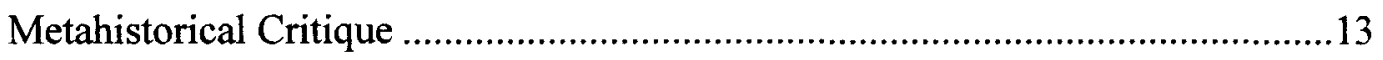

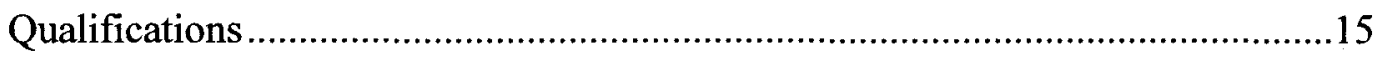

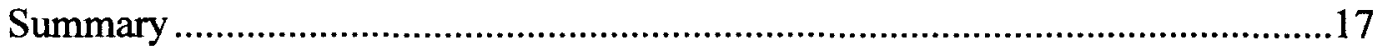

CHAPTER 1: HISTORIOGRAPHY, DISCIPLINARITY, AND METAHISTORICAL

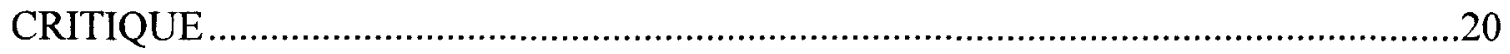

Historiography's Effect(s) on Our Perceptions of the Past, Present, and

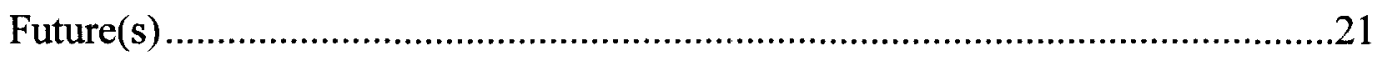

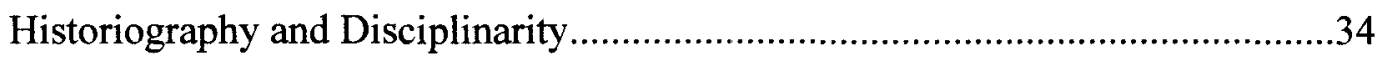

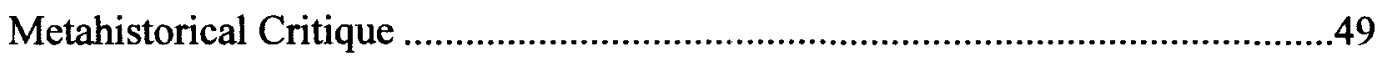

Fixing the Field: An Overview of Terms and Categories....................................66

CHAPTER 2: THE RHETORIC OF CURRENT-TRADITIONAL RHETORIC .............70

From Definition to Narrative: Richard Young and Composition Historiography.75

Rhetoric's "Decline and Fall" and CTRP .........................................................91 
Rhetoric's "Fall" and the "Rise" of Professionalism .......................................108

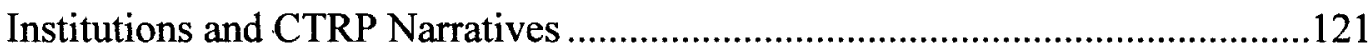

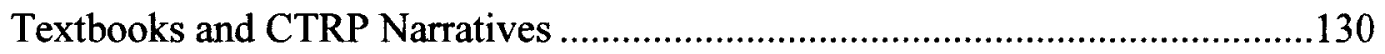

Teachers, Students, and Prevailing Narratives of CTRP ...............................141

Alternative Representations: Teachers, Students, and Competing Narratives of

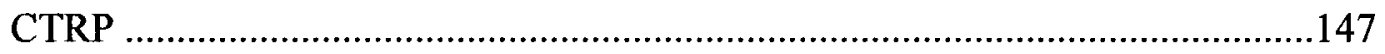

Conclusion: Releasing Ourselves from the Pattern ..........................................155

CHAPTER 3: THE QUESTION OF FIRST-YEAR COMPOSITION ........................157

Harvard $=$ FYC $=$ Composition: An Equation that Doesn't Add Up.................159

Historiography and the "Abolition" Debate ..................................................163

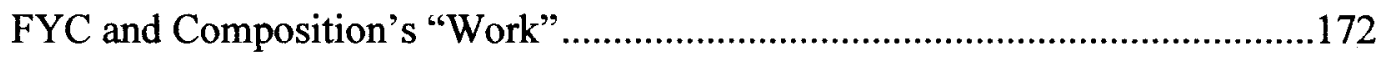

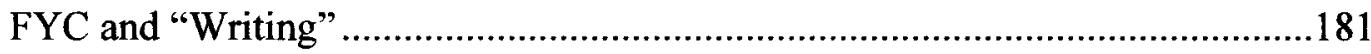

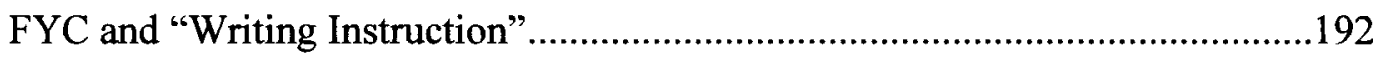

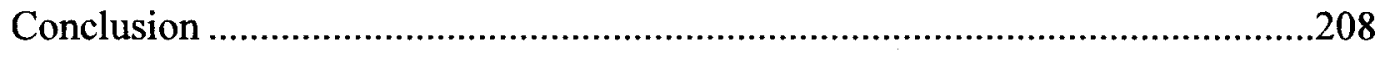

CHAPTER 4: COMPOSITION AS A(N) (INTER)DISCIPLINE .............................209

Rhetoric's "Decline and Fall" and Composition's "Split" from Literature:

Prevailing Narratives of Antagonism......................................................215

Composition, Literature, Rhetoric: Prevailing Narratives of Unity ..................227

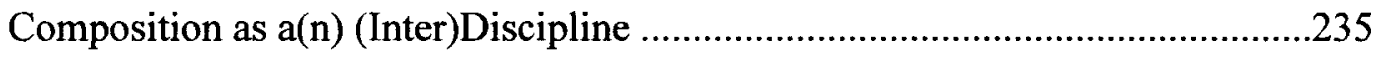

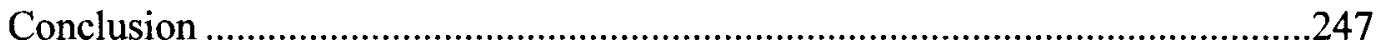

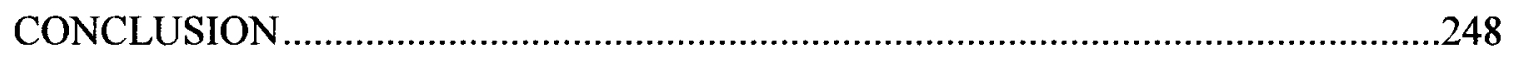

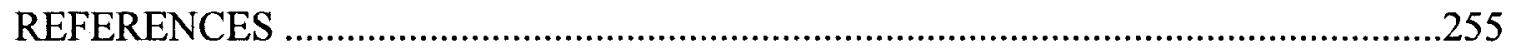

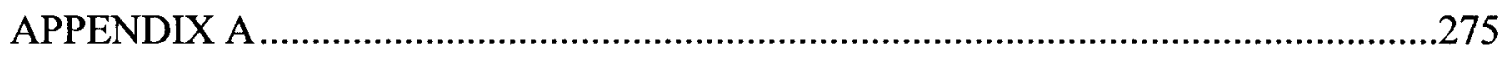




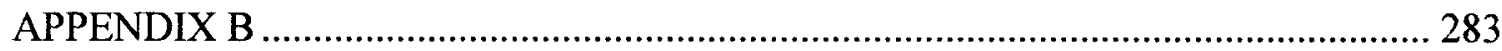

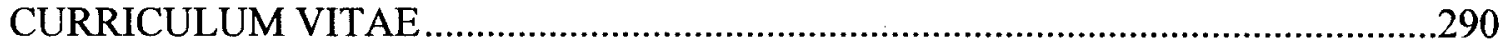




\section{INTRODUCTION}

The history of writing practices and pedagogy in the United States has become a central point of research and contention for rhetoric and composition over the last thirty years, as histories of the discipline constitute an increasingly prevalent part of the discipline's scholarship. This historicization has worked, rhetorically and politically, not only to highlight and complicate some of the central concerns of the field, but also to raise questions about, and prompt proposals for, the future of the discipline. Our histories and historiographic practices, therefore, are tied closely with the evolution of the contemporary discipline.

Since Albert Kitzhaber's 1953 dissertation, Rhetoric in American Colleges (published as a book in 1990), historians of rhetoric and composition have used their accounts of composition's past to deal with some of the central questions that trouble the field, including best teaching practices, especially those that relate to or work against what compositionists call "current-traditional rhetoric and pedagogy" (CTRP), the role of first-year composition (FYC) within the discipline and its legacy as a "service" course, and composition's ties to other disciplines such as rhetoric and literature. Some historians have also addressed the question of whether, and how, the discipline belongs in the academy: For example, in her provocative disciplinary history, Composition in the University, Sharon Crowley addresses this question by tracing composition's history to 
Harvard's introductory composition course, English A, in order to expose how the discipline's roots in CTRP have been maintained even though composition currently positions itself as a discipline that professes process (and post-process) pedagogy.

Many historians, just like other scholars in the discipline, disagree about the role that FYC should play in the discipline: Some, such as Berlin and Joseph Harris, have used their historical narratives to argue that FYC constitutes the heart of the discipline. Others, including Crowley and David Russell, argue that their historical research proves that the discipline's focus on FYC has either "credit[ed] freshman English with a larger or more cohesive effect than it has ever had" (Russell 32) or altogether debilitated the field: “... the universal requirement in introductory composition, which is the institutional manifestation of composition's service ethic, has kept the traditional goals of disciplinarity - the pursuit of knowledge and the professional advancement of practitioners - beyond the reach of composition studies until very recently" (Crowley 253).

Finally, many historians have debated how the discipline's relationship to other fields - including rhetoric, literature, communications, education, literacy and linguistics - should be understood and defined. In his seminal historical work, CompositionRhetoric, for example, Robert Connors laments the "decline and fall" of rhetorical instruction in the modern university and links this fall to composition's low status in the university: According to Connors, rhetoric courses were "sought by students" prior to the Civil War, but by the turn of the century, such courses were instead "despised and sneered at"; and while professors of rhetoric once occupied the "empyrean of named chairs," they became, over time, "oppressed, ill-used, and secretly despised" (171-72). 
Along different but related lines, Susan Miller hopes to demonstrate in Textual Carnivals that composition's disciplinary ties to literature have kept it in a problematically subservient position; she explains that "the political and social agendas that have placed native belletristic literature ... in the 'center' of education have worked against language instruction devoted to writing" (35).

In my dissertation, I analyze the prevailing and competing narratives that have emerged as a result of historians' responses to the questions described above: How should the discipline's legacy of CTRP (if it is to be interpreted as a legacy at all) be understood, especially in relation to present concerns? What role should FYC have within the discipline? And finally, how should composition's relationships be defined, and what are the effects of this relationship on composition's disciplinarity? These questions reveal larger disciplinary concerns that can be usefully illuminated, I argue, through a tracing of the resultant narratives in and through a variety of disciplinary histories. ${ }^{1}$ Of central importance to this project is my contention that a meta-analysis of composition's historiography, a process of reading I call metahistorical critique, reveals many of the primary values, beliefs, and practices that have shaped the discipline, which today create important possibilities and limitations in the ways composition scholars construct the past, present, and future of the field. Because the narratives I analyze tend to dominate disciplinary discourse, I argue throughout this dissertation that metahistorical critique works against our regular habits of thinking, reading, and writing about the past, resulting in a disruption of our usual practices and providing opportunities for other questions and narratives about the discipline to emerge.

\footnotetext{
'I define disciplinary histories as those texts that examine the history of college writing instruction and/or literacy practices - primarily situated in the U.S. - since the nineteenth century. To limit my focus, I am not studying histories of rhetoric or oral rhetorical instruction.
} 
In this introduction, I define and describe in more detail the exigence for the project, its theoretical framing, the process of metahistorical critique, and the central questions that drive my research. I also provide an overview of the structure for the dissertation with brief chapter summaries and the conclusions I make.

\section{Rationale: Historiography, Disciplinarity, and the Future(s) of Composition}

According to some scholars, rhetoric and composition's tendency toward selfhistoricization and critique works against its ability to make new knowledge, which works, in turn, against its future as a discipline. In "Sp(l)itting Images," for example, Karen Kopelson echoes other scholars' concerns (see John Mucklebauer, Kurt Spellmeyer, and Jan Swearingen) when she argues that the discipline's ongoing reflection and debate about its own disciplinary status - a central concern taken up by many, including disciplinary historians - has produced an obtrusive anxiety about how the discipline should be defined, which, she claims, "comes at the expense of taking up other critical concerns and of making other, more innovative and far-reaching forms of knowledge" (775).

In the introduction to Disciplining English, David Shumway and Craig Dionne, who use a Foucauldian framework to articulate how academic disciplines work, might appear to agree with Kopelson's concerns when they explain that disciplinary scholarship "produce[s] [knowledge that] tends toward dispersion rather than unity" (6). But Kopelson's hope that composition will move away from its concern about its disciplinarity in order to produce "more innovative and far-reaching forms of knowledge" seems unlikely given Shumway and Dionne's description of disciplinary structures, which, they argue, ultimately revolve around "problems or questions that are in some 
way self-reproducing" (6). In other words, if one of rhetoric and composition's central questions is whether, and how, the field can be defined as a discipline, then Shumway and Dionne's explanation of disciplinarity suggests that it is unlikely that rhetoric and composition will cease coming back to questions about its own disciplinarity. Thus, composition's disciplinary histories, which reveal and revolve around these primary concerns, can be understood as texts that occupy a central role in the formation and evolution of the discipline.

Disciplinary histories are also significant texts in the sense that they tend to be uniquely self-reflective about the discipline. Although she is writing about English literary studies and not rhetoric and composition, Jessica Yood explains the role of such self-reflexivity in disciplinary formation in "Writing in the Disciplines." In this article, Yood identifies what she describes as a "new genre" of disciplinary discourse in literary studies that has emerged from the late-nineteenth century to the present (see Gerald Graff, Richard Ohmann, and Robert Scholes, among others); this genre, Yood argues, promotes self-reflection and self-conscious critique, "making disciplinary meaning in the fluid practices of teaching and writing" (537). Not only does Yood's account indicate that self-reflective disciplinary critique occurs outside of composition, but, in presenting this kind of writing as a new academic genre, she suggests that it provides a way for valuing traditionally undervalued or under-represented ways of knowing in literary studies (and presumably in the university at large), knowledge concerned with pedagogy and lived experience (537).

Historians within rhetoric and composition have argued convincingly, too, that their work serves an important role in the evolution and delineation of academic 
disciplines. Maureen Daly Goggin notes in Authoring a Discipline, for example, that "historical accounts themselves both reflect and help foster the vitality of a disciplinary community insofar as they are contingent on a group's interests. In other words, history may both indicate and help sustain those interests" (xiv). Likewise, in Fencing with Words, Robin Varnum argues that the "new conception" of composition history afforded by her account of the Amherst composition program "give[s] those of us who teach writing ... new ways of conceptualizing our professional identity" (33). Ultimately, disciplinary historicization and self-scrutiny, which some may describe as a compulsive or navel-gazing practice, is neither unique to composition nor necessarily problematic.

It is because of historiography's role in shaping disciplinary self-perception that my project aims not only to identify the primary disciplinary narratives found in our histories, as well as their circulation over time and across texts, but to also explore the possible reasons for, and consequences of, these trends. ${ }^{2}$ Histories of composition are particularly important for this study in at least two ways: First, histories can provide compositionists ways to better understand how power works over and across time, especially as structures of power have influenced beliefs and practices about literacy. In "History in the Spaces Left," for example, Jacqueline Jones Royster and Jean C. Williams point out that even those histories composed with the intention of providing alternatives to the dominant perspectives forwarded by much composition scholarship continue to obscure certain narratives and silence already marginalized voices. Taking aim specifically at the way students are represented, the equation of race with basic writing,

\footnotetext{
${ }^{2}$ Although my focus throughout this dissertation remains on histories of composition, I eventually hope to study the circulation and consequences of disciplinary narratives as they are found also in proposals for the future of the discipline. I see proposals for the future of the discipline as important texts that can add to the conclusions I make in this dissertation because they highlight those disciplinary narratives (and elements of those narratives) that hold the most power over the way we think, read, and write (about) the discipline.
} 
and the way the African American presence in composition's history has largely been ignored, Royster and Williams argue that "in officialized narratives, the viewpoints of African Americans are typically invisible, or misrepresented, or dealt with either prescriptively, referentially, or by other techniques that in effect circumscribe their participation and achievements" (579).

Second, histories can help scholars better understand the origins of our contemporary disciplinary values, beliefs, and practices, leading to future, hopefully fruitful, critique and revision if these values, beliefs, and practices prove problematic. In "English Only and U.S. College Composition," Bruce Horner and John Trimbur challenge basic premises underlying the formation of college composition in the U.S., a formation that they argue worked to support a monolingual tradition and future in the teaching of writing. In critically examining this premise, Horner and Trimbur strive to "examine the history of the inevitable and to identify the cultural logics that produce it" (596). Such rhetorical work is aligned with my own goals for this project and is especially important in that it offers, as they argue, "an alternative way of thinking about composition programs, the language of our students, and our own language practices" (597).

In spite of the connection between history-writing and disciplinarity in rhetoric and composition - and although there have been multiple forums concerning the problem of historiography in rhetoric (see "Historiography... I," "Historiography ... II," and “Octalog" and "Octalog II") - disciplinary historians have rarely explored the rhetorical implications of historiography in explicit or theoretical ways while also successfully applying these explorations to their own histories. For example, although both Connors 
and Berlin theorize historiography explicitly in special issues of Pre/Text and Rhetoric Review devoted to the writing of history (see "Historiography... I," "Historiography ... II," and "Octalog" and "Octalog II"), their own histories do not reflect the theory they espouse. Connors, for example, argues that historians, when composing history, must ask: "How ... has the culture created rhetoric, and how has rhetoric then recreated the culture? Composition history cannot exist in a narrow valley of a 'history of ideas'.... Meaningful historical writing must teach us what people in the past have wanted from literacy so that we may come to understand what we want" ("Octalog" 7). Here, Connors notes an important distinction between composition and rhetorical history, arguing that historians should be able to look beyond published texts to understand the human actors and actions behind them. Connors' own history, however, is based primarily on textbook evidence that tends to assume a one-to-one correspondence between actual pedagogical practice and textbook discourse (a problem I elaborate in more detail in Chapter 2).

Several composition historians have, however, been more reflective than Berlin and Connors about the rhetoricity of their endeavors. ${ }^{3}$ In an essay that argues for a cultural-historical approach to historiography, for example, Susan Miller contends that the legitimizing role of many of composition's histories have posed problems in that they have limited historians' focus to individual actions and events, rather than acknowledging the necessary interrelation among culture, disciplinarity, and history ("Composition" 32). And composition histories sometimes reveal historians' implicit awareness of the

\footnotetext{
"When I use the word "rhetoricity," I mean that the way history is written carries rhetorical effect(s). Specifically, I draw on John Schilb's discussion in "The History of Rhetoric and the Rhetoric of History," in which he builds on Hayden White's and Dominick LaCapra's work, to explain: "While more and more scholars in the discipline of history itself demonstrate awareness that one must distinguish between 'history' as an absent referent and 'history' as the conjecture and representation for that referent, I don't find in recent histories of rhetoric clear acknowledgement that the authors are composing discourse" (238).
} 
connections between historiography and disciplinarity; this becomes particularly obvious when dominant narratives are explicitly articulated, challenged, or disrupted. For example, in arguing that other forms of evidence should be considered in composition's histories (and in writing his own revisionary history of A.S. Hill), Gerald Nelms emphasizes what he calls the "tensed unity" in historiography that occurs between historical "fact" and historiographic "fiction" (377). Likewise, in her analysis of an oftignored NCTE address, Margaret Strain argues for "an alternative way of reading" historical and archival documents that acknowledges (via Gadamer) the inevitable "intertextuality" of documents - the "dialectical interplay that permits the text to give evidence to others which have been omitted, left traces, or presented contradictions to the one in question" (220).

In spite of these valuable moments of metahistorical awareness, however, scholars in rhetoric and composition have not explicitly or fully answered John Schilb's call for disciplinary historians to "examine their discourse with greater self-consciousness, consider alternatives to it, let their text be a dialogue with other such possibilities, and, in general, let themselves enter into a dialogue with the metahistorical reflections to be found now in the discipline of history" (249). I see my project as answering this call, in that it aims to sysetmatically analyze composition's historiography to expose its disciplinary effects and implications.

\section{Theoretical Framing}

Theories of historiography in and outside of rhetoric (and/or composition), as well as disciplinary histories themselves, have proved foundational in my ability to organize, contextualize, and substantiate my understanding of composition's histories. Just as 
Schilb grounds his proposal in "The Rhetoric of History" upon an understanding of how historians such as Hayden White and Dominick LaCapra have theorized historiography, I too ground much of my theoretical framing for this project through critical historians' historiographic theory. ${ }^{4}$ For example, both LaCapra and Michel Foucault offer useful ways of thinking about historiography as rhetorical practice. Specifically, in Archaeology of Knowledge, Foucault focuses on how the "rules of formation" for disciplinary discourse work to delimit and determine the claims that can be made. When we ignore the discursive field as a context for the production of discourse, it becomes easy to assume that some kind of historical "truth" already exists and is merely waiting to be discovered; but by acknowledging the way our options for making claims have already been determined by the discursive context in which we write, Foucault argues, we can more critically understand, value, and acknowledge the role that "chance, discontinuity, and materiality" play in the processes of history and history-writing (231).

Likewise, LaCapra argues in "Intellectual History and Defining the Postmodern" that when it comes to reading and writing (about) intellectual histories, it is easy to underemphasize or reduce their complexity while also devaluing the relationship between text and context; he contends that intellectual histories contain both documentary and performative elements. Instead of understanding history-writing as an attempt to "close" history, therefore, LaCapra insists that historiography must be understood as a dialectical process that "comes to terms" with the past and acknowledges its inherent complexity and contradiction (see "Writing"). In Chapter 1, I discuss the applications of White's,

\footnotetext{
${ }^{4}$ By "critical historian," I mean those scholars working within (and sometimes outside of) the field of history who have emphasized (oftentimes using poststructuralist and postmodern frameworks) the politics of language and representation in their and others' history work.
} 
Foucault's, and LaCapra's theories of historiography to the process of metahistorical critique.

Most of the extended theorization of historiography in rhetoric and composition has occurred in relation to debates about rhetorical history/ies and tradition(s), and although this scholarship is not always easily applicable to composition histories, it has helped me categorize and contextualize histories according to their various rhetorical purposes. Among the debates published in Pre/Text, Rhetoric Review, Victor Vitanza's Writing Histories of Rhetoric, and Graff et al's The Viability of the Rhetorical Tradition, several strands of historiographic theory applicable to already-existing composition histories can be identified: First, Graff and Leff have identified "recovery" and "rereading" as two major strands of historiography existing in rhetoric. Recovery histories, which might be defined as those that look to the past to exhume previously ignored individuals and event and include Royster and Williams' "History in the Spaces Left" and Neal Lerner's "The Institutionalization of Required English," as well as Varnum's Fencing with Words and David Gold's Rhetoric in the Margins. Likewise, composition's historians have conducted compelling "rereadings" of events, texts, or individuals important to our histories in order to provide alternative explanations that question and challenge our original assumptions and current beliefs. Patricia Harkin's essay, "Child's Ballads," provides multiple alternative readings of James Francis Child, who is often credited as the founder of English (literature) studies to illustrate how disciplinary narratives can differ based on the motivations of readers and writers located in competing disciplinary areas (in this case, composition and literature). Charles Paine offers a compelling rereading of the discipline's narratives about Edward T. Channing 
and A.S. Hill in Rhetoric as Immunity, and in "The Dartmouth Conference and the Geohistory of the Native Speaker," John Trimbur revisits the accepted history of the Dartmouth conference by re-examining two documents that have been overlooked in other histories (see Harris, "After Dartmouth").

Yet another strand of composition historiography has emerged more recently and is explicitly theorized in terms of rhetorical history by Theresa Enos, Roxanne Mountford, and Janet Atwill in special issues of Rhetoric Review ("Octalog" and "Octalog II"), and can be seen in histories that take account of the relationship between composition and other disciplines, a strand I would call inter- or trans-disciplinary research. Kathryn Fitzgerald ("From Disciplining") and Arthur Applebee both trace composition's origins in relation to secondary education; David Russell emphasizes writing pedagogy across the disciplines; Donna Strickland understands composition not in terms of its emergence as an individual course, but in terms of the emergence and growth of writing programs; Horner and Trimbur argue that the relationship between composition and modern languages in the $19^{\text {th }}$ century is important in that it can help us recognize and challenge our assumptions of monolingualism in composition; Nystrand et al. trace composition according to its relationship to linguistics and literary study; and in "The 1963 Composition Revolution Will Not Be Televised," Jeff Rice considers how our understanding of the contemporary discipline would change if composition had not ignored a parallel "revolution" in media studies.

Although I do not use these categories to describe the histories I examine in this study, these discussions have helped me contextualize the motivation for and purposes of individual histories, which adds to my analysis of prevailing and competing disciplinary 
narratives in historical scholarship. I outline my categorization of the histories that comprise my study in Appendix A, and in Appendix B, I illustrate how these histories have been received and used over time.

\section{Metahistorical Critique}

In order to identify, isolate, and analyze the three prevailing disciplinary narratives for this study - current-traditional rhetoric and pedagogy (CTRP), first-year composition (FYC), and composition's (inter)disciplinarity - I use a method of rhetorical reading that I call metahistorical critique, a method I define more elaborately in Chapter 1. In my preliminary reading of the most-often cited disciplinary histories in composition, such as those written by Berlin, Connors, Crowley, and Susan Miller, I traced those themes or questions that grounded each historian's desire to historicize, and I identified prevailing narratives when several historians seemed to share common concerns: Connors

and Crowley, for example, both link the contemporary discipline to the loss of a classical rhetorical tradition; Miller, Crowley, and Connors are all concerned about how composition's ties to literature have kept it from achieving full disciplinarity; Berlin and Crowley both concern themselves with the location of FYC within the discipline (Berlin sees FYC as central, whereas Crowley wants to abolish it); and Connors, Crowley, and Miller disagree about the discipline's legacy of CTRP.

As I read beyond these central texts and navigated other macro- and microhistories (see Chapter 1 for my definition of these terms), I continued to trace these narratives as they emerged across texts, paying particular attention as I read to how these narratives were used: Did the narratives form basic premises for a scholar's argument or were they presented as a foundation for critique? Were the narratives repeated without 
question or did they evolve in significant ways over time? I also took note of each historian's stated rhetorical goals and used these descriptions to frame my understanding of each history's intervention in larger disciplinary contexts.

Metahistorical critique is particularly useful for this project because it not only illuminates some of our field's primary concerns, but it also exposes those habits of mind and practice in which composition scholars have been trained to engage. This kind of analysis, while not producing new history, participates in the revisionist historical tradition in several ways: First, metahistorical critique analyzes historical narratives in relation to one another, which foregrounds the assumptions that underlie our field's seeming "common sense" and marks gaps in our research and understanding of the discipline. Second, metahistorical critique analyzes how history is used in narratives about our present and future, which can help us see more clearly whether, and how, those narratives make claims based on differing interpretations of history. Defined in this way, metahistorical critique works to disrupt traditional conceptions of time and progress, which allows for new or revised understandings of the uses of history in composition; that is, we can understand histories as building upon and complicating one another opening up, rather than limiting, the possibilities for our research, practice(s), and ways of thinking in the future. Perhaps more importantly, however, metahistorical critique also encourages the destabilization of prevailing historical narratives; in other words, when and as prevailing narratives become visible through the process of metahistorical critique, this visibility allows for scholars to temporarily isolate, critically analyze, and revise those narratives so that they can no longer be taken for granted as the presumably unquestionable "common sense" of the field. This destabilization, therefore, not only 
makes way for alternative narratives of and about writing instruction, but it also legitimizes other ways of understanding and participating in the discipline. Because of its centrality to my argument, I develop my definition of metahistorical critique further in Chapter 1.

\section{Qualifications}

Before I continue, I want to offer a few qualifications about my project - about its treatment of time or chronology, about what I see as the purpose(s) of history, and about the inherent limitations of the study. One of the most important elements of my study has to do with time: Throughout the chapters that follow, I provide publication dates of the histories I analyze upon first mention, and I remind my readers of publication chronology whenever possible. Much of my study is grounded on the premise that the narratives composed by historians in the 1980s (and occasionally earlier) form the foundation for later narratives about composition histories. Because our earlier histories are more likely to have influenced the construction of disciplinary narratives in later histories, my critique often moves in a seemingly logical progression over time, beginning with an earlier and ostensibly more influential history to more recently published histories.

But I offer a caveat in this regard: Although my critique most often challenges those narratives established by earlier histories and holds up recent scholarship as exemplifying historiographic strategies that effectively challenge problematic narratives, I want to stress that my approach is not necessarily chronological: First, composition's foundational histories are not to be disqualified on account of a more recently published history that offers a compelling challenge. Instead, I call attention to competing narratives because they provoke new questions about the past and unsettle what we thought was 
known; the evidence does not necessarily discredit previous histories, but adds complexity to the disciplinary imagination. What's more, just as my own study would not be possible without the historical scholarship already published in rhetoric and composition, historical work published in the last decade would not be as nuanced as it is if previous histories had not come before. Second, some versions of composition's history reject or challenge prevailing narratives espoused by histories published at around the same time - so the emergence of competing narratives is not necessarily a neatly chronological event. And finally, recently published histories - no matter their depth of analysis or level of challenge to the "common sense" of the field - are not themselves above critique. Although I often point to specific histories as representing rhetorical strategies valuable to future historians of composition, I try at the same time to illustrate both the possibilities and limits of various historiographic approaches (within the limits of my own analytic capabilities).

This is not to say that I imagine an "ideal" or "true" history of composition or that I would argue that all historians employ a set of "best" historiographic strategies as they compose new disciplinary histories. I do not see some versions of history as "good" or others as "bad," some more "truthful" or in tune with "real" practices than others. Instead, I intend for this study to illuminate how historical knowledge and historiography as a rhetorical practice work within the discipline and on scholars, teachers, and students of composition.

Finally, I want to be clear about the limits of this project: First, my dissertation does not attempt to evaluate the accuracy of claims made by the historians I analyze. In positioning the voices of others alongside prevailing narratives, I do not mean to establish 
which voice is "correct"; rather, I use these voices to trouble the rhetorical boundaries that so often determine what is "intelligible" within disciplinary discourse. Second, although I hope someday to apply the theoretical concerns I raise here to the writing of a new history of the discipline, this study does not pretend to compose a history of composition, nor does it attempt to engage in the kinds of historical methods and historiographic strategies I hope future compositionists will engage. And finally, in the spirit of metahistorical critique, I have tried to remain cognizant of the effects of my own rhetoric throughout this dissertation.

\section{Summary}

In Chapter 1, I lay the theoretical groundwork for my reading of the narratives that constitute the remaining chapters. Using the theories of historiography elaborated in Foucault's, White's, and LaCapra's critical historical scholarship, I explore how historiography influences our perceptions of the past, present, and future. With this framing, I then consider how disciplinary historiography influences the professionalization of academic fields to explain the role that disciplinary histories in rhetoric and composition have had in legitimizing the field and to illustrate the connection between the disciplinary narratives found in the field's histories and its proposals for the future of the discipline. Also in this chapter, I elaborate upon my definition of metahistorical critique as a process of close comparative reading and analysis of two or more texts that intends to produce a clearer understanding of how and why rhetorical elements common to each text have remained the same or changed over time. And in the last major section of this chapter, I describe how I have selected, 
categorized, and contextualized the various histories and proposals for the future of the discipline that comprise the data for my analysis.

In each of the remaining three chapters, I trace one of the disciplinary narratives through selected histories to illuminate how the narrative has been perpetuated or challenged over time and with what political and material consequences. My purpose in presenting these comparative metahistorical critiques is threefold: First, I hope to explain how and why the discipline invokes each narrative, especially within disciplinary histories, and to what ends. Second, I use the analysis to extrapolate and examine the disciplinary values, beliefs, and practices implied in and perpetuated through historians' use(s) of each narrative. And finally, I use the analysis to identify the implied and explicit consequences (both positive and negative) suggested by the use(s) of each narrative in its prevailing and competing versions.

I trace what I call the current-traditional rhetoric and pedagogy (CTRP) narrative in Chapter 2, "The Rhetoric of Current-Traditional Rhetoric," focusing specifically on how historians have used this narrative to characterize public and professional culture, academic institutions, textbooks, teachers, and students. I argue in this chapter that composition scholars' use of prevailing versions of the CTRP narrative forward problematic representations of culture, institutions, textbooks, teachers and students through a neglect of actual historical phenomena. Specifically, I make a distinction between the disciplinary imaginary about CTRP and real pedagogical practice in order to explain the rhetorical effects of referring to CTRP as a real or unified set of beliefs and practices: the conflation of the imaginary and the real produces a flawed ideology of the discipline that masks the way social inequalities are actually created and reproduced 
within culture and through processes of schooling. This, in turn, produces theoretical and material consequences for composition as a contemporary discipline.

In Chapter 3, "The Question of First-Year Composition," I focus on the consequences of composition historians' persistent focus on first-year composition (FYC) and the debate surrounding its viability as a required academic course. As historians engage in the debate, they perpetuate an erroneous assumption that our discipline is best historicized in terms of English college-level writing instruction in the United States. I argue that because most contemporary disciplinary histories focus on FYC, the discipline tends to think of and define "work," "writing," and "writing instruction" as a problematically abstract, monolingual, institutionalized, pedagogically produced and reader-oriented practice relevant only to Americans.

Chapter 4, "Composition as a(n) (Inter)Discipline," explores how the relationship between composition and other disciplines, including rhetoric, literature, communications, linguistics, education, TESOL, foreign languages, and writing in a global context, has (or has not) been historicized. I argue that prevailing narratives about composition's relationship to other disciplines present the field's (inter)disciplinarity as a necessarily antagonistic or flawed state of being in the academy. I also problematize how historians' attention to some disciplines (such as rhetoric and literature) over others (such as education and linguistics) shape the contemporary discipline's primary concerns, and I analyze the limitations and possibilities of shifting our attention to neglected disciplines. I argue that we can intervene in the problematic representations that emerge by composing composition's "story" as an (inter)disciplinary one. 


\section{CHAPTER 1:}

\section{HISTORIOGRAPHY, DISCIPLINARITY, AND METAHISTORICAL CRITIQUE}

The history of college writing and rhetorical instruction in the U.S. currently makes up a substantial portion of research in rhetoric and composition, an area that has been burgeoning since the publication of James Berlin's historical monographs in the early 1980s. And even when the history of the discipline is not an explicit concern of composition scholarship, our history is often referenced to substantiate other claims, especially claims about how the future of rhetoric and composition should, ideally, unfold. As a field, rhetoric and composition is continually drawn to its past, but the more historical research is conducted, the more this historical knowledge complicates what we thought we knew about ourselves. This, in turn, challenges our desire for disciplinary progress and our hope that we can somehow learn from (or break with) the discipline's past. Such challenges and complications likewise disrupt the disciplinary narratives we have established and come back to, time after time.

In later chapters I explore the evolution of a handful of rhetoric and composition's most common disciplinary narratives; in this chapter, I lay the theoretical groundwork for my reading of these narratives. Specifically, I first review what scholars in the disciplines of history and rhetoric and composition have to say about the effects of historiography on our perceptions of the past, present, and future in order to establish that the study of 
historiography in our own discipline is a worthwhile endeavor. Then, I review what scholars in the fields of history and rhetoric and composition have said about the relationship between disciplinary historiography and the professionalization of academic fields. I conduct this review in order to explain the role that disciplinary histories in rhetoric and composition have had in legitimizing the field, and in order to make a convincing case for what I see as a connection between the disciplinary narratives found in the field's histories and its proposals for the future of the discipline. Third, I define and elaborate upon my method of analysis for the dissertation, a process of reading and interpretation I call "metahistorical critique." And in the last major section of this chapter, I offer definitions for a few key terms that are used consistently throughout the dissertation, as well as an explanation for how I've selected, categorized, and contextualized the various historical texts that I analyze throughout the remaining chapters.

\section{Historiography's Effect(s) on Our Perceptions of the Past, Present, and Future(s)}

Scholars in history, especially intellectual history, have become increasingly interested over the last forty years in the connections between history and rhetoric. Specifically, those who might be called critical historians - including Michel Foucault, Hayden White, and Dominick LaCapra - have drawn from rhetorical theory to challenge traditional historiographic practice in its assumption that historical research, reading, and writing can be objective. In Rethinking Intellectual History, LaCapra summarizes these historians' conclusions well when he writes that "a purely documentary conception of historiography is itself a heuristic fiction, for description is never pure, in that a fact is relevant for an account only when it is selected with reference to a topic or a question 
posed to the past" (61). Collectively, these historians argue, the ways we read and interpret historical documents and the choices we make as writers of history are political strategies: Historiography shapes the way we see and understand the world, which, in turn, carries intellectual and material consequences for decisions made in the present and the future.

Scholars in intellectual history were some of the first in the larger discipline of history to focus on the rhetorical elements of historiography, probably because they are uniquely positioned, not as "proper" historians - those working in the archives to describe important moments in history and fill in gaps in our historical knowledge - but as intellectual historians, who have traditionally documented "great men" and their ideas. Because they have been trained to take a meta-analytical view of the field in order to determine and document what makes individual figures and texts historically significant, the critical historians listed above are well positioned to question the positivist tendencies of traditional history and the rhetorical effects of historiography. ${ }^{1}$ These historians, drawing largely from structuralist and post-structuralist language theory, have posed important questions about language, texts, contexts, and history that are relevant to rhetoric and composition in general, and especially to my work here. Some of these questions include: How does discourse work, and what are the effects of discourse on our ways of being in and thinking about history? What is a historical document, and how

\footnotetext{
' Here and throughout the dissertation, I use words such as "traditional," "proper," "significant," "true," "fact," "objective," "natural," "alternative," "history," "event," and "real" with a consciousness that these words are contested because they establish problematic hierarchies of value and normalize the dominant at the expense of voices and perspectives already marginalized. Although I would prefer to call attention to the problems inherent to these terms by consistently enclosing them in quotes, this rhetorical strategy becomes tedious and, what's more, can misdirect the focus of readers. Therefore, I ask that readers assume that my use of these terms is always self-conscious and intended to highlight, rather than mask, their problematic status. When I enclose these or other terms in quotes, readers can assume I am referring to another author's use of the term.
} 
does a document work, both as object and subject? What is the relationship between language, historical texts, and the contexts in which they were produced and received? What is the relationship between reading and interpreting historical documents and writing history? And finally, what makes a historical event real? For the remainder of this section, I will review how these historians, and others in rhetoric and composition, have answered these questions in order to establish the ways in which historiography affects our ways of understanding the past, present, and future of the field.

Scholars in rhetoric and composition have certainly had much to say about how discourse works (or doesn't), and scholars in history have too, especially when referring to historiography as a specific and consequential form of discourse. For much of the nineteenth and twentieth centuries, historians defended their field as neither an art nor a science, but as a mediator between the two: on the one hand, historians argued, their work was scientific in that it excavated and analyzed verifiable facts; on the other, historiography was in many ways an art form, because it translated what would otherwise be a mere chronicle of events into a narrative, pulling those facts into coherent form. Historical knowledge could not be reduced to a simple presentation of historical events, lacking interpretation; nor did historiography permit one to stray so far from the truth that a reader might wonder if she were reading fact or fiction. Because they could not be categorized easily as either artists or scientists, therefore, historians found themselves having to defend the value of their discipline - which was once unquestioned and unquestionable - against the rise of industrialism and modern science. As scientific knowledge (and the value ascribed to it) grew, and as history's place within the academy appeared less certain, historians - in an effort to mitigate professional anxiety - 
abandoned their stances as intermediaries between art and science and instead began to call for increased objectivity in both their research and writing. Indeed, it is from this defensive posture that contemporary critical historical theory emerged, and from which these theorists - represented here by Foucault, White, and LaCapra - have been criticized by their peers in the field. ${ }^{2}$

The arguments made by contemporary critical historians challenge more traditional calls for objectivity and empiricism because they recognize the historicity and slippage of discourse, which points to the impossibility of historical research or writing ever achieving a purely descriptive mode. Foucault, for example, argues in Archaeology of Knowledge that discourse consists of groups of statements, objects, concepts, choices, and speakers that accumulate to create a "system of formation," which emerges as a result of repetition over time (74). Foucault's archaeological method of analysis, which is demonstrated in The History of Sexuality, Discipline and Punish, and elsewhere, seeks to illustrate that all discourse "has not only a meaning or a truth, but a history, and a specific history that does not refer it back to the laws of an alien development" (Archaeology 127). In other words, discourse is only made possible by the past: Discursive "formations," or "constellations," are constituted and changed over and through time; they are affected continually by past and present institutions, rules, speakers, and situations. New discursive formations, according to Foucault, allow for different possibilities of what might be said and by whom, but they only emerge out of the past.

Similarly, for White, the historicity of discourse implies a continual slippage between the past, or what has already been written, and the present, the act of writing

\footnotetext{
${ }^{2}$ I direct my attention to Foucault, White, and LaCapra because I see them as representative of the major and ongoing historiographic debates in intellectual history today.
} 
about history. White explains: "When we seek to make sense of such problematical topics as human nature, culture, society, and history, we never say precisely what we wish to say or mean precisely what we say. Our discourse always tends to slip away from our data towards the structures of consciousness with which we are trying to grasp them" (Tropics 1). For White, historical discourse "is always as much about the nature of interpretation itself as it is about the subject matter" (Tropics 4) because the historian is continually looking to the past, as represented in the historical document, and making meaning of it from his or her contemporary position for a specific audience and with particular goals in mind.

This shuttling back and forth between the past and the present calls into question what, exactly, constitutes a text or a document, especially in a historical context. Considered literally, a text would seem to be most easily defined by its material(ity), a physical (and therefore true) marker of the past. Such a definition positions the text as a passive object to be worked on - excavated and deciphered by the historian. Foucault summarizes this approach to the document well:

...ever since a discipline such as history has existed, documents have been used, questioned, and have given rise to questions; scholars have asked not only what these documents meant, but also whether they were telling the truth, and by what right they could claim to be doing so.... But ... all this critical concern ... pointed to one and the same end: the reconstitution, on the basis of what the documents say, and sometimes merely hint at, of the past from which they emanate and which has now disappeared far behind them; the document was always treated as the language of a voice since reduced to silence, its fragile but possibly decipherable trace. (Archaeology 6)

Foucault and LaCapra have both challenged this view of the historical text as a reconstitution of the past, claiming that such a perspective can become imperialistic in its efforts to absolutize and reduce the text to a static object (LaCapra, Rethinking 19). 
Instead, they suggest, a more appropriate definition of the historical document would be one that acknowledges its active role: While we work on it, it also works on us.

For Foucault, defining the historical document as active means that contemporary historians should work not from outside but from within it, "to develop it: history now organizes the document, divides it up, distributes it, orders it, arranges it in levels, establishes series, distinguishes between what is relevant and what is not, discovers elements, defines unities, describes relations" (Archaeology 6). Such a view of the document demands that the historian understand the past as "living, fragile, pulsating," a view which defines the historian's task not as fixing or settling what we know about the past, but as persistently reexamining and reorganizing historical texts, both to establish new relationships among texts and ideas and to identify discontinuity and gaps in our historical knowledge (11-13).

For LaCapra, an active view of the text means challenging the "concepts of 'inside' and 'outside' in relation to processes of interaction between language and the world" (26). At one level, this dichotomy is challenged by the fact that actual events occur at specific times and places, outside of the texts that document them - but these events are only known to us as history through their textualization. At another level, this dichotomy is challenged by the historical document in its present manifestation, as a material object that has managed to stay intact across time and space to arrive in the hands of the historian who now reads it: The historian brings to the text his or her own "outside" knowledge, experiences, and worldviews in the act of reading; but at the same time, the document makes "inside" claims on the reader, bringing her to it, asking that it be understood on its own terms. 
LaCapra furthers this challenge to the inside-outside binary by distinguishing

between what he calls the "documentary" and "worklike" elements of the text:

The documentary situates the text in terms of factual or literal dimensions involving reference to empirical reality and conveying information about it. The "worklike" supplements empirical reality by adding to and subtracting from it... The worklike is critical and transformative, for it deconstructs the given.... one might say that while the documentary marks a difference, the worklike makes a difference - one that engages the reader in recreative dialogue with the text and the problems it raises. (Rethinking 30, emphasis added)

LaCapra's emphasis on the reader here and elsewhere is an important revision to Foucault's description of the historian's relationship to the document: In order for the past to be reflected in contemporary historiography as living and active, the historian cannot be understood as the only one doing work, as Foucault's description in Archaeology of Knowledge implies. The text's documentary and worklike characteristics make dialogue between historian and text not only possible, but necessary. Together, the historian and the text confound the inside-outside binary; historian and text can never be understood as either fully inside or outside one another, but continually shifting positions, each making claims on and posing questions of the other.

The shifting positions of the reader and the historical document - the present and the past - raise the question of context, which surrounds both. Much of the traditional work of historians has revolved around contextualization - redescribing historical events as thoroughly as possible using documentary and other evidence so as to locate them in history. More recently, historians such as White have suggested that formalist analysis of historical texts provides enough of a context that looking "outside" the text becomes less important. But throughout Rethinking Intellectual History, LaCapra insists upon a middle ground, claiming that the best historiography is dialogical, acknowledging both the way 
that a historical text makes claims on its readers as well as the context in which the text was produced.

This stance recognizes the role played by language in its destabilization of the text-context binary. According to LaCapra, "nothing related to the problem of language is alien to [intellectual history]" (Rethinking 18). Language's role in the muddling of the text-context binary leads LaCapra to conclude that, in fact, "texts are events in the history of language" and he advocates that historians "understand these multivalent events as complex uses of language," which produce a "context [that] involves the reader in an interaction among past, present, and future - an interaction having bearing on both understanding and action" (Rethinking 65). Recognizing the central role played by language and texts in historical thinking enables us to think about history and historical texts as active, living, and present - rather than as distant, static objects fixed in the past.

When thinking about context along these lines, then, the question of reality also arises: On a basic level, what is it that we mean, exactly, when we refer to history? What is it - language, evidence, imagination - that makes a historical event real? What does it mean to think historically, and what are its consequences? And how does it become possible to think, read, and write about history productively if all such attempts are unreliable, incomplete, and potentially unjust?

The ambiguity of the term history is relevant to my discussion in this chapter because it carries a complicated past that challenges any easy explanation about what it is we refer to when we talk about history or, for that matter, reality. Hayden White describes the term history as ambiguous, specifically because it has been used as a term of oppression to distinguish between cultures that are supposedly "historical" - those that 
have documented their past - and "unhistorical" - those that have not produced records of the past and are therefore considered (from Western perspectives) to be outside of history. Thus, history not only refers to the object it intends to describe (the human past), but also the discourse surrounding this object (The Content 54-57). White rejects the traditional distinction between historical and unhistorical cultures on the grounds that both groups use narrative as a primary mode of discourse to describe real events. Narrative presents its own ambiguity (albeit one that I consider productive) in that it illustrates the role that imagination necessarily plays in the representation of "any past, which by definition comprises events, processes, structures ... considered to be no longer perceivable" (57). In other words, the use of narrative across cultures points to a powerful interrelation among language, evidence, and imagination - a combination which some might view with skepticism but seems to be necessary for any culture to make sense of the past.

Historical thinking, then, at least in its traditional form, is one way through which the difference represented by the "Other" - often represented in Western thinking by the delineation of unhistorical cultures - begins to seem natural, allowing for the perpetuation of systemic oppression. Understanding the history of the term history as one that has perpetuated an unjust view of humanity can help us recognize historical thinking - or what White calls a "historical self-consciousness" - as a cultural, not natural, phenomenon (The Content 14). Further, this phenomenon helps explain how and why we think about texts as "historically real," through which "[t]he indexical, iconic, and symbolic notions of language ... hold out the possibility of ... direct referentiality, creat[ing] the illusion that there is a past out there that is directly reflected in the texts" 
(The Content 209). Such an illusion, then, would seem to be particularly Western, one which defines historical events as real "not because they occurred but because, first, they were remembered, and second, they are capable of finding a place in a chronologically ordered sequence" (The Content 20).

The problematic consequences of historical thinking are preserved, I argue, through two practices standard for historians within any discipline: The preservation and collection of documents over time, and the uncritical employment of traditional historiography. In Archaeology of Knowledge, Foucault argues that all disciplines which take history as their subject (not just History proper, but the history of ideas, of science, of philosophy, of thought, of literature, etc.) are concerned with the questioning of the document. The historian's treatment of the document, for Foucault, plays a pivotal role between what he calls "traditional" and "new" approaches to history. In traditional history, monuments become, or are reduced to, documents; but in "new" history, historians seek to develop an "intrinsic description of the monument," which shifts the document from object to subject, becoming a monument worthy of study in and of itself (7).

The traditional historian's efforts to document monuments are best illustrated in the existence of the archive, which accumulates and systematically organizes documentary materials over time. While archives are necessary and useful, failure to critically examine their workings can reinforce the naturalization of historical thinking. Foucault argues that the archive is an important space for critical analysis because the archive acts as a physical manifestation that at once points to our need to categorize, contain, and "smooth out" history, while also signifying that which cannot be organized 
or explained, that which "separates us from what we can no longer say, and from that which falls outside our discursive practice" (Archaeology 130-31). Foucault advocates for new historical research and writing to shift from merely fixing facts and events (through organization and categorization) to identifying relationships among these facts, to move from writing "continuous" or "total" history to a more "general" history, which will expose differences, discontinuity, limits, gaps, and the workings of power in the past (Archaeology 10-13). These new practices of doing history seem to provide one way through which traditional ways of thinking, reading, and writing about history might be disrupted.

Although few in rhetoric and composition have theorized the role that language plays in historiography and historical thinking as extensively as White, Foucault, and LaCapra have, Nan Johnson and Janice Lauer have both acknowledged the problems that uncritical historiographic practices can cause in the constitution of our disciplinary histories. While Johnson ultimately argues for a more traditional approach to historical research and historiography in her contribution to the "Octalog" conversation about historiography, she also presents these traditional approaches as highly nuanced and attendant to the concerns of the critical historians I have discussed so far. She writes that she "proceed $[\mathrm{s}]$ on the assumption that historical research and writing are archaeological [uncovering and explaining] and rhetorical [history is figurative, not actual] activities. As an historian, I am responsible both to the claims of historical evidence and to the burden of proclaiming my enterprise as an attempt to tell "true stories"' (9-10). Without this understanding of her position as a disciplinary historian, Johnson implies, her documentation of history would ultimately fail. A decade later, in her contribution to 
"Octalog II," Lauer seems to think that most disciplinary historians have not adopted Johnson's approach, complaining that poor historiographic practices in rhetoric and composition have produced histories that "try to stuff dynamic development into static categories; that claim definitive status; that distort to promote a thesis, that puff hot air instead of arguing using evidence; and that ignore many voices to a few within a limited strand of scholarship" (30).

While many of rhetoric and composition's early histories may not live up to Johnson's and Lauer's standards, many disciplinary historians have at least addressed (if not actually applied to their own writing) the political implications of historiography. One of the most vocal proponents for recognition of the politics of historiography is Berlin, who insists in multiple publications that disciplinary historians have a responsibility to acknowledge their particular biases and reject "the claim to disinterested objectivity" ("Postmodernism" 170). Siding with White (among others), he argues in "Postmodernism, Politics, and Histories of Rhetoric" that " $[t]$ he historian of rhetoric ... is engaged in a cultural politics that cannot be avoided. In the final analysis, a history chooses a politics or is chosen by a politics: the issue of power simply cannot be avoided" (171). In their contributions to "Octalog," both Crowley and Johnson warn of the consequences when readers and writers fail to critically examine their own historiography. Crowley writes that "the intellectual categories we introduce in our histories, or the figures we study, are reified by our readers in such a way as to award them quasi-metaphysical status" ("Octalog" 7). In other words, without critical attention to the political effects of historiography, the figures, texts, and events that composition's historians have deemed significant constitute the common sense history of the field, 
which Victor Vitanza argues is the "most wide-spread form of ideology" and is "(insidiously) metaphysical [in that it] subscribes to language ... as 'transparent"" (“Notes"” 65). Johnson agrees with Crowley, arguing that historians must always struggle with the fact that even when, in theory, we "know that the nature of reality of past and present is negotiated," even when we "know that what historians do is to compel an act of attention to a text which is itself an act of attention," and even though we "know that histories are just stories, historians and readers alike tend to believe and subsequently proceed as if some stories were truer than others" ("Octalog" 18). Historians must always negotiate this tug-of-war between understanding the rhetorical nature of language and the desire to know "reality," Johnson explains, and "[i]t is the energy of this contradiction that fuels the political impact of historiography and makes this business of accounting for the past a baffling responsibility" (18).

These political concerns have, in turn, led some historians to focus on the importance of documenting extra-disciplinary context and the workings of power in disciplinary history. Robert Connors, Susan Miller, and Charles Paine have each stressed the importance of locating composition's history in relation to the cultural context that surrounds the figures, texts, and events considered significant to the discipline. In his contribution to "Octalog," for example, Connors dismisses the idea that disciplinary history should be defined within "a narrow valley of 'history of ideas,' because all of our disciplinary ideas have been based in people's struggles for a better life.... Meaningful historical writing must teach us what people in the past have wanted from literacy so that we may come to understand what we want" (7). In other words, in order to accurately portray our disciplinary history, Connors insists that historians must represent the 
political implications of that history because literacy itself is an issue deeply intertwined with dynamics of power at work. Along similar lines, Miller argues in "Composition as a Cultural Artifact" that the only way to fully understand the development of composition as an academic discipline is to approach it through a cultural-historical lens, one which understands composition "as a cultural practice" and which acknowledges how the cultural ideologies of different periods in our history worked to establish the underpinnings of our current practices and perspectives (32). Likewise, Paine argues that in order to "more accurately illustrate the relationships between culture and composition.... we need detailed accounts of individuals in which the motivation and actions of individuals can be seen in a richer and more illuminating light" (34-35).

It should be clear by now that historical thinking, interpretation, and writing carry material and intellectual consequences that ultimately affect how we understand and participate in the world on a daily basis, and how we pave the way for the future. For these reasons, careful and critical consideration of our ways of documenting, reading, and writing history is necessary for those who want to intervene in our habits of thinking, reading, and writing about the discipline's present and future, as well the students, teachers, and scholars who participate in it.

\section{Historiography and Disciplinarity}

If general historiography carries political implications, it goes without saying that disciplinary historiography does too. But prior to investigating what these implications might be - which is what this dissertation ultimately seeks to do - we must first consider the role historiography plays in shaping academic disciplines, and also why academic disciplines compose their histories in the first place. More specific to this project's place 
within rhetoric and composition scholarship, I am interested in why exposing the history of language instruction in U.S. post-secondary education has become an important activity for the discipline. And along related lines, I want to consider why scholars in rhetoric and composition have failed to bring sufficient attention to these questions when our primary focus has always been on the workings of language. In this section of the chapter, I focus on these questions in order to substantiate my claim (developed in the chapters that follow) that the way rhetoric and composition writes its history often works, first, to stabilize the field as a legitimate discipline, and second, to totalize the past or to smooth out moments of disruption and discontinuity in order to present the discipline as a unified whole, a process that produces important material and intellectual consequences.

To understand the relationship between historiography and disciplinarity, it seems necessary to return to my earlier discussion of the workings of discourse. Not only are the possibilities for contemporary discourse always constrained (and produced) by the past, but discourse is also limited by the situations, rules, institutions, and speakers that together create the context for its existence. The discourse produced within the educational system, then, presents a unique set of characteristics that need to be examined in order to understand how disciplinary historiography works as a specific, and meaningful, form of discourse within an academic context.

Institutions of higher education in the United States are constituted, generally, by a wide array of individual academic departments grouped within larger schools or colleges, which are usually (though not always) determined according to the professional goals implied by particular degrees. Beginning in the late nineteenth century, according to Burton Bledstein, the modern American university set scholars in opposition to one 
other by creating a highly competitive environment that drove individuals to mark themselves as specialists in a particular area of knowledge out of "fear for the future of a career" (300). This process of competition and specialization ultimately enabled departments to expand "by accretion, by means of the simple addition of members who both individually represented specific areas of knowledge, and individually expanded the range of a department's specialized offerings," which further benefitted the university (300). Academic disciplines in the U.S. have evolved, sometimes haphazardly, over time in response to both internal and external political and social demands, which in turn have helped define the discourse produced within the academy.

I define disciplinary discourse as discourse that has been vetted by intellectual peers, a discourse produced by and for scholars to add to a discipline's knowledge base and prompt further research and the production of new knowledge. Because scholarly research is published on account of its originality and currency, it may seem safe to assume that disciplinary discourse would achieve a certain level of objectivity and validity that other discursive forms do not. But as many scholars know from personal experience working in the academy, discourse produced within educational institutions is at least as political as discourse located outside of academia. Further, separating types of discourses according to their circulation "inside" or "outside" the academy becomes problematic if one agrees with Foucault, as I do, that educational systems hold the "political means of maintaining or of modifying the appropriation of discourse, with the knowledge and the powers it carries with it" (Archaeology 227, emphasis added). I would add that, whether it circulates inside, outside, or in between the public and academic spheres, disciplinary discourse carries a significant amount of political weight in the 
public domain because of the cultural value ascribed by the public to higher education: Both within and outside of academia, intellectuals act as purveyors and arbiters of what counts as new knowledge, thus establishing the rhetorical boundaries for the discursive sphere.

In order to understand disciplinary discourse as a particularly powerful mode of discourse, it is important to consider how disciplines themselves work. Above, I defined disciplinary discourse as a form of discourse through which scholars "add to a discipline's knowledge base and prompt further research and the production of new knowledge." While I will ultimately maintain that this definition is a valid one, it contains internal contradictions that can help illustrate how disciplines act as constantly evolving but seemingly stable entities. The first problem with my definition is that it assumes that the contents and boundaries of discourse are knowable. I argued earlier that all discourse has a history; however, it does not follow that this discursive history is known or even acknowledged in present discourse. Take, for example, the constellation of texts (books, monographs, journal articles, responses, retrospectives, review essays, book reviews, online publications, etc.) that are published within a given year and relevant to a specific discipline: While the constellation might seem at first relatively small (considering the many constellations in what might be called a discursive galaxy outside the discipline), only a handful of these texts will be read by an individual scholar, and that scholar will explicitly reference only a small percentage of that handful in the work that she produces over the next ten or twenty years. The fact that this scholar is unaware of the larger field of discourse in her discipline, even within a single year, does not invalidate her work (unless, of course, she fails to acknowledge the texts deemed by other scholars are most 
relevant to her specific focus); although her knowledge of disciplinary discourse is limited, our scholar's use of the few texts she is familiar with in later scholarship will ultimately fulfill my definition of disciplinary discourse, in that it will add to the discipline's foundation of knowledge and pave the way for future research and the production of new knowledge.

Although this explanation might console our hypothetical scholar (and the rest of us), it does not settle the issue; instead, it leads us to the second problem inherent to my definition, which is ultimately caught up with the first: My definition assumes that discourse is positivistic, that what a scholar says and writes in the present explicitly or consciously takes from and builds upon or revises what was said in the past. ${ }^{3}$ But in relation to the discursive constellation of texts available to and relevant within a single discipline, scholars "do not communicate solely by the logical succession of propositions that they advance, nor by the recurrence of themes, nor by the obstinacy of a meaning transmitted, forgotten, and rediscovered; they communicate by the form of positivity of their discourse" - in other words, while what is actually said in a given discipline is not actually positivistic (because an individual scholar cannot know the full span of a discipline's discourse), the rhetoric of disciplinary discourse (the shape of an argument, the presentation of empirical research, etc.) takes a positivistic form (Foucault, Archaeology 126). So positivity is a fundamental but ultimately paradoxical characteristic of disciplinary discourse.

The positivistic element of disciplinary discourse produces rhetorical boundaries and creates the illusion that disciplines themselves are stable entities; while disciplines

\footnotetext{
${ }^{3}$ When I use the word "positivistic," I am drawing on the (now largely discredited) philosophy that the development of knowledge is causal and progressive, and that advances in knowledge necessarily occur in logical and chronological fashion.
} 
may evolve over time, it can seem as though this evolution occurs in a logical, objective, and systematic fashion. But when considering a single discipline's discursive constellation, or the inter- and trans-disciplinary galaxy that constitutes what might be called academic discourse writ large, it becomes clear that describing the evolution of a single discipline as logical, objective, or systematic is decidedly illogical. But this does not mean that a discipline's workings are impossible to decipher. Instead, Foucault offers a different explanation for how to conceive of disciplines: he argues that disciplines should not be conceived of as hosts to an infinite number of discursive possibilities, but as "system[s] of control in the production of discourse, fixing its limits through the action of an identity taking the form of a permanent reactivation of the rules" (Archaeology 224). While a single scholar may, indeed, face - and take advantage of - a wide range of discursive possibilities for the production of knowledge, Foucault argues that "it is probably impossible to appreciate [disciplines'] positive, multiplicatory role without first taking into consideration their restrictive, constraining role" (224).

The constraint described by Foucault "functions socially much more than intellectually," according to David Shumway and Craig Dionne (6). Indeed, Maureen Daly Goggin affirms the importance of the social element in her definition of disciplines, which she describes as entities "made up of individuals who are enmeshed in complex webs of institutions that both make possible a range of problems and activities but also limit these. That is to say, disciplinary practices are carried out in real places by real people with their own complex arrangements of political, cultural, racial, sexual, and gendered ideologies and identities" (Authoring xxii). Shumway and Dionne agree, arguing that the acknowledgement of the specifically social element of academic 
disciplines is one way through which scholars can resist the conventional glorification of disciplines as "traditions devoted to timeless essence"; this attitude, they contend, "misleads us into thinking that, while the quantity and accuracy of knowledge has changed, knowledge itself has not" (4). In other words, this traditional attitude toward the production of knowledge ignores the power dynamics inherent to the process of disciplinarity and the maintenance of the rhetorical boundaries enclosing disciplinary discourse. Disciplinarity, Shumway and Dionne argue, is ultimately an effort at unification, an effort which "naturalizes the discipline's boundaries and legitimizes its right to exclude other disciplines from its territory" (6), thus masking the fact that knowledge-making is ultimately a culturally defined, supported, and produced process. As this explanation shows, it is impossible to separate discourse from disciplinarity, or to remove either from the larger context of the educational apparatus at work. The push-and-pull relationship between disciplinary discourse and disciplinarity itself helps explain, at least in part, the purposes that disciplinary histories serve for the process of disciplinarity and why some histories may enjoy a more popular or positive reception than others within a given discipline. Disciplines such as psychology, sociology, history, anthropology, communications, and rhetoric and composition tend to struggle with their collective disciplinary identities because they can be loosely categorized together as human sciences, a label which indicates that these disciplines study human actions and developmental processes. The identity struggle these disciplines encounter stems, in part, from the fact that human actions and processes are not necessarily predictable or logical: because humans, as objects of study, resist stabilization, scholars in the human sciences must engage nonscientific methodologies, 
such as qualitative data-gathering or textual analysis, to approach their subject. While these methods are necessary and appropriate considering each discipline's subject and purpose, engaging these methods has the potential to delegitimize a discipline, especially young or emerging disciplines, in the eyes of those who value more objective and empirical methods.

Much of the scholarship published within the contemporary human sciences especially that scholarship intended to trace out a discipline's past, mark out its present boundaries, and/or envision its future - might best be described as anxious. However, this anxiety should not be seen as necessarily negative; disciplinary histories, for example, use this anxiety to justify their investigation of the past, an investigation which, in its uncovering, secures the legitimacy of contemporary disciplines. As such, disciplinary histories can be considered integral to the establishment of disciplinarity in the human sciences.

Even as they collectively stabilize the human sciences within the academy, disciplinary histories are ultimately constituted by political acts of interpretation. If a whole genre of texts serves a political purpose, as disciplinary histories do, then it follows that disciplinary historiography plays a political role in the shaping of disciplines. We might locate the processes of disciplinarity, then, in the writing of disciplinary history itself, which is shaped according to the limits and possibilities allowed through disciplinary discourse. In other words, we can assume that disciplinary historians interpret the past with a specific interest in supporting a discipline's claim to legitimacy. And this interpretation - of events, figures, and texts in a discipline's history - may be quite reductive because of the political goals of the genre. LaCapra explains why this 
kind of reductivity may be a necessary, albeit problematic, element of disciplinary historiography:

... a discipline may constitute itself in part through reductive reading of its important texts.... [which] render the texts less multifaceted and perhaps less critical but more operational for organized research. Here the decisive role of certain disciplines and practitioners lies not in the finetuning of a paradigm enunciated in 'founding' texts but in the active reduction of those texts to their paradigmatic level. (Rethinking 60, emphasis added)

In other words, while acts of reductive reading may seem counter-productive to a discipline's explicit goals (and problematic in general), they occur because they help establish those goals in the first place. Because of the integral place these practices have in the establishment and maintenance of a discipline's place in the academy, it does not seem productive to dismiss reductive reading as essentially flawed. Instead, I argue that scholars should promote a critical awareness and analysis of these practices, so that we can better understand how and why they occur within the contexts in which they are produced. Developing this awareness can help advance a meta-critical understanding of disciplinary values, practices, and beliefs - which, I contend, is vital for disrupting those that are problematic and promoting those that align well with our scholarly goals.

To understand how disciplinary histories function within rhetoric and composition, I examine how disciplinary histories function within the discipline of history, which today struggles with its disciplinary identity even as a comparatively wellestablished discipline in the human sciences. After conducting this brief examination, I apply the knowledge gained to rhetoric and composition, a much younger discipline with an arguably shorter past, to help elucidate more specifically why disciplinary histories have served such an important function for the discipline. 
Earlier, I described history's struggle with its identity as neither an art nor a science and its attempts to mitigate the anxieties produced by its location. To summarize: The discipline of history first defended its in-between position as a positive addition to the academy in that it "occup[ied] ... an epistemologically neutral middle ground that supposedly exists between art and science" (White, Tropics 27). Later, historians succumbed to the ideologies extolled by the rise of science and modernity, authorizing many within the discipline to "[fall] back on the view that history is after all a semiscience" and call for empiricism in research methods and increased objectivity in historiography (White, Tropics 27). More recently, some historians (including White and LaCapra, among others) have drawn from structuralist and post-structuralist theories of language to argue for a more nuanced vision of historical methods and historiography, one which takes their rhetorical nature into account.

Within historical studies, the subdiscipline of intellectual history works in ways analogous to disciplinary history in other fields, including rhetoric and composition. Intellectual history takes stock of those significant texts and figures that have guided major transformations in thought and epistemologies. Traditionally, intellectual history has exhibited little self-consciousness about how or why a text or figure achieved significance and took the concept of significance for granted, merely documenting these figures and texts for the purposes of posterity. More recently, scholars such as White and LaCapra have become interested in what, exactly, constitutes significance in the first place. For White, it is the underlying rhetorical structure of a historical argument that determines how a historical text will be received by other historians, as well as the public. He writes: "the link between a given historian and his potential public is forged on the 
pretheoretical, and specifically linguistic, level of consciousness" (Metahistory 429). LaCapra's argument is similar to but less deterministic than White's: "If intellectual history is anything," he writes, "it is a history of the situated uses of language constitutive of significant texts" (Rethinking 18-19). In the same passage, LaCapra agrees with White that the question of language is impossible to ignore when considering the role it plays in positioning a figure or text as significant within intellectual history, but he also emphasizes the difficulty involved in defining the consequences of language in a conclusive way, which is what White's stance implies.

The writing of intellectual history, or disciplinary history more generally, presents specific problems for disciplinary historians in that they are positioned within the very discipline they intend to document. White argues that a distinction must be made between disciplinary historians and other scholars according to the questions they must ask. Some of these questions include:

What is the structure of a peculiarly historical consciousness? What is the epistemological status of historical explanations, as compared with other kinds of explanations that might be offered to account for the materials with which historians ordinarily deal? What are the possible forms of historical representation and what are their bases? What authority can historical accounts claim as contributions to a secured knowledge of reality in general and to the human sciences in particular?" (Tropics 81 ).

Because disciplinary historians write both within and for a given discipline, the way in which a historian answers these questions will shape not only how the discipline evolves, but also how current and future scholars perceive, work within, and articulate new questions about it. In fact, White argues that history would not have achieved professionalization if it had not "politiciz[ed] historical thinking" - in other words, if it had not negotiated the contours of disciplinary discourse and "mark[ed] out" what is and 
is not worthy of attention within the discipline through its historiography, history would not have been able to defend itself as a discipline (The Content 62).

Historians of composition have, like White, acknowledged the problem posed by their positions writing both within and for the discipline. John Schilb argues that this positioning works against historians' ability to self-consciously acknowledge the rhetoricity of their endeavors. He explains that problems in disciplinary historiography arise because historians "share a belief that composition studies has suffered from lack of attention to its past ... hold similar notions of the major figures of the past ... tend to follow the same principles of periodization ... display similar affinities for intellectual history, and ... reveal a common desire to see the teaching of writing become more respectable" (240). Berlin agrees, writing that to avoid this problem, "historians must become aware of the rhetoricity of their own enterprise" ("Octalog" 6). And in a later essay, Berlin becomes more specific about how this awareness might be accomplished, suggesting that historians adopt a historiographic method that:

demands honesty of the historian, a candid acknowledgement of her ideological stance, her conception of perfect economic, social, and political arrangements, her vision of utopia.... The historian then owes it to us and to herself to tell us where she stands so that we can know whether we want to stand with her. ("Revisionary" 127)

While Berlin's suggestions clearly respond to some of White's concerns, other important questions emerge: How easily is this kind of self-conscious positioning accomplished in the actual process of writing history? And in what ways does this positioning move beyond mere articulation of one's biases to new ways of writing history? My analysis of the histories themselves in later chapters will address these questions in more detail. 
Given the above explanation for how and why disciplinary histories work within larger processes of disciplinarity, I'd like to gesture towards the specific questions that arise in relation to disciplinary histories in rhetoric and composition: What roles have our histories played in the shaping of our field? How have our histories intervened in disciplinary discourse to create new possibilities and limitations for what can and cannot be said in our scholarship? And finally, why has exposing the history of language instruction in U.S. post-secondary education become such an important activity for the discipline? Although I cannot dwell on these questions at length here, they ground my discussion of the prevailing narratives found in these histories in later chapters. For now, I'd like to offer a few hypotheses based on what I've discussed so far in this chapter.

Like the discipline of history rhetoric and composition has politicized historical thinking and historiography. Scholars in rhetoric and composition have theorized how disciplinary histories have worked to legitimize the field as a whole. ${ }^{4}$ In the introduction to Authoring a Discipline, an analysis of the emergence and evolution of scholarly journals in rhetoric and composition over time, Goggin argues that "historical accounts themselves both reflect and help foster the vitality of a disciplinary community insofar as they are contingent on a group's interests. In other words, history may both indicate and help sustain those interests" (xiv). Both Schilb and Paine agree, explaining that our histories have not merely pointed to and maintained disciplinary interests, but that they have also been used to appease our anxieties about legitimacy. Schilb contends in "The History of Rhetoric and the Rhetoric of History" that the writing of disciplinary history had increased (and continued to increase) in the 1980 s because "we have more people

\footnotetext{
${ }^{4}$ The texts I discuss here are largely aimed at a rhetoric and composition audience. Although they draw on some of the same theories of historiography I discuss in this chapter, they do not claim to speak to others outside rhetoric and composition.
} 
anxious to legitimize the teaching of writing as a serious affair, [who are] therefore anxious to persuade all writing teachers to think about the contingent nature of their pedagogies so they can revise them for better" (237). Paine develops this idea, adding that disciplinary histories

[are] remarkable ... [in] how self-consciously [they have] strived to be useful, to help reform the way we teach our students. These histories, in other words, were more than intellectual delights for those interested in history; they acted as a social force that shattered ... the pat, tired notions about how compositionists thought about their discipline, how they conceived of themselves as members of the English-department community, and how they taught their students. (27, emphasis original)

The discipline's histories, at least in part, have helped the field achieve professionalization and legitimacy in the academy, not only in establishing its boundaries and scope, but also in changing the attitudes and practices of its members.

By considering the important role language plays in shaping our understanding of the world around us, we can understand why uncovering previous methods of language instruction is an important task. Making sense of past pedagogy about language and actual applications of this pedagogy in writing can provide contemporary scholars a better sense for how language works, especially in relation to processes of power, and, more specifically, with a better sense for the manner in which writing and writing pedagogy has been applied both in and outside of the classroom. Additionally, historical exploration of post-secondary writing instruction can help us better understand the relationship between dominant ideologies and processes of schooling: For example, we could understand Harvard's current-traditional approach toward writing pedagogy in the late nineteenth century - and its institution in many elite schools across the United States - as a method through which the elite could indoctrinate an emerging (and potentially 
powerful) middle class in values and beliefs by which they would control themselves and not encroach on the treasured power of the elite (see for example Miller, Textual Carnivals 45-76). At the same time, we might understand the conterminously progressive approach at the private, black liberal arts Wiley College in Marshall, Texas, in the late nineteenth century (described by David Gold in Rhetoric at the Margins) as an example of how less powerful populations in the United States made use of alternative writing pedagogies and practices to subvert and resist the ideologies prominent in elite institutions such as Harvard. These examples begin to demonstrate the uses and value of historical research and scholarship in rhetoric and composition.

It should be clear by now that disciplinary histories and historiography more generally in rhetoric and composition carry consequences that are worthy of study, especially given the field's focus on language. So why hasn't more attention been directed toward this genre of texts? Some might argue that historiography has occupied a significant amount of our attention, at least as evidenced by forums such as Octalogs I, II, and III, as well as special issues devoted to the subject of historiography (especially in the context of the history of rhetoric) in Pre/Text and RSQ (see "Historiography ... I," "Historiography ... II," and "Feminist Historiography"). Some scholars, particularly Lauer and Schilb, have pointed to the lack of metahistorical analysis of our disciplinary histories as a specific gap in our scholarship that deserves attention (Lauer 31; Schilb, "The Rhetoric" 237-62).

While I agree that these discussions have been important for the discipline's theorization of historiography, they have not taken as their primary object of analysis the actual historiographic practices that are employed in the writing of history for the 
discipline. In other words, few in our field have examined the historiography actually used in rhetoric and composition's disciplinary histories (and when they have, it has been unsystematic; see for example Lisa Mastrangelo), so although we may agree in theory on the politics of disciplinary historiography, the discipline lacks a systematic understanding of how these theories are or are not employed in practice, and with what consequences. In Appendix B, I trace the reception and use of our disciplinary histories in contemporary scholarship. This chart shows how our disciplinary histories have been received and cited and provides justification for my project: I argue that a systematic and critical analysis of disciplinary historiography is necessary because we rely on and repeat certain versions of the discipline's past more often than others. As I show in the chapters that follow, neglecting competing narratives carries material and intellectual consequences for students, teachers, and scholars today. Such an analysis is important for rhetoric and composition because historiography both limits and opens up the possibilities for scholars' rhetorical construction of, and action within, the present and future of the field.

\section{Metahistorical Critique}

The remaining chapters of this dissertation engage in a metahistorical critique of disciplinary histories in rhetoric and composition. My analysis draws on the theories of discourse and historiography discussed previously in this chapter, and it is specifically focused on the structure, trends, and implications of our discipline's historiographic practices. In this section, I first discuss how my method of analysis is similar to, but distinct from, others which have been employed to pursue questions about disciplinary historiography. Then, I use this analysis to forward an extended definition of what I mean by metahistorical critique in the context of this dissertation. Next, I explain the 
intervention I hope to make within (and possibly outside of) the discipline, and finally, I gesture toward the implications of this analysis, especially in terms of a revision to current habits of thinking about history, and historiographic practices more generally, within the discipline.

Before I proceed, however, I'd like to be clear: By metahistorical critique, I refer to a process of close comparative analysis of specific rhetorical elements (in this case, narratives) that are common across a corpus of texts sharing similar rhetorical purposes (here, texts that historicize an academic discipline) and that are published over a specific period of time (for this project, texts published between 1980 and 2010). Metahistorical critique is conducted systematically; that is, I isolate and analyze how a single rhetorical element manifests itself throughout the selected corpus of texts. I argue that metahistorical critique provides a critical approach through which scholars can isolate and analyze the underlying values, beliefs, and assumptions that motivate the production of a set of texts. I offer this definition only as a starting point: It is developed considerably in the discussion below and is best understood in practice by my analysis of disciplinary histories in rhetoric and composition in the chapters that follow.

For most historians, as well as those rhetoric and composition scholars interested in historiography, my use of the term "metahistorical" likely calls to mind Hayden White's use of the term in the title of his first major publication, Metahistory. My use of the term is related to, but distinct from, White's. White was one of the first historians to apply language theory to theories of history and historiography, and his position remained unapologetically formalist throughout his career, even as his explanations of the theory evolved. In Metahistory, White argues that before any historical text is written, the 
historian's motives for writing have already been determined by a tropological premise metaphor, synecdoche, metonymy, and irony - upon which the historian's argument will be constructed or shaped. The trope that drives any given narrative tends to be chosen (consciously or not) according to the time period in which the historian is writing because, according to White, certain forms of argument are valued over others by specific audiences at particular points in time. Because tropes "prefigure" the text, these tropes ultimately drive a historian's rhetorical strategies in composing the text. A given scholar's historiographic "style," White explains, comprises cognitive (argumentative), aesthetic (emplotment), and ethical (ideological) rhetorical strategies that each allow for four possible modes of articulation, which inform the text as a whole. These strategies and modes are available because of the trope that governs the historian's writing. White argues that although the surface features - or narrative - of a text may appear markedly different, all historical texts composed during a given time period tend to share common tropological assumptions at their foundation about what, exactly, makes for a "good" or "persuasive" historical narrative.

White's intervention in historical theory is significant in the sense that many of his contemporaries would argue that the "understructure of the historical work" is not grounded in language, but instead "consist[s] of the theoretical concepts explicitly used by the historian to give his narratives the aspect of an 'explanation"' (Metahistory $\mathrm{x})$. For White, the theoretical concepts (or data) that others would argue make up the foundation of a text actually work with the text's narrative structure to create the illusion that the surface features of the text constitute its whole. Underneath the text's data and narrative components, White contends that a deeper "metahistorical" structure - consisting of 
available rhetorical strategies as well as "precritically accepted" linguistic tropes underlies every historical text (Metahistory ix). By understanding the "deep structure" of historiography as ultimately language-driven, White is able to "characterize ... the different interpretative strategies" used by nineteenth-century historians (specifically Hegel, Michelet, Ranke, Tocqueville, Burkhardt, Nietzsche, Marx, and Croce) and also to make sense of the fact that "although nineteenth-century historical thinkers studied carefully and completely, within the limits of their several competences, the same 'data' in the historical record, they came to such different and seemingly mutually exclusive conclusions about the meaning and significance of those 'data' for their own time" (Metahistory 431). Simply put, White's theory offers a language-based way of understanding how different historians, all writing at around the same time and working with similar sets of data, can construct seemingly contradictory narratives about what happened in the past.

White's justification for his theory of historiography has evolved over time. In Metahistory, White claims that by understanding historiography as grounded in language, rather than in factual data or explanatory theories, we can then understand historians as necessarily subjective in relation to their research and writing, which therefore makes it impossible to make critical value judgments of different historiographic "styles." These conclusions are particularly valuable for White because they allow him to argue against those historians advocating for increased objectivity and empiricism in the discipline. In Tropics of Discourse, published five years later, White builds on his previous thesis by arguing that his theory might "provide protocols for translating between alternative [historiographic] modes which, because they are taken for granted either as natural or as 
established truth, had hardened into ideologies" which would in turn "permit us to mediate between contending ideologues" in a more ethical, and therefore meaningful, way (22). Finally, in The Content of the Form, White argues that shifting attention from the content of a historical text to its form allows us to interrogate how historians "establish, through the articulation of their texts, the plausibility of their discourse by referring the 'meaning' of these ... to a complex sign system which is treated as 'natural' rather than as a code specific to the praxis of a given social group, stratum, or class" (193). In other words, White maintains here that focusing on the rhetorical elements of historiography actually denaturalizes the disciplinary discourse that we so often take for granted, which opens it up to productive analysis and critique.

I agree with White's focus on historiography-as-rhetorical and appreciate the larger goals he has in mind for understanding historical texts through this "metahistorical" lens. White's definition of "metahistory," while not synonymous with my own, informs my thinking about how historiography works and why its critique is worthwhile. However, I find fault with White's dogmatically formalist stance, which opens his theory up for critique on the grounds of it being too relativistic, and also for his contention that rhetorical tropes "prefigure" - or exist prior to - the text, a claim that carries potentially oppressive implications.

Although much of White's later theory on historiography, disciplinarity, and narrative (especially those essays collected in The Content of the Form) seems to be informed by post-structuralist theory, he never relinquishes his formalist claim that the meaning of a historical text can ultimately be gleaned from the text itself. For example, in his discussion of the historiography of the autobiographical text The Education of Henry 
Adams, White argues that his formalist analysis addresses the problem of the text-context binary, which historians continually struggle with (see my discussion of this struggle earlier in this chapter). He writes that

... the problem becomes resolvable from the semiological perspective.... [W] hen we inquire into the context of a work such as the Education, we are interested above all in the extent to which that context provided resources for the production of the kinds of meanings that this text displays to us. To have information about this aspect of the text's context would not illuminate the operations of Adams's work in their specificity.... On the contrary, it is the other way around: the context is illuminated in its detailed operations by the moves made in Adams's text. (The Content 212).

But by maintaining a clear distinction between content and form, White actually preserves the text-context binary, in spite of his claims to the contrary. Further, because White insists that all historiography produced in a given time period shares a common linguistic trope that shapes a historian's choices, it becomes impossible to make judgments about the relative value of different historiographic strategies and modes, a claim that - if pushed to the limit - could be interpreted to mean that any historiographic practice is acceptable. Indeed, several of White's explanations for his theory seem to encourage a relativist interpretation; take for example the following quote from The Content of the Form, in which White discusses the relationship between imagination and historical "reality": "One can produce an imaginary discourse about real events that may not be less 'true' for being imaginary. It all depends upon how one construes the function of the faculty of imagination in human nature" (57, emphasis added). LaCapra argues that this extension of formalism, when applied to historiography, is problematic in that it reduces "critical self-reflection, theoretical inquiry, and rhetorical mode ... to debates about the referential content of propositions, the applicability of operational rules of 
method, and the embellishing or expressive style of a constricted, subjective, and often pear-shaped notion of style" (Rethinking 15). I agree with LaCapra and would add that this kind of a reduction, which White may not support but for which his theory allows, enables scholars to disregard the content of historical texts in favor of form, which could, in turn, facilitate faulty research or claims.

While White has claimed that an apolitical relativism does not necessarily follow from his formalist stance, I would argue otherwise, specifically because his theory depends on the assumption that all history is grounded in a tropological paradigm that exists prior to the text. White therefore conceives of rhetorical tropes (and only a handful, at that) as natural ways of making meaning in a text. Such a conception not only privileges dominant ways of making meaning while foreclosing alternatives, but it also protects White's theory from extended critique: Because White has named specific tropes as natural and prior to writing, it becomes difficult to identify other narrative forms that do not fit into his scheme - his theory demands circular logic that draws all possibly alternative forms of narrative back to its central claim, and he demonstrates this circularity in many of the examples he provides. Further, White's contention that tropes exist prior to a text effectively disempowers the writer - either by limiting the responsibility he must take for his own writing, or by preventing her from intervening in problematic reading, writing, and thinking habits through her historiographic practices. Finally, I would even go so far as to argue that White's insistence on an outside contradicts the foundation for his argument, that our ability to imagine the historical real - or to think historically - is constructed in and through language: If the "grounds of [historiography's] coherence and consistency.... are ... poetic, and specifically linguistic, 
in nature," then it would follow that there is no outside of the text or language - yet that is exactly White's final conclusion (Metahistory 30).

I find Foucault's archaeological method of analysis more satisfying, for my purposes, than White's explanation of the metahistorical components of historiography. For Foucault, archaeological inquiry means asking how already existing discourse allows for, and/or limits, what can and cannot be said in the present and future (Archaeology 131). Foucault prefers to call what he does archaeology because it accounts for how his analysis of a specific text (or group of texts) illuminates the text's rhetorical action within larger "systems of simultaneity, as well as the series of mutations necessary and sufficient to circumscribe the threshold of a new positivity" (The Order xxiii). More tangibly, one might imagine disciplinary discourse as the sedimentation of texts over time, of which we can only easily see the surface (or rhetorical boundaries); if we excavate the textual layers underneath using Foucault's archaeological practice, we begin to understand how the surface came into being. This kind of excavation reveals that the discursive sphere is constituted not only by the accumulation of texts over time but also by textual resistance to rhetorical boundaries, manifested through erosion, fissures, and even clean breaks from what would otherwise appear to be a cohesive landscape of disciplinary discourse.

Foucault, like White, is primarily interested in language; unlike White, however, Foucault does not acknowledge an outside of, or prior to, a text - in other words, rather than being shaped by a "precritically accepted paradigm," a text emerges out of the discourse that came prior to it. Foucault refuses to prioritize content over form (or vice versa); instead, he is interested in how both work to constitute a universe of discourse, within and against which new discursive formations become possible. In The Order of 
Things, Foucault writes that he is most interested in the intersection between the production (or in his words, ordering) of culture and its formal reception (or reflection), which raises the question, "[O]n what basis [do] knowledge and theory become possible"? (xxi).

This question is fundamental for my own definition of metahistorical critique, which is directed at both the content of our prevailing disciplinary narratives - those figures, texts, and events that we highlight in our disciplinary histories, as well as the historiography that shapes them. Building on Foucault, metahistorical critique asks, How has rhetoric and composition "ordered" its culture through the selection and organization of figures, texts, and events it considers significant to its history? How has the discipline "reflected upon" - theorized or made sense of - this data through its historiography? In what ways has the production of particular historical narratives become possible, and in what ways can we understand the reception of these narratives (which is identifiable through repetition, resistance, and revision) as evidence of the (implied or explicit) values, beliefs, and practices primary to the discipline?

What Foucault's archaeology does not do, and what the process of metahistorical critique must, is acknowledge the marked differences between and among texts, especially in terms of the politics of production and reception, both within and outside of the academy. Metahistorical critique must provide contextualization for the texts it analyzes that is at once sensitive to the purposes or expectations of the text's genre, author, and audience, while also remaining cognizant of the dynamics of power that surround these purposes and expectations. Additionally, metahistorical critique must 
acknowledge and be realistic about the limitations inherent to historical research and writing, especially those challenges presented by the archive.

Considering White's and Foucault's shortcomings, LaCapra's analysis of intellectual historiography comes closest to my own goals for metahistorical critique. LaCapra takes a middle ground that alleviates some of the problems that White's theory implies. Historians, according to LaCapra, shouldn't expect a text to be analyzable in and of itself, because close formalist analysis alone cannot (re)produce the text's context. Further, he argues that when historians repeatedly fix texts in history - effectively distancing themselves as readers - they risk sterilizing or limiting these texts as passive objects. Instead, LaCapra urges historians to acknowledge the ways in which historical texts actively make claims on readers, while at the same time also identify the context within which a text was produced and received. LaCapra argues that this kind of increased contextualization can also help historians avoid the problems implied by Foucault's approach, in that such contextualization will allow historians to both acknowledge a specific text's genre and purpose, as well as achieve an improved understanding of how texts work within their "lived reality" - neither of which Foucault does adequately (Rethinking 41-42). It is LaCapra's hope that intellectual historians are able to learn from White and Foucault but also move beyond them to achieve a more nuanced approach toward history and historiography that is both dialogical between historian and text and sensitive to the dynamics of power that affect the production and reception of texts in their particular historical, social, and intellectual contexts.

In Rethinking Intellectual History, LaCapra outlines several major areas of traditional historiography that have generally been neglected or treated problematically 
by intellectual historians; I would like to review these here because I find them applicable to my own theory of metahistorical critique. First, LaCapra considers the relationship between authorial intention and text; he argues that historians should never assume that "authorial intentions fully control the meaning or function of texts" because such an assumption ignores the fact that the "author may in good part discover his or her intentions in the act of writing or speaking itself" (36-37). The relationship between intention and textual production also raises the issue of interpretation: what makes the reading of a historical text "good"? For LaCapra, "[a] 'good' interpretation" is one that does not aim to close the book (so to speak) by assuming a one-to-one correlation between author, text, and reader, but rather aims to "make [one's] argument as informed, vital, and undogmatically open to counterargument as possible" and to "[reactivate] the process of inquiry opening up new avenues of investigation, criticism, and selfreflection" (38). In terms of what I do in the chapters that follow, this means that as I read and analyze disciplinary histories, I must avoid assuming that historians fully intend to engage in the historiographic practices that they, in fact, use. This kind of assumption presents obvious problems when, for example, a historian inconsistently applies the perspective or bias he or she may have clearly outlined in the introduction or preface to the rest of the text - it would not be fair, in cases like these, to assume that the writer was fully in control of the historiography that constitutes the text. Language is more complicated than that.

A second problem that LaCapra addresses is the question of how we should understand the relationship between texts and society. Because every text is born out of a tradition of texts and into a particular time constituted by specific and shifting dynamics 
of power, LaCapra insists that all historiographic analysis must keep the "lived reality" of the production and reception of texts in mind. LaCapra's argument here is grounded in Derrida's work, which highlights the question of how one can adequately "relat[e] long and intricate traditions ... the specific period of time ... and the specific text" (44). The process of establishing this context is not a simple one; texts are best understood, according to LaCapra, as variations of other texts over time and should be "seen as the 'place' where long tradition and specific time intersect ... [texts effect] variations on both [tradition and time]" (44). For my own purposes, this means that as I analyze disciplinary histories, I must consider each one as part of a larger constellation of related texts, each of which is making small interventions in the context of a much longer tradition. Related to the text's production, we must also consider its reception: LaCapra's discussion highlights the question of what, exactly, makes a text "significant" or particularly valuable within the context of its production and reception over time. He writes that the process of canonization is "a procedure not only of selection but of selective interpretation, often in the direction of domestication" (45). As such, a truly "critical historiography" must "relat[e] the existing series of interpretations, uses, and abuses of a text or a corpus to a reading that one tries to make as good as possible" (45). In other words, LaCapra implores the intellectual historian to avoid taking the significance of canonized texts for granted and to strive instead to approach "significant texts" with a critical attitude, one "that relates an informed interpretation of complex texts to the problems of how those texts have been adapted to - and in certain ways have allowed - important uses and abuses over time" (46). In terms of my analysis of rhetoric and composition's disciplinary histories, this means that I must consider not only texts in 
and of themselves, but also how others in the discipline have interpreted, used, and challenged those texts to compose their own. My definition of the process of metahistorical critique allows for these considerations, especially in that I trace the articulation and revision of specific disciplinary narratives across a variety of disciplinary histories and over time.

Another problem that LaCapra discusses relates to the narrow conception of relevant discourse communities traditionally employed by intellectual historians: When referring to significant texts, figures, and events, an intellectual historian is usually most interested in the discourse community that primarily consists of a contemporary academic or intellectual audience. LaCapra identifies two problems with this conception: First, it limits the historian's "attempt to recreate the dialogue of others" to "historicist and documentary" concerns (50), which prevents historical texts from being understood as contemporary and living documents that continue to "work" on their readers. Second, the work of "establish[ing] influence or the existence of a shared 'paradigm' through the enumeration of common presuppositions, questions, themes, or arguments" can distract the historian from delving into "how the borrowed or the common actually functions in the texts in question" (52, emphasis added). And finally, this definition excludes others beyond the immediate intellectual community who may also be involved in conversations about the past - including "dead or distant (even future) 'others," as well as members of the general public (52). LaCapra explains that "[t]he contemporary person-to-person group may have a lesser significance for the actual production of 'ideas' and in any case its role is always supplemented by relation to others through their texts or other artifacts" (52). In terms of my study, then, I must not only consider disciplinary histories in terms 
of their intellectual or academic contexts, but also in terms of their relationship to the past, as well as to those readers, texts, and artifacts that are located outside of the official disciplinary or institutional context we would generally define as a disciplinary historian's community. This, in turn, raises the question of whether, and how, disciplinary histories - and the history of composition itself - interact outside of the academy and influence the culture at large.

Related to the question of how texts should be understood in relation to particular discourse communities, LaCapra also examines how we should understand single texts in relation to whole constellations of texts (or "discursive formations," as Foucault would call them). He explains that problems inhere in our desire to "unify" groups of texts as either continuous, discontinuous, or progressive; he wants to disrupt this desire, arguing that "[ $[$ ]he relation among aspects or elements of a text, and a fortiori among texts in a corpus, may involve uneven development and differing forms of repetition or displacement that put in question simple models of intelligibility" (55). In terms of metahistorical critique, this means that as I analyze disciplinary histories, I must resist the urge to always categorize texts according to their unifying properties. While such categorization is often necessary, a more valuable critique is one which also works against such tendencies and allows the text to resist a fixed location within a larger constellation; such practice requires that I engage in dialogue with individual texts, asking not only where they fit but where and why they don't, and considering what a single text's ambivalence or resistance to simple categorization might mean.

Finally, LaCapra critiques White's formalist attention to the relationship between a text and its structure in order to make what I take to be his most important point, that 
the "analytic distinctions or structural oppositions" White is so focused on are ultimately bound up by the "actual functioning of language, including the use of language by theorists attempting to define and defend analytic distinctions or oppositions in their conceptual purity" (57). For LaCapra - as for myself - the reason why we should study the production and reception of scholarly texts, especially texts that are deemed significant for a discipline, is not because they had influence, but rather because their significance can tell us something about the interplay between language and power. LaCapra explains: “... dominance implies some form of subordination or exclusion, and how this relationship is established must be investigated" (58). This explanation justifies my own focus on what I call the "dominant" narratives that run through composition's disciplinary histories. I am not so much interested in the existence of these narratives (though their existence deserves explanation), but instead in how these narratives work to establish, repeat, contest, or disqualify the values, beliefs, and practices that constitute and maintain our discipline as such.

At the beginning of this section, I defined metahistorical critique as a process of close comparative analysis of specific rhetorical elements (in this case, narratives) that are common across a corpus of texts sharing similar rhetorical purposes (here, texts that historicize an academic discipline) and that are published over a specific period of time (for this project, texts published between 1980 and 2010). Drawing on White's efforts to denaturalize disciplinary discourse through rhetorical analysis but rejecting his formalist approach, I contend that a comparative critical analysis of historiography can reveal some of the primary values, beliefs, and practices that shape our scholarship and our teaching, 
which in turn create important possibilities and limitations in the way scholars in rhetoric and composition think, read, write, and/or teach (about) the discipline's history.

Foucault's definition of archaeology as critical practice helps substantiate my definition of metahistorical critique, in that it affirms the value of analyzing the sedimentation of historiography across texts and over time. In excavating the discursive constellation represented by disciplinary histories in rhetoric and composition, I can investigate disciplinary discourse - and disciplinarity itself - as a process made possible only by what was said in the past. LaCapra's warnings about the oft-neglected elements of intellectual history offer important caveats for what should be categorized as disciplinary discourse. Specifically, disciplinary discourse can include: the larger constellation of texts that informs the historian and within which a specific history will be produced; the historian's previous publications and/or stated intentions for producing a specific history; and also other scholars' interpretations, uses, and challenges to previous histories and the general public's reception of previous histories, both of which translate into contemporary expectations that drive the production and reception of new disciplinary histories. This context must also be considered in light of institutional and cultural power dynamics, which may work in favor of or against the production of specific histories over others. Metahistorical critique must expose and use this context, I argue, in order to work productively against scholars' habits of thinking, reading, writing, and teaching. This can, in turn, result in the dialogical attitude toward histories that LaCapra advocates, which ultimately translates into a disruption of our usual practices of historical thinking and historiography, providing opportunities for other questions and alternative perspectives about the discipline's history to emerge. 
Metahistorical critique, while not producing new history, participates in the revisionist historical tradition in several ways: First, it analyzes historical narratives in relation to one another, which does not simply explain how and why these narratives exist, but also highlights how they work: In other words, metahistorical critique foregrounds the assumptions underlying rhetoric and composition's common sense and marks gaps in our historical research. Second, metahistorical critique analyzes how history is used in narratives about our present and future, which can help us see more clearly whether, and how, those narratives make claims based on variously problematic or legitimate understandings of history. Defined in this way, metahistorical critique works to disrupt traditional conceptions of time and progress and allows for new understandings of the uses of composition history; that is, we can understand histories as building upon and complicating one another - opening up, rather than limiting, the possibilities for our research, practice(s), and ways of thinking in the future.

Perhaps more importantly, however, metahistorical critique also encourages the destabilization of historical narratives; in other words, my analysis questions the discipline's prevailing narratives, which tend to unify history through processes of categorization. This does not mean that I hope to dismantle or do away with historical narratives altogether: this would be naïve, impractical, and impossible. Rather, because metahistorical critique makes prevailing narratives more visible, scholars can temporarily isolate, critically analyze, and revise those narratives so that they can no longer be taken for granted as the presumably unquestionable common sense of the field. This destabilization, therefore, not only makes way for alternative narratives of and about writing instruction, but it also legitimizes other ways of understanding and participating 
in the discipline. Finally, such destabilization may help us move away from those narratives that we no longer find useful or relevant.

\section{Fixing the Field: An Overview of Terms and Categories}

Throughout this dissertation, I use a number of terms that could be contested by my readers. Although I recognize that language is always in flux, and although my review of the literature above indicates that I should resist categorization altogether, such definition and categorization is necessary. I offer a few definitions here in an attempt to stabilize these terms for the purposes of my project and clarify my intended meaning.

I use the terms macrohistory and microhistory to indicate the span of time and kinds of events, institutions, or groups of people that a particular history attempts to document. For my purposes, a macrohistory attempts to provide an overview of major disciplinary developments over a long span of time. For example, I define James Berlin's, Robert Connors', and Sharon Crowley's book-length histories as macrohistories because each covers 80-120 years of disciplinary developments. Macrohistories also trace developments in the field according to elite academic institutions, such as Harvard, and/or a timeline of events that were well-known or visible to those participating in the field at the time. For example, Berlin, Connors, and Crowley all discuss the reports of the Harvard Committee on Composition and Rhetoric, which were published and widely cited in the late nineteenth century, as well as the establishment of major disciplinary organizations such as the Modern Language Association (MLA) and the National Council of Teachers of English (NCTE).

A microhistory keeps its focus narrow in comparison, examining developments over a smaller span of time, a single institution, and/or a specific population (such as 
women or African Americans). Two examples of book-length microhistories that I refer to in this dissertation include David Gold's Rhetoric at the Margins, which examines three Texas institutions of higher education that served women, the working class, and African Americans, and Robin Varnum's Fencing with Words, which focuses on a particular figure - Theodore Baird - who directed writing instruction at Amherst College between 1938 and 1966.

Macrohistories and microhistories participate in the construction of prevailing and competing narratives about the discipline's past. For the purposes of my analysis, I define a prevailing historical narrative as one that would be recognized by most contemporary scholars as the common sense history of the discipline. Prevailing narratives are recognizable because they appear in contemporary non-historical scholarship as "nutshell" versions of the discipline's history (and then used to ground other claims) or they are called to mind via a single word or phrase (i.e. current-traditional rhetoric and pedagogy or CTRP). Usually, prevailing narratives were initially established in earlier (often macro-) histories of the discipline (see for example, Albert Kitzhaber's dissertation and James Berlin's historical monographs) and have been preserved over time through frequent citation and repetition. In the chapters that follow, I analyze prevailing narratives about CTRP, first-year composition (FYC), and composition's relationship to other disciplines.

Competing historical narratives are those that offer a version of the discipline's past that competes with or challenges the version offered in a prevailing narrative. Competing narratives usually offer new historical evidence or alternative interpretations of old evidence that adds complexity to - and therefore challenges the viability of - 
prevailing narratives about composition's past. For example, David Russell's macrohistory, Writing in the Academic Disciplines, challenges prevailing narratives about FYC in that he exposes a long history of writing instruction outside of first-year composition courses and outside of composition studies itself.

Because a single disciplinary history can refer to several different narratives, a single history may also participate in the construction of both prevailing and competing narratives. For example, as I argue in Chapters 2 and 3, Jessica Enoch's microhistory, Refiguring Rhetorical Education, can be seen as both participating in and challenging the construction of prevailing narratives about CTRP and FYC. In Appendix A, I have indicated my categorizations of (macro/micro) and the (prevailing or competing) narratives used within (FYC, CTRP, DISC) the histories read and analyzed for this dissertation.

In articulating these narratives and illustrating them with textual examples from a variety of histories, I do not intend to create a false binary between "good" and "bad" versions of history. Rather, I conduct this metahistorical critique of our prevailing and competing narratives for three reasons: First, I hope to show how metahistorical critique can lead to a more consistent acknowledgment and emphasis of the complexity of composition's past. Second, I intend to outline how specific disciplinary values and beliefs motivate the construction of our historical narratives. Finally, I want to demonstrate how a sustained and systematic analysis of our historiography may lead to productive and continual revision of our historical narratives, as well as a revision of our habits of thinking, reading, and writing (about) the discipline's past. This final point, I argue, can lead us, in turn, to revise our interpretations of the present and future of the 
discipline, as well as those students, teachers, and scholars who participate in its construction. 


\section{CHAPTER 2:}

\section{THE RHETORIC OF CURRENT-TRADITIONAL RHETORIC}

In contemporary composition scholarship, references to current-traditional rhetoric and pedagogy (CTRP) are both frequent and unsurprising. We need only look to a recent issue of $C C C$ - a special issue on the future of rhetoric and composition - for evidence: Two out of the eight articles refer explicitly to current-traditional rhetoric, and both of these invoke the discipline's history to make an argument about the future (Colomb 24; Ianetta 63). More significantly, neither of these essays defines "current traditional," suggesting that the concept is so entrenched in our collective imaginations that it has become a disciplinary given. And although Thomas P. Miller at least employs "scare quotes" when he uses the phrase in The Evolution of College English (12, 145, 209), his usage, compounded with the absence of a definition for the term, further supports my contention that CTRP has become so ingrained in disciplinary rhetoric that it acts as a rhetorical trope, oftentimes signifying practices, values, and beliefs far beyond (or beside) its referent.

CTRP, according to prevailing definitions, represents an approach to writing that values the final product over the process of composition, which in turn values surface features over the content of what is said and implies a one-to-one correspondence between a writer's mind and his or her writing. I am able to compose this definition 
because CTRP is recognizable even when it is not named. For example, in two canonical examples of composition scholarship - Donald Murray's "Teach Writing as a Process Not Product" and Sondra Perl's "The Composing Processes of Unskilled College Writers," the phrase "current traditional" is never used, even though the idea of CTRP clearly creates the exigence for their arguments. ${ }^{1}$ Murray aims to correct approaches to student writing that emphasize product over process, and Perl presents findings from her empirical study in order to argue that pedagogical emphasis on error (or surface features) over content is fundamentally flawed. Composition histories, too, tend to take the concept of CTRP for granted: Terms such as product, grammar (or error, correct/ion/ness), form/al/ulaic (or system/atic, standard/ized, mechanic/al, schema/tic), exposition, and style (or surface) often substitute for, or are combined with, explicit uses of the phrase current traditional. Further, references to CTRP are often paired with, or exchanged for, words or phrases that convey strongly negative connotations - e.g., exclusion(ary), disappointing, pervasive, decay(ed), static, backward, contentless, and, my personal favorite, "a recipe for pain" (Crowley, Composition 227).

CTRP can therefore be understood as a rhetorical trope that refers not necessarily to actual pedagogical beliefs or practices, but instead to what I call, drawing on John Guillory, composition's "disciplinary imaginary.” Describing how the process of literary canon formation works, Guillory defines the imaginary as a "scene in which a group of readers, defined by a common social identity and common values, confronts a group of texts with the intention of making a judgment as to canonicity" (28, emphasis original). Guillory sets this scene against actual pedagogic practice; he argues that the confluence

\footnotetext{
${ }^{1}$ I use the term "canonical," in part, because these essays are anthologized in Cross-Talk in Comp Theory, a common text used to introduce graduate students to the major conversations of the field.
} 
of practice and the imaginary produces a collective understanding of canons as universal or real in a material sense. He explains: "There is indeed a real and irresolvable discrepancy in the relation between the historical specificity of works and the factitious universality of the canonical form, which aspires to transhistorical validity by masking the pedagogic function of disseminating this year's orthodoxy" (60-61). In similar ways, composition's disciplinary imaginary evolves out of the confluence of an imaginary scene - in which a group of scholars, defined by a common social identity and common values, confronts an archive with the intention of making a judgment about its contemporary value - and actual practice located in and lost to history. Because the archive represents both the presence and absence of local values, beliefs, and practices always already bound up in the past, the discipline collectively refers to historically specific and locatable archival materials as though these materials have a "transhistorical validity" that represents actual practice across institutions and over time. The disciplinary imaginary about CTRP, then, takes "found" and "accessible" materials (such as those presented in John Brereton's The Origins of Composition Studies: textbooks, institutional and individual publications, examinations, and student writing) to represent "real" values, beliefs, and practices (such the early discipline's arhetorical understanding of writing, overemphasis on the surface features of writing, and problematic assumptions about the relation between quality of mind and writing).

This distinction between the disciplinary imaginary about CTRP and real pedagogical practice is an important one for my analysis because most historians refer to CTRP as a "real" or unified set of beliefs and practices rather than as an imaginary construction used to forward disciplinary goals. From this point forward, I will refer to 
actual historical phenomena as real (no quotes) and the results of the process of conflation from actual phenomena to the disciplinary imaginary as "real" (within quotes). ${ }^{2}$ When historians do not make the distinction between the imaginary and real historical phenomena, their conflation produces an ideology of the discipline that forwards flawed representations of American and institutional culture, textbooks, teachers, and students. In contrast, articulating and maintaining this distinction enables us to interrogate problematic assumptions about the agents of the discipline's history and to understand better how and for what purposes the discipline perpetuates or challenges prevailing narratives about CTRP.

Before continuing, I want to offer an important caveat: I do not suggest that in making a distinction between the real and the imaginary, some historians come closer to historical "truth" than others. Because real practice will always remain lost to history, the composing of any narrative must necessarily but will always inadequately attempt to fill in gaps in our historical knowledge through well-reasoned methods of interpretation; all historians must ultimately imagine a real that can never be known. My argument, therefore, is one that advocates historians to employ a critical historiographic strategy, one which calls attention to the inevitable imprecision of narrative, self-consciously reflects on the role of the disciplinary imaginary in the construction of narrative, and

\footnotetext{
${ }^{2}$ By actual historical phenomena, I mean those materially grounded events, practices, beliefs, and values that are inextricably bound within a specific past and are both documented and undocumented in the archive. By process of conflation, I mean the process by which historical narratives create interpretations of real phenomena through language, thereby moving materially grounded events, practices, beliefs, and values toward a larger understanding of history, which I refer to as the disciplinary imaginary. Also, I differentiate my use of real/"real" from Lacan's and Jameson's use of the Real, which indicates actual phenomena from which subjects are inevitably separated through language. The Real, in combination with the Imaginary and the Symbolic, suggests that there is an "outside" to language, which naturalizes the idea that some figures and perspectives are simply - and must remain - unintelligible because they cannot be understood within the Symbolic order.
} 
maintains, rather than settles, tensions about actual practice that emerge through the telling of a narrative.

My references to CTRP throughout this chapter should not be understood as references to real pedagogical practice, but to composition's disciplinary imaginary about CTRP; in other words, I am interested in explicating what I see as the problematic disciplinary consequences of understanding CTRP as "real," and I am also interested in how, why, and to what ends the discipline uses CTRP as a trope to represent a set of values, beliefs, and practices that are decidedly unreal. Of course, my own reliance on CTRP in this essay - even though I refer to it as an imaginary construction - illustrates what Karen Kopelson calls a "deep irony" of deconstruction: In examining prevailing narratives of CTRP, I must also employ the very construction that I see as problematic (775). With Kopelson, however, I propose that "we make a concerted, collective effort to release ourselves from" problematic "pattern[s]" of representation (775). In the case of my analysis, these patterns are those that make the fusion of the disciplinary imaginary and the "real" appear self-evident, which in turn reifies the aforementioned flawed representations of culture, institutions, textbooks, teachers, and students and creates the illusion that these understandings are accurate and natural.

Releasing ourselves from these patterns of representation does not mean, for me, that the discipline attempt to rid itself of its historical narratives or even value some at the expense of others. Rather, I contend that, in order to better understand - and possibly intervene in - those disciplinary values, beliefs, and practices that motivate our theory and practice, we must not only produce new histories but must also continually and critically interrogate narratives as they evolve over time in their prevailing and competing 
forms. Metahistorical critique of prevailing and competing narratives about CTRP illustrates how disciplinary historiography can be understood as a rhetorical practice that both reflects and shapes the field's larger beliefs, values, and practices. In this chapter, therefore, I trace what I call the CTRP narrative as it has been used, challenged, revised, or otherwise confronted, in the discipline's histories over time. In the sections that follow, I outline what I consider to be prevailing narratives of CTRP, against which I then compare competing versions of the same narrative articulated in a variety of disciplinary histories.

My purpose in presenting this critique is threefold: First, I hope to explain how and (more importantly) why the discipline invokes this narrative within disciplinary histories, and to what ends. Second, I intend to extrapolate and analyze the disciplinary values, beliefs, and practices implied in and perpetuated through historians' use(s) of this narrative. And finally, I use this analysis to identify the implied and explicit material and theoretical consequences (both positive and negative) suggested by the use(s) of CTRP narratives in their prevailing and competing forms.

\section{From Definition to Narrative: Richard Young and Composition Historiography}

The discipline's first explicit use of the term "current traditional" can be found in Daniel Fogarty's 1959 Roots for a New Rhetoric. As Paul Kei Matsuda points out in "Process and Post-Process: A Discursive History," Fogarty "describe[d] the 'traditional' ways in which textbooks taught principles of writing and rhetoric at the time," but his definition of CTRP did not contain the level of description that we associate with it today. ${ }^{3}$ Robert Connors points out that Fogarty "was no friend of composition" - and he

\footnotetext{
${ }^{3}$ By "definition," I mean a description of a set of beliefs and practices that characterize a concept. This should be understood in contrast to "narrative," which, according to the $O E D$, is "[a]n account of a series of
} 
coined the term to generalize, in one fell swoop, "the entire teaching tradition up to that point" in order to "see it supplanted by a new philosophical rhetoric" (CompositionRhetoric 4). Fogarty's usage was relatively inconsequential until the late 1970 s, when Richard Young elaborated and popularized the idea of CTRP as a position against which the field might define itself (Connors 70). Indeed, in my review of disciplinary histories, most of the scholars who measure the evidence of the history of writing instruction against a specific definition of "current traditional" (see Crowley, Methodical Memory 13; Hollis 34-35) choose the definition Young used in his 1978 essay, "Paradigms and Problems: Needed Research in Rhetorical Invention." He writes:

The overt features [of the current-traditional paradigm] ... are obvious enough: the emphasis on the composed product rather than the composing process; the analysis of discourse into words, sentences, and paragraphs; the classification of discourse into description, narration, exposition, and argument; the strong concern with usage (syntax, spelling, punctuation) and with style (economy, clarity, emphasis); the preoccupation with the informal essay and the research paper; and so on. (31)

Young's definition of "current traditionalism" made its way (in variously truncated and/or hyperbolic forms) through the lore and scholarship of the discipline thanks in large part to this essay, Young's general prominence as a composition scholar in the midst of the emerging process movement, and the year-long NEH post-doctoral seminar he held in 1978-79 entitled "Rhetorical Invention and the Composing Process.",

The idea of "current traditionalism" caught on so quickly after Young added it to disciplinary vocabulary because the concept, unnamed in composition scholarship up to that point, had already been circulating as a viable way of thinking about the discipline's

events, facts, etc., given in order and with the establishing of connections between them" - and which contains agents and conflict.

${ }^{4}$ According to Byron Hawk, attendees of Young's NEH seminar included James Berlin, Lisa Ede, Robert Inkster, Charles Kneupper, Victor Vitanza (among others), and speakers included Linda Flower, Richard Ohmann, Alton Becker, Richard Enos, Janice Lauer, and Henry Johnstone (among others) (21). 
past, thanks to Kitzhaber's (as yet) unpublished dissertation. In fact, participants at Young's NEH seminar read Kitzhaber's dissertation, which gave it increased exposure and contributed to the emergence of prevailing narratives about CTRP and composition history (Hawk 22; Donahue, "Disciplinary Histories" 232). Although Kitzhaber never used the term current traditional, Patricia Donahue points out that his description of composition at Harvard, especially his description of Barrett Wendell's pedagogical practice, matches "the institutional model that modern historians of composition refer to as 'current traditional'" (232). Another example of how Kitzhaber's interpretation of history likely influenced Young's definition of "current traditional" can be seen in his conclusion that at the end of the nineteenth century, Harvard's 1892 and 1896 "Reports of the Committee on Composition and Rhetoric" "emphasized only one aspect of composition - mechanical correctness... This emphasis on superficial correctness," Kitzhaber argues, "contributed in no small measure to the ideal of superficial correctness that was to dominate composition instruction for many years thereafter" (47).

Although many scholars, including Connors, George Pullman, Matsuda, and Byron Hawk have commented on the inadequacy of the term current traditional to accurately reflect the actual rhetoric and practices employed in composition pedagogy from the mid-nineteenth century into the twentieth, I am interested, for the time being, not in whether the term is accurate (more on that later), but in how it has been explicitly and implicitly defined in our histories, how these definitions have produced a prevailing, seemingly unified, narrative about CTRP, and what disciplinary values, practices, and beliefs are implied by the general acceptance of this narrative. Both Matsuda and Hawk have linked the definition's dissemination from Young to two of composition's early 
historians, James Berlin and Sharon Crowley (Matsuda 71; Hawk 49-85); below, I explicate this link, in order to sketch out an even more intricate web of the CTRP's genealogy over time and across our histories.

In "Richard Whately and Current-Traditional Rhetoric," Berlin's definition of CTRP involves a direct (and lengthy) repetition of Young's definition in "Paradigms and Problems." As he introduces Young's definition, Berlin calls CTRP "the most common method of teaching writing today" - a claim he reiterates throughout his corpus but for which he does not provide evidence (10). In his later books, Berlin no longer calls on Young's definition explicitly; instead, he composes three markedly different definitions of CTRP: In Writing Instruction in Nineteenth-Century American Colleges, Berlin characterizes CTRP as "the triumph of the scientific and technical world view ... [it] accepts ... mechanistic faculty psychology, but removes ethical and all but the most elementary emotional considerations from the concerns of rhetoric" (62-63). Three years later, in Rhetoric and Reality, Berlin defines CTRP as "positivistic and practical in spirit ... designed to provide the new middle-class professionals with the tools to avoid embarrassing themselves in print. In short, this was the rhetoric of the meritocracy" (35). And in Rhetorics, Poetics, and Cultures, which is less a history than a proposal for the future of the discipline, Berlin provides a more extensive definition of CTRP, explaining that:

Current-traditional rhetoric does not deal with probabilities ... but with certainties ascertained through the scientific method. There is no need to teach invention ... since the truths of any matter under consideration reveal themselves to the correct application of scientific investigation.... The major work of the rhetoric classroom, then, is to teach budding young professionals to arrange the materials ... their expertise has enabled them to locate and to express themselves in accordance with the highest standards of grammar and usage. (28-29) 
What is most interesting to me, in comparing these three definitions, is the evolution of CTRP from a definition - describing the characteristics of a set of beliefs and practices to a narrative, containing (as any good story should) agents and conflict. This evolution, I argue, is one way in which materially grounded and locally real practices are conflated with the disciplinary imaginary to produce a problematic ideology of the discipline.

While Berlin follows Young in defining CTRP as "a paradigm, a set of implicit assumptions" in "Richard Whately" (10-11), he conflates "rhetoric" with "paradigm" in later definitions. Young and the early Berlin use the word "paradigm" to mean "a conceptual or methodological model underlying the theories and practices of a science or discipline at a particular time" $(O E D)$, and thus "paradigm" can be understood as a relatively neutral observation about a given community's worldview. However, Berlin's later designation of CTRP as a "rhetoric" allows him to ascribe it value with political implications. In fact, grammatically speaking, "rhetoric" in Berlin's description even possesses agency. In Writing Instruction, CTRP has the ability to both "accept[] the mechanistic faculty psychology" and "remove[] ethical and all but the most elementary emotional considerations," against the "concerns" of (true? traditional?) rhetoric (62-63, emphasis added). In Rhetoric and Reality, rhetoric possesses a "spirit" (35); and in Rhetorics, Poetics, and Cultures, it "deal[s]" not "with probabilities ... but with certainties" (28, emphasis added). At other moments in these passages, rhetoric seems to lack agency and is instead acted upon by outside agents, which include for Berlin "the scientific and technical world view," "the meritocracy," and "the rhetoric classroom." Grammatical problems aside (only one of these three nefarious "agents" could accurately meet the $O E D$ 's definition of the term as actually "exerting power"), Berlin's 
conflation of "paradigm" with "rhetoric," and then his attribution of power to "rhetoric" is significant in terms of the kind of narrative it creates for the discipline: CTRP becomes, on the one hand, an allegorical character spanning a long time period (up to a century depending on the version of history read) against which the contemporary discipline must struggle and ultimately define itself. At the same time, contemporary composition must protect itself from "the meritocracy," a nebulous - and therefore all the more villainous character that deliberately exploits rhetoric, using it in the service of reprehensible (academic, middle-class, business, scientific ... pick your poison) interests. Charles Paine comments on this move from definition to narrative in Berlin's work, specifically in his use of the term current traditional. Citing not only Berlin but also Connors, Crowley, Donald Stewart, Theresa Enos, and Richard Lloyd-Jones, Paine writes: “As some historians have portrayed things, current-traditional rhetoric itself has come to resemble one of the villains. That is, current-traditional rhetoric has assumed so central a place in much of the history that $i t$ often seems a central figure in American rhetoric's great lapse - a historical agent itself" (29, emphasis original). When CTRP becomes an agent in our historiography, as Paine argues it has, readers are likely to mistake the disciplinary imaginary for actual practice.

Like Berlin, Crowley argues throughout her corpus that CTRP is the "most pervasive discursive practice ever used in writing instruction," and not only in historical terms: she maintains that CTRP continues to be "alive and well" (Methodical xiii, 139). Also like Berlin, Crowley draws explicitly on Young's definition to compose her own: In The Methodical Memory, her book-length explication of CTRP's theory of invention, she describes CTRP in the following way: 
With regard to invention, I elaborate Young's " and so on" as follows: current-traditional rhetoric occults the mentalism that underlies its introspective theory of invention; it subscribes to the notion that "subjects" - the "matter" of discourses - are mental configurations whose existence is ontologically prior to their embodiment in discourse; it prefers the discursive movement from generalization to specification; it concentrates on expository discourse; it recommends that the inventional scheme devised for exposition be used in any discursive situation; and it translates invention out of the originating mind and onto the page. In other words, this rhetoric assumes that the process of invention can be graphically displayed in discourse. (13, emphasis added)

And as my italicization of the words above highlights, Crowley follows Berlin in ascribing agency to CTRP. In defining CTRP as an agent, Crowley may be attempting to dislodge what she perceives to be a common perception among contemporary composition instructors: that CTRP is "a natural, self-evident, and universal system for the invention of discourse written in school" (xii). Specifically, the agency ascribed to rhetoric is inconsistent with most of Crowley's other descriptions of CTRP: More often than not, when Crowley refers to CTRP, she adjusts her phrasing so that the actors who ostensibly promulgate CTRP practices and beliefs - such as textbook writers, textbook rhetoric, teachers, and administrators - actually act, in a grammatical sense. ${ }^{5}$

But rhetoric's agency in the passage above is significant, I argue, because it represents one of the few moments in Crowley's work where she clearly defines CTRP as such. For example, in "The Current-Traditional Theory of Style: An Informal History," her 1986 precursor to The Methodical Memory, Crowley never presents a specific definition of "current-traditional rhetoric"; instead, she assumes - like most composition

\footnotetext{
${ }^{5}$ For example, when she traces the intellectual history of CTRP theory through textbooks, Crowley pins agency on textbook writers, rather than on CTRP itself, writing: "The list of those who wrote currenttraditional textbooks is impressive, not only because of its size but because some authors held impressive scholarly credentials, often in fields other than composition.... Hundreds of other current-traditional textbooks were written by scholars or teachers whose most enduring claim to fame lay in their participation in the major textbook tradition associated with American composition instruction" (70)
} 
scholars - that her audience will understand exactly what she means when the following sentence opens the essay: "One of the more remarkable features of the textbook tradition now called 'current-traditional rhetoric' is its stability" (233). And in Composition in the University, the moment in the text that comes closest to establishing a definition for "current traditionality" describes its presence according to "signs" that "appear in descriptions of composition programs at colleges and universities all over the country" and in "the best-selling composition textbooks" which "incorporate process-oriented composing strategies into a current-traditional scheme" (212). So although Crowley may hope to denaturalize CTRP, her failure to interrogate the concept in fact cements its naturalness.

Given that Crowley is a self-proclaimed polemicist, it should come as no surprise that her historical research on CTRP creates a compelling narrative about its effects. According to the definition above, CTRP can be blamed for popularizing a theory of invention that privileges the individual mind and assumes that the quality of an individual's writing unequivocally reveals the value of the mind at work, which in turn implies serious, oppressive consequences for students. For Crowley, CTRP "suffers from intellectual poverty; ... stands in for writing; and ... shifts discursive authority away from students and onto the academy" (13). Similar to Berlin's version of the narrative - but in this case directed solely toward the modern university and not necessarily to the world "outside" of it - Crowley frames CTRP's theory of invention as "complicit with the professional hierarchy that currently obtains in the American academy" (139). Further, this theory "compl[ies] with certain institutional needs. And its limitations are not only pedagogical; they also inhere in its subscription to an outmoded epistemology. Its 
continued use raises a serious ethical question as well" (140). Although the "needs" of the institution are not specified in this passage, the rhetoric Crowley uses here (and elsewhere) to describe the consequences of "current traditionalism" is clearly meant to raise the hackles of those liberal-minded compositionists whom she imagines as her readers - those who would resist being drawn into "compliance" with "the institution" and who intend to employ a contemporary pedagogy that avoids epistemological limits or ethical problems. Clearly, Crowley means to implicate all of us and - more importantly to inspire us to act. Indeed, we seem to be left with no other option, because to challenge this narrative would ostensibly mean promoting a conservative (oppressive?) pedagogy that inevitably serves institutional (inhuman?) goals, which would then return us right back to where we began, with CTRP. Crowley's historiography, therefore, in masking the distinction between real practice and the disciplinary imaginary, makes it more likely that scholars who draw on her work will maintain similarly ambiguous explanations of the history of writing instruction.

As Hawk and Matsuda point out, both Berlin and Crowley are clear inheritors of Young's vision of the discipline as evidenced in their repetition and development of his definition of current traditionalism. But they are not the only influential historians who refer to Young's definition and develop it as they compose their own narratives about the discipline: Both Michael Halloran and Connors add to the genealogy of the prevailing CTRP narrative in significant ways. Like Berlin and Crowley, Halloran, in his early work, nods to Young as he summarizes what he means by CTRP in a 1982 essay cited in later histories, "Rhetoric in the American College Curriculum: The Decline of Public Discourse." Unlike Berlin and Crowley, however, Halloran does not attempt to modify 
Young's definition; he merely paraphrases it to affirm that the shift from oral to written communication in the nineteenth-century American college forced rhetoric to undergo a "demotion ... to a minor place in the curriculum" and led to the "detachment of classical learning from the general concerns of rhetoric" (257). In fact, he emphasizes Young's role in the propagation of CTRP as a disciplinary concept in order to point to its internal (and inherent?) contradiction, which in turn allows Halloran to question (but not necessarily challenge) CTRP's burgeoning status as a disciplinary "given" and highlight his own purpose in writing the essay. He writes:

Richard Young has popularized the term "current-traditional rhetoric" for the theory and pedagogy that until recently dominated the wasteland of freshman composition. The term "current-traditional rhetoric" seems to me an odd one. First, it's an oxymoron of sorts: what's current is almost by definition not traditional. More importantly, current-traditional rhetoric bears very little resemblance to the rhetorical tradition. The question I'd like to address in this essay is, How did we get from the rhetorical tradition to current-traditional rhetoric? (245)

Here, Halloran misses what I think was an important opportunity to challenge the accuracy, value and consequences of CTRP's place in disciplinary lore; instead, he takes its truth - incongruity and all - for granted and perpetuates its "givenness" by repeating the term, relatively uncritically, through the remainder of the essay and in his later work. ${ }^{6}$ For Halloran, the fundamental question about the history of writing instruction in American colleges is not the concept of "current traditionalism" itself (even though, as I will demonstrate later in this chapter, it should be), but rather how CTRP came to be. Halloran's fusion of the "real" and the disciplinary imaginary allows him (and others who

\footnotetext{
${ }^{6}$ I say "relatively uncritically" because I think that Halloran is doing some important work to challenge the prevailing narrative in his later work, as I will illustrate later in this chapter. See "From Rhetoric to Composition," for example.
} 
use his work) to construct CTRP as a straw man that must be knocked down in order for the discipline to return to the classical rhetorical tradition.

Connors, too, both recognizes Young's role in the dissemination of "current traditionalism" as a disciplinary given and misses an opportunity to interrogate the concept as a part of the disciplinary imaginary, separate from actual practice, which may have unsettled CTRP's hold in the ideology of the discipline. Although he uses the phrase "current-traditional rhetoric" uncritically in much of his earlier work, he makes an explicit effort to question the term in Composition-Rhetoric. He explains:

... the original title of this book was to have been Current-Traditional Rhetoric. I found, however, that as I worked through the chapters one by one I was becoming less satisfied with that widely accepted term for the subject accumulating under my pen. Finally, I simply could not underwrite the term any longer, and in this book I have ventured to suggest a new term, "composition-rhetoric." (4)

For Connors, composition-rhetoric provides a much-needed alternative to Fogarty's and Young's phrasing in that it avoids the strongly negative connotations of the discipline's use of current traditional and can more broadly refer to "that form of rhetorical theory and practice devoted to written discourse" (6). Indeed, Connors asserts that the term composition-rhetoric offers the discipline a distinctively positive alternative to the discipline's common understanding of CTRP; this alternative, according to Connors, will encourage the discipline to value - instead of decry - the history of writing instruction in the United States. Connors argues - against Fogarty specifically, Young implicitly, and the discipline's view of CTRP in general - that "composition-rhetoric [is] a genuine rhetoric, with its own theoria and praxis. Contemporary scholars have strongly criticized earlier forms of it as being pedagogically destructive, but we should also remember many things we still find useful in writing pedagogy were evolved before 1960 " (7). The term 
is also useful, Connors adds, in that it will prompt composition historians and scholars to understand the discipline's past as resisting oversimplification and decontextualization. He writes, "What we have reified as a unified 'current-traditional rhetoric' is, in reality, not a unified or an unchanging phenomenon" (5). Connors intends, therefore, for his use of composition-rhetoric to indicate that written discourse "is a modern rhetoric, quickly changing and adapting, driven by potent social and pedagogical needs.... Thus we can never speak of 'composition-rhetoric' without stipulation, for it has existed in a variety of forms and constantly evolved" (7).

Connors' attempt to free composition's history from our contemporary misconceptions is both admirable and important. However, in spite of his best intentions, merely replacing one term with another does not dislodge the assumptions that ground the original - which, I argue, is what must happen if we are to revise our historical knowledge and historiographic practices in a meaningful way, and which is one of my primary goals in conducting this metahistorical critique. And indeed, as a textual artifact of one historian's attempts to do this, Composition-Rhetoric presents a useful case in point about the difficulty inherent to challenging our prevailing narratives in lasting ways. Specifically, Connors' history perpetuates two assumptions that stem from Young's initial definition, assumptions already called into question by other historians prior to the book's publication: First, while Connors' history is based "on found and on sought archival sources," these sources include only textbooks, other professional (published) books, and published journal articles (22). Although the non-textbook sources add an important dimension to Connors' work that his earlier scholarship often failed to consider, it is textbook and professional/published evidence that ground Young's 
characterization of CTRP in "Paradigms and Problems," and these sources also form the basis for many of composition's other early versions of history, including those written by Kitzhaber, John Michael Wozniak, Berlin, and Crowley. Because these (kinds of) sources are what initially substantiated the CTRP narrative - which takes textbooks out of their specific contexts and purposes to constitute "real" evidence of practice - it seems likely that (re)using the same sources, in much the same way, would merely reify the prevailing narrative. Further, Connors returns to textbooks time and again without heeding the advice of other historians such as Susan Miller, JoAnn Campbell, Gerald Nelms, and Robin Varnum, all of whom had suggested and exemplified alternative ways of "doing" history prior to the book's publication. ${ }^{7}$ In fact, Connors explicitly acknowledges and then summarily rejects the revisionist scholarship of Miller, Wallace Douglas, Berlin, Sue Carter Simmons, and Victor Vitanza in the introduction to Composition-Rhetoric, dismissing their historiographic strategies as too trendy and overtheorized. He writes, "Choosing and promoting a theoretical perspective as your own personal Master Trope - the terministic screen through which you propose to look at everything - pins you in time, wriggling like a bug on a board. It will sooner or later relegate your work to the realm of the Historically Interesting" (21). Connors, in other words, defends his method of analysis and historiographic approach on the grounds that it will maintain his position as an authoritative historian for much longer than the revisionist historians he mentions.

Second, while Connors' phrasing is meant to promote an expansive and objective view of the history of writing instruction that requires constant contextualization and

\footnotetext{
${ }^{7}$ Some of the alternatives suggested by the historians listed here include the collection of oral histories, examination of student writing, and acknowledgement of writing and curriculum going on outside of composition and/or the first-year course.
} 
qualification, in actual practice, his history continues to project narratives similar to Kitzhaber's, Berlin's, and Crowley's, among others: Like these other disciplinary historians, Connors' narrative is based primarily on textual evidence that is mostly representative of elite universities and published authors; it generalizes about whole groups of people; and it promotes a static and homogenous view of history. One example of this tendency can be seen in Connors' explanation of the shift from oral to written rhetoric in American universities, which he explains in the first chapter of CompositionRhetoric: He argues that the "agonistic [oral] educational culture," which was "the central element in education" for "over two thousand years[,] ... died out almost completely" thanks, in part, to women's entrance into the academy (26-27, emphasis added). ${ }^{8}$ Throughout the chapter, Connors barely acknowledges other possible reasons for the shift, therefore neglecting the possibility of other practices that are not represented in the documents he relies upon; when he does recognize other possibilities, he defends his line of reasoning as the most plausible by saying that "These [other] reasons for the growth of written rhetoric, real though they are, do not ... explain the sharp decline of oral rhetoric and of education in oratory, debate and argument" (54, emphasis added). For Connors, the classical rhetorical tradition "ffefll into desuetude" because "it could no longer be the province of men only [and it therefore] ceased to satisfy male psychological needs" (54, emphasis added). This "fall" is set against the "rise" of written composition, which he describes as "the province of both men and women" because it is "private,

\footnotetext{
${ }^{8}$ Connors grounds his argument on the presumption that oral argumentation is agonistic and masculine; because it was unacceptable for women to perform publicly in front of men, women's presence in the rhetoric classroom meant that all students had to engage in writing, a more acceptable "irenic" and feminine activity, instead (23-68). The premises of Connors' argument in this chapter were met with strong critique by feminist composition scholars, most notably Roxanne Mountford (see Mountford's "Feminization of Rhetoric?" and Connors' response, "Adversus Haereses").
} 
multimodal, interiorizing" (54). In aligning men with the oral tradition and ascribing classical rhetoric a "high" position from which it can fall, Connors' historiography constructs late-nineteenth-century writing instruction - and the women who motivated it - as "low," at least until the supposed revival of rhetoric in the discipline's contemporary manifestations.

A second example of Connors' tendency to oversimplify the history of writing instruction, despite his stated intentions, can be seen in his portrayal of "Modern composition-rhetoric," which for Connors designates the period between 1910 and 1960 . Throughout Composition-Rhetoric, Connors employs this classification to indicate a "period of relative stasis," after which little that had changed during the "Early American," "Postwar," and "Consolidation" periods (1800-1910) would change again until contemporary composition began to demand disciplinary legitimacy. Connors writes that the Modern period represents the same period "that is usually associated with the pejorative uses of the term "current-traditional rhetoric"" (13). Although Connors clearly intends to reject the negative connotations implied by CTRP in his use of the phrase "composition-rhetoric," he ultimately agrees with those connotations when it comes to the "Modern" period. Indeed, for Connors, the entirety of the period's fifty years is described as follows:

The Modern period of composition-rhetoric is defined by the almost absolute reign of a freshman composition requirement and the habits and industries that grow up around such a dominant institution.... During the Modern period, it becomes a truism that student dislike for Freshman Composition is exceeded only by the dislike of its teachers... Theoretically, the Modern period features a heavy reliance on the relatively few rhetorical ideas that lasted through the heavy winnowing of the Consolidation period.... One of the results of this narrowing of theory was to make the teaching of writing an intellectual backwater after $1910 . .$. Composition became known as a low-level grind, as a grueling 
apprenticeship, as a kind of teaching to pass through as quickly as possible. By 1910, Modern composition-rhetoric was firmly in place, carried forward almost exclusively in textbooks, which represented the only organ of tradition in the field of composition teaching.... this static form of composition-rhetoric flourished and spread to generation after generation of new composition teachers ... who knew no other rhetorical or pedagogical way.... And so things remained for almost half a century. (13-14, emphasis added)

Thus, Connors does not do away with prevailing narratives about CTRP, but rather reinforces them in what he seems to believe is a more complex explanation through his attempts to periodize the history of writing instruction. In short, Connors' historiographic practice fails to stand up to his own assertion that "What we have reified as a unified 'current-traditional rhetoric' is, in reality, not a unified or an unchanging phenomenon" (5). In interpreting textbooks and elite institutions as unambiguous evidence of "real" practice, Connors' historiography participates in the construction of a flawed ideology of composition that, as I will demonstrate later in the chapter, implies debilitating material consequences for the agents of composition, especially students and teachers.

Before continuing, I want to emphasize that I do not mean for this critique to be interpreted as an attempt to invalidate Berlin's, Crowley's, Halloran's, or Connors' historical research; indeed, their work has ultimately enabled my own. Nor do I mean to imply that we necessarily need to eliminate the narratives that drive our histories, and I certainly do not want to suggest, as Pullman does in "Stepping Yet Again into the Same Current," that "[t]rue histories" are somehow separable from, and "less profoundly motivated by political (or juridical) agendas" than, "rhetorical narrative[s]" (16). So although the rhetorical power of prevailing narratives about CTRP should be clear by now, this power should not be mistaken for a problem in and of itself. Instead, I want this metahistorical critique to illuminate how and why narratives work, as rhetoric, for and 
within the discipline. In effect, I argue that as we construct narratives of and about the history of the discipline, it is just as important to direct our critical attention to the rhetorical effect(s) of these narratives.

\section{Rhetoric's "Decline and Fall" and CTRP"}

My analysis so far suggests that the definitions of CTRP borrowed, revised, and advanced by composition historians paved the way for a series of prevailing narratives that promote a view of history that neglects non-elite institutions and fails to acknowledge the possibility of diverse perspectives, which in turn limits disciplinary discourse about contemporary composition and its agents (public and private culture, academic institutions, textbooks, teachers and students). In this section, I analyze how these definitions and their attendant narratives are also bound up in historians' explanation of shifts from oral to written rhetorical culture in mid-nineteenth-century America. Later, I will demonstrate how these explanations lead to problematic descriptions of the professional culture of the later nineteenth century and the modern university. These accounts, especially when they take prevailing narratives of CTRP for granted, ultimately affect how historians characterize the agents of the discipline's past: institutions (including the academy, curriculum, and classrooms), textbooks (and their authors), teachers (and their pedagogy), and students (and their writing).

One of the central questions for disciplinary historians has been: How, why, and to what ends did the shift from oral to written rhetoric in the mid-nineteenth century affect the teaching of writing in U.S. colleges? Although historians' answers to this question vary, all who attempt to answer it agree on two premises that relate directly to

\footnotetext{
${ }^{9} \mathrm{I}$ also discuss rhetoric's "decline and fall" as a prevailing narrative about composition's disciplinarity in Chapter 4.
} 
contemporary understandings of CTRP, as well as interpretations of institutions, textbooks, students and teachers: First, disciplinary historians agree that there was a marked shift, one that affected public and private culture, academic institutions, teachers, and students. Second, all agree that the shift carried consequences that can be tied to composition's place in the academy today. While these assumptions are grounded in historical evidence, a historian's agreement with prevailing CTRP narratives can lead to a problematic interpretation of available evidence.

Historians who subscribe to prevailing CTRP narratives assume that the shift from oral to written rhetoric in public culture can be tied to the emergence of CTRP, which they then associate directly with a diminishment of civic participation and democratic debate in public and private culture, a negligence or eclipse of classical rhetoric, ${ }^{10}$ as well as the disappearance of the classical curriculum in institutions of higher education. Paine recognizes and argues against this connection in the introduction to The Resistant Writer, noting that:

Very often, nineteenth-century composition has been portrayed as an intellectual and social abyss that swallowed up any and all ideas of rhetorical complexity. For whatever reasons, went the argument, the history of rhetoric fell into a period of stagnation and decay.

Concomitantly, so declined rhetoric's prestige and sense of mission; so too deteriorated the community's sense of importance and purpose. (25)

The association that some scholars in the discipline have made, and which Paine and I comment on, has enabled scholars to make sense of its past as a cohesive series of events that have led to composition's contemporary manifestation. In presenting the emergence and evolution of CTRP as a unified shift, the discipline has often made sense of, and

\footnotetext{
${ }^{10}$ When I use the phrase "classical rhetoric" from this point forward, I use it self-consciously as a contested term that is often problematically conflated with a single and monolithic Western tradition. Although I would like to enclose the phrase in quotes every time I use it, I do not because such usage becomes cumbersome and distracting for the reader.
} 
subsequently rejected, the developments of the late nineteenth century in order to reach further back to another ostensibly unified rhetorical tradition that appears to better match contemporary disciplinary values. $^{11}$

Metahistorical critique helps illuminate the problematic consequences of this association between mid-nineteenth-century cultural transformations and CTRP. Specifically, this association takes the definition of classical rhetoric for granted, failing to interrogate the assumptions about race, culture, and class that ground the term. This failure likewise supports a hierarchy in which classical rhetoric is conceptualized as the most valuable form of rhetoric, which in turn marginalizes other rhetorical traditions, practices, and beliefs. Second, it promotes a sense that the shift had consistent effects across all American colleges. Finally, the contrast of classical rhetoric in opposition to CTRP frames CTRP as inherently arhetorical. Because the historians who make this connection are widely cited and not always challenged in our scholarship, we can assume that these fundamental problems continue to be disseminated. As these basic assumptions are propagated, then, so are their material effects.

Many historians have argued that the rise of CTRP can be tied directly to the shift from oral to written rhetoric; these historians all characterize the shift as a defeat for classical rhetoric in terms of the tradition itself, college curriculum, and American civic culture in general. Connors makes this connection in "The Rhetoric of Mechanical Correction," an essay in which he analyzes the shift according to pre- and post-Civil War cultural change. He writes:

\footnotetext{
${ }^{11}$ In addition to problematically presenting the shift from oral to written rhetoric as a unified movement, historians of composition have often neglected the discipline's historical ties to literacy and education and have instead tended to privilege the discipline's (weaker) ties to Western/classical traditions of rhetoric. This neglect works to eclipse composition's interdisciplinarity, a problem I discuss in Chapter 4.
} 
The forty years 1865-1905 were years of wrenching necessity and desperate invention for rhetoric. Like the rest of the traditional college curriculum, rhetorical instruction was forced to move away from the abstract educational idea of 'mental discipline' and toward more immediate instructional goals. The immediate goals, in this case, came to involve, not more effective written communication, but rather, simple mechanical correctness. (35, emphasis added)

In Composition-Rhetoric, when introducing his historical explanation for composition's low status, Connors uses more dramatic language to describe the shift:

Before we can understand anything else about the evolution of composition-rhetoric, we must understand [the] extraordinary decay in rhetoric's status and perceived worth.... This chapter will examine some of the reasons for the desuetude into which rhetoric fell during the period 1840-1910, with the resulting disciplinary structure being what I am calling Modern composition-rhetoric. (172, emphasis added)

As I noted earlier, Connors conceives of "Modern composition-rhetoric" as a static period in which little rhetorical theory was generated; thus, he is arguing here that rhetoric's demotion led to stagnation in the American college curriculum and, although he would not use the term himself, to the perpetuation of CTRP. In this particular chapter of Composition-Rhetoric, Connors intends his presentation of the supposed fall of rhetoric $^{12}$ to explain the historical precedent that was set in early English departments for the discipline's contemporary labor practices; he seems to suggest that the rebirth of rhetoric in the late twentieth century has the potential to disrupt these unethical practices. But Connors' portrayal of history is oversimplified, which suggests that any solutions arrived at through this version of history will not fully resolve the problem. In examining Connors' historiographic approach across these texts, then, we can see how a handful of "real" practices are fused with the disciplinary imaginary to construct flawed

\footnotetext{
${ }^{12}$ Just as my use of the phrase "classical rhetoric" is to be read as contested, so should my use of the words "fall" or "decline" to describe what happened to rhetoric in the nineteenth century. As my deconstruction of composition's historiography in this chapter and others will demonstrate, I do not agree that these words adequately or appropriately describe this part of composition's history.
} 
understandings not only of the history of writing instruction but also the contemporary discipline.

Halloran promotes a comparable version of rhetoric's demise, connecting it to the shift from oratory to writing as well as to the emergence of CTRP in several essays that are cited widely throughout our historical scholarship. In "Rhetoric in the American College Curriculum," he describes the shift as follows:

While the classical idea had not disappeared altogether [by the end of the eighteenth century], it had gone into a severe eclipse from which it has not yet emerged, if indeed it ever will. The most obvious changes were the move to a primary focus on written rather than oral communication, the demotion of rhetoric to a minor place in the curriculum, and the detachment of classical learning from the general concerns of rhetoric. (257, emphasis added)

In "Rhetoric and the English Department," an essay in which Halloran uses the history of writing instruction and the rhetorical tradition to validate the place of rhetoric in English studies, Halloran separates classical rhetoric from writing in order to privilege the classical tradition as a more "advanced art" than the "impoverished rhetorical theory" represented by writing instruction in the nineteenth century (5-6). In his 1990 essay "From Rhetoric to Composition," Halloran reinforces this hierarchy, describing the transition from oratory to writing as one in which "[m]uch of great value was lost," especially rhetoric's civic function (176). He describes the transition as follows: "Heuristic theory and procedures virtually disappeared, and the sense of audience was narrowed. In place of a rich array of stylistic forms and techniques was the flat voice of mechanical correctness. The greatest loss was of a large social purpose for writing, a social role for which rhetorical art was necessary equipment" (176-77, emphasis added). 
And in the introduction to the edited collection, Oratorical Culture in NineteenthCentury America, Halloran and Gregory Clark describe the emergence of CTRP as one driven by the modern university's "need for a rhetoric of morally neutral and exclusionary discourse" to support the "professional ethos" of American culture at the time. In order to satisfy this need, Halloran and Clark argue, CTRP ultimately "neglect[ed] classical invention" (21, emphasis added). Like Connors, Halloran represents the recent history of writing instruction as a marked loss in the context of the classical tradition of rhetoric. ${ }^{13}$ As I suggested at the beginning of this section, Halloran likely portrays the past this way in order to make it easier for contemporary scholars to connect current theory and practice with an older and presumably richer tradition. However, examining the historiography across these texts illustrates how practices at prominent and elite institutions - practices which, in this case, carry strongly negative connotations - can become folded into the disciplinary imaginary as "real."

In The Methodical Memory, a book focused entirely on CTRP's theory of invention and its effects, Crowley seems to agree with Halloran and Clark's explanation of rhetoric's fall. ${ }^{14}$ Invention, according to Crowley, is a necessary element of "the maintenance of a complete and effective theory of rhetoric" and is "a central insight of classical rhetoric - that the generation and deployment of discourse is intimately related to the possession of cultural power" (168). Crowley's description of classical rhetoric here is contrasted with contemporary composition: She likens the inventional theories

\footnotetext{
${ }^{13}$ Because my focus is limited only to composition's disciplinary histories, I cannot address how others, such as literary and cultural historians, have portrayed nineteenth century rhetoric and pedagogy. For one literary historian's take, readers might consult Sandra Gustafson's Eloquence is Power: Oratory and Performance in Early America.

${ }^{14}$ Crowley's Methodical Memory takes up previous scholars' claims that CTRP lacked a theory of invention altogether. She wants her critique to show that CTRP, indeed, had a theory of invention but that this theory was fundamentally flawed.
} 
grounding CTRP to the rhetoric of the late Roman Empire, "where rhetoricians earned their keep by composing and delivering highly ornamented and elaborate display pieces exercises whose wit and ingenuity were meant only to amuse their rhetorically sophisticated audiences" (168, emphasis added). Just as Halloran and Connors do, Crowley glosses over specific beliefs and practices so that composition's history appears unified; this ultimately enables her to link the values of contemporary composition with a seemingly stronger, more legitimate, tradition.

Finally, Douglas' oft-cited contribution to Richard Ohmann's English in America, "Rhetoric for the Meritocracy," also frames CTRP (he does not use the term, but he probably would have had the essay been published after 1978, the year of Young's definition) against (presumably classical) rhetoric. Although he is "willing to see a connection between many practices of current composition teachers and those that can be inferred from the works of any of the great rhetoricians," he rejects some scholars" argument that composition might be accurately described as "rhetoric under another name" (98). With more force than Connors, Halloran, and Crowley, Douglas constructs classical rhetoric in direct opposition to CTRP in order to ascribe the classical tradition more value. He writes:

... I do not even see anything very interesting in questions that concern a possible relation between rhetoric and composition, or in those that concern a reversal of history that might transform composition back into rhetoric or just make the alleged connection more apparent. The interesting questions are those that ask why and how rhetoric in its truncated and debased modern form has been able to survive, and indeed flourish, as the study of written composition, or as practice in the production of written composition and communications. (98-99, emphasis added) 
Just as Connors' and Halloran's historiography simplifies the past, so too does Douglas' use of words such as "truncated" and "debased," especially when presented in contrast to contemporary composition.

I am less interested in whether these historians' depictions of classical rhetoric are accurate (in general, they uphold an idealized version of the Western tradition) than in how these depictions are used in our histories to obscure the distinction between real practices and beliefs and the disciplinary imagination. The neglect of this important distinction promotes a problematic understanding of the history of contemporary writing instruction in the United States that, in turn, marginalizes other traditions and perspectives. First, while some of these historians - Connors and Halloran especially work to contextualize and complicate the shift from a primarily oratorical to print culture, their efforts are limited because their projects attempt to describe such a large span of time: It is inevitable that charting the history of writing instruction and cultural transformations in American colleges across the nineteenth and into the twentieth centuries will gloss over meaningful details that might give us a more nuanced sense of history. And second, their depictions of the classical tradition assume that this tradition is monolithic, uncontested, and can stand for all perspectives and traditions that are civic in nature. Although these historians' purposes - which are generally related to ascribing legitimacy to the contemporary discipline - and the limits of their histories are usually made clear within the texts themselves, the historical narratives contained therein have been disseminated widely in disciplinary scholarship over the past thirty years. This dissemination illustrates how the prevailing narratives forwarded within these histories and others are promulgated to support various purposes, including analyses of 
contemporary student writing, pedagogical and institutional critique, proposals for the future of the discipline, and continued research in the history of composition. ${ }^{15}$

Jessica Enoch's Refiguring Rhetorical Education provides one example of the effects of this transmission: Enoch's important revisionist work documents the rhetorical pedagogy of marginalized figures (Lydia Maria Child, Zitkala-Sa, Jovita Idar, Marta Pena, and Leonor Villegas de Magnon) around the turn of the century. Her portrayal of these teachers is both nuanced and convincing; however, she frames their practices in the introduction to the book in terms of the classical rhetorical tradition, making connections between these figures and "educators such as Protagoras, Isocrates, Aristotle, Cicero, and Quintilian" (5). Enoch claims that the educators in her study "invented new forms of rhetorical education that aimed to reshape dominant power structures" (7); however, because it is unlikely that these educators would have been working solely from the Western tradition, I question whether or not these pedagogical practices can or should be traced to classical rhetoric. But at the same time, Enoch's attempt to make this connection - especially given her citations of both Halloran and Crowley in the same section makes sense: The disciplinary imagination, and the narratives produced therein, does not provide other ways to explain, authenticate, or even account for, alternative traditions or practices in the nineteenth and twentieth centuries. Enoch's view may be limited in part because she must explain the complex practices, values, and beliefs uncovered by her historical research according to the discipline's popular conception of CTRP and its (apparent) opposite, classical rhetoric. While Enoch's uncovering of these marginalized perspectives is invaluable for the discipline, couching these perspectives within a

\footnotetext{
${ }^{15}$ In pointing out the uses to which history has been put in composition scholarship, I do not mean to imply that these purposes are problematic; I merely want to remind my readers of the rhetorical effects of disciplinary historiography.
} 
tradition from which they may not have been working risks a recentralization of the dominant at the expense of the marginalized. In attending primarily to those practices that "make sense" within the disciplinary discourse authorized by prevailing narratives about CTRP and classical rhetoric, we may silence already marginalized, historically specific voices.

Enoch's rhetorical strategy makes sense especially because our historiography tends to present the classical rhetorical tradition as inherently valuable. As demonstrated by Connors, Halloran, Crowley, Douglas, and Enoch, disciplinary historians usually associate the classical tradition with positive language: For Connors, rhetorical instruction means "effective written communication"; for Halloran, the tradition holds "[m]uch of great value"; for Crowley, "classical" rhetoric is "complete and effective"; Douglas describes the "classical" rhetoricians as "great"; and Enoch need only list the tradition by name to remind us of its value. Collectively, these historians employ a rhetoric that assumes a nearly incontestable hierarchy according to which the classical tradition holds the most value because of its supposed support of democratic and civic concerns. While some historians acknowledge the undemocratic and exclusionary uses to which the classical tradition has been put (including Crowley and Nan Johnson; also cf. Eagleton), many also defend the tradition in spite of its flaws (Enoch 6; Halloran 177). This defense likely occurs because the disciplinary imaginary presents both CTRP and the classical tradition as singular and unified traditions, delimiting other readings of the same history. As such, historians are confronted with a binary opposition between which they must choose and ultimately defend, even when that defense implies a promotion of racist, sexist, and/or elitist views. 
Few historians depict classical rhetoric and CTRP as fundamentally interrelated traditions. Miriam Brody is one of the few who refuses the prevailing narrative that implies a clear split between the old and new; as a result, she produces a reading of history that does not defend problematic perspectives and allows for questions about history that deserve further attention: She argues in Manly Writing that because masculine ideology permeates classical rhetoric's explanation of style, gendered writing has been "too easily dismissed" by rhetoricians (5). She then connects classical rhetoric's gendered ideology to the modern composition course, arguing that "the composition course ..., however newly minted its gatekeeper function may have been, retained its place in an older tradition, representing writing at the turn of the century as work for the manly agon of public life, and the purpose of its teaching as the character training such agonistic endeavor required" (161). According to Brody, therefore, the classical tradition not only perpetuated an elitist and exclusionary ideology, but the tradition and its attendant ideology is directly connected to - not detached from - contemporary composition, especially CTRP. Brody's argument provides a strong feminist argument worth considering; however, it still relies on the binary of classical rhetoric versus CTRP. This reliance demonstrates how entrenched our prevailing narratives have become in the disciplinary imaginary and how difficult it is to "release ourselves" from those habits of representation promoted within our prevailing narratives.

Because Connors, Halloran, Crowley, and Douglas connect the emergence of CTRP with the shift from oratory to writing in the nineteenth century, their historiography implies that this shift occurred uniformly and produced similar effects across a variety of groups and institutions. Narratives established in several recent 
histories, however, compete against these claims by considering a wider variety of archival materials. ${ }^{16}$ Enoch's history, in spite of its problematic framing, provides one obvious case in point that challenges the suggestion of a unified movement from classical rhetoric to CTRP in late nineteenth-century American culture. Beth Ann Rothermel's two micro-histories of rhetorical education at Westfield State Normal School in Massachusetts and Heidemarie Z. Weidner's micro-history of nineteenth-century writing instruction at Butler University also resist this suggestion: Because they assume that questions about rhetorical education should remain open to debate, Rothermel and Weidner argue that rhetorical education did not disappear from the American college curriculum, especially at smaller institutions, such as private Midwestern colleges and normal schools, which are largely ignored in macro-histories. In "A Sphere of Noble Action" Rothermel explains that although Westfield's history may appear on the surface to support prevailing narratives about the shift from oral to written rhetoric, "close study also suggests that ... this transformation was a complicated and even incomplete one, one that I propose to show was more a remolding of the rhetorical tradition than a truncation" (38-39). Further, Rothermel suggests in both essays that even as a more conservative curriculum was instituted at the school in the early twentieth century, thanks to the pressures of the Massachusetts Board of Education, faculty countered this pressure by "continu[ing] to represent the study of oral and written expression in more complex terms, as an exploration of the process of communication" (“'Our Life's Work”" 152-53). Although Rothermel's interpretation of the available evidence is not beyond critique, her

\footnotetext{
${ }^{16}$ As I note in the introduction to the dissertation, my critique often highlights how our historiographic practices and historical research methods have improved over time, often producing impressive disciplinary effects. In spite of recent progress in this regard, however, earlier historical narratives often persist in contemporary non-historical scholarship.
} 
work is valuable for the discipline because it reminds compositionists that multiple conclusions can be made about our history; and what's more, we still have much to learn. Weidner's investigation of the two women who held the Demia Butler chair of the English department at Butler University similarly challenges prevailing narratives of CTRP. Her study suggests that rhetorical education was alive and well not only in writing courses, but also across disciplines, including literature, natural history, and psychology (63).

Although both Rothermel and Weidner, like all historians, construct a narrative that is ultimately open to debate, their work deserves attention because it demonstrates the value of situating various kinds of historical evidence - including "presidents' reports, board and faculty minutes, university catalogues, instructors' lecture notes and diaries, faculty publications, student themes and journals, student magazines, and alumni memoirs" (Weidner 59) - within their socio-historical contexts. This nuanced examination of the archive not only adds complexity to the disciplinary imaginary but marks and maintains a distinction between the two. Further, the competing narratives constructed in Rothermel's and Weidner's research exemplify recent shifts in disciplinary values - shifts that can be seen, for example, in scholarship that calls for increased attention to habitually marginalized institutions and voices.

A final consequence of historians' attempts to connect CTRP with the cultural transformations of the nineteenth century is the characterization of CTRP as inherently arhetorical. Such a characterization is problematic, first, in that it neglects the initial connection made by Fogarty between "current" and "traditional" rhetorical practices: Hawk explains that in Roots for a New Rhetoric, "Fogarty charts Aristotelian rhetoric, 
outlines current-traditional rhetoric, and displays them adjacent to a diagram of the ideas of Richards, Burke, and the General Semanticists. In short, to discover the new rhetoric he has to delineate the old rhetorics" (14). In other words, for Fogarty, CTRP is obviously rhetorical: his complaint about contemporary practice has to do not with the loss of a classical tradition but with the fact that its pedagogy is based on the classical tradition rather than a contemporary one (Hawk 14-15). Further, Hawk explains that even though Fogarty's new rhetoric ultimately rejects the classical tradition, "major figures in the field, including Young, set up current-traditional rhetoric in opposition to new classical rhetorics, which supports a narrative of retreat and return: classical rhetoric retreats during the dominance of current-traditional practices but is returning in the late twentieth century" (15).

The fact that Young deliberately (and significantly) revised the meaning of the term current traditional helps to substantiate my earlier claim that part of the reason Connors, Halloran, Crowley, and Douglas construct prevailing narratives of CTRP against the seeming demise of rhetoric is not necessarily to represent actual practices but rather to serve disciplinary needs. These needs are reflected in the disciplinary imaginary, which appropriates historical evidence for its own purposes, making sense of artifacts according to larger disciplinary beliefs and values. This kind of appropriation is inevitable in the construction of prevailing and competing narratives; therefore, it is our responsibility as scholars to continually analyze our always-evolving narratives to better understand not only what the discipline gains from our explanations of the history of composition, but also what it loses. Clearly, the prevailing narratives that emerged out of Young's reversal helped the discipline connect itself to a well-respected tradition that 
could add legitimacy to the contemporary field. Further, making this move helped Young validate his own and others' research in "new classical rhetorics" as viable. But much is lost in Young's reversal - and even when contemporary historians work to complicate or dismantle those understandings of our past that have spun out from Young's definition, they must generally rely on those prevailing narratives for their work to be intelligible and acquire value within disciplinary discourse.

Another effect of understanding CTRP as fundamentally arhetorical is that it ignores other ways of interpreting the cultural context that ostensibly produced CTRP, as well as the purposes for which CTRP might be used. For example, a number of historians, including Susan Miller, Douglas, Halloran, and Crowley, have blamed Edward T. Channing, the third Boylston Professor of Oratory and Rhetoric at Harvard, for formalizing the "split" between old and new rhetoric, which they argue also promoted the rise of individualism, literary study and CTRP in higher education. ${ }^{17}$ Again, these historians conflate actual practice (in this case Channing's published writing and speeches) with the disciplinary imaginary (which interprets the historical evidence about Channing as representative of larger cultural and institutional trends).

Elizabeth Larsen offers one alternative to this interpretation in her microhistorical account of Channing's role in the move from oral to written rhetoric at Harvard. Larsen revises this characterization by attending closely to Channing's writings and speeches; she argues that Channing's intentions have been misinterpreted and that instead of vilifying him according to our contemporary view of history, we need to understand him as a progressive educator located within, and responding to, his cultural context. She

\footnotetext{
${ }^{17}$ I want to stress that I do not endorse the connections made by historians among "individualism, literary study, and CTRP"; these are not necessarily related but have been made to appear so through historiographic practice.
} 
explains that because composition has failed to understand writing within its nineteenthcentury context, as a technology that "had visibly overwhelmed" the orally-based classical tradition (160), the discipline has also failed to make sense of nineteenth-century assumptions about writing versus oratory. She explains:

As we examine the model in terms of increased use of writing, we can see that as writing (and reading) became increasingly influential in rhetorical education they raised ambiguities. And we can see how aspects of currenttraditional rhetoric - its reliance on innate ability, its turn to the personal, and its focus on written products and error - can be traced to assumed differences between writing and oratory. (164)

Specifically, Larsen argues that in order to better understand Channing, we need to understand all "[t]heories and pedagogy of composition and rhetoric" as "themselves rhetorical responses that attempt to make sense of the world around" (169). In interpreting Channing as a figure who was "struggling" with contemporary cultural developments, Larsen shows how composition can benefit from entertaining multiple conclusions about historical evidence rather than attempting to settle the issue, as other histories have done (169).

With the questions raised in Larsen's history, compositionists should move to understand historical evidence that would otherwise seem current-traditional instead as a complex, situated, and always-already rhetorical response to cultural changes in the nineteenth century (169-70). Larsen's analysis provides one example of how future historians might successfully separate real practice from the disciplinary imaginary without falling back on prevailing narratives about CTRP to "make sense" of historical evidence. Indeed, because Larsen measures Channing's speeches and writing against his own historical and institutional context, instead of against ours, she avoids vilifying Channing as a figure who stands in for the demise of rhetoric, the rise of CTRP, and the 
long reign of English literary study in the modern university. Metahistorical critique demands that we acknowledge and borrow strategies such as Larsen's for future historiographic practice.

The connections disciplinary historians have made between mid-nineteenthcentury cultural change and the emergence of CTRP in college-level writing instruction have clearly been influential and have enabled us to develop stronger claims for disciplinary legitimacy. But as we can see from the competing narratives produced by other historians, the connection is a loose one at best and remains recognizable in disciplinary discourse due to repeated conflation of actual practice with the disciplinary imaginary. In his critique of composition historiography at the beginning of Rhetoric as Immunity, Paine argues "that histories that have ... link[ed] larger cultural issues to specific phenomena in composition ... have been content to demonstrate merely that such relationships exist. They do not specify how larger cultural issues have actually influenced the transformation of composition theory and practice" (30). I agree. However, I would add that we need to employ metahistorical critique to better acknowledge the material effects of our historiographic practices. While the shift from oratorical to print culture is a well-documented one, it is intimately bound up in questions of literacy, inclusion, and education; the causal relationships constructed and forwarded within prevailing (and sometimes competing) narratives about CTRP produce consequences that materialize in our interpretations of public and private culture, in our negotiations with(in) institutions, in the writing of our textbooks, and in the way we approach pedagogy, other teachers, and our students. Before I turn to the way that prevailing and competing narratives of CTRP represent institutions, textbooks, students, 
and teachers and to what ends, I analyze, first, how and why these narratives interpret mid-nineteenth-century culture and the rise of professionalism.

\section{Rhetoric's "Fall" and the "Rise" of Professionalism}

Historians who subscribe to prevailing CTRP narratives also point to the rise of professionalism ${ }^{18}$ and specialization in the modern university - associating it with the rise of industrialism and individualism in public culture - in order to posit that these trends facilitated the entrenchment of CTRP in U.S. colleges. While industrial development in public culture certainly affected private and academic culture throughout the nineteenth century, the discipline's historians tend to emphasize the effects of industrialism within academic culture in order to demonstrate that increasing division and departmentalization within the university had deleterious effects on the study of rhetoric in its classical form. Because rhetoric is interdisciplinary, historians argue, it did not easily fit within a single discipline - and thus lost its footing in the modern American university. This account seems logical enough, at least when the modern university is defined according to examples such as Harvard's, and works, for contemporary scholars, to help explain rhetoric's fragmented and seemingly inferior location(s) in the academy. Further, historians explain, the rise of industrialism in public American culture led to increased demand for specialization of knowledge and thus the valuing of professionalization within the academy. Largely drawing on Bledstein"s discussion of the "culture of professionalism," composition historians argue that the academic culture of the mid- to

\footnotetext{
${ }^{18}$ When I refer to professionalism in this chapter, I mean for it to refer to those attitudes and desires that privilege so-called "white-collar" or "middle-class" occupations and the skills associated with these jobs. While this privileging is not without its problems, I intend for this critique to complicate the flat negative/positive dichotomy that usually emerges in our disciplinary discourse in relation to this attitude.
} 
late-nineteenth centuries - associated as it was to industrialism in the public sphere therefore also contributed to the demise of rhetoric and the rise of CTRP.

As a consequence of this complex web of associations, many composition histories portray professionalism and practicality as problematic values that are manifested in the rise of CTRP and lead to social stratification and elitism, which appears inevitable when culture lacks the supposedly rich and democratic tradition of classical rhetoric. Such a portrayal is erroneous in that it fails to separate actual practice from the disciplinary imaginary, ultimately promoting an ideology of composition that ignores how professional and practical values might also serve marginalized parties and interests in significant ways. Additionally, this view promotes oversimplified and flawed explanations of how American institutions of higher education work and have worked with(in) public culture, how textbooks were written and used, how teachers taught and thought, and how students performed in (and reacted to) the classroom in response to all of these factors. These problematic explanations lead not only to misconceptions of composition history, but also to unsound views of contemporary education, textbooks, teachers, and students, two problems which perpetuate systems of injustice that contemporary scholars wish to subvert. A close analysis of the prevailing and competing narratives that associate (or attempt to detach) professionalism with CTRP can help the discipline better understand how these problems occur in our historiography and how we might avoid them as we continue to uncover new histories of writing instruction.

The association between professionalization and the rise of CTRP can be located most explicitly in Douglas', Berlin's, Crowley's, and Clark and Halloran's versions of composition history. The title of Douglas' essay, "Rhetoric for the Meritocracy," almost 
speaks for itself in this regard, but a closer analysis helps demonstrate how and why

Douglas makes this connection. In the essay, Douglas analyzes Channing's and Charles

W. Eliot's roles in the foundation of CTRP and modern composition at Harvard; as I

discussed above, Douglas is one of the many composition historians who blames

Channing and other Harvard figures for the demotion of classical rhetoric and forecloses

alternative interpretations of them - such as Larsen's interpretation of Channing as a

figure responding to the demands of contemporary culture. In his critique, Douglas links

Channing's description of the modern orator to individualist, private, and professional

values driven by market demands rather than those of the community. Citing Channing's

Lectures Read to the Seniors in Harvard College (1856), Douglas explains that

Channing's view of the modern orator is:

... a quite radically new view of rhetoric.... Its paradigmatic image is that of a man thinking, of a man whom "increased knowledge" has made "more contemplative," less likely to turn to public occasions for "excitement," who "feel[s] the most deeply when alone," who is not insensitive to the imagination of the passions, but who is always tempering them with judgment. Channing's somewhat Platonic effort to preserve the dynamics of ancient rhetoric by calling up the judgment is a valiant one, surely. But what one sees, or at least what I see, is a man in a study ... who is contemplating the information, ideas, and opinions in some interesting journal "devoted to literature, art, and politics." It's all very solitary, very romantic. Or perhaps, more accurately ... it is a vision of economic man and of the ineluctable, or at least automatic, controls of the free market, as they could be transferred to the market place of ideas and the commerce of public discussion. (116-17)

For Douglas, Eliot's long reign as Harvard's president corresponds with

Channing's role in transforming rhetoric from classical to modern, social to individual,

public to private, and from egalitarian to elitist. Eliot is widely accepted as the figure who transformed Harvard from a provincial college to elite research university based on the German model of education, and Douglas' depiction fuses "real" actions with the 
disciplinary imaginary as he ties this transformation directly to the rise of professionalism, exclusion, and - as might be expected - CTRP. Eliot intended to promote "only an increasing professionalization of the gentlemanly ... profession" through the transformation; and while this might seem to justify the specialization and departmentalization Eliot instituted in the new university, Douglas conflates this possibility with the disciplinary imaginary when he argues that Eliot's true purpose was to transform Harvard into a "growth industry" that would make the older, classical curriculum appear irrelevant and uneconomical for potential students (127). This conflation assumes consciously oppressive intentions on the part of institutions and administrators: Although Eliot ostensibly wanted to make Harvard education broadly accessible to students from all classes, poor students were to be tested repeatedly according to "a sort of primitive accumulation of value-producing character traits" (128), while wealthier students, who required no testing, would gain from Harvard "a kind of moral superstructure, a set of driving principles" that were elitist in nature (129). Indeed, according to Douglas, Eliot's vision of the "new" Harvard was "one that converted poor and rich, or anyway those who had endured and demonstrated their 'capacity and character,' their open-mindedness and 'sense of public duty,' into one body, 'the sons of Harvard.' To characterize them, Eliot ... went back to the ancient concept of aristocracy .... an aristocracy of achievement" (129). Eliot's rhetoric, therefore, demonstrates for Douglas the beginnings of modern composition's "rhetoric of the meritocracy," which works as "a selection mechanism, a recruiting ground for new men for the apparatuses of state and industry, some few of whom might even come to walk the corridors of power themselves" (132). Douglas' elucidation of composition's origins can 
be understood, on the one hand, to benefit the modern discipline in that he calls attention to and warns against ways in which cultural expectations about literacy - in combination with institutions, administrators, and teachers - can produce exclusionary views and practices. On the other hand, because it conflates the "real" with the disciplinary imaginary, Douglas' historiography rejects other interpretations of the same figures and texts, while it also eclipses other sites, figures, and practices that also comprise composition's history - thus promoting a problematically narrow definition of professionalism. ${ }^{19}$

Douglas' cynical view of composition history is cited and supported in both of Berlin's historical monographs, which suggests that Douglas' explanation held lasting value for the discipline. In Writing Instruction in Nineteenth-Century American Colleges, Berlin repeats the connection Douglas makes between industrialism and composition instruction, and makes the connection all the more persuasive by depicting the culture of professionalism as having monolithic, uniform causes and effects:

Most schools, both private and public, began to view themselves as serving the needs of business and industry. Citizens demanded it, students demanded it, and most important, business leaders - the keepers of the funds - demanded it. The ability to write effectively - then as now - was one of the skills that all agreed was essential to success; ... Harvard made the composition class the sole course required of all students in an otherwise elective curriculum. (60)

In this passage, Berlin moves from an overview of "most schools," to generalizations about the public's "demands" for "effective" writing, to the institutionalization of FYC (and CTRP) at Harvard. Berlin therefore constructs a chain of causation that fixes diverse groups and perspectives within an expansive - and unrepresentative - view of history.

\footnotetext{
${ }^{19}$ While Douglas' interpretation of Eliot's thetoric may be defensible, my point here is that Douglas' historiography forecloses the possibility of other interpretations; this foreclosure is at the heart of the problem I address throughout the dissertation.
} 
In Rhetoric and Reality, Berlin borrows Douglas' language to make a similar connection about the rise of $\mathrm{CTRP},{ }^{20}$ this time connecting it also to the rise of scientism in public culture. He explains: "The fact that current-traditional rhetoric was a product of the new, elective university is crucial. This university, a uniquely American phenomenon at the time, was at once committed to the scientific method and to the creation of a professional meritocracy consisting of an emerging middle class" (36). As Berlin develops this claim, business and industry interests are depicted as ubiquitous and their effects are, once again, portrayed as monolithic and uniform. The following passage exemplifies Berlin's historiographic tendencies in this regard:

Since all truth was considered to be external to the individual, to be discovered through correct perception, the doctors or lawyers or engineers or business managers - having been certified as experts, as trained observers, in their disciplines - felt they were surely correct in discovering that economic and political arrangements that benefited them were indeed in the nature of things. And the fact that all of the members of this new class tended to agree - tended to discover the same truths - when they turned to decision-making in political and social matters only confirmed their sense of being objective and accurate. Thus, acting in the name of science, the new professionals used current-traditional rhetoric to justify their privileged status in society. (37, emphasis added)

Here, as elsewhere, Berlin not only oversimplifies the perspectives of the middle class, but he interprets their perspectives according to his contemporary Marxist understanding of class; he seems to assume that those people with (or having aspirations to) economic power always desire and employ that power to marginalize others. Additionally, Berlin's historiography problematically ascribes a high degree of power to a small number of people while also flattening their views into a single, unrepresentative perspective. This

\footnotetext{
${ }^{20}$ Incidentally, Berlin does not cite Douglas in this passage, which suggests to me that the idea of the "rhetoric of the meritocracy" had become so commonplace to prevailing narratives about CTRP that there was no longer any reason to locate the origin of this use of language. Indeed, Berlin uses the word "meritocracy" three times between pages 36 and 37, which serve as the introduction to the section of Rhetoric and Reality documenting the rise of CTRP in the American academy.
} 
inaccurate portrayal associates scientism, professionalism, specialization and the middleclass as inherently negative, just as Douglas does in "Rhetoric for the Meritocracy." Given Berlin's direct reference to Douglas, it seems likely that Berlin shares similar goals and intends to inform contemporary scholars about the repressive potential of literacy education. But Berlin has an additional purpose in composing his histories; as he examines the history of writing instruction and vilifies CTRP, he hopes that his monographs will "vindicate the position of writing instruction in the college curriculum" (Rhetoric and Reality 1). Seen in combination with his attack on the culture of professionalism in the mid- to late-nineteenth century American college, Berlin's stated purpose contains a deep paradox: If the discipline were to acquire the legitimacy Berlin calls for here, this achievement would seem to correspond with the very middle-class values and culture of professionalism that he critiques. This contradiction becomes increasingly evident as we examine Berlin's historiography, and it is perpetuated as other scholars continue to cite his monographs without critically examining the rhetoricity of his historiography. Perhaps this helps explain why the discipline continues to express anxiety over its location in the academy despite explicit efforts of scholars such as Berlin to resolve the problem.

Both Crowley and Clark and Halloran follow Berlin's lead in associating professionalism directly with the rise of CTRP in the academy. In The Methodical Memory, Crowley writes that "current-traditional rhetoric works precisely because its theory of invention is complicit with the professional hierarchy that currently obtains in the American academy.... the only ... explanation for its tenacity is its compliance with certain institutional needs" (139-40). Here, Crowley explains the "tenacity" of CTRP by 
claiming it carries a specific function in the academy, and with this logic, she sets her readers up to either agree or find themselves implicated in the problem. These problems are further cemented by the ambiguity of phrases such as "the professional hierarchy" and "certain institutional needs" - phrases that confuse the distinction between actual practice and the disciplinary imaginary.

Clark and Halloran's introduction to Oratorical Culture in Nineteenth-Century America is more explicit in its condemnation of a similar concept, the "professional ethos," which they believe, in contrast to Berlin, was more powerful in setting the stage for CTRP than scientism or industry. For Clark and Halloran, the "professional ethos" of the mid-nineteenth century "define[s] knowledge-bearing communities as private enclaves of specialists and knowledge as an economic commodity rather than moral virtue" (22). Clark and Halloran argue that it is the "professional ethos" of the nineteenth century that sets up two separate binaries related to CTRP: in one, the "professional ethos" classifies "knowledge-bearing communities" as either public or private and in the other, the "professional ethos" describes knowledge as either "an economic commodity" or "a moral virtue." While it may be possible for an individual to have the attitude critiqued by Clark and Halloran, their generalization of the attitude as one held by a wide variety of people thus glosses over the diverse motives and beliefs held by those who might be described as valuing the "professional ethos." Clark and Halloran's argument encourages contemporary scholars to draw on the classical rhetorical tradition to avoid those problems represented by the "professional ethos" - but in presenting the two in direct opposition to one another, they forward the same binaries that they claim the "professional ethos" creates. In so doing, Clark and Halloran portray professionalism as 
having an ahistorical functionalism, suggesting that this attitude led directly to currenttraditional practices. This problematic portrayal therefore reduces the diversity of perspectives contained within "knowledge-bearing communities" of the mid- to latenineteenth centuries and ignores the complex relationships among cultural values, money, and power - and how these affect what counts as knowledge.

Paine, Kathryn Fitzgerald, and David Gold each provide compelling arguments that complicate the assumptions about professionalism made by Douglas, Berlin, Crowley, and Clark and Halloran. Examining these complications, especially against prevailing narratives about CTRP, can help the discipline better understand not only the material consequences of our historiographic practices, but can also help us identify rhetorical strategies that might "release ourselves from the pattern[s]" of representation that we find problematic, which in turn will tell us much about the limits and possibilities inherent to the narratives we construct.

First, Paine, who focuses on the similarities between contemporary composition and Channing's and A. S. Hill's pedagogical goals, highlights the problems that emerge when we make causal claims about public cultural trends and changes within academic culture. His historical work demonstrates that, in fact, "nineteenth-century American intellectuals ... felt very much at odds with mainstream American culture.... To assume that Hill, Channing, and other patrician intellectuals were in simple allegiance with business interests is to subscribe to a clumsy and inaccurate model of class organization" (22-23). Paine, like Larsen, argues in his analysis of Hill and Channing that, although their final conclusions about rhetoric may have been misguided, they were responding in understandable ways to cultural demands. According to Paine, Channing and Hill hoped 
that their instruction in rhetoric would enable their students to insulate (or "immunize") themselves against dominant culture - objectives that are not outdated, but in fact align with many of our contemporary goals (180). In composing this history, Paine utilizes Larsen's historiographic strategy of contextualizing these early Harvard figures according to their time and place; for example, in his analysis of Channing, Paine argues that Channing hoped his students at Harvard would learn to use "rhetorical training ... to 'resist' [the] real world - where citizens were coerced into certain habits of communication - and to bring their newly invigorated versions of proper and ideal discourse ... into that fallen world" (47-48). Paine positions Hill similarly, writing that "Because of his experience in journalism and because of his social position as a Harvardian 'patrician intellectual,' Hill, like Channing, found himself 'at odds' with mainstream late-nineteenth-century American culture" (87). In considering both figures according to their social class and intellectual biases, Paine moves away from prevailing interpretations and forces readers to consider Hill and Channing as figures with goals and values similar to our own. Employing this interpretive strategy ultimately helps Paine argue that the public professional culture of the mid- to late-nineteenth century was not as monolithic in its influence on the academic sphere as prevailing accounts suggest.

While Paine adds complexity to our understanding of the relationships between nineteenth-century public and academic culture, both Fitzgerald and Gold focus on actual practices in order to question the negative assumptions underlying Douglas', Berlin's, Crowley's, and Clark and Halloran's references to professionalism and its variants. Specifically, Gold's and Fitzgerald's historical research demonstrates the multiple ways in which professionalism - especially as manifested in vocational or career-oriented 
training - can be interpreted as an educative value, especially for marginalized populations. In "A Rediscovered Tradition," Fitzgerald focuses on the history of multiple normal schools in Wisconsin to trace an alternative tradition of writing instruction to the European influences of Pestalozzi and others. She argues that the normal schools in her study were able to develop a critical pedagogy, akin to contemporary ideals, within an otherwise oppressive educational climate because of their unique focus on "professional rather than academic preparation" and also because they had access to a European intellectual tradition of school- (as opposed to college-) oriented theories of education in addition to the standard composition textbooks normally associated with the rise of CTRP in American colleges (244, emphasis added). In other words, Fitzgerald argues, it is the professional nature upon which normal schooling was grounded - the training of teachers - that allowed a more progressive view of writing instruction to emerge at around the same time as CTRP was supposedly dominating composition in other U.S. colleges. Because she examines another site of education, values, and practices - located outside of Harvard and grounded upon other theories of education - Fitzgerald's analysis favors an ideology of composition that does not arbitrarily discount the potential value of professionalism for disciplinary agents. Fitzgerald's historical research thus encourages compositionists to acknowledge and ascribe value to the professional desires of students, a move that recognizes the practical concerns that motivate our students. This recognition is important for students because it values their desires as legitimate; further, this recognition is valuable because it reminds compositionists to question their assumptions about or critique of student desires. 
Gold focuses on three educational institutions in Texas "neglected by previous historical study" in Rhetoric at the Margins: All three of these institutions - Wiley College, an HBCU, Texas Women's University, and East Texas Normal College "served a similar function ... providing [students] with a means of socioeconomic and community pride" (115). Gold's study, like Fitzgerald's, takes into account and values the practical goals of students, whose "main reason [for] attend[ing] college - then as well as now - is for the purpose of professional advancement" (155). Indeed, although "[m]any of us in the humanities with liberal or radical sentiments are suspicious of anything that smacks of professional or vocational training, seeing it as a compromise with a market-driven value system that already devalues our own work," Gold concludes that this suspicion is a contemporary interpretation that does not necessarily align with even the most progressive educators at the turn of the century (155). Together, Gold's and Fitzgerald's histories suggest that dismissing professionalism as a suspect or worthless value actually reifies the same elitist and exclusionary perspectives that historians such as Douglas et al. presumably oppose. I would argue, too, that one of the reasons composition has tended to ignore many of the "alternative" educational sites that more recent histories have brought to the forefront - including normals, HBCUs, rural, female and religious colleges, literary and debate societies, and formal and informal literacy programs - can be attributed in part to disciplinary historians' focus on an ahistorical and functionalist view of professionalism. The lack of viability for this focus continues to be illustrated by the historical evidence present in recent, more nuanced histories of college writing instruction. 
As we can see via metahistorical critique, Clark and Halloran's definition of "professional ethos," along with Douglas' and Berlin's "rhetoric of the meritocracy" and Crowley's "professional hierarchy," reinforces a series of problematic binaries - and, thus, hierarchies of value - that relate directly to prevailing narratives about CTRP: these historians set classical against modern, social against individual, public against private, and egalitarian against elitist in order to discharge the second word of each pair and promote a particularly ahistorical view of the "culture of professionalism" in the nineteenth century. This interpretation of history, manifested and forwarded as it is through prevailing narratives about CTRP, encourages contemporary scholars to glorify a seemingly monolithic classical rhetorical tradition without regard for the complex history of writing instruction. This kind of historiography ultimately results in a debilitating understanding and treatment of students, as well as an oversimplified view of public culture, institutions, and teachers.

The competing narratives produced in more recent histories such as Gold's and Fitzgerald's are valuable for the discipline because their historiographic practices challenge the disciplinary imaginary through a highlighting of new and varied historical evidence. I argue that this highlighting provides a positive example of how specific rhetorical strategies might be used by future historians in continuing to challenge and disrupt binaries such as those promoted by Douglas, Berlin, Crowley, and Clark and Halloran. Application of these strategies will therefore promote different and enabling interpretations of composition students and teachers, especially in relation to public culture and academic institutions. At the same time, Fitzgerald's and Gold's histories, like many others, must employ prevailing narratives about CTRP to "make sense" of new 
historical evidence. As I noted earlier, this kind of reliance demonstrates the difficulty of getting away from prevailing narratives of CTRP. However, I would also contend that our ability to isolate this part of the problem through metahistorical critique is productive in that it should motivate future disciplinary historians to find new frameworks for the interpretation of historical evidence and new language with which to describe it - in other words, it should prompt "a concerted, collective effort to release ourselves from the pattern reflected here." As I continue this analysis, I intend to show how the progressive sequence of dichotomies produced by historians' acceptance of prevailing CTRP narratives projects chains of association that ultimately restrict the ways in which the discipline can describe and understand institutions, textbooks, teachers, and students. At the same time, I will discuss the limits and possibilities inherent to competing narratives of CTRP.

\section{Institutions and CTRP Narratives}

Although descriptions of rhetoric and composition's institutional context are rarely separated from discussions of textbooks, teachers, and students in our disciplinary histories, I separate them here, rather artificially, because doing so allows me to demonstrate how the power of CTRP's prevailing narrative(s) enables the discipline to conceive of these various agents in problematic ways, conceptions which can (and do) perpetuate systems of marginalization already in place. Specifically, my review of composition histories suggests that prevailing narrative(s) of CTRP employ and promulgate characterizations, first, of the academic institutional context, curriculum, and first-year composition course as inherently antithetical to the interests of the discipline (in both its classical and modern configurations), as well as teachers and students. Second, 
CTRP's prevailing narratives designate those textbooks produced during the nineteenth and most of the twentieth centuries as a homogeneous group that ultimately promotes a linear, unimaginative, product-oriented view of writing. This characterization is also often coupled with an implicit or explicit assumption that textbooks directly correlate with actual pedagogical practice. Third, within prevailing CTRP narratives, teachers and students are, more often than not, represented as non-agentive subjects who are acted upon or forced to act by outside (usually inanimate) agents. An exception to this can be seen in histories that ascribe agency to teachers, in which case their actions tend to be depicted negatively. Students occasionally achieve agency when framed according to the CTRP narrative, but when they are, they are characterized as resistant or resenting subjects, oftentimes in response to teachers but (importantly) not to the institution or textbooks. Finally, prevailing narratives about CTRP assume that CTRP is a "real" rhetorical theory and pedagogical practice.

As is demonstrated in Douglas' example in the previous section, for many compositionists, Harvard is the most readily available institutional analogue for CTRP (and, for that matter, for FYC, which I deal with in more detail in chapter 3). Patricia Donahue remarks in her conclusion to a recent collection of disciplinary micro-histories that nearly every essay in Local Histories refers to Harvard as a disciplinary signifier or narrative when it is conflated with the disciplinary imaginary to represent the discipline's origin: "As the story goes," she explains,

freshman writing began to assume shape as a separate academic program at Harvard in the nineteenth century, and the Harvard model was then widely reproduced elsewhere.... The Harvard narrative as a story of origin and imitation has become so deeply entrenched within our discipline as to function as an "always already" beyond which it can be difficult to go. (222) 
And although many have disputed the degree of influence ascribed to Harvard by historians such as Kitzhaber, Berlin, Connors, Donald Stewart, Crowley, and others, the word "Harvardization" still works as a "useful synecdoche for what happened in the closing years of the nineteenth century," according to Halloran ("From Rhetoric" 176). Indeed, even historians who want to work against prevailing narratives of CTRP must still refer to Harvard to make their work relevant, as many of the micro-histories in the Local Histories collection show. Despite Donahue's and Halloran's deliberate acknowledgement that Harvard acts as a signifier for multiple institutions of higher education and often gets folded into the disciplinary imaginary, neither considers to what ends this conflation has occurred or why, in Halloran's case, it is worth defending. As I proceed with this metahistorical analysis, I demonstrate that the "Harvardization" of composition has limited the discipline's habits of representation and offer an explanation for how this conflation has nevertheless benefited the discipline in some important ways. $^{21}$

If we return to the binaries associated with professionalism, it is not difficult to see how Harvard acts as CTRP's institutional equivalent: as the quintessentially modern American university, it celebrates the individual and caters to the elite. Its private and exclusionary nature gives it (and its students, faculty, and administrators) higher cultural capital and, ostensibly, more political power. And, according to prevailing narratives, Harvard's model (of CTRP as practiced in required FYC) carried great influence and was replicated across institutions of higher education all across the United States (see Stewart "Harvard's Influence"). In other words, Harvard itself (and its representatives, especially

\footnotetext{
${ }^{21}$ See also Chapter 3, where I critique the relationship historians have established between Harvard and first-year composition.
} 
Channing and Hill, Eliot, and Francis J. Child) has often been blamed for the rise of CTRP. On the one hand, this fusion between Harvard and the disciplinary imaginary has highlighted for the discipline the capabilities of an institution to repress and marginalize those who already hold little power. On the other hand, I argue that this blame is not only misdirected in that it connects composition studies to a single, unrepresentative institutional context, but it also constrains the available options for the discipline's selfdescription.

Susan Miller's feminist macrohistory, Textual Carnivals, illustrates how an attempt to revise previous accounts of composition history becomes limited when it fails to distinguish between the real and the disciplinary imaginary. ${ }^{22}$ In this account, Miller wants to disrupt our most popular disciplinary narratives; specifically, she argues, this means giving voice and value to those people who composition generally takes to be its "subjects" - that is, students and teachers - and "making them 'relevant' to contexts we already find greater than the sum of their parts" (3). Unlike the macrohistories composed by Berlin and Connors, Miller's analysis is supplemented by archived department catalogues and institutional surveys, and her intent is to compose a feminist and culturalmaterialist history that highlights the value of student and other "commonplace" writing practices, especially in contrast to what she sees as a literary bias in English studies.

While her feminist perspective provides an important intervention in traditional historiographic assumptions and practices, Miller's revisionist attempt fails to adequately subvert prevailing narratives of CTRP (or FYC and the literature/composition binary, as I discuss in Chapters 3 and 4). In her analysis of more than seventy-five catalogues

\footnotetext{
${ }^{22}$ Of course, as I note in my discussion of the real and the disciplinary imaginary, I do not want to suggest that a historian can ever directly connect with the real, as it is inevitably lost to the past. My point here is that Miller takes the disciplinary imaginary for granted and does not explicitly draw attention to it as such.
} 
representing fifteen universities (67), Miller finds that "Composition has not been a poor or preservative version of classical rhetoric, or a unified application of the modes and of mechanical correctness, or an indoctrination to monolithic literary values that appear designed to counter other professional interests - except in its introductory form" (73, emphasis original). So, although her study reveals that "[u]ndulating and distinct curricular purposes comprise 'English' and the writing taught in it," Miller does not dispute prevailing narratives about freshman composition, Harvard (represented in this passage by Eliot), and their relationship to CTRP (73). Indeed, for Miller, it is the formalization of first-year composition, represented in elite institutions like Harvard, that allows "the new university" - which she describes as "this repressive new institution of the mother tongue" - to "implicit[ly] discriminat[e] among students" and "organiz[e] and stratify[] many functions in society" $(55) .{ }^{23}$ Here, we can see Miller move from an ostensibly "real" practice - the first-year course's "intense focus on mechanical correctness" $(60)$ - to the disciplinary imaginary without making a distinction between the two; as a result, Miller's historiography suggests that the establishment of composition at Harvard was a "conscious[]" decision on the part of administrators, meant to 'test students' knowledge of graphic conventions, to certify their propriety, and to socialize them into good academic manners" (66). Such historiography effectively forecloses the rhetorical possibilities through which first-year composition might be evaluated and described. ${ }^{24}$

This preservation of prevailing CTRP narratives about institutions - especially couched as it is within Miller's feminist and revisionist perspective - results in an

\footnotetext{
${ }^{23}$ Importantly, English cannot be accurately described as the "mother tongue" in a nineteenth-century American context.

${ }^{24} \mathrm{I}$ discuss what 1 see as possible alternative interpretations more thoroughly in Chapter 3.
} 
upholding of a problematic ideology of composition: First, this ideology attributes a high degree of power to academic institutions, which in turn sustains prevailing assumptions about students and teachers as relatively powerless. Second, it reduces the problem of CTRP to a single institutional source ${ }^{25}$ instead of acknowledging the complex relations among culture, public and private institutions, administrators, students, and teachers - all of which work together to shape practice. Third, this view of institutions overlooks the many individuals who actually construct and drive institutional theory and practice. And finally, this view of institutions assumes that all educational institutions serve repressive functions.

I wish to emphasize here that our understanding of how academic institutions have worked in relation to writing instruction will not necessarily change in positive ways once we turn our attention away from Harvard; rather, I claim that historiography that maintains the distinction between actual practice and the disciplinary imaginary can productively disrupt the problems I outlined above, even if the historical evidence supports prevailing narratives about CTRP. One example of this kind of historiographic practice can be found in Kenneth Lindblom, William Banks, and Rise Quay's essay "Mid-Nineteenth-Century Writing Instruction at Illinois State University: Credentials, Correctness, and the Rise of a Teaching Class." Lindblom et al.'s analysis of the practices and theory instituted at Illinois State Normal University, which they describe as "militaristic" and "rule-bound" (96), supports "the more traditional 'Harvard Narrative' of composition history" in many ways (103). However, their micro-history disrupts prevailing narratives that associate Harvard's influence with CTRP in that "the context

\footnotetext{
${ }^{25}$ Some historians have certainly acknowledged the important roles played by John Genung and Fred Newton Scott in order to show how Harvard's institutional power was challenged. However, my focus on Harvard here represents the focus of many of our most widely cited histories.
} 
and timing of [Harvard's] history is significantly different, as are the attitudes with which correctness was rationalized and enforced" (103). Lindblom et al.'s analysis competes with prevailing narratives about CTRP in important ways: Specifically, they triangulate their analysis, examining not just the theories of composition professor Albert Stetson, but also letters written by two of his students, all in relation to "officialized accounts and other historical examinations of ISNU pedagogy" (95). Because this triangulation focuses on a variety of practices usually considered separately, it resists a reductive interpretation of what might appear on the surface to be yet another example of Harvard's clout. Further, while Lindblom et al.'s history calls Fitzgerald's generally positive conclusions about normal school pedagogy in "A Rediscovered Tradition" into question, their history does not ultimately discount Fitzgerald's research. Instead, they hope that their history will motivate future historians to value "alternative[s] to a more ideal history of composition" (112). Lindblom et al.'s work leads to a productive interrogation of both competing and prevailing narratives about CTRP that neither fully affirms nor denies these narratives but instead emphasizes the value of keeping our conclusions about history unsettled, creating impetus for further research.

Metahistorical analysis of Gold's “"Eve Did No Wrong”" and Jane Greer's “"No Smiling Madonna" helps illustrate the kind of history that can be masked when Harvard is assumed to work as an appropriate institutional metaphor within prevailing narratives about CTRP. In "“Eve Did No Wrong,"” Gold surveys archival documents at Florida State College for Women, a public women's college, in order to compare student writing to the prevailing understandings of women's education around the turn of the century. Instead of assuming that evidence of CTRP in some composition courses represents all of 
the writing and writing instruction that occurred at FSCW - as historians who understand CTRP through disciplinary representations of Harvard have - Gold looks instead across the English department's course offerings and, like Lindblom et al., uncovers a complex narrative: "Students were ... exposed to a wide range of pedagogical approaches. Under Chair William Dodd, writing instruction at the college combined a current-traditional emphasis on correctness with an early and long sustained turn to the social" (W181). He finds that "the rhetorical environment at FSCW created a robust climate of expression for students that complicates our understanding of the development of women's education in speaking and writing" (W179). Gold argues that "a confluence of competing forces combined to shape instruction, reminding us that we cannot easily draw clean causal lines between ideology and pedagogy, fit instruction into neat epistemological categories, or rely solely on first-year composition for evidence of rhetorical instruction" (W181). Here, Gold explicitly rejects those patterns of representation that encourage scholars to blur the lines between actual practice and the "neat ... categories" of the disciplinary imaginary. At the same time, Gold relies on the same problematic categories he wants to work against - by presenting various pedagogical approaches as current-traditional or social in order to make sense of historical evidence that would not otherwise be intelligible within prevailing narratives about CTRP. As a result, Gold's historiographic choices ultimately reinforce those patterns of representation that designate certain practices as "dominant" and others as "alternative." These patterns of representation, in turn, solidify a hierarchy of value that calls attention to certain practices over others and promotes the sense that seemingly unintelligible practices and perspectives do not fit the discursive sphere, which therefore makes them seem unsuitable for analysis. Gold's example 
affirms how difficult it is to "release ourselves from the pattern" of problematic representation and suggests that we need to isolate and define rhetorical strategies that will more successfully avoid this pattern through continued metahistorical critique.

In "'No Smiling Madonna," Greer also uncovers a complex institutional history that would not be easily explained according to prevailing accounts of CTRP, and I argue that her historiographic practice illustrates one rhetorical strategy that could help solve the problems that Gold encounters. In this article, Greer documents the role of "socialist and feminist" Marian Wharton in her development of the English curriculum at the shortlived People's College, a distance education program located in Fort Scott, Kansas. Wharton's writing curriculum had as its "explicit goal" the "empowerment of the working class" (249), but, as Greer's analysis of Wharton and her textbook Plain English demonstrates, "even the most liberatory educational agendas can inadvertently cooperate with conservative interests in broader culture" (267). Greer interprets Wharton's pedagogical approach as both disciplinary and empowering for students; this interpretation both supports prevailing narratives about CTRP and popular representations of academic institutional culture at the same time as it rejects these narratives in favor of competing narratives similar to Gold's. Greer's conclusions about Wharton and the People's College are deliberately unsettling. She explains that "[r]ather than attempting to 'salvage' Wharton's pedagogical agenda by integrating ... two contrasting stories of her work or 'fixing' the contradictions by privileging one story over the other," she intends for her work to illustrate the value of complexity in our historical narratives. Because Greer calls attention in her historiography to both the prevailing and competing narratives that emerge out of a single site of writing instruction and does not 
attempt to resolve the seeming contradictions between these interpretations, she successfully demonstrates at least one rhetorical strategy with which historians might subvert problematic patterns of representation.

\section{Textbooks and CTRP Narratives}

Composition historians' early overreliance on textbooks as a key source in tracing the history of writing instruction has been, at this point, well documented by Miller, Nelms, Varnum, and Gold, among others. I intend in this section, therefore, not to prove that textbooks have been used problematically in our disciplinary histories - indeed they have - but rather to analyze how prevailing and competing narratives about CTRP have both shaped and restricted the discipline's understanding of textbooks. Prevailing narratives' focus on textbooks has provided an important starting point for the discipline to understand its history; further, this focus has encouraged compositionists to take a critical stance toward the rhetoricity of contemporary textbooks. At the same time, prevailing narratives about CTRP have made it acceptable within the discipline to interpret textbooks in ways that sustain, rather than challenge, popular definitions of CTRP through habitual conflation of textbook evidence and the disciplinary imaginary. Specifically, disciplinary narratives about CTRP promote an ideology of composition that assumes textbook use has a one-to-one correlation with actual pedagogical practice. Further, these narratives construct and perpetuate popular misconceptions of teachers, teaching, students, and student writing. Finally, these narratives and their attendant ideologies encourage compositionists to interpret textbooks that contain "evidence" of CTRP negatively, thereby forwarding the view that CTRP is inherently arhetorical and that "practical" skills are antithetical to the goals of contemporary composition. Through 
metahistorical critique, we can better understand how, and to what ends, competing narratives have problematized this ideology.

Two early essays by Connors and Berlin provide good starting points for an analysis of how prevailing narratives about CTRP have framed composition's discussions of textbooks. In his 1981 essay, "Richard Whately and Current-Traditional Rhetoric," Berlin attempts to revive Whately's importance as a rhetorical scholar; he argues, in effect, that had certain portions of Whately's rhetorical theory been incorporated in A. S. Hill's and John Genung's textbooks, The Principles of Rhetoric and The Practical Elements of Rhetoric, we might not have the same kind of "tradition" as the Hill/Genung brand of CTRP that, Berlin argues, was evident in composition at the time. What's interesting to me is not whether Berlin is correct about Whately, but how he ties a prevailing narrative about CTRP directly to Hill's and Genung's textbooks. Drawing on Young's definition of the CTRP paradigm, Berlin contends that Young's "list" of CTRP features "is immediately familiar to any teacher who has even glanced at the table of contents of the numerous sample composition textbooks which yearly arrive in the mail" (11). After quoting Young's definition in full, Berlin turns to Hill's and Genung's textbooks, claiming that these textbooks comprise "[t]he immediate sources of this paradigm" (11, emphasis added). Then, Berlin summarizes the features of Hill's and Genung's textbooks in such a way that they obviously match up with Young's definition of CTRP: First, "[t]he part of the text concerned with the four modes of discourse emphasizes argument at the expense of persuasion. Even argument, however, is diminished as it is made no more than the equal partner of description, narration, and exposition" (17); this explanation corresponds well with Young's argument that CTRP 
"[classifies] discourse into description, narration, exposition, and argument" (qtd. in Berlin 11). According to Berlin, "[t]he other part of the text - usually half of the work and frequently more - is devoted to problems of style and usage" (17); this explanation supports Young's claim that CTRP has a "strong concern with usage (syntax, spelling, punctuation) and with style (economy, clarity, emphasis)" (qtd. in Berlin 11) Hill's and Genung's textbooks "[treat] ... the word, sentence, paragraph, and the essay as a whole" in order to "[reduce them] to a set of critical principles which are to be applied to the written product, not learned as a process" (17), which again matches Young's description of CTRP as "[analyzing] discourse into words, sentences, and paragraphs" and "[emphasizing] the composed product rather than the composing process" (qtd. in Berlin 11). While I find Berlin's conflation of the real with the disciplinary imaginary problematic in ways that I detail further below, his efforts to match historical textbook evidence with contemporary practice highlights how knowledge of composition history can add depth to the contemporary discipline's knowledge about itself. Further, Berlin's emphasis on the connection between contemporary practice and the rhetoric of textbooks was and is valuable for the discipline because it isolated at least one avenue through which problematic practices emerge and can therefore, with critical awareness, be avoided in the future.

Like Berlin's "Richard Whately," Connors' 1986 essay, "Textbooks and the Evolution of the Discipline," also relies on prevailing narratives about CTRP, a reliance that helps fix the boundaries of the discipline's habitual approach toward textbooks as artifacts of pedagogy for analysis. To his credit, Connors' evaluation of Hill's and Genung's textbooks (among others, including Barrett Wendell's) is much more nuanced 
than Berlin's; just as Paine and Larsen strive to understand Channing within his cultural context, Connors recognizes that nineteenth-century textbooks represent authorial responses to cultural demands. He explains: "In Hill, Genung, and Wendell we have the first attempts at a modern written rhetoric, the first rhetoric of the century to really go beyond the orally-based theories of earlier rhetoric" (109). Further, in this essay at least, Connors does not see the emergence of CTRP as a definite signifier for the loss of classical rhetoric; here and elsewhere in his early work, he emphasizes the connections between CTRP and the classical tradition. ${ }^{26}$ In "Textbooks," Connors contends that one reason "these books are important [is] because they carry on the central formal characteristic of oral rhetorical theory: they are atomistic in perspective, dividing and subdividing the subject into many, many discrete classes, levels, figures, skills, behaviors, and rules" (109, emphasis original).

In spite of these qualifications, however, Connors' conclusions are ultimately shaped by prevailing narratives of CTRP, which he describes here as "that set of practical and theoretical doctrines" that evolved between 1860 and 1900 (107). In Hill's, Genung's, and Wendell's textbooks, Connors sees the "classic elements of currenttraditional rhetoric": "the modes of discourse, Unity, Coherence, and Emphasis, the patterns of exposition, Clearness, Force, and Energy, [and] the organic paragraph" (109). And although Connors traces the "formal characteristic[s]" of these textbooks to the classical tradition, he argues that "much of the theoretical content of these three books

\footnotetext{
${ }^{26}$ See, for example, Connors' 1981 essay, "Current-Traditional Rhetoric: Thirty Years of Writing with a Purpose," in which he characterizes CTRP as a "dynamic entity forever in flux" that "is a palimpsest of theories and assumptions stretching back to classical antiquity" (208). However, as can be seen in my discussion of Composition-Rhetoric at the beginning of this chapter, Connors is not consistent in his evaluation of CTRP (or "composition-rhetoric"). Our ability to notice this kind of historiographic inconsistency - across texts and over time - can lead to further questions and research; I argue this is one of the values of conducting metahistorical critique.
} 
was recent" (109, emphasis original). For Connors, because the development of these textbooks' content is modern, this development illustrates both the rise of CTRP and composition's detachment from the classical tradition. Moreover, Hill, Genung, and Wendell "created the rhetorical theory that would shape American composition" and "[remain] the heart of composition textbooks for over sixty years" (109). Instead of analyzing the textbooks as evidence of historically specific values and practices, Connors' interpretation is subsumed within a prevailing narrative of CTRP.

Connors' analysis suggests, first, that the "theoretical content" of these textbooks was "original," leaving readers with a sense that the texts were composed outside of, or separate from, specific discursive traditions. This assumption implies, therefore, that the contemporary discipline can easily dismiss nineteenth-century rhetorical theory and replace it with a richer tradition, such as that represented by "classical" rhetoric. Promoting such a dismissal means, in turn, also dismissing the beliefs, values, and perspectives of those who helped produce rhetorical theory, purposefully or inadvertently, in nineteenth-century U.S. Second, because these were the "most popular" textbooks, Connors' analysis does not allow for consideration of other textbooks produced at the same time, which would have carried influence within other institutional and disciplinary contexts, even if that influence was less remarkable. ${ }^{27}$ As more recent histories have shown (see for example Carr et al. and Greer), other textbooks were being produced at the same time as Hill's, Genung's and others, but these textbooks have been habitually neglected within our historical accounts of writing instruction because of our focus on dominant institutions, figures, and perspectives. In one sense, this focus has

\footnotetext{
${ }^{27}$ Connors bases his claims of textbook popularity primarily on the number of editions a textbook underwent and the length of time it remained in publication.
} 
helped the discipline make sense of larger public and institutional beliefs about literacy in the nineteenth century, and it is admittedly justifiable in a practical sense, since the documented popularity of these textbooks helps ground any claims that historians may wish to make about them. However, Connors' and other historians' focus on these dominant voices and popular textbooks has been forwarded not only by the material constraints of archival research, but by also an ideology of composition that hides ostensibly minor voices and practices.

And finally, Connors' assertions about the longevity and ubiquity of CTRP are based primarily on his analysis of textbooks published after Hill's, Genung's, and Wendell's, which he claims show little development or originality (110). This final claim forwards the presumption that textbooks represent actual pedagogical practice, which risks substantiating an unjust and unfortunately persistent stereotype of teachers. In fact, Connors illustrates how this substantiation can occur when he explicitly places the blame for composition's supposed "stasis" between 1900 and 1940 (a stance that shifts slightly but is ultimately maintained in Composition-Rhetoric) on teachers. I quote at length to demonstrate the nature of his historiography:

The most important cause of the morbidity that has caused some historians to label 1900-1930 the "Dark Ages" of composition was, however, the appallingly ignorant and reactionary nature of the audience for textbooks after 1900: the writing teachers. Interesting theory was not forthcoming because it did not sell as well as it had in the 1890's. And why not? Composition was moribund during this time for the same reason that had caused the popularity of simplistic textbooks a century before: the qualifications of the teachers in the classrooms. (111, emphasis added)

Here, Connors illustrates the damaging consequences that uninterrogated historiography can have for disciplinary agents: Because he conflates textbook evidence with the disciplinary imaginary, which supports prevailing narratives about CTRP, Connors can 
compose a seemingly "logical" chain of causation that both simplifies history and produces demeaning accounts of teachers and their pedagogical practice. Because historiography is a rhetorical practice that shapes and supports contemporary values, beliefs, and practices, and because Connors has been and continues to be widely cited in disciplinary scholarship, we can assume that this unfortunate chain of associations has helped naturalize and perpetuate oppressive patterns of thinking, reading, and writing about teachers of composition, especially those who are already marginalized thanks to unethical labor practices.

As I noted earlier, many historians since Connors and Berlin have challenged our discipline's overreliance on textbooks as historical evidence for actual values, beliefs and practices; however, these challenges do not invalidate the value of textbook analysis altogether. Carr, Carr, and Schultz, for example, argue in Archives of Instruction that their analysis of textbooks in the nineteenth and twentieth centuries avoids the problems perpetuated by Berlin and Connors because they keep questions about textbook interpretation open to debate. They stress the importance of placing

textbooks within their tradition ... [in order to clarify] what various books have in common - the topics conventionally covered in each, the materials recycled or appropriated from earlier texts in the tradition - and ... also make[] visible how they differ - their idiosyncratic treatments of familiar materials, the occasional strategic reworking of normative practices. (1617)

They contend that this contextualization "has allowed us to trace the intermittent migration of routines, practices, and principles from one tradition to another and to investigate the quite diverse relationships of each textbook tradition to various cultures of literacy and modes of textual production and reproduction" (17). Instead of interpreting textbooks as evidence to support prevailing CTRP narratives or as proof of what actually 
happened in the classroom, as Berlin and Connors do, Carr et al. strive for complexity in their analysis of nineteenth-century textbooks. In fact, they see their analysis as an explicit rejection of the way that prevailing narratives of CTRP have dominated textbook analysis in our histories, writing that:

Close readings across these textbook traditions challenge several familiar ways of characterizing nineteenth-century textbooks. It is more appropriate and useful to understand rhetorics as practical than as belletristic or current-traditional; to see that readers inculcate practices of analysis and notions of propriety while providing training in oral performance; and to understand composition books as prompting invention and composing processes and not simply imposing correctness. (206)

Carr et al.'s strategies of contextualization are important for the discipline because these rhetorical strategies at once value the practical goals of students and refuse those patterns of representation that indicate that textbooks can and should be interpreted as direct signifiers of actual values, beliefs, and practices.

Carr et al.'s claim that composition textbooks have been and are used rhetorically supports Greer's and Fitzgerald's analyses of how textbooks were used at the educational institutions they study; together, these historians demonstrate the value of assuming that our knowledge about the history of writing instruction remains unsettled. As I discussed in the previous section, Greer specifically analyzes Marian Wharton's textbook, Plain English, which ultimately defined the English coursework at the People's College. Greer finds that Wharton's textbook neither completely affirms nor rejects common disciplinary understandings of CTRP. She explains that:

Despite [Wharton's] expressed desire to help working-class students understand that they could play a role in re-shaping our continually evolving system of language and thus redefine "correctness," Plain English is actually a complex interweaving of resistance to and compliance with the dominant linguistic systems that privilege formality, 
conciseness, and the rules of grammar accepted by the economic elite. (263)

In the case of the People's College, Greer is correct in conflating Wharton's pedagogy with Plain English because all courses were taken by correspondence - as such, the textbook can be understood as a direct representation of Wharton's perspective and would have had a particularly profound influence over pedagogy. Greer's conclusions about Wharton are nuanced:

... [Wharton] shifted among contradictory positions: encouraging working-class students to seize control of language, yet disciplining their unruly language practices so that critics of the labor movement could not dismiss them as ignorant; helping to define the mission of the People's College as an institution that would teach students how to think, yet developing an English textbook that fits into the tradition of grammar guides that ask students only to fill in blanks; offering pointed critiques of the traditional educational establishment and its politics, yet designing a pedagogy that would then allow working-class students to sound as if they too had spent years at elite universities. (268)

Greer's analysis about Plain English constructs an important narrative for the discipline that competes directly with Berlin's and (especially) Connors' conclusions about textbooks, teachers, and prevailing narratives of CTRP: First, Greer's history uncovers alternative textbook traditions that are otherwise neglected within prevailing narratives; second, it challenges flawed assumptions about teachers and about the static nature of composition pedagogy in the first half of the twentieth century; and finally, it resists easy explanations for how textbooks "fit" within composition history. Greer's analysis supports prevailing narratives about CTRP to a certain extent, but it also exposes the limitations of these narratives. I argue that the discipline can benefit from her historiographic approach in much the same way that it benefits from Lindblom et al.'s in that, because Greer refuses to couch her findings neatly within either prevailing or 
competing narratives, she affirms the value of maintaining complexity in the discipline's representation and interpretation of textbooks.

Fitzgerald, too, arrives at conclusions that compete with Berlin's and Connors': Her analysis of how textbooks and grammar instruction were used at Wisconsin normal schools at the turn of the century in "A Rediscovered Tradition" is worth our attention because it isolates yet another rhetorical strategy that future historians might draw on as they attempt to effectively subvert problematic patterns of textbook representation. Whereas Greer interprets the grammar exercises and "traditional" structure of Plain English as necessarily correlating with arhetorical purposes (and indeed, this correlation may be correct, given that students were "taught" by the textbook rather than by a teacher), Fitzgerald's analysis calls this assumption into question. She argues, against prevailing narratives about CTRP, that the teaching of grammar does not necessarily lead to an arhetorical or uncritical application of this knowledge, and she grounds her contention on the different pedagogical traditions that influenced these schools. In her analysis of the grammar discussions held at a normal-school teacher conference held in Oshkosh, Wisconsin, Fitzgerald explains:

Though normal faculties bought into the common notion that grammar study improves logical thinking, their approach to implementing the belief in their teaching practices was different from that of academic colleges.... [The discussions about grammar at the Oshkosh conference] effectively illustrate the point that a pedagogical perspective provided the potential to pry open academic subject theory to critical evaluation. (236-37)

In other words, Fitzgerald's historical research demonstrates that evidence of grammar instruction does not necessarily lead to or correspond with the disciplinary imaginary's definition of "current-traditional" pedagogical practices. Metahistorical critique helps us 
understand, value, and build upon Fitzgerald's contribution in the context of other historiographic practices and prevailing narratives about CTRP.

Finally, Berlin's and Connors' historical work rests on the assumption that "[d]uring the eighteenth, nineteenth, and early twentieth centuries, composition theory and pedagogy were overwhelmingly shaped by one great force: textbooks" (Connors, "Textbooks" 100). But, as Robin Varnum's research reminds us, this claim rests on another problematic assumption: that textbooks were always used in writing instruction. In Fencing with Words, Varnum provides a compelling counter-history to those histories that depend on textbook evidence. She takes as her subject the Amherst 1-2 writing program, overseen by Theodore Baird, which used no textbooks whatsoever and positioned student writing at the center of the classroom. Much of her evidence stems from archival research at the institutional site, as well as collection of oral histories from Baird's students and colleagues. She argues that the Amherst program, and others like it, "has been overlooked" because "it flourished during a period when the teaching of composition was supposed ... to have been governed by an obstructive 'currenttraditional paradigm", (7). Further, Varnum argues that "the kinds of materials historians have chosen to examine and the lenses through which they have examined them have kept them from seeing some of what was to be seen" - such as sites of writing instruction that lacked textbooks" (7). Metahistorical critique brings Varnum's history into high relief when set against prevailing narratives about CTRP. Specifically, Varnum's focus on absence highlights the disciplinary imaginary's dependence upon "found" and "accessible" materials, a dependence that obscures the fact that historical archives contain both present/locatable and absent/lost beliefs, values, and practices. Varnum's history 
contributes to the discipline, then, not only in that it adds to our general knowledge of composition history, but also in that it reminds us that we need to continually pay attention to absences or gaps in our knowledge and to always maintain distinctions between real (often absent) practices and the disciplinary imaginary, which is built out of available artifacts. When we do this, I argue, we move closer toward "releas[ing] ourselves from" those problematic "pattern[s]" of representation of textbooks, allowing for new and surprising interpretations of pedagogical practice that values the everyday challenges faced by teachers and students of composition.

\section{Teachers, Students, and Prevailing Narratives of CTRP}

Just as certain institutional and textbook examples become folded into narratives about CTRP as "real" signifiers of bad theory and practice, so too do teachers and students. In this section and the next, I conduct a metahistorical critique of prevailing and competing narratives about CTRP in order to explicate how the discipline has represented teachers and students and with what theoretical and material consequences. Many disciplinary historians have brought students and teachers to the forefront of their histories to demonstrate the marginalized roles they have historically occupied due to unethical cultural, institutional, and administrative views and actions. However, my analysis reveals that these same historians - who hope their scholarship will promote inclusive and ethical approaches to students and teachers - have often composed histories that unwittingly reinscribe the same patterns of injustice that they hope to work against. This becomes especially clear when examining histories that forward prevailing narratives about CTRP, in that the historiography contained therein promotes an ideology of the discipline in which students and teachers are presented as individuals who either 
lack agency or are acted upon by outside agents (including culture, institutions, and even textbooks). When teachers are described as having agency according to prevailing narratives, their actions tend to be described negatively. And students who attain agency in our histories are most often depicted as resentful or resistant to the classroom environment. In my analysis of prevailing and competing narratives of CTRP in this section and the next, I maintain that the discipline's ability to treat teachers, teaching, students, and student writing fairly and to represent them ethically in our scholarship (in the present, past, and future) depends, in part, on our willingness to interrogate, acknowledge, and manipulate both the possibilities and limitations inherent to our narratives about CTRP.

Brereton's The Origins of Composition Studies provides one example of a history that composes a prevailing narrative about CTRP in relation to students and teachers. This collection was and continues to be an important contribution to composition history in that Brereton reproduces primary materials previously only available in archives including original composition textbooks, institutional surveys, student writing, examinations, and journal articles - for the discipline's use and analysis. Brereton clearly intends to challenge some popular misconceptions about composition's history: He notes, for example, that "early composition theorists and practitioners were very aware of what they were doing, and often made quite conscious choices.... And the documents display a great deal of diversity, which may belie the notion that things were so uniform - or so uniformly bad" (xiv). However, Brereton's historiography in the introduction to the book conflates the disciplinary imaginary with the beliefs, values, and practices specified within these documents and belies his earlier qualifications because he repeats a version 
of the prevailing CTRP narrative. He connects CTRP with the loss of a classical tradition in American colleges, writing: "This book chronicles the move from composition at every stage of a student's college career to composition confined to the first year, and from a saturation in a rhetorical tradition of some two thousand years to its replacement with a new, streamlined curriculum which ... emphasized error correction and the five modes of discourse" (17). Continuing, Brereton connects the shift to CTRP with the writing teacher, who can best be described as "the accomplice of the authorities, or in fact the enforcer.... a stern taskmaster skilled in rooting out falsehood and cant" whose pedagogy was largely "adversarial" (19). Students, according to Brereton, "were expected to listen, to be kept under control, and to be passive learners" (18), performing "in fear of the teacher's scorn" (19).

Although Brereton does not dwell for long on these characterizations, the effects of his historiography are important to consider: Because he fails to distinguish between the specific contexts in which these documents were produced and the disciplinary imaginary, which allows for and supports prevailing narratives of CTRP, Brereton's historiography supports an ideology of composition that represents teachers, on the one hand, as agents of institutional desires who act out what little authority they have in opposition to students. Students, on the other hand, are characterized as passive subjects, acted upon by both teachers and institutions. While Brereton is careful to qualify most of the other claims he makes in the introduction to Origins, his subscription to prevailing narratives about CTRP in the case of teachers and students demonstrates, first, how difficult it is to move away from these narratives in meaningful ways even when one's intention is to highlight the specificity of the archive. And second, this subscription to 
prevailing narratives about CTRP illustrates the consequences of our habits of representation: Because Brereton's contribution to composition studies is widely cited and highly regarded in the discipline, his repetition of problematic patterns of representation has the potential to make these characterizations of students and teachers appear "natural" to those who take his historiography for granted.

By the time Origins was published, many of the stereotypes of teachers and students in the above passages were already in place. For example, in much of his work, Connors attributes the rise of CTRP to the demands made on composition teachers by the individualized attention to students required in the teaching of writing (in contrast to oratorical instruction, which could be given in lectures to large groups of students), as well as by increased college enrollment. In Composition-Rhetoric, he claims that "Composition courses of the latter nineteenth century became hells of overwork that drove away all those teachers who were upwardly mobile and ground down those who were not" (189, emphasis added). In The Methodical Memory, Crowley arrives at similar conclusions, writing that CTRP attained popularity because of this overwork. She explains that "if the theory of composition used were highly formalized [with CTRP], the work of grading papers could be simplified, since harried teachers could ignore the content of their students' themes and would only need to assess the degree of their conformity to the formal features prescribed by the lectures and the textbook" (11, emphasis added). Between these two passages, Crowley and Connors construct a familiar narrative that clearly connects prevailing narratives of CTRP with teachers: Institutional demands create "hells of overwork" that require teachers, in their "harried" state, to scramble for "simplified" solutions that they can "prescribe" to students. In these 
passages CTRP seems to have been born out of teachers' ignorance of rhetorical theory and lack of agency (or creativity) when confronted by the institution's new standards.

Many have substantiated Connors' and Crowley's contention that composition teachers around the turn of the century experienced an increased workload, in part because they had to teach writing instead of oral rhetoric to large numbers of students. I am not disputing this fact. What I would like to call attention to, here and elsewhere, is how Connors' and Crowley's historiography supports a particularly negative depiction of teachers, a depiction that ultimately engenders theoretical and material consequences for the contemporary discipline. Connors and Crowley intend, in this passage and others like it, to establish that there is a historical precedent for the unethical labor practices that can be seen today in composition studies (and, for that matter, in the university at large). However, because they describe composition courses in the late-nineteenth century as a form of "hell" and teachers as eager to escape, Connors' and Crowley's historiography also promotes an ideology of composition that represents teachers as passive subjects who would acquiesce to teach writing under these circumstances only because they had no other choice. This conception of composition delimits how the discipline perceives teachers' desires and also how it defines "work." Connors and Crowley, in other words, speak for teachers and impose their own values onto diverse figures who occupy very different moments in history than our own. When our historiography constructs representations of teachers as passive, as Connors' and Crowley's do, this representation carries over into our contemporary interpretations of the needs and desires of teachers. This representation, therefore, works rhetorically to keep teachers in their often-already marginalized locations in the academy. 
Susan Miller disagrees with Connors' and Crowley's claims about the relationship between changing institutional demographics and the rise of CTRP, but metahistorical critique shows that Miller's historiography ultimately forwards similarly problematic representations, in this case of students and student writing. In an effort to highlight the oppressive potential of institutions, especially in relation to students, Miller argues in Textual Carnivals that the rise of CTRP occurred as a deliberate effort (made by an unspecified but reprehensible agent) to stratify and exclude students within the new professional culture of the university. Against Connors' and Crowley's explanations, Miller writes:

We consequently mistake a cause for a result if we attribute new composition assignments and textbook treatments of them to numbers of students. Instead, those numbers and textbooks precisely fit the purposes for establishing such a course at all. Both the earliest 'theory' behind composition and its practical implications divided written texts from actual writing situations. (61)

Indeed, for Miller, it is the (malicious) academy that, through its institutionalization of FYC and promotion of CTRP, "strip[s] from new students and a nation of unschooled potential writers their needs and desires to create significant pieces of writing" (55), that "reduce[s]" student writing to "objects of inconsequentiality" (59), and, in turn, abandons student writing, which is "left in its self-contained world of textual features, where its consequences are already limited to intransitive matters of "quality" (198). In other words, because Miller takes the existence and effects of CTRP for granted, she portrays student writing as though it can have no value if it is the product of CTRP, and she depicts students as helpless subjects upon whom CTRP works. ${ }^{28}$

\footnotetext{
${ }^{28}$ The problems I note here about Miller's representation of students and student writing are exacerbated by the fact that she never analyzes actual student writing in Textual Carnivals.
} 
Miller's historiography results in a debilitating representation of students:

Because students are represented as passive, it is the institution that must change; until the institution acts differently, students will continue to produce poor or "inconsequential" writing. The problem with this depiction has not to do with whether or not the institution has power (indeed it does), but rather with the fact that, within Miller's historiographic framing, students can and never will have power, which therefore devalues any writing that they happen to produce. ${ }^{29}$ Further, Miller describes those individuals who lack an education as a "nation" of "potential" writers - according to her historiography, until they have been "schooled," individuals are not and cannot be authors. Again, because the institution is depicted as having an overwhelming degree of power, the individual who writes - as well as what he or she composes - lacks value. Commendably, Miller intends her history to rescue students from exclusionary values, practices, and beliefs; this goal is shared by many scholars in composition. But despite her best intentions, Miller's descriptions of students and student writing, in these passages and elsewhere, ultimately reify these problematic values, practices, and beliefs because they rely on prevailing narratives about CTRP.

\section{Alternative Representations: Teachers, Students, and Competing Narratives of}

\section{CTRP}

Several historians offer compelling alternatives to Connors', Crowley's, and Miller's characterizations of students and teachers. I argue that these characterizations are available to these historians because they resist merging the real with the disciplinary imaginary; in maintaining the distinction, historians compose competing narratives about

\footnotetext{
${ }^{29}$ Importantly, when Miller writes about students in contemporary composition, she attributes and even emphasizes their agency as writers. See for example "How Writers Evaluate Their Own Writing."
} 
CTRP. In this section, I analyze competing narratives within the context of prevailing narratives about CTRP in order to demonstrate, via metahistorical critique, how alternative representations of teachers and students can produce different material and theoretical consequences for the discipline and its agents. Although these competing narratives are not always effective at fully revising problematic patterns of representation, I intend for this analysis to show how a self-conscious interrogation of these patterns is an important first step in eventually subverting or disrupting them in lasting ways.

Susan Kates' Activist Rhetorics and American Higher Education, 1885-1937 provides alternatives to prevailing representations of teachers and pedagogical practice during the late-nineteenth to mid-twentieth centuries. Through her analysis of three groups of educators working at markedly different sites - Mary Augusta Jordan of Smith College, Hallie Quinn Brown of Wilberforce University, and Josephine Colby, Helen Norton, and Louis Budenz of Brookwood Labor College - Kates provides compelling evidence that demonstrates that rhetorical education likely occurred during the Progressive Era, a time period that other historians such as Connors dismiss as dominated by CTRP. Additionally, she uses this claim to make a clear distinction between the disciplinary imaginary and actual people and practices. She explains that "these educators drew attention to language 'deviations' of their students in ways that did not simply divide language practices into 'correct' and 'incorrect' English.... they recognized and respected the ways that language is tied to a sense of self and community" (15). Because she makes this distinction clear, Kates portrays teachers as having agency and good intentions. Kates' descriptions of Jordan, Brown, Colby, Norton, and Budenz stand in stark contrast to Connors' and Crowley's descriptions of pedagogy and teachers around 
the turn of the century: These educators, according to Kates, are deliberate in their pedagogical approaches, knowledgeable about the workings of language, and sensitive to their students' needs and positions in the world. In short, Kates' historiography constructs an interpretation of these educators that understands them, generally, within their historical contexts rather than her own.

Like Kates, Beth Ann Rothermel's history of writing instruction at Westfield State Normal School offers a generous interpretation of faculty values, beliefs, and practices about writing throughout the nineteenth century and into the twentieth. Rothermel, like Kates, describes Westfield's teachers as thoughtful, intelligent, and considerate of their students. Further, she describes professors as having support within an institutional context that promoted "[a] faith in the role of teachers, regardless of gender, as molders of community" - which she argues encouraged writing instructors to adopt active roles in the education of their students (39). Rothermel's historiography conveys that teachers had agency at Westfield Normal: She explains that, once the Massachusetts Board of Education pressured the school to change the curriculum so that it would be more "professional" and "practical," the faculty resisted - they

followed directives only in part, designing courses in composition that continued to require study in the 'practical art' of rhetoric.... They also continued to promote student involvement in extracurricular activities.... Westfield instructors of the late-nineteenth century strove to prepare future teachers not just to 'write and speak,' but to feel 'at home ... on the platform.' ("A Sphere of Noble Action" 54, emphasis added)

Westfield's faculty, according to Rothermel, "design," "promote," and "strive" - verbs that imply the kind of creativity and agency that is required in everyday teaching, in the nineteenth century and today. 
Some, such as Melissa Ianetta, might argue that Kates' and Rothermel's historiography constructs an "ideal" pedagogue, a representation that could be flawed in and of itself. In "Disciplinarity, Divorce, and the Displacement of Labor Issues," Ianetta warns against those "stories of disciplinarity" that become "emancipation narratives" through their historiography (69). I agree: without critical analysis, "ideal" representations will produce new problems and gaps in our knowledge. While we should continue to conduct critical analyses of all historiography, it is important to recognize the rhetorical consequences of assuming, with Kates and Rothermel, that teachers have (and have had) agency. I argue that this assumption is important and correct, not only because it acknowledges complex workings of power, but also because it encourages multiple and diverse interpretations of contemporary teachers. In assuming that teachers have some degree of agency, intelligence, and creativity, we not only add complexity to our historical knowledge, but we also add complexity to the disciplinary imaginary, which helps make distinctions between real practices and the imaginary more obvious. This added complexity, in turn, encourages compositionists to engage in new patterns of listening to and representing teachers in the past and in the present, which can reshape our narratives in ways that will subvert, rather than reinscribe, systems of marginalization.

Students and student writing also attain complexity in histories that highlight the differences between the real and the disciplinary imaginary and produce narratives that compete with those such as Miller's. Those historians who have examined actual student writing in the nineteenth and early twentieth centuries have found that writing is not "insignificant" to the students themselves, nor is it "self-contained" or "intransitive," as 
Miller assumes it to be. The descriptors exemplified in Miller's work (and others) devalue student writing as unreal and assume that the "practical implementations" of CTRP “divide[] written texts from actual writing situations" (Miller 61, emphasis added). While Miller intends for this characterization to highlight the oppressive potential of academic institutions, it in fact has the rhetorical effect of delimiting the possible and appropriate desires of students and overlooks evidence of these desires in student writing itself. Thus, it seems safe to say - and indeed, metahistorical analysis of competing narratives shows - that the desires outlined by Miller and others likely represent our desires, not those of students in the past or present. Just as problematic representations of teachers and pedagogical practice perpetuate the systems of oppression that scholars in contemporary composition hope to disrupt, so too do flawed representations of students and student writing.

In "Thinking Like That," Kathleen Welsch finds evidence that student writing was relevant to and meaningful for students in the nineteenth century, even as she measures this evidence against the disciplinary imaginary. Through a close examination of the writing of Mahala Pearson Jay, a 22-year-old female student at Oberlin and Antioch Colleges, Welsch contends that "Mahala no more wrote in an academic vacuum than students do today; the context of her time provided her compositions with a logic relative of her historical moment as well as her choices as a writer" (16). Further, although Mahala's expository writing “offers no personal disclosures about her life or interests," this does not mean that it is "unengaged" or "impersonal," descriptors used by Connors to describe the effects of CTRP on student writing in his 1987 essay, "Personal Writing Assignments" (Welsch 19-20). Welsch's interpretation disrupts popular 
assumptions about students and student writing as framed by prevailing CTRP narratives. I argue that because Welsch presents student writing as engaged and personal, her historiography constructs a representation of students themselves as having value - a goal that clearly aligns with those of contemporary compositionists. Welsch's analysis illustrates an important strategy with which historians might rhetorically maintain a separation between actual practice and the imaginary.

Some historians, including JoAnn Campbell and Sue Carter Simmons, interpret students as having agency through close analysis of their writing. Both of these historians examine student writing at Radcliffe, and both conclude that female students' writing exemplifies personal agency; they do not agree, however, about how this agency can or should be interpreted. Metahistorical critique of these histories allows us to compare how and why these authors construct their arguments in different but related ways, to acknowledge and interrogate the disciplinary values that these arguments uphold, to recognize gaps in our knowledge, and to isolate the limits and possibilities of our current historiographic practices.

In "Controlling Voices: The Legacy of English A at Radcliffe College 18831917," Campbell conducts a textual analysis of themes written by three Radcliffe students, Dorothea, Annie, and Mary Lee, in order to examine these women's experiences of writing and pedagogy at Radcliffe. She finds that two of the women, Dorothea and Mary, both recognize and respond negatively to the "banking theory of education," which was "alive and well at the turn of the century" (475). The awareness Campbell ascribes to these students encourages us to understand students as having agency in response to composition pedagogy; however, because Campbell's 
interpretation is couched within prevailing narratives of CTRP. Her reading of one of Mary's essays draws on common assumptions about the effects of CTRP on student writing:

In this lucidly angry essay, completely covering several pages and all the margins, Mary articulated her needs as a student: to be allowed to give opinions in a voice she felt expressed her individuality, and to receive a response to the content of her writing. The emotional pain of English A is reflected in her language of physical abuse, "bumped and battered." Although she didn't turn this draft in, she saved it along with her other themes, a record of the effects of an emphasis on correctness and what the student lacks. (475, emphasis added)

On the one hand, because Campbell's reading is backed by factual evidence that students at Radcliffe did not meet regularly in conferences, her interpretation of these students' writing seems plausible and affirms the repressive potential of teachers and institutions that composition has come to recognize and resist. On the other hand, however, Campbell's interpretation leads to a limited understanding of students and student writing: In the passage above, Campbell assumes that because Mary's writing "completely cover[s] several pages and all the margins," Mary is angry. Here, it seems that Campbell relies on the disciplinary imaginary to help her make sense of Mary's anger, which leads her to interpret Mary as a student who is resistant to the teacher, who, in his "emphasis on correctness and what the student lacks," prevents her from "giv[ing] opinions in a voice she felt expressed her individuality" and ignores "the content of her writing" (475). Mary is also angry because the institution and first-year composition "abuse" her and force her to save, but not turn in, the draft. While Campbell may indeed be correct in her interpretation of Mary, the fact that this interpretation so closely matches the representation of students and student writing in prevailing narratives about CTRP should prompt us to consider other readings and the conclusions to which they lead. 
Simmons' interpretations of student writing in "Radcliffe Responses to Harvard Rhetoric" offers an example of an alternative reading. In contrast to Campbell, Simmons finds that student writing - even theme-writing that meets "standard" academic expectations - is subversive. Simmons evaluates the writing of one student, Annie, which was produced in multiple composition courses over the span of her college career. Simmons' analysis aligns with Welsch's contention that what we would label "academic" writing today is not impersonal or unengaged; Annie's acquisition of so-called academic discourse, Simmons argues, allowed her to "[find] ways of writing with authority that positioned [Barrett] Wendell [her professor] as her equal. Annie found ways to integrate successfully her commitment to teaching and her observations and experiences as a student with the academic writing requirements she had to meet" (281). Because her conclusions are similar to Campbell's but give more credence to student writing according to the terms set by the students themselves, Simmons' analysis provides an alternative explanation for student responses to pedagogical practice and institutions, which in turn leads to a more nuanced understanding of composition history and contemporary students.

Although Simmons and Campbell agree that students at Radcliffe were resistant to institutional and pedagogical constraints, Simmons' refusal to confuse actual practice in this case academic prose - with the disciplinary imaginary, which assumes that academic prose is not personal, allows her to produce a more complex interpretation of students and student agency. While Simmons' interpretation may not ultimately be correct, and it does not necessarily discount Campbell's interpretation (since after all, we can never know the true desires or intentions of students), I argue, as I did in relation to 
teachers above, that Simmons' historiographic strategy is significant here. Like Kates' and Rothermel's rhetorical strategies, Simmons' historiography forwards an assumption that students have agency and act on that agency in complex ways that do not necessarily match what the collective disciplinary imaginary suggests. Because Simmons promotes this assumption through her historiography, she refuses the folding of the real into the imaginary and advances other ways of thinking, reading, and writing about students and student writing. In turn, the discipline comes one step further to releasing itself from problematic patterns of representation, especially those perpetuated within prevailing narratives of CTRP.

\section{Conclusion: Releasing Ourselves from the Pattern}

In dissecting disciplinary historiography across texts and over time, my analysis demonstrates that prevailing narratives about CTRP have served important rhetorical purposes for the discipline: Many of our early historians, including Berlin, Connors, Crowley, and Miller, were motivated by the potential ways in which the writing of history could help the field reject potentially oppressive pedagogical and rhetorical practices. As the discipline continued uncovering its history, prevailing narratives about CTRP helped composition highlight and move away from problematic practices. My own goals align with these early historians: I too hope that my scholarship will support and advance ethical values, beliefs, and practices.

This critique also shows that prevailing narratives about CTRP forward problematic representations of teachers and students. These representations - which neglect multiple and varied actual practice as they describe nineteenth- and twentiethcentury composition classrooms as "hells of overwork," teachers as "stern taskmasters," 
and student writing as "objects of inconsequentiality" - produce serious material consequences for students and teachers today. If we fail to intervene in these historiographic practices, we participate in the continued marginalization of students and teachers, especially those who lack institutional, economic, and/or cultural power. Although more recent historians, including Welsch, Kates, Rothermel, Campbell, and Simmons, have begun to revise our historiographic practices in meaningful ways, the competing narratives about and against CTRP that they produce often continue to rely on prevailing narratives - the same ones that have produced problematic ideologies of the discipline. This reliance exemplifies both the difficulty of maintaining a distinction in our historiography between real practices and the disciplinary imaginary, as well as the power of prevailing narratives, which seem to demand that new scholarship be "intelligible" according to its habits of representation.

The process of metahistorical critique exemplified in this chapter can help contemporary compositionists recognize, isolate, and revise the discipline's historiographic practices. Further, this process can help future historians of composition disrupt those practices that produce marginalizing effects, harness those practices that promote social justice, and foster a greater awareness of how historiography works as a rhetorical practice with significant political and material consequences. 


\section{CHAPTER 3:}

\section{THE QUESTION OF FIRST-YEAR COMPOSTION}

Just as references to current-traditional rhetoric and pedagogy (CTRP) in our histories often stand in for, or point toward, other disciplinary concerns, so too do references to first-year composition (FYC). ${ }^{1}$ For historians of rhetoric and composition, FYC represents a locus of origin for the discipline, sometimes even standing in for composition writ large. Additionally, FYC has helped perpetuate long-standing debates in our histories and elsewhere about whether or not the course should be universally required. Although disciplinary conversations and debates surrounding FYC are quite familiar to contemporary scholars, I argue throughout this chapter that FYC's centrality to particular threads of composition history ultimately limits how contemporary composition defines "writing," "writing instruction," and its "work."

In this chapter, I argue that first-year writing courses' centrality to the discipline's prevailing historical narratives carries material and intellectual consequences for students, teachers, and scholars of composition - especially given recent calls in our scholarship

\footnotetext{
${ }^{1}$ When I refer to FYC, I refer to introductory writing courses intended for first- or second-year students at the college level; for the sake of language diversity, I use "first-year course" and "freshman course" somewhat interchangeably with FYC throughout this chapter. However, I am aware that these designations do not, and cannot, account for the diversity of writing programs or introductory writing courses institutionalized within the United States and abroad; I use the designation self-consciously as an inadequate but necessary "umbrella" term for the prevailing historical narrative that I describe and challenge throughout the chapter.
} 
for the internationalization of the discipline (see for example Christiane Donahue, Bruce Horner and Min-Zhan Lu, among others). Because most contemporary disciplinary histories focus on the teaching of English composition in the United States from the latenineteenth century on, I argue first that rhetoric and composition has problematically limited the purview of its "work" (by which I mean research and scholarship) to sites of English-only, college-level writing and writing instruction in the U.S.. Second, I contend that rhetoric and composition's histories have implicitly defined "writing" as an abstracted, monolingual, institutionalized, pedagogically produced and reader-oriented practice relevant only to Americans. And finally, I argue that the discipline's historical accounts define "writing instruction" as a practice that occurs only within formal institutions of higher education and usually in the context of FYC, employs arhetorical pedagogical methods, and produces inherently negative effects for students and teachers. Together, these implicit (and sometimes explicit) definitions set rhetorical constraints on the "work," "writing," and "writing instruction" that can be considered "intelligible" within contemporary disciplinary discourse.

In the sections that follow, I demonstrate how disciplinary histories of rhetoric and composition have habitually traced the discipline's origins to Harvard in 1885 , have assumed the centrality of FYC, and have used this assumption to produce limiting definitions of our key terms. I use specific examples from our most widely cited histories to illustrate how the discipline's historiography has constructed a central role for FYC and has helped maintain debates from which contemporary scholars have made a concerted effort to move away. Then, using examples from recently published histories of composition, I contend that these definitions can only be revised and broadened through a 
troubling of the discipline's habits of historiography. And finally, in an effort to dislodge these problematic assumptions and sketch out possible revisions to contemporary definitions of "writing," "writing instruction," and composition's "work," I propose that composition scholars engage in a systematic troubling of its historiographic practice because the discipline's current "common sense" results in material and intellectual problems for contemporary students, teachers, and scholars. Through this troubling of disciplinary historiography, I contend, composition can better account for a variety of educational contexts, a diverse range of students and teachers, and can more consistently acknowledge the wide range of research outside of FYC that contemporary scholars already undertake.

\section{Harvard $=$ FYC $=$ Composition: An Equation that Doesn't Add Up}

Our most frequently cited histories locate the discipline's origins at Harvard in or around 1885, the year that Harvard began requiring all freshmen to take English A, a year-long writing course. ${ }^{2}$ John Brereton traces the contemporary discipline to this point of origin because the course represents the "first modern composition program" (8). Brereton argues that the course was important not because it was the first time composition courses were offered in higher education (it wasn't), but because Harvard's program was the first writing program, and it successfully "allied the modern university with a new emphasis on English and ... raise[d] writing and English literature to the level of more hallowed studies like mathematics and classics" (8-9).

While I don't dispute the facts presented by Brereton, I am interested here in accounting for how our assumptions about Harvard's influence have produced the historical narratives about FYC most familiar to us today, and with what consequences.

\footnotetext{
${ }^{2}$ For about a decade before 1885 , the course was required of all sophomores.
} 
This tracing of the modern discipline to Harvard is also often justified through a reference to Harvard's influence as a "leader of the time in curricular reform" (Berlin, Rhetoric and Reality 20). The logic proceeds as follows: Because Harvard instituted a single course in composition as a general-education requirement in the late-nineteenth century, and because Harvard was the most influential institution of higher education in the United States, first-year courses in composition were developed at colleges all across the country. Moreover, the logic suggests, the content of these courses and the pedagogical approach(es) used at Harvard were imitated invariably across institutions over time. I challenge this logic by claiming that composition's origins and content are provisional and are ultimately determined by our historiographic choices. Using metahistorical critique, I outline below how our prevailing narratives have produced this logic and "normalized" it, making it available for frequent (mostly unchallenged) repetition in contemporary scholarship. In the analysis that follows, I question the centrality of Harvard and English A, as well as FYC, to our understanding of the discipline's history.

We can see how Harvard's influence came to be taken for granted in our histories by examining portions of Albert Kitzhaber's, Robert Connors', and James Berlin's histories alongside one another. In Rhetoric in American Colleges, Kitzhaber writes that Harvard's English A was "the parent of all latter courses in freshman composition.... For the remaining years of the nineteenth century it was regarded as a model course in rhetoric and widely imitated throughout the United States" (61, emphasis added). 
Likewise, Connors' attention to Harvard in the introduction of CompositionRhetoric demonstrates his perception that the contemporary discipline originated at Harvard and can be traced from that point of origin. In the section devoted to the Consolidating period of composition-rhetoric in America, during which the theories and methods of composition teaching were consolidated in colleges," the only institution described in any detail is Harvard, ostensibly because English A became "the prototype for the required freshman course in composition that within fifteen years would be standard at almost every college in America. (11, emphasis added)

And in Rhetoric and Reality, Berlin uses the same language as Connors when he describes Harvard's English program as the "prototype" for the contemporary English department (20). But unlike Connors, who sees Harvard's "consolidating" influence as problematic because it "radically simplified" a previously complex "generation of competing ideas and theories" about writing (Composition-Rhetoric 12), Berlin portrays the early instantiation of the English department at Harvard more optimistically in that he claims that its "initial purpose ... was to provide instruction in writing" (20, emphasis added). While Berlin agrees with most historians that the institution of entrance exams in writing and English A at Harvard was intended to appease the public and act as a stopgap for the growing number of middle-class students who desired and were gaining access to a college education, he ultimately sees English A as the last vestige of the older (but presumably better) classical curriculum which held that extensive instruction in rhetoric was a necessary component of the curriculum for college students. In fact, English A provides for Berlin evidence that, at Harvard, "writing [was considered] so central to the new elective curriculum ... that ... by 1894 [it] was the only requirement except for a modern language, and by 1897 was the only required course in the curriculum" ( 20 , emphasis added). 
In addition to a near-universal locating of composition's disciplinary origins at Harvard and within the context of FYC, historians have often conflated FYC with the discipline as a whole. Within the context of the recent history of the field - by which I mean the development of composition since the $1950 \mathrm{~s}$ - our tendency to produce this conflation is understandable: After all, the establishment of the Conference on College Composition and Communication (CCCC) in 1949 was grounded upon the question of how best to approach the first-year course, which at the time varied between required freshman-level communications and composition courses. And 1963 marks for many the beginning of the contemporary discipline in large part because it was the first year when CCCC was devoted primarily to composition and rhetoric, rather than speech communications (see Kitzhaber "4C"). Stephen North explains: "This group [CCCC] could then, as now, claim an institutional power base of considerable potential. The freshman course was something nearly all of the rapidly increasing number of college students would take, and represented in many cases the largest chunk of an English department's budget" (14).

I am not arguing against the realities of FYC that grounded our contemporary evolution or to suggest that teaching is not a central part of our work. Rather, my purpose in outlining this history is to illustrate how our historiography is at least partially responsible for the rhetorical possibilities available to us today in making sense of the past, present and future of composition. According to this account, then, it seems that our contemporary efforts to professionalize the discipline have been substantiated as a result of the apparently ubiquitous requirement of FYC. Composition managed to achieve status as a "legitimate" academic discipline as a result of these mid-century developments, all of 
which were premised upon the existence of the first-year course; this fact has led scholars documenting the discipline's history to conflate FYC with the discipline as a whole.

But locating the discipline's origins at Harvard and conflating composition with FYC results in particularly narrow ways of thinking, reading, and writing about the "work" of composition and posits narrow definitions of what counts as "writing" and "writing instruction" in our scholarship. In questioning Harvard's and FYC's centrality, I align myself with David Russell, who argues that "a narrow focus on the history of composition courses may ... credit freshman English with a larger or more cohesive effect than it has ever had" (32). And this narrow focus has important consequences. Going beyond Russell, I mean in this chapter to interrogate not only the basic assumption that our discipline is best historicized in terms of FYC as it was first established at Harvard, but also to challenge the assumption that our discipline is best historicized in terms of English-only, college-level writing instruction in the U.S. ${ }^{3}$ Instead, I use metahistorical critique to suggest that the outlining of a more expansive past - one that acknowledges multilingual writers, international institutions, and formal and informal sites of writing instruction - enables a more productive future for the discipline.

\section{Historiography and the "Abolition" Debate}

When historians conflate the introductory course with composition as a whole, they do so by constructing FYC as central to - if not comprising the entirety of - the writing curriculum at most academic institutions. With this conflation, composition's "work" appears to be grounded on the existence of FYC, which misguides scholars"

\footnotetext{
${ }^{3}$ In fact, some of the rhetorical problems that I address throughout this chapter are complicated by the fact that scholars rarely distinguish between "disciplinarity" - an abstraction (see my definition in chapter 1) and departments or programs, which are locally designated "units," materially grounded in specific institutional contexts. Although I try throughout this chapter to remain aware of and maintain this distinction, I run into problems because the histories I examine often fail to make this distinction.
} 
attention toward debates about the course's legitimacy. Specifically, these debates center on whether or not first-year courses should be required of all university students. To be sure, contemporary scholars have urged composition to move beyond these debates. And while we can see some progress in this regard in recent publications, especially scholarship that proposes a shift in curricular and disciplinary focus from FYC to vertical "writing studies" programs (see Charles Bazerman, S. Miller, Doug Downs and Elizabeth Wardle), I argue that we cannot effectively move beyond these debates until we recognize - and dislodge - their cementation within our histories and, thus, within the discipline's prevailing narratives about FYC.

Because our histories have primarily focused on documenting the development and evolution of freshman writing since the late-nineteenth century on, disciplinary historians have used their work to contribute, in no small part, to these debates. In order to demonstrate how these debates show up in our histories through particular characterizations of FYC, I present textual examples from three of composition's bestknown and widely cited historians: Berlin, Connors, and Sharon Crowley. These excerpts show how our most popular histories participate in the rhetorical production of a history that remains locked on Harvard and introductory writing, sustaining what some might call an excessive attention to debates about FYC's requirement as a general education course. I use this metahistorical critique to argue, ultimately, that historians' participation in the "abolition" debate has constrained the discursive sphere in profound and consequential ways, especially in relation to those definitions of disciplinary "work," as well as "writing" and "writing instruction," that are currently available to compositionists. 
James Berlin introduces Rhetoric and Reality by characterizing the first-year writing course as one that "responds quickly to changes in American society as a whole, with literacy ... serving as the intermediary between the two - between the writing course and larger social developments" (5). He concludes the book with the following characterization:

Writing instruction has been dramatically transformed in the past twentyfive years - $\mathrm{a}$ transformation that is salutary and ongoing. We have begun to see that writing courses are not designed exclusively to prepare students for the workplace, although they certainly must do that. Writing courses prepare students for citizenship in a democracy, for assuming their political responsibilities, whether as leaders or simply as active participants. Writing courses also enable students to learn something about themselves, about the often-unstated assumptions on which their lives are built. In short, the writing course empowers students as it advises in ways to experience themselves, others, and the material conditions of their existence. (188-89)

Berlin's description is an optimistic one. For him, freshman composition is flexible, democratic, and adaptive to political and cultural change, and also empowering to students.

Robert Connors does not share Berlin's optimism about what the freshman course can or should be. In "Overwork/Underpay: Labor and the Status of Composition Teachers since 1880," an essay that historicizes composition's - and composition teachers' - ostensibly "low" place in the academy, Connors reinvokes the "decline and fall" narrative (discussed in chapters 2 and 4) and summarizes the history of writing instruction as follows: "Rhetoric has changed in a hundred years from an academic desideratum to a grim apprenticeship, to be escaped as soon as practicable" (181). For Connors, the change occurred, first, because the shift from oral to written rhetoric in the mid- to late-nineteenth century created "a completely different set of demands" for 
teachers. "Writing," he explains, "is an interior activity, and although techniques can be used to share writing among students, a primary transaction in any serious composition course came to be seen as between the student and the teacher. Each student came to be seen as deserving a measurable individual chunk of the teacher's time and energy" (184). Second, because composition was one of the few courses still required in the modern research-oriented university of the late-nineteenth century, and because college education was becoming increasingly accessible, student numbers in the courses increased dramatically. According to Connors, then, the freshman course demands intensive interaction between student and teacher; it expects individual and autonomous writing practices; and, as I discussed in the previous chapter, Connors believes that the first-year course produces a "hellish" classroom and oppressive professional environment from which teachers want to escape.

Crowley composes perhaps the most scathing review of the first-year course. In the lead essay of Composition in the University, she writes:

University and college faculty imagine composition as the institutional site wherein student subjectivity is to be monitored and disciplined. The continuing function of the required composition course has been to insure the academic community that its entering members are taught the discursive behaviors and traits of character that qualify them to join the community. The course is meant to shape students to behave, think, write, and speak as students rather than as the people they are, people who have differing histories and traditions and languages and ideologies. (8-9)

While Connors focuses on the effects of FYC for teachers, Crowley focuses on the consequences for students: according to her account, the first-year course "disciplines" students into academic and social conformity, which ultimately benefits those already in 
power, in this case university and college faculty - and in other passages, the general public and even capitalists. ${ }^{4}$

Berlin's, Connors', and Crowley's competing characterizations of FYC reflect many of composition's larger concerns about its "work." The tensions that inhere within their historiographic practices embody the same tensions with which the discipline as a whole struggles: On the one hand, according to Connors' and Crowley's accounts, the universal requirement of FYC troubles our progressive sensibilities about the relationships among literacy, education, and power. On the other hand, for historians such as Berlin, the requirement of freshman composition provides us first with a site from which we might, as individual teachers and scholars, provoke social change and, second, a site from which we can engage in research and produce new knowledge on writing processes and pedagogies. In other words, the progressivism valued by so many compositionists - a value upon which the contemporary discipline has largely defined itself - can be either oppressive or liberating, depending on various cultural, institutional, and pedagogical contexts. Further, because our "work" - by which I mean both pedagogy and scholarly research - has been grounded, historically, in the first-year composition course, we have been, and continue to be, torn between either detaching ourselves from the "low" and service-oriented image implied by a general education course or engaging with it to support our civic-minded research and pedagogical goals.

The competing representations of FYC offered by these historians connect directly to the positions these historians take in larger disciplinary debates about the course's viability as a required part of the university curriculum. Perhaps unsurprisingly,

\footnotetext{
${ }^{4}$ Although Crowley's argument may seem extreme and has been critiqued by a few such as David Russell and Bruce Horner, others have repeated her claims without question (see Debra Hawhee's "History and the Harbrace College Handbook" and Donna Strickland, "The Emergence of Writing Programs" for example).
} 
Berlin sees FYC as central to the discipline; in Rhetorics, Poetics, and Cultures, which is less a history of the field than a proposal for its future, he reasons:

While those in literary studies in the English department may have argued that writing was an accomplishment easily mastered in the lower grades, the testimony of experience in the United States ... indicated otherwise.... Rhetorical accomplishment acquired through direct instruction in the college classroom had always been an important fixture of the college curriculum in the United States. (27)

In contrast, Crowley favors the abolition of FYC as a universal requirement, arguing in "A Personal Essay on Freshman English" that the universal requirement "exploits teachers of writing, particularly part-time teachers and graduate students" (Composition 241); "[it] exploits students" (241); "[it] has negative curricular effects" (242); "[it] negatively affects classroom climate" (242); "[it] has negative disciplinary and institutional effects" (243); and "[it] has negative professional effects" (243). And Connors - who dubs the contemporary debate spurred forward by Crowley the "New Abolitionism" - agrees that the first-year course should not be universally required, writing, "I still believe that we have more of a chance today than ever before to rethink in a serious and thoroughgoing way the best methods for working on student literacy issues and that we can do so without harming the best interests of either our students or our colleagues" ("The Abolition Debate in Composition" 294).

Positioning these textual examples alongside one another allows for a metahistorical view of prevailing historiographic practices, which produce characterizations of FYC that carry rhetorical consequences and create boundaries for disciplinary discourse. Berlin's, Connors', and Crowley's representations of FYC are strategic and enable these scholars to effectively participate in the debate about FYC's viability as a required course; each history takes a strong and competing stance in relation 
to the debate. For Berlin, because the course authorizes student participation in public life - a primary goal for many compositionists - it should be understood as central to the discipline. But because Connors and Crowley understand the universal requirement of FYC as having a marginalizing effect on students and teachers, the best way to relieve the field of its tacit participation in such marginalization is to do away with the requirement, allowing students to self-select the course.

Although Berlin's, Connors' and Crowley's historical accounts about FYC - and the positions they take in relation to the debate - are probably the most familiar to contemporary scholars, they are not the only compositionists who have used disciplinary history to adopt clear positions in the "abolition" debate. For example, in a special issue of $C C C$ honoring the journal's fiftieth year of publication, Marjorie Roemer, Lucille Schultz, and Russel Durst historicize the debate over FYC's usefulness as a required course to ultimately defend its value. They argue that FYC is:

... our primary field site: the site which generates most of our scholarship and research, the site where we train graduate students to be teachers, the site that spawned the Writing Across the Curriculum and other disciplinebased writing programs, the site that inaugurated the field of basic writing. It is where we do our most visible work and where others learn from us. (385)

In fact, they argue, scholars who favor the elimination of $\mathrm{FYC}$ as a required course uphold a "fundamentally elitist view of the English department mission and its move toward full disciplinarity" (378).

Maureen Daly Goggin and Steve Beatty also use an account of the discipline's history to voice their concerns about FYC's viability. In "Accounting for Well-Worn Grooves: Composition as a Self-Reinforcing Mechanism," they argue that FYC achieved a flawed but dominant status within the discipline because of three closely related events 
at Harvard in the late-nineteenth century: the creation of the entrance exam, the formation of English A, and the report of the Harvard Committee on Composition and Rhetoric (36). Goggin and Beatty contend that "[ $[\mathrm{t}]$ here is precious little evidence that compulsory first-year composition has ever worked" (36), but they do not support FYC's abolition; instead, they argue that the only way composition can escape from its "groove" is through the construction of a "parallel alternative system that focuses on the study of literate practices" (56).

As these examples illustrate, historians promote a particular view of FYC's place in contemporary composition studies through strategic historiographic practices. But as I indicated earlier, I am less interested in which side of the "abolition" debate each historian ends up on than in how these historians construct the debate through particular representations of FYC and the discipline as a whole, and with what consequences. While all of these textual examples provide compelling reasons to question or defend the value of FYC, the debate itself is limited and limiting because it relies on an assumption that FYC is central to understanding and resolving composition's disciplinary challenges. ${ }^{5} \mathrm{As}$ such, each of these historical accounts forwards a narrow definition of what counts as the discipline's "work" - a definition that conflates FYC with composition as a whole and presumes the centrality of FYC to the purview of composition scholarship. This conflation is further solidified by the historical nature of these accounts: Because each scholar adopts a historical perspective, it becomes difficult for readers and critics, especially those without historical expertise, to enter the debates without adopting similar

\footnotetext{
${ }^{5}$ As I note in the introduction to this dissertation, I see some of composition's contemporary challenges as related to an increasingly diverse student population, the need for global communications, our lack of knowledge about K-12 and extracurricular writing practices and pedagogy, and the academy's increasing reliance on contingent faculty.
} 
assumptions about FYC's relationship to the history of composition. In order to avoid these problems, I argue that contemporary scholars need to challenge accounts of disciplinary history that centralize FYC, especially those that use this centrality to bolster arguments about the course's ultimate viability.

Because of the conflation between FYC and the discipline as a whole, composition is conceived within many historical accounts as a discipline of writing and writing instruction produced within and for the purposes of general education in the United States. From this portrayal, "writing" can then be constructed rhetorically as an abstract, reader-oriented process in which teachers act as passive consumers of studentgenerated prose. Implicitly, then, "writing" in these accounts really means student writing, in English, produced for the purposes of institutional assessment and advancement. Further, "writing instruction" is narrowly conceived as a form of composition pedagogy authorized by and for institutional purposes, produced in relation to students, who presumably receive and employ it for educative ends. And finally, composition's "work" is portrayed in these historical accounts as clearly related to the goings-on of FYC, which places rhetorical constraints on alternative definitions of the "work" that can or should be included within composition's purview.

In contrast, when historians portray FYC and, thus, the larger discipline using more expansive definitions of composition's work - definitions that, for example, understand FYC as one writing course among many or that look outside of higher education for evidence of writing and writing instruction - their arguments can go much further in expanding the discursive sphere and promoting sustainable futures for the discipline. With broader definitions about what counts as the discipline's work, the 
"abolition" debate becomes less relevant or useful. What's more, historically grounded arguments about composition's purview carry more clout when refusing to focus narrowly on FYC because they can affect disciplinary and curricular decisions beyond the first-year course. And having more flexible definitions of what counts as disciplinary work requires that critics wishing to engage historically grounded arguments present their own assertions according to these larger definitions. Such an unsettling, in turn, holds the potential not only to fundamentally change historiographic practices but also to broaden the definitions of "work" considered intelligible within composition's discursive sphere.

\section{FYC and Composition's "Work"}

My discussion above of the connection between disciplinary historiography and contemporary debates surrounding FYC's viability as a required university course provides a clear example of how our prevailing narratives about FYC - narratives that locate composition's origins at Harvard in the late-nineteenth century - maintain such limiting debates and resist expansive definitions of what constitutes composition's "work." The limitations of our discourse become particularly evident in light of the changing contexts of higher education in the twenty-first century, in which the "work" of our discipline should address global contexts of writing, multilingual students, writing across disciplines and outside of the academy, and writing practices and pedagogy in K12 education. In this section, I move away from the "abolition" debate and concentrate particularly on the specific intellectual and material consequences produced for our work by uncritical repetition of prevailing narratives about FYC. I propose that the discipline reread and reconsider its prevailing historical narratives through the lens of metahistorical critique in order to open up the discursive sphere. This proposal is grounded in a central 
premise throughout this chapter - that we cannot alter the discipline's problematic "common sense" in a meaningful way until we locate and disrupt those prevailing narratives in our histories that allow for its rhetorical production and maintenance.

When our histories encourage us to trace our origins to Harvard, we are more inclined to pursue and portray our contemporary work within the rhetorical boundaries such a context implies: Our work makes the most "sense" if it relates to elite American institutions of higher education and remains relevant to introductory college composition. ${ }^{6}$ Although my argument may seem circular in that it relies on the notion that Harvard actually represents American higher education, this is part of my point: the discipline's historiography encourages this kind of circularity and ignores the underlying class and resource biases that have likely motivated compositionists to perpetuate this association. These boundaries, therefore, pose challenges for the identification and development of writing research that is not directly related to FYC and/or to higher education in the U.S.; as a result, other contexts for composition research - including pedagogical practices employed within primary and secondary schools, or writing practices in international contexts - are more likely to be neglected or marginalized. Let me be clear: I am not attempting to argue that such research does not get published; rather, I am arguing that compositionists are less likely to imagine or identify research outside of these boundaries, especially if their livelihood (tenure) depends upon swift publication. ${ }^{7}$ Ultimately, keeping FYC in the center when we map out the discipline's

\footnotetext{
${ }^{6}$ Going further, one might even argue that our prevailing narratives encourage us to frame our work within those nineteenth-century contexts of writing instruction tied to Harvard and English A.

${ }^{7}$ Although it may seem as though I am overstating the case here, a quick examination of the last year's issues (March 2010 - March 2011) of College English and CCC helps substantiate my point: Not counting review essays, $C C C$ published 19 articles related to university contexts, 1 article related to multilingual or international contexts, 2 articles related to non-university contexts of writing, and 3 articles that did not clearly fit into any of these categories. The case for College English is slightly different, in that three of the
} 
"territory" hinders many scholars' efforts to disrupt the conflation of FYC with the larger discipline. ${ }^{8}$ And this kind of historiographic mapping further limits the success of our efforts to broaden the work that we can conduct as composition scholars.

Byron Hawk and John Heyda have critically examined the reasons why we so often consider FYC the center of the academic curriculum and our scholarship. According to both Hawk and Heyda, FYC occupies a central place in disciplinary narratives because the course represents the locus of composition's struggle for identity at different moments in the discipline's history. As I discussed in the previous chapter about CTRP, the emergence of required composition at Harvard in the nineteenth century often marks for the discipline the "decline and fall" of rhetoric, which in turn enables composition to construct a "narrative of retreat and return" (Hawk 14). According to Hawk, the narrative is most often constructed as follows:

The early nineteenth century ... saw the devaluation of rhetoric due to the Enlightenment elevation of logic, the value of romantic individuals, and the rise of national literatures throughout the nineteenth century. To fill the void left by rhetoric's displacement, composition emerged in the late nineteenth century largely due to a literacy crisis that provided the exigence for what has become first-year composition. But the separation of composition from literature through the development of a separate conference in 1949 allows a space for rhetoric's return. (14)

\footnotetext{
last six issues have been special issues devoted to a single topic (Jewish rhetorics, Chinese rhetorics, and contingent faculty). In the issues that were not special issues, 14 articles were clearly related to university contexts, 2 related to multilingual or international contexts of writing, 1 related to non-university contexts of writing, and 3 that did not fit into these categories. For more on the relative invisibility of international and multilingual issues in composition scholarship, see Christiane Donahue's 2009 article, “'Internationalization' and Composition Studies: Reorienting the Discourse."

${ }^{8}$ Of course, FYC's centrality in our historical narratives provides only one explanation for why compositionists habitually focus on the classroom context. Tom Fox offers another reason that emphasizes the complexity of this issue when he argues that "composition's constant focus on pedagogy" can be explained by the fact "that the classroom is where composition teachers usually feel their absence of political power [in relation to the rest of the academy] the least. There, at least marginally more than in other institutional arenas, we have the feeling that somehow we control the conditions of our work" (568).
} 
This narrative, Hawk explains, satisfies composition's "situational need to delineate a territory ... (to define a them to exclude and an $u s$ to identify with)" (14, emphasis original). Likewise, Heyda employs a territorial metaphor to explain the emergence of CCCC in the 1950s and the "Fight[] over Freshman English" that ensued between communications and composition, writing "Both [communications and composition] had claims ... to large chunks of a vast but unstable expanse of academic real estate reserved for first-year literacy courses, and wrangling over these claims was due to take center stage" ( 665 , emphasis added). As he explores the role played by communications in the solidification of composition's disciplinarity, he argues that the struggle between the two disciplines was, in effect, necessary for composition to delineate its disciplinary territory. We can see from both Heyda's and Hawk's accounts that the discipline's narratives about - and attitude toward - FYC are, more often than not, strategic. Much like CTRP has become a part of the disciplinary imaginary and stands in for "real" practices and beliefs, prevailing narratives about FYC are meant to do much more than merely paint a factual portrait of the discipline's history. They are meant, also, to demarcate historical eras and events against which the contemporary discipline can measure itself in terms of origins and progress, and these narratives, as Lisa Ede points out in Situating Composition, are motivated by the implicit and seemingly unquestionable goal of achieving disciplinarity (17). And while I do not mean to dismiss the value of this documentation or suggest that historians themselves are not aware of their own strategies, I want to highlight, through metahistorical analysis, that the rhetoric of this documentation produces intellectual and material effects for the discipline's future(s). 
When it comes to the discipline's territorialization of "academic real estate," prevailing narratives that position FYC in the center of our debates tether disciplinary conceptions of the "work" of composition to English-speaking pedagogical contexts within the American higher educational system. Hawk's description of the retreat-andreturn narrative provides a helpful case in point: First, as Hawk portrays it, the narrative depends upon a narrow definition of "literacy crisis," a definition based on Harvard's series of reports in the late nineteenth century documenting the "illiteracy" of the middle class hoping to gain entrance to the school. But such a definition is obviously problematic in that literacy, for the purposes of Harvard, means much more than the basic ability to read and write; it values reading and writing in English only; and it assumes an audience of a particular social class with a negative attitude toward the influx of immigrants arriving in the United States around the turn of the century. This definition, in other words, assumes an audience who would understand and identify with the "Enlightenment elevation of logic," "the value of romantic individuals," and the "rise of national literatures." ${ }^{99}$ Second, composition's development is narrated as a direct response to Harvard's establishment of the required first-year-course. In this way, we implicitly define "writing instruction" as that which occurs as unspecialized, general-education training within contexts of higher education. In composing and sustaining this narrative in our histories, we limit our ability to justify "work" that moves outside of or beyond these definitions. Because we keep FYC in the center when we map out the discipline's

\footnotetext{
${ }^{9}$ For examples of test essays that illustrate this point, see David Bartholomae's "Writing on the Margins: The Concept of Literacy in Higher Education."
} 
territory, our efforts to broaden the work that we can conduct and/or market as composition scholars are restricted. ${ }^{10}$

Our centralization of FYC within disciplinary histories points toward another problematic assumption related to the discipline's "work": our prevailing narratives about FYC assume that the course is ours. Just as the abolition debate's focus on FYC problematically constrains disciplinary discourse, prevailing historical narratives that centralize FYC are premised on a faulty assumption that the discipline "owns" first-year courses in writing. In fact, whether or not composition hopes to keep FYC as a mainstay in the university and disciplinary curriculum, this assumption of ownership may prevent us from communicating effectively, as rhetors, in response to university administration and the general public, parties that often (also) assume ownership of FYC. Chris Fosen's "University Courses, Not Department Courses" offers one illustrative case in point: In the article, Fosen describes his experience as a member of the English composition faculty at California State University-Chico who struggled, alongside other members of the department, to resolve tensions between composition's expectations about the purposes of and best pedagogical approaches for FYC - which defines FYC as a discipline-specific course - and the university's expectations for FYC - which sees FYC not as a "department course," but as a "university course," a part of the general education (GE) curriculum. Fosen argues that because he and his colleagues at CSU-Chico conceived of FYC as a part of composition only, they were unable to translate their disciplinary discourse so it made sense within the "grammar" of GE. He argues that

\footnotetext{
${ }^{10}$ More often than not, those scholars who do conduct research outside of university contexts are labeled as somehow "outside of" composition (see for example Deborah Brandt, who is usually defined as a "literacy scholar" rather than a compositionist).
} 
we should consider the notion that composition is a general education course owned and often tightly controlled by the university. First-year composition is not solely our course; it serves multiple acculturative purposes in the university, and many discourses outside of composition impinge on how it is taught and administrated. (12-13)

Only when "we recognize the institutional pressures to serve that writing courses may face within general education," Fosen argues, will we "be better able to respond to them" (13). No matter how often members of the discipline may resist the "service" orientation of FYC, this orientation will always exist so long as the first-year course remains a part of the general education curriculum. Instead of merely resisting the location of FYC within the academy, compositionists will be best served by working to dislodge FYC from its central location within disciplinary discourse and (re)defining the discipline according to alternative terms of what counts as our "work."

When we refuse to portray FYC as central to the discipline's past and present, we can understand and evaluate FYC as a course not necessarily owned by composition, as Fosen advocates, and therefore as not necessarily central to our "work." While some may read my call for this refusal as a call for the elimination of FYC altogether - returning us to the tired abolition debate or moving us toward the supposed end of the discipline - I want to clarify that this refusal would merely result in the decentralization of FYC within disciplinary discourse, which does not mean that concerns about FYC or teaching would or should be pushed out of the discursive sphere altogether. I argue that this kind of a rhetorical shift can actually provide the discipline with a more flexible and therefore more convincing base from which to claim its legitimacy. Decentering FYC allows us, first, to achieve greater rhetorical control over our contemporary location in the academy, and it also allows us to revise our historical narratives in meaningful ways. Specifically, 
releasing our ownership of FYC encourages us to trace our disciplinary origins not only to Harvard but to a wide variety of educational contexts, including mono- and multilingual environments; elementary, secondary and post-secondary institutions; and formal and informal educational situations located within and outside of the United States. This retracing, in turn, creates new conditions of possibility in our discourse conditions that encourage, perhaps even demand, that we acknowledge contemporary writing and research across cultural, national, and linguistic borders.

William DeGenaro's account of the rise of the two-year college (TYC) in the United States provides one example of an alternative educational context through which we might (re)trace the discipline's history and also with which we can critique our "work," especially as it relates to the "ideology of service" that haunts composition's contemporary and historical identity. DeGenaro argues that the history of TYCs runs parallel to the history of FYC in four-year institutions of higher education in that both are grounded on inherent and problematic paradoxes related to the concept of equal opportunity; importantly, both histories point to problems related to the "low" value of certain kinds of labor in the academy:

The origins of first-year composition and the community college follow strikingly similar trajectories. Both composition and the two-year college boast mythologies of equality and assistance for those entering higher education who are perhaps less prepared for the academic rigors therein. Yet critics have pointed out that the community college has played a role in decreasing the aspirations of its students.... Critics of college composition, similarly, have argued that the writing course has been used as a tool for ideological and linguistic discipline and conformity.... Sketching the similarities between these two movements within higher education is a means for further understanding the disparaging of lowerdivision labor. (195-96) 
DeGenaro's research demonstrates the value of investigating educational histories outside of the generally accepted context for the discipline, FYC: Not only can this kind of investigation refuse the centrality of the first-year course, but it can help us develop a richer portrait of the discipline's history and it demonstrates how new analytic tools such as metahistorical critique can be used to address contemporary concerns in composition.

Collectively, analyzing Hawk's, Heyda's, Fosen's, and DeGenaro's scholarship through a metahistorical lens helps illustrate how our understanding of composition's purview is determined, in part, by disciplinary historiography and begins to illuminate the different trajectories of inquiry that might be followed once we interrogate basic assumptions grounding the discipline's prevailing narratives about FYC. These narratives, which locate the discipline's origins at the moment in which FYC was instituted as a required course for freshmen at Harvard, restrict what counts as composition's work, which, in turn, produces several important intellectual and material consequences: First, as Christiane Donahue makes clear in her 2009 article, “"Internationalization' and Composition Studies," the production of research about writing and writing instruction outside of American contexts of higher education "has been highly partial, portraying the issue in particular ways, largely export based, that ... might create obstacles for U.S. scholars' thinking and thus impede effective collaboration or 'hearing' of work across borders" (214). I attribute this partiality in part to prevailing narratives about FYC. Second, prevailing narratives about FYC mask composition practices and pedagogies outside of U.S. institutions of higher education. This problem is heightened when we consider those practices and pedagogies engaged by groups already habitually marginalized in our scholarship, such as multilingual people and members of 
the working class. Third, prevailing narratives about FYC normalize certain pedagogical practices that might be interpreted as problematic - such as maintaining a singular focus on essay writing - that might tie us to the past instead of allowing us to account for, and participate in, changing contexts of writing in the present and future. And finally, prevailing narratives about FYC in our histories work against the desires of contemporary scholars who wish to revise conceptions of what counts as composition's work in a lasting and meaningful way. To counter these problems and open up rhetorical space for alternative and/or new definitions of what can be valued as our work, we must reevaluate our prevailing narratives, reject the centrality of FYC to our understanding of history, and trace our origins to other educational sites, especially those that are informal or unauthorized, multilingual, and international.

\section{FYC and "Writing"}

Just as prevailing narratives about FYC maintain narrow definitions of what counts as appropriate "work" within composition, these narratives also sustain limited definitions of what counts as "writing." Tracing the discipline's origins to Harvard means we are more (though not necessarily) inclined to define "writing" as it would be defined within Harvard's particular institutional and historical context: as college-level, studentgenerated, pedagogically mandated, institutionally confined prose written in English for a single audience, the teacher, whose job is to read, evaluate, and return. ${ }^{11}$ Clearly, many contemporary compositionists have resisted such a definition through their research and teaching - demonstrating that the discursive sphere is not as restrained as the above definition suggests. I argue, however, that the dominance of prevailing narratives about

\footnotetext{
${ }^{11}$ Although these characteristics may not be unique to Harvard - indeed, they could be applied to most U.S. universities - my point is that, because we trace our origins to Harvard (which is often held up as the quintessential American university), our attention remains locked on university-level writing practices.
} 
FYC in our histories (and elsewhere) works rhetorically to sustain related, seemingly "common sense" assumptions about writing that carry important intellectual and material consequences. In this section, I elaborate what I see as three specific consequences of the uncritical repetition of our prevailing narratives about FYC: First, our prevailing narratives ignore informal sites of writing and writing instruction; second, they construct students as uneducated and lacking agency; and third, they neglect multilingual and international sites of writing and writing instruction. I conduct my analysis by presenting examples, when available, of recent historical research that disrupts our prominent stories about what counts as writing. I use these examples not because they are well known, but because they are not - they are promising, but relatively anomalous, examples of recent historical research. I analyze these competing narratives through the lens of metahistorical critique to illuminate gaps in our historical knowledge and point toward the enabling effects that occur when we produce revise our narratives and refuse to take FYC's centrality for granted.

When our origin story and associated narratives about FYC are not challenged in our histories and elsewhere, our historiography perpetuates assumptions that writing worth studying is produced within predominantly white American four-year college contexts. When we unsettle Harvard's place as the discipline's primary point of origin, we can then imagine new histories that centralize other points of origin, highlighting perspectives and harnessing values that have been traditionally marginalized in our histories - activities which enable new conceptions of the discipline's future. For example, Kathryn Fitzgerald's research on normal schools establishes an intellectual and pedagogical connection between normals and composition. Fitzgerald argues in "A 
Rediscovered Tradition" that "several contemporary attitudes about composition theory, methods, teachers, and students" can be traced back to European pedagogical traditions, which promoted "the interrelation of theory and practice; the responsibility of the discipline for teaching teachers to teach; the agency and autonomy of the teacher; the linguistic competence of the student; and the possibility of a critical stance toward textbooks" (225). In contrast to historians' habitual focus on seventeenth- and eighteenthcentury theory produced by rhetoricians such as George Campbell and Hugh Blair, Fitzgerald's focus allows composition to mark out a different kind of heritage, one that does not denounce the recent past and that values the education that occurs outside of traditional four-year college contexts. This shift in focus, in turn, encourages scholars to consider new interpretations of teachers and students, such as those who are portrayed in Fitzgerald's description above as having agency, independence, creativity, and intelligence.

Jacqueline Jones Royster and Jean C. Williams, as well as Susan Jarratt, have published microhistories that challenge assumptions of Harvard's centrality to the history of composition and provide clues about the intellectual and material consequences that may result if we engage in a more systemic disruption of the Harvard narrative. Specifically, both Royster and Williams' "History in the Spaces Left" and Susan Jarratt's "Classics and Counterpublics" explore the institutional significance of Historically Black Colleges and Universities (HBCUs), which were established at around the same time that major curricular and structural changes took place at Harvard in the mid- to latenineteenth century. In contrast to prevailing narratives about FYC, which assume Harvard had a monolithic influence on other institutions' curricular decisions, HBCUs 
such as Fisk, Atlanta, and Howard universities modeled and maintained a curriculum based on that of classical liberal-arts colleges such as Amherst, Weslyan, and the Seven Sisters Colleges, which emphasized the study of speech, debate, and writing framed within the tenets of classical rhetorical theory. In centralizing institutions habitually marginalized in our histories, the narratives produced by Jarratt and Royster and Williams should remind us of the limits of Harvard's influence, as well as the limits of our historical imaginations: Disciplinary histories that repeat the "narrative of retreat-andreturn" described by Hawk base this narrative on the centrality of predominantly white and elite institutions of higher education. I argue that shifting our perspectives to HBCUs and related sites of schooling helps illustrate the value of refusing to centralize the Harvard version of FYC within our historical narratives: Jarratt's and Royster and Williams' scholarship highlight the endurance of rhetorical education through the nineteenth century and into the twentieth and emphasizes its particular importance for marginalized populations. ${ }^{12}$ Together, the historical research produced by Fitzgerald, Jarratt, and Royster and Williams shifts our attention to the diverse range of educational contexts within what we define as the tradition of higher education. We must build from these examples if we want to redefine "writing" as that which is not necessarily tethered to the development of FYC at Harvard, or to the traditional college context.

At the same time, these histories, which are all histories of post-secondary education, should remind us of the limits of our assumptions about where we should look for historical evidence of writing practices. Only a few disciplinary historians have looked beyond the first-year writing curriculum for evidence of writing practices, and

\footnotetext{
${ }^{12}$ Of course, these historians are not the only scholars who make this point; see also Jessica Enoch and David Gold, among others, who historicize other populations and institutions in the U.S. habitually neglected in composition scholarship.
} 
even fewer have directed their attention to secondary or elementary sites of writing instruction and practice. ${ }^{13} \mathrm{I}$ interpret this scarcity of research as a consequence of prevailing narratives about $\mathrm{FYC}$, which assume the educational context for $\mathrm{FYC}-$ the traditional four-year college - is central to our understanding of the discipline's past, present, and future. As a result of this assumption, prevailing narratives about FYC produce problematic constructions of students, their educational histories, the first-year course, as well as the larger discipline.

Specifically, narratives that assume the centrality of FYC and Harvard portray students as neophytes in the first-year writing course, new to writing and new to writing instruction. Because our historical representations have traditionally begun and ended with FYC, historians have often failed to acknowledge the long history of writing experience and schooling that students bring with them to FYC. When previous writing or writing instruction is acknowledged, it is often portrayed as problematic or inadequate - an experience to be erased or corrected by FYC. As a consequence of these limits in our research (or the limits of our lack of research), students are understood to be passive, inexperienced, uncritical and easily malleable, and FYC is portrayed as having a significant and permanent influence on students' writing lives. While these claims may be somewhat accurate for particular students, assuming it of all disables an ultimately empowering conception of students and also limits our ability to teach them effectively.

Examining the few histories that do acknowledge writing practices and pedagogies outside of FYC and prior to higher education can help us imagine how revision of our prevailing narratives about FYC might help dislodge narrow and

\footnotetext{
${ }^{13}$ Here, I refer specifically to histories of rhetoric and composition; histories in the field of education have documented pedagogical practices within primary and secondary schools, but these escape our attention because they do not obviously "fit" within the discipline.
} 
problematic views of students, the first-year course, and the larger discipline. Susan Miller's 1991 account, one the first disciplinary histories to contest FYC-heavy descriptions of composition's history, compiles a "print ethnography" of university catalogues between 1920 and 1960 to illustrate the wide variety of composition courses available to students during an era some historians have dismissed as stagnant (67). She writes that when we associate the discipline primarily with $\mathrm{FYC}$, "we cage ourselves" by "cooperat[ing] with a bad story" that ascribes value to literary writing over and against "low" or "common" writing (76). David Russell's Writing in the Academic Disciplines also moves beyond FYC and stands as the only comprehensive macro-history of writing and writing instruction across the disciplines and outside of composition to date. Just as Miller's examination of university catalogues challenges assumptions about FYC's centrality to the discipline's history, Russell's exploration calls attention to the inadequacy of this assumption. Although "the great majority of students have had no conscious, systematic, discipline-specific writing instruction" (18), at least not until the last few decades when WAC and WID programs began to be established, Russell finds several "tacit traditions of student writing" that have evolved across disciplines over the past 150 years, traditions that include "the notebook, the research paper, the laboratory report, the case study, the essay examination, and so on, through which faculty have taught students the writing of the discipline, though perhaps less consciously or less effectively than with direct instruction" (19). Importantly, Russell points out the limits of his research, writing that "these tacit traditions ... have rarely been studied, much less from a historical perspective" and the sources he does use are "inevitably piecemeal and 
often ambiguous" $(19,20)$ - suggesting that much more historical research needs to be conducted.

Miller's and Russell's explorations of the writing curriculum beyond FYC and outside of composition provide us with several historiographic lessons: First, prevailing narratives about FYC limit the discipline's ability to define its work as legitimate. Miller writes that "if we look for a history of 'composition' as a history of its freshman conduct - the mechanical, modal repressions that naturalistic historians of composition focus on we cannot find a legitimizing past" (76). Additionally, narratives that maintain FYC's centrality within the writing curriculum produce marginalizing consequences for student writers. Miller argues that "composition's own version of its historical legitimacy in rhetoric and its limited self-definition as a freshman course allow new departments devoted to the 'best' written language [English literature] to perpetuate the claim that they can judge, and dismiss, the majority's perpetually worst" (76). In other words, when we historicize composition by exclusively following the FYC trajectory, we participate in a privileging of popular conceptions of "literature" (for Miller, this means the passive consumption of texts), which diminishes the value, and thus plausibility, of advanced study in and the production of "non-literary" writing. ${ }^{14}$ Such a privileging, Miller's logic suggests, therefore strips students of their agency, diminishing their potential to become active participants as writers in the world around them.

\footnotetext{
${ }^{14}$ In building on Miller's argument here, I distance myself from Miller's assumptions about the study of literature; while she equates literary study with passivity, my own experiences as a student and teacher of literature have demonstrated that literary study is often an engaged and engaging pursuit. I build on Miller here not because I necessarily agree with her premises, but because I find her conclusions about students valuable and indicative of what a historian's attention to students and student writing outside of FYC can give to the discipline.
} 
Russell's historical research in writing across disciplines affirms Miller's argument in that following a narrow FYC historical trajectory masks writing that occurs, and has historically occurred, outside of composition. Compositionists who assume FYC's centrality to the history of the discipline are more likely to also assume that FYC is central to their students' contemporary writing experience and education. As a result of these assumptions, compositionists may convey to their students that writing or writing instruction outside of FYC is less valuable, and perhaps less rhetorical, than the writing produced in the context of the first-year course. What's more, when this misperception of "writing" is forwarded - implicitly or explicitly - through our historiographic or pedagogical approaches, we sustain disconnections that already exist between rhetoric and composition and other academic disciplines. Historians such as Russell actively work to prevent such disconnections; however, I argue that such problems are inevitable until we systematically resist those prevailing historical narratives about FYC that sustain them.

But beyond highlighting these rhetorical effects, both Miller's and Russell's histories gesture toward other research and historiographic strategies - including metahistorical critique - that future historians of the discipline can employ to avoid this centralization. Miller urges scholars who refuse FYC's centrality to the discipline's history to identify "disruptions in nineteenth-century educational history temporarily" because these disruptions provided "legitimacy ... to many kinds of writing," not just literary writing (76). ${ }^{15}$ The gaps acknowledged by Russell might be read as evidence of

\footnotetext{
${ }^{15}$ By "disruptions," Miller is referring to historical evidence that has largely been overlooked in our disciplinary narratives, including the evidence from the early twentieth-century course catalogues she examines in Textual Carnivals. She writes: "The catalogue descriptions of English, which evolved into an
} 
those "disruptions" that Miller believes deserve more attention. Both Miller's and Russell's histories help open up opportunities for future research and complicate our prevailing narratives about FYC. Together, Miller's and Russell's works demonstrate that it is through an awareness of and highlighting of inconsistencies that compositionists can add complexity to our historical knowledge and, perhaps, reconstruct our sense of the future.

One inconsistency that deserves further interrogation is illustrated well by Lucille Schultz's research in nineteenth-century writing practices and pedagogies at the primary and secondary levels of schooling - the only history of its kind directed toward an audience of compositionists. In The Young Composers, Schultz locates composition's beginnings not at Harvard but at the establishment of primary and secondary public schooling in the United States. In so doing, Schultz calls into question the basic and prevailing assumption that composition history can and should be traced to institutions of higher education. She argues that this assumption ignores the majority of the U.S. population in the nineteenth century, a population who would have been much more likely to have been schooled in writing at the elementary and secondary levels but much less likely to have had access to college. As such, Schultz argues, we miss some of composition's strongest theoretical and practical ties, as primary and secondary schools are "where what we think of as personal or experience-based writing began" and "where the democratization of writing was institutionalized" (4). In other words, just as Miller's and Fitzgerald's histories do, Schultz's history provides composition with a more expansive version of its recent past.

increasingly literary curriculum, show the centralized composition that historians have addressed to be one, but not necessarily the overriding, kind of writing that English first included in its curricula" (68). 
But Schultz's research does more than merely give composition a past that it can smile about: First, her history reminds us that students come to college and the first-year course with many years of schooling and writing experience behind them - not all of it worth erasing or in need of correction. Second, her history disrupts our most basic assumptions about what counts as "writing" in our histories. While prevailing narratives about FYC would define "writing" as motivated by and produced within college contexts, Schultz's history broadens the discursive sphere to suggest that "writing" worth our attention might in fact be produced outside of, even prior to, the college experience. And our attention need not ground itself in primary and secondary sites of education - with Schultz's revisions to our narratives, we might be more eager to more consistently historicize the "extracurriculum," as advocated by Anne Ruggles Gere, or religious spheres where literacy practice and instruction habitually occurs but is rarely studied, and to writing produced in informal contexts prior to college.

In its expansion of the discursive sphere and our historical imagination, Schultz's history motivates me to point out another problematic assumption about what counts as "writing": Prevailing narratives promote the assumption that "writing" means writing in English, written by and for native speakers of English. But just as Schultz is interested in pursuing the connection between composition and the long history of public schooling in the United States, I am interested in the connection between composition and the United States' long history of immigration and multilingual literacy practices. Our disciplinary histories have, for the most part, failed to explicitly call attention to the history of nonEnglish writing instruction in the United States; one history that gestures toward this possibility is Jessica Enoch's chapter about Chicano/a writing practices and pedagogy in 
Refiguring Rhetorical Education. ${ }^{16}$ What is most interesting to me about this chapter is that Enoch gathers most of her evidence about rhetorical education in Laredo, Texas from a Spanish-language newspaper, La Cronica. Enoch never discusses the paper as a Spanish-language text; instead, she translates the articles into English and interprets them based on that translation, never raising the question of how the newspaper's original language - and Enoch's subsequent translation - might affect the narrative she constructs. Besides a handful of Spanish words or phrases (accompanied by their English translations) scattered throughout the chapter, the only evidence that clearly illustrates $\mathrm{La}$ Cronica's original language is found in a photocopy of one page of the newspaper (140). Enoch intends throughout Refiguring to ascribe value to otherwise neglected sites of rhetorical education, but because she must make her research intelligible within already existing rhetorical boundaries, she does not highlight Spanish writing practices - and in fact she erases them through her translation. As such, the history centralizes dominant, English-only sites of writing and writing instruction, thus reinscribing prevailing narratives about FYC and muffling the same voices she intends to amplify.

But in spite of the limitations of Refiguring, the history helps raise important questions about how composition has habitually defined "writing" as an English-only practice and suggests important reasons for rethinking and revising our prevailing narratives about FYC: Not only could we begin to redefine writing as a multilingual practice, but we should begin to search for evidence of histories that would illuminate

\footnotetext{
${ }^{16}$ In Mestiz@Scripts, Damian Baca argues that composition historians' lack of attention to non-English writing practices and instruction has limited its purview in substantial ways. Although the book primarily examines contemporary Mestiz@ scripts (for a definition of what Baca means by "Mestiz@," see page 2) and cannot accurately be categorized as a "history" of the discipline, Baca emphasizes the need for revised historical accounts of the discipline; he writes: "In my own field of English Compositoin, Metsiz@s appear only recently as unnamed linguistic 'problems' in remedial or standard first-year writing seminars. After a few months when the semesters end, Mestiz@s curiously disappear from English Composition scholarship and its civilized world of the art of letters" (xv).
} 
immigrant literacy and learning practices in the United States. Additionally, such a revision would enable us to more easily locate composition scholarship within international contexts - as many scholars are already advocating ( see Horner et al. and C. Donahue) - which would therefore widen the scope of our research as well as the discursive sphere to include multilingual and non-English "writing" and uncover the perspectives such writing represents. ${ }^{17}$

\section{FYC and "Writing Instruction"}

In spite of more recent historical scholarship that complicates prevailing narratives about FYC, our most widely cited histories remain focused on FYC and uphold Harvard's place as composition's institutional origin. As a result, "writing instruction" tends to mean, for compositionists, the "teaching of introductory college writing." And because nineteenth-century writing instruction at Harvard is often associated with CTRP and because prevailing narratives about FYC locate the discipline's origins there, historical evidence of such practice at other institutions has often been interpreted as proof that required freshman composition produced similar effects for a variety of students across institutions and over time. ${ }^{18}$ What's more, evidence of pedagogy such as the teaching of grammar and skills-and-drills approaches to the teaching of writing is often understood as monolithic practice, arhetorical and disempowering for all students no matter the context. In this section, I explore the consequences of these interpretations for students, teachers, and the discipline as a whole, especially in terms of our

\footnotetext{
${ }^{17}$ Xiaoye You's Writing in the Devil's Tongue begins the work of historicizing composition in an international vein, as he explores composition's evolution in China.

${ }^{18}$ For evidence of this kind of interpretation in historical studies as well as proposals for the future of the discipline, see especially those who argue against the requirement of FYC, including Crowley (Composition in the University), Debra Hawhee's "History and The Harbrace College Handbook," Gary Olson's "The Death of Composition as an Intellectual Discipline," Jasper Neel's "Reclaiming Our Theoretical Heritage," and Charles Bazerman's "The Case for Writing Studies as a Major Discipline."
} 
constructions of the discipline's future. In order to demonstrate how our prevailing narratives about FYC have limited how we define "writing instruction" in our histories, and in order to gesture toward the effects of this boundary-making, I engage in a metahistorical critique of our histories. Within this section, I analyze excerpts from some of our most widely cited histories against excerpts from histories that produce competing narratives, focusing particularly on how FYC's content, pedagogy, and student writing are portrayed in both. I argue that we need to harness and build upon those historiographic strategies exemplified in competing narratives because they resist centralization of FYC and enable a reconceptualization and expansion of what we mean by "writing instruction," which ultimately affects contemporary composition scholars, teachers, and students.

As I noted earlier, the content of the first-year course in composition has, more often than not, been characterized in our disciplinary histories according to prevailing CTRP narratives; most often, prevailing narratives about FYC describe the course's daily activities according to textbook evidence. Robert Connors' description of FYC in "The Rhetoric of Mechanical Correctness" epitomizes many early historians' assumptions about what has been taught, historically, in the first-year classroom. He writes: "Throughout most of its history as a college subject, English composition has meant one thing to most people: the single-minded enforcement of standards of mechanical and grammatical correctness in writing" (72). Likewise, in tracing the interrelated histories of the MLA and NCTE organizations, Myron Tuman also focuses on the exterior features of assessment in FYC and assumes that these features adequately represent the content of the course. Tuman describes the requirement of English A at Harvard as: 
an extension as well as a rejection of rhetoric, which throughout the [nineteenth] century had been increasingly becoming [sic] a study of the formal properties of literature and thus naturally expanded to include the study of the formal properties of composition about literature. In order to pass this writing assignment, the student was under no obligation to demonstrate either an innovative or personal understanding of the material under consideration - orthodoxy in interpretation and correctness in expression, each in accordance with a prescriptive canon, were the rule. (344)

Both Connors' and Tuman's examples rely on interpretations of the content of FYC that focus narrowly on how teachers may have approached instruction in grammar or the "formal properties" of writing. As I elaborated quite thoroughly in Chapter 2, these interpretations are problematic because they conflate "real" evidence of the content of FYC - particularly textbook evidence - with actual pedagogical practice. For my purposes here, I am not as interested in proving that this conflation occurs as I am in elaborating the consequences of these interpretations as they relate to teachers, students, and the discipline writ large.

First, in portraying FYC as a relatively content-less and mechanically oriented course, prevailing disciplinary narratives portray the methods used to teach FYC as streamlined and rigid, which results in unflattering and - as I will demonstrate shortly sometimes inaccurate representations of the methods used to teach writing in the United States over the last 150 years. The college entrance exam is one apparatus that composition historians have focused on in their critique of FYC. Although the entrance exam at Harvard predates the establishment of English A, Patricia Donahue notes in "Disciplinary Histories" that many scholars - beginning with Kitzhaber - have made connections among the Harvard examination, the "decline and fall" of rhetoric, and the first-year course. For Kitzhaber and others, "[ $t]$ he deficiencies the examination was 
designed to reveal were the same deficiencies the freshman rhetoric course was designed to rectify. As the scope of rhetoric began to narrow, as rhetoric became transformed into rhetoric/composition, its connection with remediation increased" (Donahue 232). As I discussed in Chapter 2 and as Donahue begins to illustrate in this essay, portraying the nineteenth-century "shift" from (oral/classical) rhetoric to (written) composition as a "decline" poses problems because it oversimplifies the practical pedagogical, administrative, and institutional approaches necessitated by dramatic changes in American and global culture. ${ }^{19}$

Likewise, when we assume that the college entrance exam produces directly negative effects for FYC - and rhetoric in general - we facilitate a problematic oversimplification of the exam's relation to the course that carries consequences for students and teachers. Making a direct connection between the entrance exam, an institutional apparatus designed to exclude or rank undergraduates, and the purpose of FYC in the nineteenth-century college obscures several important contextual facts: First, the entrance exam existed prior to Harvard's instantiation of it; Mary Trachsel explains in Institutionalizing Literacy that " $[\mathrm{t}]$ he mechanism of entrance examinations was itself a carryover from the classical era when preparatory students were required to demonstrate their mastery of classical texts and languages before they would be granted admission to college" (51). Second, the exam was not primarily created by writing teachers; and finally, the entrance exam tested not only literacy skills, but also knowledge in math, history, science, geography, and other subjects (Trachsel 50-74).

\footnotetext{
${ }^{19}$ By "dramatic changes in American and global culture," I refer to the rise of industrialism, increased print literacy, and the various social movements occurring in the American public sphere throughout the nineteenth century.
} 
Although I don't disagree that the way students were tested in literacy in the nineteenth century is, from a contemporary perspective, problematic, metahistorical analysis makes clear that criticizing the exam's definition of literacy without contextualizing it as part of the historical record is insufficient, nor can we appropriately shift our critique of the exam directly to FYC, because such a critique assumes that the agents in charge of the exam were also in charge of the content of the first-year course. Crowley's discussion of the exam helps substantiate my point about the problems that emerge from this kind of assumption. Making a direct connection between Harvard's entrance exam and the content of FYC, she writes:

The function of the course that followed on the heels of the examination, then, was to establish a site in which students might undergo the repeated and continuous punishment earned by their failure on the exam.... Freshman English was the site wherein students' writing was put on continuous display so that its lacks could be remarked, and so that their papers could be measured against each other and against Harvard's disciplinary standard as well. This reading of the daily theme as punishment-through-exercise explains why no exit exam was demanded at the close of English A.... The point of the required course is not to acquire some level of skill or knowledge that can be measured upon exit; it is instead to subject students to discipline, to force them to recognize the power of the institution to insist on conformity with its standards. (74)।

Here, Crowley assumes that teachers of writing at Harvard (and, implicitly, elsewhere) were in cahoots with administrators in charge of the entrance exam. Her Foucauldian characterization portrays composition teachers in the nineteenth century as arbitrarily disciplinary, demeaning to students, and disengaged with the needs or desires of students - a characterization grounded in the direct correlation Crowley makes between the exam and methods of teaching FYC. Further, Crowley assumes in this passage that student writing, manifested in daily themes, is merely an "exercise," perceived by students and teachers as meaningless and punishing. These depictions not only ignore historical 
evidence that students and teachers of composition were engaged rhetorically with their work, but such representations of students and teachers also encourage contemporary scholars to assume they can divine the intentions and values of teachers (and students) in the past through their participation in a specific course or set of assignments. ${ }^{20}$ In establishing this connection between the nineteenth-century first-year classroom and the contemporary writing course, Crowley's historiography also pushes compositionists to define "writing" according to those definitions promoted within prevailing narratives of FYC, which define "writing" narrowly as "academic discourse" and "essay writing" and fail to reflect how writing practices - both in and outside the classroom - have changed dramatically over time.

What's more, the association made by Crowley and others between the entrance exam and FYC becomes complicated when one moves into the late-nineteenth century, at which time test-makers shifted their focus from testing in composition to testing in literature, a move that many argue helped secure literature's ascension as an academic discipline (and simultaneously ensured composition's descension into the margins). While early instantiations of the exam might have attempted to regulate writing, historians such as Kathryn Fitzgerald have suggested that the exam's shift in focus from writing to literature may have instead occurred because test-makers determined that they could not adequately test arhetorical or acontextual writing and that it would be easier to systematically test students' knowledge of literature. Fitzgerald explains that:

[T] he legitimation of literature as secondary English's central component was the contingent outcome of local material and discursive practices at work within and between institutional sites in conditions of asymmetrical

\footnotetext{
${ }^{20}$ This is not to say that historians should avoid analyzing the evidence available to them, but rather that historians need to challenge the seemingly "common sense" assumptions that ground historiography in passages such as this.
} 
power relations. The records reveal that in meetings called in the early 1890 s to thrash out college/secondary school articulation, literature became central not primarily through intellectual or ideological discussions of its value relative to other potential topics for the English curriculum, but rather in the process of perfecting the technology of testing for college admission. ("From Disciplining")

In other words, the historical narrative that connects entrance exams with the pedagogical methods employed in FYC is not as seamless as Crowley and others portray it to be. While Fitzgerald's research is certainly not above critique, her argument is valuable, for my purposes, because it demonstrates how questions about history might be kept open instead of foreclosed. In particular, Fitzgerald's claim disrupts previous historians' assumptions that test-makers were not self-reflective about the complexity inherent to processes of writing: making the move from testing composition to literature suggests that administrators and teachers at both the college and secondary level were likely aware of the inherently rhetorical nature of writing. Moreover, Fitzgerald's competing narrative about the shift points toward another way of understanding composition - not as a discipline struggling for legitimacy, but as one that is ultimately interdisciplinary, a point I elaborate in Chapter 4.

Conflating entrance exams with the actual content of FYC also devalues the everyday work of teachers and assumes the worst of students' engagement with writing and writing instruction. When this conflation occurs, we suggest that teachers do the same work in the classroom as exams do on their own; what's more, this conflation assumes that students passively consume instruction, whether in the classroom or in relation to the exam. As such, historiography that upholds this conflation produces lasting consequences for composition teachers and students. 
Russell's history provides another good example of how decentralization of FYC and broader definitions of "writing instruction" may produce significant and lasting intellectual effects for the larger discipline. He writes that historically, "faculty [outside of composition] have tended to mistake the inevitable struggles of students to acquire the new rhetorical conventions of a discipline for poor writing or sheer ignorance" (18). This misperception of writing - and writing instruction - across the disciplines affects composition's ability to be conceived as a legitimate discipline by those outside of it; because rhetoric and writing is often misconstrued as "transparent," then writing instruction - in composition or across disciplines - will continue to be marginalized. But when we define our work beyond the immediate discipline, we can identify ourselves as well-positioned advocates for discipline-specific writing instruction and work to build bridges between and among disciplines. Russell explains that "[a]t the curricular level, if professionals are not aware of the role rhetoric plays in their own discipline, then they will see little need to teach it" (17). Russell's historical research, in other words, helps us broaden our contemporary view of what counts as "writing instruction" and paves the way for better communication with, and improved teaching within, other disciplines.

Our disciplinary historiography suggests that writing instruction within FYC produces direct and specific, usually negative, effects for students. Debra Hawhee, for example, argues in "History and The Harbrace College Handbook" that handbooks like the Harbrace function in the FYC classroom as material representations of CTRP that "[articulate] what is deemed important subject matter" and that "effectively shape teacher and student subjectivities - that is, they discipline the writer" (504). Hawhee's archival study of the evolution (and popularity) of the Harbrace College Handbook connects 
handbooks directly to FYC, as well as its students and teachers. She concludes that it is because of the continued use of handbooks such as the Harbrace that "the first-year writing course remains where it began - on 'remedial' ground," which in turn keeps "composition teachers" from "break[ing] out of their working class status" and "studentwriters" from "see[ing] themselves as authors" (522). Crowley makes a similar argument when she contends that "[t]he continuing function of the required composition course has been to insure the academic community that its entering members are taught the discursive behaviors and traits of character that qualify them to join the community" (89).

Both Hawhee's and Crowley's rhetorical portrayals of students in relation to FYC in these passages engage in what Bruce Horner, drawing on Anthony Giddens, has critiqued as a "functionalist error" prevalent in composition scholarship; that is, both scholars "attempt[] to explain the unintended consequences of actions by renaming those consequences as fulfilling the needs of a social systems, imputing a teleology to those systems, which are imagined as operating behind the backs of social actors" $(122-23){ }^{21}$ This error, played out in Hawhee's and Crowley's historiographic practice, carries specific material and intellectual consequences that influence our contemporary understanding of and approach toward students, as well as our vision of the future. First, students are characterized as neophytes, new to writing and writing instruction. Before entering the university and FYC, Crowley's and Hawhee's rhetoric suggests, students did not write and were not exposed to writing instruction. Students' writing experiences in primary and secondary educational contexts are flatly ignored, which suggests that these experiences lack value. Second, Crowley's historiography in particular portrays the

\footnotetext{
${ }^{21}$ In effect, Giddens acts as a corrective here to the influence of Foucault in Crowley's and Hawhee's work.
} 
adoption of academic language as a zero-sum equation: If one adopts the language of the university, one loses the language of the community; if a student assimilates to the university culture, he or she loses his/her sense of self. ${ }^{22}$ As former university students ourselves, many of us in composition can surely attest to the failings of this equation; however, Crowley's historiography maintains an unself-conscious hierarchy that values scholar over student. Third, academic discourse is assumed to be singular and monolithic - an assumption that others, such as Russell, would trouble. Finally, and perhaps most importantly, students' needs and desires are neglected in Hawhee's and Crowley's historiography; neither acknowledge the material and intellectual currency of mastering the "discursive behaviors and traits of character" valued within the university context. This neglect positions students rhetorically as passive consumers of writing instruction, lacking agency in FYC and other academic contexts of writing.

The historiographic practices illustrated by, but certainly not unique to, Hawhee and Crowley authorize contemporary and future teachers and scholars of writing to place the blame for student success, failure, or resistance on a single course - FYC - rather than on their own habits of writing, thinking, and teaching (about) students. As such, prevailing narratives about FYC sustain problematic representations of the relation between teacher and student, presenting this relationship as lacking the agency or negotiation that necessarily occurs in the writing classroom. David Gold and Scott Zaluda both offer historiographic alternatives to the prevailing historical narratives about FYC, therefore complicating prevailing conceptions of FYC's effect on students and student writing. Their historiographic strategies point toward other practices that future historians

\footnotetext{
${ }^{22}$ Hawhee's and Crowley's historiography lead them toward the either/or habits of thinking explicated well within the debate between David Bartholomae and Peter Elbow in 1995 (see "Writing with Teachers" and "Being a Writer vs. Being an Academic").
} 
of composition could more systematically employ as they attempt to disrupt problems such as those outlined above. In "“Eve Did No Wrong': Effective Literacy at a Public College for Women," Gold looks beyond FYC to demonstrate that female students attending Florida State College for Women (FSCW) in the early twentieth century held a great deal of rhetorical agency within the university and in the local community. Gold neither centralizes FYC in his analysis of student writing at FSCW nor assumes FYC produced a direct effect on student writing, thus producing a competing narrative about FYC in which students are framed as active and engaged within both the university and the community, and student writing is assumed to be representative of complex rhetorical practices. He argues: "To the extent that these [writing] classes reproduced bourgeois subjectivity, they also encouraged students' self-confidence as writers and promoted writing in public forums" (W179). Gold's historiography in this passage and throughout the article encourages compositionists to perceive students, student writing, and writing instruction generally as complex, producing multiple negative and positive effects.

Zaluda's examination of writing instruction at Howard University between 1919 and 1931 likewise provides a competing narrative about FYC and its effects on students that broadens our definition of what counts as "writing instruction." While "college catalogues of the teens and ' $20 \mathrm{~s}$ " describe courses that engaged in "the practice of intensive grammatical drilling in both credit-bearing and non-credit writing sections," Zaluda does not automatically interpret these courses as "evidence that Howard's faculty held a view of writing as an elementary skill to be acquired or remedied prior to the study and practice of rhetorical forms and prior to serious intellectual development" (237). Instead, Zaluda favors an interpretation that "accord[s] essay assignments and exams" in 
the English department and outside of it "not only intellectual but [also] social and political significance" (237). Such an interpretation is especially important in the context of an HBCU, but implicitly, Zaluda's perspective forwards a view of composition history that defines all writing and writing instruction - even when it involves drills and discipline - as potentially progressive. In his examination of writing assigned across the curriculum at Howard University, Zaluda argues that:

HBCU student and faculty writing in the field of sociology cannot be seen simply as a mechanism for linguistic acculturation or the reproduction of prevailing ideas. Writing in sociology and across the curriculum at Howard University and other HBCUs was an act of demythologizing race and culture and reinscribing them as "constantly changing" social and political concepts. (253)

Because Zaluda, like Gold, looks both at and beyond FYC for evidence of writing instruction at Howard, his microhistory allows for a more complicated conception of writing pedagogy's effects on students. Drills-and-skills courses at HBCUs and elsewhere did not just work on otherwise marginalized students, but students may have found agency within these courses and as they moved through the writing curriculum. Zaluda's and Gold's analyses provide valuable alternative lenses through which future historians of composition can interpret their historical data and conceive of the future more expansively. Additionally, analyzing Gold and Zaluda in relation to one another highlights the advantages of metahistorical critique as a tool of analysis, in that this critique highlights the importance of questioning our assumptions about the place of FYC in composition's past and present, as well as the positive rhetorical effects for students, teachers, and the discipline at large that can emerge through a constant troubling and broadening of the discipline's definitions of "writing instruction." 
Finally, prevailing narratives about FYC often define "writing instruction" as "writing instruction for introductory college English"; and as such, "writing instruction" is often associated with a long and troubling history of academic labor issues. For example, both Connors and Brereton argue that the containment of writing instruction to the first year at Harvard and elsewhere produced "a kind of teacher slavery" (Brereton 18) because, while the numbers of students enrolled in each required composition course increased through the latter half of the nineteenth century, the course itself "demand[ed] by its nature an essentially individualized pedagogy" (Connors, Composition-Rhetoric 188). As a consequence, FYC "came to be despised" and "bitterly resented by college faculty members" (Connors, Composition-Rhetoric 184, 185). As a result of the blurring between FYC and problems much larger than the single course, FYC becomes a scapegoat for many historians, who perceive the course as directly exploitive of teachers and the discipline at large (again engaging in the functionalist error I noted earlier). I argue that by making FYC the scapegoat, we misdirect our focus and miss an opportunity to change larger systems that work against many scholars and teachers - not just compositionists - who work at the university level.

Connors outlines other negative consequences for teachers and the discipline at large in "Licensure, Disciplinary Identity, and Workload," a chapter of CompositionRhetoric; here, he attributes unethical labor practices directly to the requirement of FYC in American colleges: First, FYC became a gateway course not only for students, but also for graduate students or new college instructors with Ph.D.s in literature who were required to teach composition as a kind of rite of passage before attaining the experience necessary to teach advanced courses in their own specialties, and "[n]ew instructors [in 
the early twentieth century] were regularly assigned three, four, or five sections of composition - sometimes while they were still attempting to finish their own dissertations" (196). Therefore, "young instructors quickly came to hate rhetoric and composition" (196). What's more, faculty members' general disdain for FYC, as well as their lack of pedagogical training, led to "exceedingly poor composition teachers" and teaching, according to Connors (198).

While I do not doubt that poor teaching of composition occurred in the late nineteenth and early twentieth centuries or that the pessimistic attitudes about the firstyear course Connors describes existed, I argue that poor teaching and pessimistic attitudes are not unique to teachers of composition or the first-year course; these kinds of problems have always existed in all areas of education and would not be resolved if composition achieved "true" disciplinarity or if the requirement of FYC were eliminated within universities across America (see Jurgen Herbst). Perhaps unsurprisingly, Connors' sweeping generalizations about teachers of composition - including those with specialties in literature - during this time period have been complicated by other disciplinary historians and demonstrate unconventional historiographic strategies which have the potential to revise the discursive sphere in lasting ways. JoAnn Campbell, for example, details the close relationship between Gertrude Buck - a rhetorician - and Laura Wylie a literary scholar - at Vassar College at the turn of the century in "Women's Work, Worthy Work." Campbell argues that the close and respectful relationship between Buck and Wylie resulted in a "democratic[]" English department that "shar[ed] power, rewards, and resources, and constructed a pedagogy rooted in cooperation" (27). Together, 
Campbell shows, Buck and Wylie deliberately studied the writing process and developed a curriculum that reflected their research (36-37).

Patricia Donahue and Bianca Falbo also complicate Connors' assumptions about literature professors' neglect of pedagogy and rhetoric as they uncover another side of Francis A. March, whom many have called the "father" of English studies. In "(The Teaching of) Reading and Writing at Lafayette College," Donahue and Falbo argue that narratives in literary disciplinary histories that "privilege[] ... the March who taught reading, who taught literature" neglects "the 'other' March, the one who could as easily be identified as a progenitor of composition" (45). They write, "[t]he celebration of March as a 'pioneer' of literary study hides from consideration his nuanced attention to writing and the interaction between reading and writing, and distorts the range of his contribution to English study - his advocacy, as he put it, of 'the abundant use of writing"” (52). Donahue and Falbo's microhistory, in combination with Campbell's, further complicates and deepens our narratives about FYC and its effects on teachers in the past and present. This complication first suggests that there is much more recovery and revisionist work to be done before we can assume we understand what it would have been like to teach composition a century ago; and second, it warns us that we should be cautious when assuming that prevailing historical narratives provide clear lenses through which we can interpret the present and future.

In fact, the problems described by Connors and Crowley - and complicated through Campbell's and Donahue and Falbo's microhistories - are systemic, intertwined with structures of power within the university and not exclusively locatable in the existence and requirement of a single course. Connors' and Crowley's arguments are 
grounded in two faulty premises: First, they both seem to assume that teaching the universally required course in composition is an undesirable goal for people who have earned PhDs. This assumption, while likely applicable for some, neglects those who enjoy - and perhaps even prefer - teaching FYC. Second, both scholars build their arguments on the premise that men and women who hold doctorates are (or were) only qualified for jobs within academia and would not choose or aspire to other career paths after completing graduate school. Consequently, the rhetoric of these historians maintains narrow and elitist myths about the purpose of higher education in the United States; their historiographic practices, in other words, help perpetuate the divide between town and gown that so many compositionists aim to dissolve.

Moreover, when historians and other compositionists place the blame for unethical employment practices on $\mathrm{FYC}$, members of the discipline who hope to change those practices (of whom there are many) are likely to (mis)direct their activism toward the discipline and the role of FYC within it, rather than at hierarchies embedded within the university system. As I explained previously, this misdirection is precisely what happens when disciplinary histories trace composition's pasts according to the development of FYC across institutions of higher education. Maintaining this singular focus on FYC carries the rhetorical effect of naturalizing structures of power that not only exist far beyond the course and discipline, but that also allow such inequalities to persist at a local level. As a result, changes to practices and policies within the discipline may resolve some problems at a local level, but they will do little to change the larger university systems that perpetuate the problem. 


\section{Conclusion}

Throughout this chapter, I have shown how metahistorical critique is a useful analytic tool with which compositionists can identify, isolate, and revise those narratives that produce not only a limiting sense of the discipline's history, but also a limiting vision for the future. My critique of the historiography that both produces and resists prevailing narratives about FYC allows the discipline, first, to recognize and move away from narrow debates about whether or not introductory writing courses should be required, and second, to dislodge narrow conceptions of what counts as "work," "writing," and "writing instruction" in composition studies. When we develop new narratives of origin, we help establish the rhetorical conditions necessary to achieve what contemporary scholars have already begun to advocate - an expansion of the discursive sphere that acknowledges geo-political realities and maps the field of "rhetoric and composition" onto multilingual, cross-institutional, and global contexts of writing. 


\section{CHAPTER 4:}

\section{COMPOSITION AS A(N) (INTER)DISCIPLINE}

In this chapter, I focus on the manner in which our histories frame composition as a unique academic discipline distinct from or in opposition to other disciplines. As I have already touched on in previous chapters, composition histories often present the discipline's emergence as a direct response to composition's antagonistic relationship to English literature or its failed relationship with classical rhetoric; these stories of antagonism and decline construct the discipline's most familiar and prevailing narratives about composition's disciplinarity. But other narratives reject stories of a clear "split" between composition and literature or the "decline and fall" of classical rhetoric, instead suggesting that it is more accurate to historicize the discipline as inevitably intertwined and working with English literature and rhetoric. ${ }^{1}$ Still other versions of composition's history find its relation to disciplines beyond literature and rhetoric more useful in making sense of its evolution to the present; these competing, much less prevalent, narratives historicize composition in terms of its relationship to education, speech

\footnotetext{
${ }^{1}$ In suggesting that English literature and rhetoric are autonomous disciplines in relation to composition, I recognize the artificial and arbitrary nature of this separation. It may make more sense, instead, to call literature, rhetoric, and composition sub-fields of English studies rather than separate disciplines. However, I have chosen to keep these areas separate in my discussion because composition's histories have often treated them separately; this separation actually constitutes the heart of the problem I address in this chapter.
} 
communications, English as a Foreign or Second Language (EFL or TESOL), linguistics, modern or foreign languages, psychology, and even the sciences.

As in previous chapters, I use metahistorical critique in this chapter to trace prevailing and competing narratives about composition's disciplinarity so as to highlight the values and beliefs that ground our historiographic practice, a move which in turn allows compositionists to intervene in, revise, or harness those strategies that forward our contemporary goals and practices. Specifically, I align myself with those scholars, including Steven Mailloux, Louise Wetherbee Phelps, and Bronwyn Williams, who construct rhetoric and composition as an interdiscipline.

Mailloux, whose focus is on rhetoric, sees "the historical relations among those disciplines focused on oral and written rhetoric - on literature, speech, and composition"; he hopes the multidisciplinary historical approach he takes in Disciplinary Identities will "encourage dialogue among the teachers and scholars most responsible for research and training in the language arts" (2). In Composition as a Human Science, Phelps describes composition's relationship to literature as an "accident" which "completely misrepresents and distorts its proper relation to other disciplines" (45). She urges composition to "reconstruct its relationship with literature, reinterpret its sometimes parasitical relationships with other disciplines, and participate in complex networks of inquiry" and argues that composition can only be defined as "logically subordinate to [rhetoric and literature] if looked at from their own altitude... However, from the perspective of composition itself, it has a surplus of meaning with respect to any cross-discipline within which it falls" (77-78). And in a recent article, Williams urges composition studies to look beyond college-level writing practices and pedagogy, into fields as diverse as " $\mathrm{K}-12$ 
literacy education, ethnographic and international literacy studies, and media studies" because, quite simply, the field is already moving in these directions (129). The problem, Williams argues, is that even as compositionists move into these interdisciplinary areas of research, they are not communicating with - or being cited by - scholars in "complementary fields" whose research is "astonishingly similar" to that being conducted on the fringes of rhetoric and composition (129). Williams concludes that compositionists need to engage "a broader conception of what the field can and should be" by making "conscious connections to the work and people in other literacy-related fields in ways that broaden our ideas of scholarship" (130).

In aligning myself with Mailloux, Phelps, and Williams and defining composition as an interdiscipline, I mean that composition's focus on writing practices and pedagogy implies and necessitates interaction among myriad disciplines. I argue that defining composition as an interdiscipline is the most beneficial for its future because this definition encourages productive relations between and among disciplines which obviously inform and are informed by contemporary studies of composition. Additionally, this definition authorizes composition's work within and across disciplinary borders - work that is already going on but is oftentimes pushed to the margins of our discourse or redefined as something other than composition. ${ }^{2}$

I agree with contemporary scholars' efforts to (re)define composition as an interdiscipline; however, such a definition will not make sense within disciplinary discourse until scholars begin to recognize the discipline's lack of historical discourse

\footnotetext{
${ }^{2}$ In particular, I am thinking of scholars habitually overlooked within composition studies because their work is intertwined with education, literacy (especially New Literacy Studies), linguistics, TESOL, writing centers, and WAC (see for example Lucille Schultz, Joel Spring, Theresa Lillis, Roz Ivanic, Allan Luke, Alastair Pennycook, Brian Street, and others).
} 
about composition's interdisciplinarity. In "Seeking New Worlds," Williams points out that:

[a]s exciting as ... cross-disciplinary scholarship ... might be to those of us who engage issues and ideas beyond college writing, such work can also feel as if we are pulling against the gravitational tide, that we are making individual efforts rather than being part of a more systemic reorientation of the field. (137-38)

My project participates in the "systemic re-orientation" Williams promotes. In addition, I contend that proposals for the discipline's future(s) - proposals like Williams' - which call for recognition that composition's role in the academy is a necessarily interdisciplinary one will not succeed unless our historical narratives are revised in such a way that they systematically account for composition's strong interdisciplinary past.

I am not alone in arguing that our prevailing historical narratives of composition's disciplinarity hold sway over its self-definition. Maureen Daly Goggin and, more recently, Bruce Horner and Min-Zhan Lu have called for composition scholars to make sense of the discipline by critically examining and expanding the terms with which it defines itself. Goggin argues that compositionists need to "understand our own complicity in the [marginalized] position we currently hold. We need, in other words, to consider how we name and define ourselves, and how the definitions we generate may serve as fetters" (199). For Goggin, composition studies will remain "misunderstood, ... marginalized, and ... powerless" if its focus is relegated to the confines of the "college writing classroom rather than more broadly to all aspects of literate practices" (199, $200) .^{3}$

\footnotetext{
${ }^{3}$ While I would not characterize composition as Goggin does, I must acknowledge that others in composition would. Her point is valuable especially in light of those critics who might argue that defining composition as an interdiscipline will dislodge its claims to legitimacy.
} 
And in "Working Rhetoric and Composition," Horner and Lu want the terms "rhetoric, composition, and rhetoric and composition" to be linked "with a rich and changing array of practices, bodies of knowledge, and institutional sites" because such a connection may lead rhetoric and composition to act as "an institutional space for developing alternatives and forms of resistance to hegemonic forces and relations" (473). At the same time, though, they worry that

this possibility is effectively limited by the tendencies to treat the meaning of each of the terms as stable and self-evident; to use them interchangeably and uncritically with "writing," "English," and "literacy"; and to treat rhetoric and composition not as mutually dependent and constitutive, but as mutually exclusive or in hierarchical order. (473)

Horner and Lu and Goggin want composition studies to be redefined through broader, more flexible, and interdisciplinary terms. For Goggin, composition scholars must "find powerfully flexible frames to redefine ourselves" in spite of "the ways in which the academic landscape has been plowed and staked" (205). For Horner and Lu, redefinition means asking how our work intersects with - and might be simultaneously distinguished from - the work of scholars from disciplines as diverse as "speech and communications, media studies, journalism, and literature," while also acknowledging how those "in the fields of education and applied linguistics" have already contributed to composition scholarship (487). Others including Williams, Phelps, and John Brereton suggest that composition needs to also investigate its ties to psychology, sociology, ethnography, media studies, and philosophy.

Although I advocate for a reenvisioning of composition's history as an interdisiciplinary one in order to support the calls of contemporary scholars who hope composition's future will also be interdisciplinary, I must also acknowledge the material 
risks implied in this argument: First, an embracing of composition's interdisciplinarity can potentially limit its legitimacy and autonomy in the eyes of university administrators. At a time when budgets are strained and departments already suffer too many financial cuts, this concern is not a trivial one. What's more, scholars who submit interdisciplinary research for publication face a difficult challenge as they position themselves within multiple disciplinary boundaries at once; they must anticipate and negotiate potential misunderstandings and tension that are not as likely to arise if publishing firmly within clear disciplinary boundaries. If composition is to self-identify as a fundamentally interdisciplinary discipline, are our scholars prepared to take on the additional rhetorical and material work such self-definition implies?

I cannot claim to have answers that will satisfy all concerned parties; however, I will say that I think it is possible for compositionists to retain and defend their autonomy as they explore interdisciplinary connections. ${ }^{4}$ What I call for in this chapter is not a retraction of our claims to disciplinarity; nor do I argue that we attempt to regularly publish outside of composition, as some scholars have suggested we might (see Williams 142). Instead, I call for a systematic recognition within our disciplinary discourse that composition's history, contemporary research, and future interests overlap with other disciplines. In other words, I want to encourage historians and other compositionists to engage in a consistent unsettling of the discursive sphere, a continuous challenging of

\footnotetext{
${ }^{4}$ Although I cannot claim that this proposal will necessarily alleviate or address the myriad material realities associated with making the move to interdisciplinary self-definition, I want to restate the premise upon which my argument is built (a premise shared with many members working in the discipline): rhetorical choices produce material consequences. Although shifting the discursive sphere is a gradual and slow process, the process itself is worthwhile in that each change allows for new intellectual and material consequences, which ultimately allows for new perspectives to be made "intelligible" within disciplinary discourse.
} 
what counts as knowledge within the rhetorical boundaries created by our disciplinary discourse.

In this chapter as in others, I analyze textual examples from composition's histories in relation to one another to demonstrate how and why these narratives have been used and repeated over time. I use this analysis to identify the rhetorical effects produced by these prevailing narratives; specifically, I show that our prevailing historical narratives constrain the discursive sphere, therefore limiting contemporary scholars' ability to achieve the interdisciplinary focus for which they advocate. Next, I use metahistorical critique to examine historical accounts of composition that challenge prevailing narratives, arguing that these examples offer important historiographic strategies that challenge and expand the discursive sphere. These strategies, therefore, gesture toward ways in which composition might be systematically rehistoricized as an interdiscipline in the future. I contend that this project of rehistoricization has the potential to benefit contemporary scholars, teachers, and students while also opening up new possibilities for the future of a discipline that is already and has always been engaged in interdisciplinary work.

\section{Rhetoric's "Decline and Fall" and Composition's "Split" from Literature: Prevailing Narratives of Antagonism}

As I have already discussed in previous chapters, since Albert Kitzhaber composed his dissertation on the history of composition, ${ }^{5}$ compositionists have habitually framed the discipline's past against developments in English literature and classical rhetoric throughout the mid- to late-nineteenth century. Usually, this framing has been

\footnotetext{
5 As I explain in Chapter 2, Kitzhaber's dissertation was not published as a book until 1990 but became available to many scholars in the late 1970s thanks to Richard Young and others. Several historians - most notably James Berlin and Robert Connors - cite Kitzhaber in work published in the 1980s.
} 
supplemented with a focus on the formation of English studies at Harvard, the institutional location which best encapsulates, for our most widely cited historians, the "decline and fall" of classical rhetoric in the university and the "split" between English literary studies and written communication. In this section, I trace the evolution of these two versions of composition's prevailing narratives about disciplinarity by conducting a metahistorical analysis of selected histories that employ these narratives. I conduct this analysis in order to acknowledge how these narratives have served the discipline and to demonstrate the inadequacy of such framing for contemporary composition, especially when it aims to define itself as an interdiscipline.

In Chapter 2, I elaborated on the assumptions I see driving the "decline and fall" narrative in relation to the development of prevailing narratives of current-traditional rhetoric and pedagogy (CTRP). Here, I summarize the narrative and outline three specific consequences for composition's construction of disciplinarity that emerge. In the "decline and fall" narrative, compositionists represent the discipline's past as directly linked to the classical rhetorical tradition but interrupted by a unified cultural shift from oral to written rhetoric in the mid- to late-nineteenth century, a shift marked most clearly within higher education by a change in pedagogical approaches toward rhetoric that emphasized mechanical correctness and style over substance and invention - thus constituting rhetoric's "decline and fall" in the American academy.

Many historians (among them Robert Connors, Michael Halloran, Sharon Crowley, and Wallace Douglas, as I discuss in Chapter 2) take the shift for granted as a unified one, most often describing it as a pedagogical movement from supposedly democratic or civic rhetorical instruction to seemingly arhetorical CTRP - a movement 
unchallenged until rhetoric and composition instituted itself as an ostensibly legitimate academic discipline in the middle of the twentieth century. While I do not dispute that historians constructed this narrative through an examination of available historical evidence, my argument in Chapter 2, as here, is that the "decline and fall" narrative encourages scholars to understand composition's history as unfolding in a relatively monolithic, unified, and linear fashion. This narrative has allowed composition to claim legitimacy as an academic field because scholars can claim the contemporary discipline as one that recovers a lost classical heritage. However useful the "decline and fall" narrative may have been, it is, like all narratives, a rhetorical construction.

I call attention to the "decline and fall" narrative here because I see it as one that problematically delimits the terms through which composition defines itself: In the wake of smoothing out a complicated past, the narrative neglects myriad institutions, pedagogies, students, and teachers, which could collectively offer the contemporary discipline a broader, more nuanced, and interdisciplinary base upon which to claim legitimacy. Let me explain: Narrating composition's history according to its ties to (or loss of) a classical rhetorical tradition predisposes contemporary scholars, first, to understand rhetoric as monolithic, having a clear and uninterrupted lineage and, second, to hold up this tradition as an ideal against which disciplinary developments today or in the future may be assessed. While having such an ideal may appear unproblematic at the surface, I argue that this ideal, as a rhetorical construction, ensures the invisibility of rhetorical traditions already marginalized in our scholarship (see Baca) and forces these marginalized traditions to be interpreted according to a classical framework that 
reinforces Western values, beliefs and practices (see my discussion of Enoch in Chapter 2).

Further, understanding the contemporary discipline according to its ties to classical rhetoric suggests that this disciplinary tradition (if it can, indeed, be called a discipline) is central to understanding the work of contemporary composition. Let me be clear: I do not take issue with the association of composition with rhetoric - in fact, I think this connection is a fundamental one that must be made in any discussion about writing. Rather, the process of centralizing a contested, often only loosely defined, tradition in composition's conversations about disciplinarity privileges a rhetorically constructed set of abstractions (the term "rhetoric," after all, is not a "thing" in and of itself; the term sprouts myriad - and diverse - associations) over what some might argue are stronger ties to more clearly defined academic disciplines such as education (see my discussion of Fitzgerald in Chapter 2 and Schultz in Chapter 3). ${ }^{6}$ Within prevailing narratives about rhetoric's supposed "decline and fall," this privileging consequently erases lines that might be productively drawn between composition and disciplines other than rhetoric, therefore dismantling scholars' efforts to define the contemporary discipline as an interdiscipline.

Finally, defining composition according to its relationship with the classical tradition of rhetoric actually (re)produces a problematically narrow definition of "rhetoric," which, paradoxically, works against the desire of contemporary scholars who

\footnotetext{
${ }^{6}$ I characterize rhetoric as a "contested" and "often loosely defined" discipline for two reasons: First, there is a large body of scholarship that has called rhetoric's disciplinarity and history into question (see, for example, collections edited by Victor Vitanza, as well as Richard Graff and Michael Leff), and second, because both composition and communications - two disciplines that are usually separate - claim it as their own. Other scholars - including David Fleming and John Mucklebauer - have gone beyond the question of rhetoric's disciplinarity and have highlighted the ambiguity of the term "rhetoric" itself.
} 
wish to challenge our assumptions about and expand what we mean by "rhetoric" and those "traditions" associated with it. The following excerpt from Thomas Miller's The Formation of College English helps illustrate my argument:

As the art of drawing on popular values to persuade the public about what it ought to do, rhetoric has historically been associated with the ethical and political concerns of moral philosophy.... While such civic concerns are a well-recognized part of the history of rhetoric, modern rhetoric and composition courses have largely concentrated on moving students from the domain of personal experience to the conventions of academic essays, with public issues often providing a convenient backdrop for that transition. (7)

Here, T. Miller makes a distinction between rhetoric and so-called personal and academic writing; from this distinction, T. Miller expresses a desire that teachers will increasingly "work[] to develop more explicitly politicized ways to approach sites of conflict," a project that he sees as comprising "an integral part of the general expansion of rhetoric and composition beyond the confines of academic discourse" (7, emphasis added).

By creating and maintaining a distinction between rhetoric and various forms of writing habitually assigned by teachers in first-year composition (FYC), Thomas Miller constructs a hierarchy that values explicitly politicized writing over academic or personal writing. What's more, because this hierarchy suggests that academic or personal writing cannot easily be defined as rhetorical, T. Miller's historiography devalues the work of many teachers and students in the writing classroom. In fact, although he "hope[s] that this movement will converge with work on community literacies and cultural studies to revitalize and broaden rhetoric's traditional concern for how people draw on popular values to resolve conflicts and deliberate ... shared problems" (7, emphasis added), this hope is grounded on prevailing narratives of the "decline and fall" of rhetoric and (re)produces the narrow definitions of rhetoric he hopes to "broaden," while also 
forwarding problematic assumptions about (seemingly apolitical) classroom writing. I argue that $\mathrm{T}$. Miller misses the opportunity to effectively expand the discursive sphere about composition's role as a(n) (inter)discipline in that he identifies only a small portion of writing practices and pedagogies as potentially rhetorical - and deliberately excludes those that are academic and personal. This missed opportunity is reflected in and perpetuated through T. Miller's historiography, which takes the "decline and fall" narrative for granted. As a result, T. Miller's historiographic practice ultimately repeats constrained conceptions of rhetoric and keeps classical rhetoric as the center of our discourse about composition's disciplinarity.

As I noted above, I am not arguing that composition should sever its ties to rhetoric, however defined; rather, I claim that composition does not need to rely on prevailing narratives of rhetoric's "decline and fall" in the nineteenth century in order define itself as a discipline. Composition's reliance on the "decline and fall" narrative prevents it from exploiting the interdisciplinary characteristics inherent to the study of both composition and rhetoric. What's more, when compositionists maintain this reliance in their historiography, they risk an arbitrary categorization of writing practices, which therefore constructs and perpetuates hierarchies of writing that can problematically carry over into contemporary teaching practices - the very teaching practices that historians such as T. Miller explicitly intend to change.

Some disciplinary historians have also critiqued the "decline and fall" narrative. Susan Miller, for example, calls this narrative the "neoclassical" approach to composition historiography; in Textual Carnivals, she writes that:

[The neoclassical] story of composition provides catalogues of the greats ... to create an impression that what goes on in current writing instruction 
and research is either the result of, or a needed reaction to, wellestablished precedents. In this approach, the dominant theme is continuity and union. Historical discontinuities and fragmentations are seen not only as unfortunate, but as the results of practices that lie on a spectrum bounded by inadvertent idiocy and overt maliciousness. (36)

Later in the same chapter, S. Miller explicitly critiques the historiographic strategies ingrained within this narrative, pointing out that "the language in these accounts is a lament against fragmentation of rhetoric that might well be interpreted differently" (39, emphasis added). For S. Miller, a different interpretation would lead scholars to understand rhetoric's "fragmentation" not as evidence of a monolithic or linear past, but as evidence that the discipline continually adjusts to new technologies of writing and to the changing contexts of writing and reading over time. S. Miller's interpretation allows for an expansive definition of rhetoric while also challenging the centrality of classical rhetoric to composition's self-definition (39).

Susan Miller's critique in Textual Carnivals is helpful for outlining the limitations of the "decline and fall" narrative. Indeed, at the time of its publication in 1991, S. Miller's account of composition's history posed a formidable feminist challenge to disciplinary historiography up to that point, in that she deliberately gave voice and value to students and teachers, people who composition generally takes to be its "subjects." In spite of this important intervention, however, S. Miller's argument also points to - and in some ways participates in - another problematic prevailing narrative about composition's disciplinarity, the "split" narrative. This narrative, which documents the separation of composition and literature within English departments, presents its own set of problems because it centralizes literary studies within composition's disciplinary discourse. 
The narrative is usually rendered as follows: At the beginning of the nineteenth century, Harvard created the Boylston Professorship of Rhetoric and Oratory, to which John Quincy Adams was first appointed. Between Adams' appointment in 1806 and Edward T. Channing's, the third Boylston Professor appointed in 1819, the application of classical rhetoric was emphasized at Harvard. However, because Channing used literary examples to substantiate his lectures and because he often used these examples to illustrate mechanical and stylistic concerns, many historians interpret his role as moving toward literary studies while also attempting to systematize and streamline the teaching of writing. Francis J. Child, the fourth Boylston Professor in 1851, entered the position despising the work of reading and grading student writing and holding a firm desire to move English studies from a rhetorical to a literary focus. In 1876, Child became the first Professor of English, where he developed Harvard's program in English literature, and Adams Sherman Hill became the fifth Boylston Professor, where he allowed the shift from "rhetoric" to "composition" to prevail, creating a "split" between composition and literary studies. According to the account published in the Bedford Bibliography for Teachers of Writing, Hill then "continued the rule-bound focus on written composition begun by Channing," making it "clear that composition was a second-class subject and that rhetoric [would] hardly [be] mentioned" - thus ensuring literature's privileged position within English departments everywhere. In fact, the Bedford account of the history of composition composes both the "decline and fall" and the "split" narratives. Because the book represents an authoritative and introductory but seemingly comprehensive overview of composition's development as a discipline, its reproduction of these narratives seems particularly significant in light of my argument here. 
The "split" narrative documented in the Bedford Bibliography and elsewhere deserves to be questioned for three reasons: First, the narrative emerges out of historians' limited focus on the pedagogical and intellectual decisions made by Channing, Child, and Hill at Harvard. ${ }^{7}$ Second, this focus has prompted compositionists to construct an interpretation that problematically attributes these key actors with an influence over the development of composition that carries into the twenty-first century: many historians have argued that the "split" between literature and composition was motivated primarily by Channing, Child, and Hill and that these figures ensured that composition would remain locked in a "low" position in the academy from the late-nineteenth century into the present. Finally, this interpretation is grounded upon a flawed premise (a functionalist error) that literature's centrality within English departments actually caused the marginalization of composition. This assumption, I contend, is not only questionable because it misinterprets effects for a cause, but it also creates problematic rhetorical boundaries for composition's discourse and returns the field perpetually to a construction of its disciplinarity according to - and often against - the parallel development of English literary studies as a discipline in the U.S. academy.

Susan Miller's historical account of composition, therefore, both resists the "split" narrative while also inadvertently sustaining it. S. Miller argues that historians of English studies (including Gerald Graff, Arthur Applebee, and others) have ignored the development of composition studies while problematically romanticizing the study of English literature. According to S. Miller, these accounts make writing invisible within

\footnotetext{
${ }^{7}$ For my challenge to Harvard's centrality within composition's history, see Chapter 3 . For challenges to the Bedford Bibliography's representation of Channing, see my discussion of Elizabeth Larsen's and Charles Paine's work in Chapter 2. For challenges to popular representations of Child, see Patricia Harkin's "Child's Ballads."
} 
disciplinary histories of English and construct English studies as a "history of authorship and of the authorized voice, whose origins, successes, and privileges are not bound to the material circumstances of either readers or writers" (27, emphasis original). This version of history, S. Miller argues, privileges the "'polished' surface of language" (55), the passive consumption of texts (27), and a " "pure' literary history" over "actual writing practices" which "highlight[] the "low"" elements of writing, "suggest[ing] fissures, hesitations, conflicting purposes, and the multiple origins of ideas" (27).

While S. Miller's analysis articulates an important corrective to popular histories of literary studies in the U.S. and illuminates composition's role in the development of English literature as an academic discipline, I contend that S. Miller's historiography actually works against her larger purposes, in that it centralizes literature within English studies, makes literature appear more cohesive than it actually is, and accepts as fact the historical and continued marginalization of composition within English departments. Take for example the following passage, in which S. Miller argues that Charles Eliot Harvard's president between 1869 and 1904, largely credited with transforming Harvard into the influential modern university we know it as today - intended to marry literature and composition in the English department but employ them separately for specific but complementary purposes. She writes:

... the two pursuits of literature and composition were joined immediately as "high" and "low," advanced and elementary. Equally to the point, they were one bourgeois effort at delight and instruction, leisure and work - a necessary but nonetheless unified "division of labor" in Eliot's desires to satisfy within a designated "new elite"... Composition is clearly a site for the "low," in all its senses. As an intrinsic portion of the new American educational system, composition shared in the same tendencies to institutionalize functionally "pure" systems that characterized the entire nineteenth century. (53) 
Because her historical account of composition continually refers to and argues against English literature's "high" place on the academic hierarchy, S. Miller's reading and writing of composition's disciplinarity relies on the assumption that writing has always been and is presently perceived as "low."

I do not question the veracity of S. Miller's argument about writing's historically "low" status within specific institutional contexts; many historians have substantiated this claim. Instead, I want to draw attention to how this assumption works to delimit disciplinary discourse. S. Miller grounds her argument on the premise that composition currently occupies, and has always occupied, a "low" institutional position. This premise, as a generalization, disallows evidence to the contrary (see my discussion of JoAnn Campbell and Patricia Donahue and Bianca Falbo in Chapter 3) and thus predisposes composition to define its disciplinarity according to the assumption that the field occupies, and will continue to occupy, a marginal position in the academy.

Additionally, although she means to recuperate composition's place as a "legitimate" academic discipline, S. Miller's historiography, as represented in the passage above and elsewhere, works from and supports three faulty assumptions that carry rhetorical consequences for the discipline today: First, she assumes that composition's developments are deeply intertwined with literature's; second, she argues that composition has traditionally been pushed aside because of the "rise" of English literary studies; and finally, she attributes to figures such as Eliot deliberate, elitist, and ultimately malevolent desires (in this case, she argues that Eliot used composition to stratify students). I argue that the underlying assumptions driving S. Miller's historiography limit the success of her larger historical project, which has the potential, theoretically speaking, 
to broaden composition's historical discourse and legitimize those writing practices and pedagogies largely ignored within popular histories of English literature in the United States. But because S. Miller's historical account always returns composition to its fraught relationship with English literary studies, composition's disciplinarity is constructed accordingly. Thus, S. Miller's historiography constrains contemporary scholars who would define composition's past, present, and future as one that is largely interdisciplinary in nature.

The delimiting effects of composition's prevailing narratives about its disciplinarity are presented in high relief when examining scholarship outside the discipline. Take for example, Daniel Coffey's 2006 article, “A Discipline's Composition: A Citation Analysis of Composition Studies," published in the Journal of Academic Librarianship. Drawing heavily on Robert Connors' account in Composition-Rhetoric, Coffey's summary of the history of the discipline clearly echoes both the "split" and "decline" narratives. Coffey writes:

English Departments ... sprung up widely at the end of the $19^{\text {th }}$ century. And these became the obvious - although often less than welcoming home for rhetoricians: the discipline-less, doctorate-less holdovers from an earlier era of American higher education. As a result, for the greater part of the $20^{\text {th }}$ century, rhetoric-composition suffered as a weak cousin to the academic discipline of literary ... study, and rhetoricians, who were saddled with the additional task of composition instruction, found themselves carrying a much heavier workload. (156-57)

Because Coffey's profession depends on tracking trends within disciplinary scholarship, we can assume that his depiction of composition's history is representative of how a scholar outside of composition, literature, or rhetoric might depict our history (if they are to depict it at all). And because Coffey so easily folds both the "split" and "decline" 
narratives into the short passage above, we can see the rhetorical effects of disciplinary historiography outside of composition studies.

\section{Composition, Literature, Rhetoric: Prevailing Narratives of Unity}

The "split" and "decline" narratives are repeated frequently in composition scholarship; however, as illustrated by Susan Miller's critique of the "neoclassical" narrative above, they do not go unchallenged in disciplinary histories. In Chapters 2 and 3, I presented evidence from various histories that question the accuracy of the "decline" narrative; not only have historians recently called attention to the persistence of classical rhetorical education in a wide range of institutions outside Harvard, but they have also questioned historians' assumptions that the relationships among textbooks, teachers, and students was arhetorical during the nineteenth century. Also, in Chapter 3, I used evidence from JoAnn Campbell's and Patricia Donahue and Bianca Falbo's historical research to demonstrate that a clear, marginalizing "split" between composition and literature was not universally experienced within English departments in the nineteenth century.

So although I have, in a sense, already used these scholars' histories to challenge the viability of these narratives, I call attention to these prevailing narratives yet again in order to demonstrate how they limit composition's discourse and produce important consequences for those who would like to exploit composition's (inter)disciplinarity. In this section, I analyze what I call the "unifying" narrative, a narrative which challenges prevailing narratives of "split" and "decline" but which produces limiting consequences. The "unifying" narrative calls for composition to understand its past not as antagonistic to rhetoric or literature, but rather as evolving alongside, even with, both disciplines. This 
"unifying" narrative is useful for the contemporary discipline in that it acknowledges important links among language-based disciplines; what's more, this narrative moves composition one step closer to identifying itself as an interdiscipline. At the same time, however, the "unifying" narrative does not go far enough because it maintains rhetorical boundaries similar to the "decline" and "split" narratives. I contend that this narrative makes composition intelligible only in relation to literature and/or rhetoric, thus masking the role composition has played with(in) other disciplines.

Rather than repeating my previous discussion in Chapters 2 and 3, I focus here on textual evidence that exemplifies how the "unifying" narrative uniquely benefits composition's definition of itself as a discipline. These examples illuminate how composition's relationship to rhetoric and literature has, in some cases at least, had productive rather than marginalizing effects, especially in relation to issues of gender and the extracurriculum. At the same time, I use these examples to illustrate the limits of the "unifying" narrative in moving us toward an interdisciplinary understanding of composition's past, present, and future.

Julie Garbus's and Kathryn Conway's examinations of rhetorical education at private women's institutions during the nineteenth and twentieth centuries together construct a persuasive version of the "unifying" narrative that carries positive consequences for composition's understanding and representation of gender and writing instruction. In her contribution to the Local Histories collection, Garbus highlights the figure and pedagogy of Vida Scudder, an influential literature professor at Wellesley at the turn of the century. Garbus argues that Scudder understood literature as a form of rhetoric and thus should be of interest to compositionists because she offered rhetorical 
training to her female students. What's more, Garbus contends, the particular rhetoricalliterary training provided by Scudder empowered women in the nineteenth and twentieth centuries to become "educated, moral citizens who could think independently and carefully, discern intellectual and moral truths, and articulate those truths for the good of the community" (79). In this microhistory, Garbus refuses to assume literature and composition were "split" within the English department at Wellesley - and this refusal is impressive in light of existing historical literature, which equates the structure of Wellesley's English department with actual pedagogical practice and the status of composition in relation to literature (cf. Patricia Palmieri's Adamless Eden, cited in Garbus 80).

In "Woman Suffrage and the History of Rhetoric at the Seven Sisters Colleges," Conway analyzes women's institutions (her study also includes Wellesley) during the late-nineteenth and early twentieth centuries, framing her examination of rhetorical education in relation to its effects for the woman's suffrage movement in the United States. Like Garbus and other historians, Conway interprets the rhetorical training provided for women at the turn of the century as highly influential. According to Conway's study, female students studied oratory in the classroom and had the freedom to discuss and debate suffrage because of the single-sex educational context. Women's rhetorical training in the classroom thus trickled into the public sphere. Conway explains:

The woman suffrage movement was the first public campaign for women's rights in the United States launched and sustained by women who had received formal rhetorical training. These women pioneered both in higher education and in public speaking; they were among the first women to attend college in the United States, and many put their education to work as pro- and anti-suffrage speakers. In particular, 
alumnae of the Seven Sisters colleges gained prominence in this public debate. $(203)^{8}$

By tracing women's education into their political and public lives, Conway's study provides concrete examples of how rhetorical preparation has been useful for women's participation in the public sphere in the United States. And because this training was offered within English departments where rhetoric was neither on the "decline" nor seen as a separate pursuit from literature or composition, Conway's account confirms both the viability of the "unifying" narrative as well as its use as a lens through which scholars might better understand connections between gender and rhetorical instruction. Together, Conway's and Garbus's microhistories demonstrate how the "unifying" narrative can produce valuable intellectual and material effects for composition's definition of disciplinarity today; specifically, by understanding composition, rhetoric and literature as developing in tandem, compositionists can more effectively represent women in their histories while also acknowledging the empowering potential of rhetorical education for women and other marginalized populations, both at the turn of the century and today.

One interesting and perhaps surprising example of the "unifying" narrative is evident in discussions of non-academic literary clubs popular in the nineteenth century. Several historians, including Anne Ruggles Gere, Elizabeth McHenry, and Shirley Brice Heath, have pointed to these clubs as important examples of the relationship between literature and literacy development. In Intimate Practices: Literacy and Cultural Work in U.S. Women's Clubs, 1880-1920, Gere analyzes the activities of a wide variety of

\footnotetext{
${ }^{8}$ Although my focus is not on the accuracy of Conway's history, I think it's important to note that many historians would question Conway's claim that the woman suffrage movement was the "first public campaign for women's rights in the United States launched and sustained by women who had received formal rhetorical training." This claim, which is grounded on formal contexts of education only actually highlights one of the many problems that emerge out of composition's narrow focus.
} 
women's clubs around the turn of the century in an effort to legitimize their activities and define their work as intertwined with the professionalization of English studies. Gere argues that women's clubs have been largely ignored in historical accounts of English studies because the male-dominated discipline "had to discredit clubwomen's literary projects in favor of their own; they stigmatized the literacy practices of women's clubs to enhance those of professors" (214). Moreover, accounts of the history of English studies "also reduced [clubwomen] to a single type - white, middle class, and educated," which "made it easier to portray [the discipline] in monolithic terms" (216). Additionally, historical accounts of the development of literature refuse to look outside of postsecondary educational institutions, meaning that:

These accounts ignore or are institutionally blinded to the fact that when English professors were claiming their professional territory in higher education, thousands of women's clubs conducted, outside the academy's walls, projects of consuming and producing texts. (216-217)

In looking beyond institutional walls for the history of English studies and valuing the women's roles in both "consuming and producing texts," it becomes clear that Gere defines English studies as inseparably related to writing practices and pedagogy. Although the women studied "literature," Gere sees the clubs and clubwomen as an important component of the history of composition studies. She writes that contemporary disciplinary histories:

...overlook the Mormon clubwomen who saw invention as the most important part of writing, the working-class women who read their papers at local and regional meetings, and the women from all social locations who entered essay competitions or became published authors. (243)

Following Gere's logic through these excerpts illustrates how the "unifying" narrative helps composition move toward self-identification as an interdiscipline, one that has 
grown (and continues to grow) through its rich association with other disciplines, including but not limited to literary studies.

Like Intimate Practices, Elizabeth McHenry and Shirley Brice Heath's "The Literate and the Literary: African Americans as Writers and Readers, 1830-1940" documents the relationship between literacy and the study of literature, this time in relation to African Americans. In this essay, McHenry and Heath resist popular conceptions of African American literacy in the nineteenth and twentieth centuries, conceptions that define it as the ability to sign one's name or to read or as signified by highly valorized figures such as Frederick Douglass and Harriet Jacobs (261). McHenry and Heath argue that these conceptions, especially when paired with scholarly attention to the "oral" traditions of African Americans, ignore large numbers of middle- and upperclass African Americans who participated in an impressively literate - and literary - U.S. history (262-63). In focusing on the activities of African Americans' participation in literary societies, McHenry and Heath assume, like Gere, that writing and reading practices outside the academy are inextricably interrelated. They write:

The work to be done in restoring accuracy and cross-class representations of African American writers extends beyond classrooms. Scholars need to give much more attention to the range of written genres in relation to oral genres of African American authors, as well as to their readership - the people and places for whom written materials become central interaction and action. (274)

Like Gere, McHenry and Heath refuse to separate the study of literature from writing practice and pedagogy; in "unifying" the two, they challenge standard representations of African American readers and writers. Additionally, their history also reveals a rich history that marries reading to writing practices, thus challenging disciplinary discourse that understands composition as inherently "split" from literature. 
Although Gere's and McHenry and Heath's research concentrates on what Gere calls the "extracurriculum" and not disciplinarity within an academic context, I use these two textual examples to suggest that the "unifying" narrative might push compositionists to revise popular conceptions of disciplinarity; that is, when we broaden our definitions of what counts as literary study, we can also revise definitions of composition so as to understand it as a(n) (inter)discipline. In developing our terms, we might also resist racist and sexist attitudes that ground our definitions of what activities count toward disciplinarity. And just as Garbus's and Conway's research suggests positive consequences for composition's understanding of and ability to serve marginalized populations, so too do Gere's and McHenry and Heath's histories: In shedding light on composition's diverse and expansive history, these historians' scholarship unsettles the rhetorical boundaries of disciplinary discourse established through primary narratives of "split" and "decline," allowing scholars to more easily centralize marginalized groups within the discipline's history, development, and future.

Collectively, Garbus's, Conway's, Gere's, and McHenry and Heath's histories demonstrate how and why the "unifying" narrative has benefited composition in intellectual and material ways: First, the "unifying" narrative expands the discursive sphere, allowing composition to define itself in positive relation to rhetoric and literature. And second, in challenging prevailing narratives of "split" and "decline," the "unifying" narrative makes visible histories of writing practice and pedagogy engaged by groups of people habitually pushed to the margins of disciplinary discourse - which in turn allows more scholars, teachers, and students of writing to identify themselves as a part of the past and future of composition. 
But although questioning the "split" and "decline" narratives produces important benefits for composition, disciplinary histories that revise the story of composition's past and produce prevailing narratives of "unity" among composition, rhetoric and literature often continue to limit the purview of historical and contemporary scholarship in much the same way as the original "split" and "decline" narratives do. Even as these histories attempt to revise and reject prevailing narratives of the history of writing instruction in the United States, Conway's and Garbus's histories label certain pedagogical practices "rhetorical," and Gere's and McHenry and Heath's histories define the activities of women's and African American clubs as "literary" so as to make these practices intelligible within contemporary disciplinary discourse. While these rhetorical moves are not necessarily problematic in themselves, my point is that their reliance on composition's obvious ties to literature and rhetoric delimits the possibility that these pedagogical practices and extracurricular clubs will be defined, and therefore valued, for their connections to a broader range of disciplines. ${ }^{9}$

Some might point out at this juncture that scholars face an inevitable mandate to make their research intelligible to a specific disciplinary audience; in response, I contend that interdisciplinary research in composition will not be recognized and valued as such until we systematically challenge our prevailing historical narratives. My claim is simple: Until we acknowledge in our histories the multiple ways in which composition has borrowed from, built upon, and influenced a wide variety of disciplines, contemporary

\footnotetext{
${ }^{9}$ For example, writing instruction defined as "rhetorical" might also be defined in terms of educational or political theory, speech communications, or psychology. And the participation of women and African Americans within literary clubs might also be understood as pointing to the development of political science, government, history, or even the study of language.
} 
calls for a recognition (or redefinition) of composition as productively interdisciplinary will not succeed in persuading skeptical audiences. ${ }^{10}$

\section{Composition as a(n) (Inter)Discipline}

In this section, I conduct a metahistorical critique of a variety of texts that have established historical connections between composition and disciplines other than rhetoric and literature. I use this analysis to argue that, although composition's history is distinct from that of other disciplines - and although there are many reasons why we have composed historical narratives establishing this distinction - composition has much to gain from acknowledging our past as one that is deeply intertwined with a variety of disciplines. First, when we revise our prevailing narratives to reflect composition's past as interdisciplinary, we can more easily rework those historical accounts that rely narrowly on composition's relations to "rhetoric" and "literature" to explain its disciplinarity. Second, revising our prevailing narratives enables composition scholars to communicate with the disciplines we so often borrow from in our scholarship and also with those non-composition scholars with whom we interact regularly at our home institutions. Finally, in identifying our own history as interdisciplinary, we become identifiable to other disciplines as a valuable and mutually reciprocal resource. I argue, therefore, that our hopes for an interdisciplinary future will flounder until the story of our past is retold as an interdisciplinary one.

Here, I answer those scholars, such as Phelps, Williams, Mailloux, Goggin, and Horner and Lu, who have called for composition's redefinition as an interdiscipline by

\footnotetext{
${ }^{10}$ When I use the phrase "skeptical audiences," I am thinking of two specific groups: Those who see composition's past primarily in terms of its relationship to rhetoric and/or literature, and those who worry that defining composition as an "interdiscipline" may mean the discipline will break apart at the seams or lose its claims to academic legitimacy.
} 
presenting examples from the handful of disciplinary histories that have made connections between composition and other disciplines to show how we might more cohesively revise our prevailing narratives along interdisciplinary lines. I do this to demonstrate, first, that composition can claim an interdisciplinary past; second, to show how this path strengthens our claims for an interdisciplinary future; and third, to illustrate how the construction and maintenance of a prevailing historical narrative of "interdisciplinarity" can effectively benefit scholars, teachers, and students of composition in the present and future, while also promoting discourse between disciplines that is mutually beneficial.

Because they both focus on language use, the disciplines of speech communications and linguistics are the two fields outside of English literature and rhetoric most clearly tied to - and the most likely to be recognized as a part of composition's history. In two separate articles published in the same issue of College Composition and Communication (CCC) in honor of its fiftieth anniversary, John Heyda and Diana George and John Trimbur document composition's victory in what Heyda calls the "turf wars" of the 1950s," during which both composition and speech communications claimed ownership of the first-year course. For Heyda and George and Trimbur, the eventual exclusion of speech communications from the purview of rhetoric and composition represents a loss for the discipline. Imagining what composition might have gained from "a long-term partnership with communications," Heyda argues that a continued relationship with communications would have helped composition remain attentive to aural rhetorical elements such as speaking and listening, and it would have helped composition establish a certain degree of disciplinary autonomy, perhaps even 
diffusing the power differentials it normally experienced within home departments of English (680). For George and Trimbur, the divorce of communications and composition in the $1950 \mathrm{~s}$

reproduces deeply-engrained logocentric allegiances to the verbal over the visual by holding the intellectual authority of written text over the presumably derivative and immature character of visual communication, thereby making the image subservient to the word (697).

In reconstructing and revaluing the contributions (or potential contributions) speech communication at one time offered to composition studies, George and Trimbur and Heyda provide at least one trajectory through which the discipline could be effectively rehistoricized: These histories refuse to assume that the visual and aural components of persuasion are irrelevant within contemporary composition studies, thus disrupting the rhetorical boundaries established by our prevailing narratives about disciplinarity. Heyda and George and Trimbur, therefore, encourage the contemporary discipline to revitalize its attention to the aural and the visual and look beyond composition's most widely cited journals and scholars to those of speech communications and remain open to its offerings.

While Heyda and George and Trimbur lament a seeming "loss" of our connection to speech communications, their arguments seem to be challenged by the fact that compositionists today often publish in cross-disciplinary journals such as Rhetoric Society Quarterly and Rhetoric Review, which also publish communications scholars. Additionally, composition has turned its attention to visual rhetoric since the publication of Heyda's and George and Trimbur's articles, and some scholars, including Krista Ratcliffe, Michelle Balliff, and Cynthia Selfe, have recently called attention to the aural components of composition studies. This evidence does not make Heyda's and George and Trimbur's proposals for the future irrelevant, however; instead, it demonstrates how 
our prevailing historical narratives - which construct composition as an autonomous discipline - may mask evidence of an ongoing and interrelated past.

Both Sharon Crowley and Robert Connors have traced the complex historical relationship between composition and linguistics, especially as it developed around the mid-twentieth century. Although their historiography continues to rely on some of the problematic assumptions I have already deconstructed in previous chapters, their acknowledgement of ties between composition and linguistics deserves attention here. Crowley contends that scholars attempted to integrate linguistic theory into composition practice and theory "primarily because of the intellectual poverty that characterized instruction in writing" ("Linguistics" 481). She argues that linguistic theory appeared attractive at this time to some scholars for two reasons: first, because compositionists were eager to attach themselves to a discipline with some clout in the academy; and second because of composition's historical emphasis on the study and teaching of grammatical correctness. In spite of her problematic claim that "intellectual poverty characterized instruction in writing," Crowley's conclusions are worth paying attention to because she sees the contributions of applied linguistics as ultimately positive for composition studies. Crowley explains that, despite some scholars' reservations about the field's viability,

[1]inguistics taught teachers to look at the language actually used by their students as a departure for instruction; [linguistics scholars] emphatically rejected the claim made by more traditional teachers that instruction should present students with an ideal language to which their own linguistic performance must be made to conform. (501-02)

Connors' brief acknowledgement of linguistics' influence in CompositionRhetoric is similar to Crowley's, though it is couched within a larger discussion of 
composition's attitude toward mechanical correctness (162-70). He uses the account to urge compositionists to understand the "balanc[e] between formal and rhetorical considerations [as] a delicate one" (170). Although both of these historians interpret the ties between linguistics and composition as limited in scope, the evidence they provide of a shared history provides an important beginning that might be revisited by scholars interested in rehistoricizing composition as an interdiscipline. ${ }^{11}$

Specifically, Connors' and Crowley's interpretations of linguistics' contribution to composition history suggest that much more than formal grammar can be learned about language acquisition from the study of linguistics. And indeed, some scholars trained in linguistics, including Suresh Canagarajah and Paul Kei Matsuda, have recently received attention in composition scholarship. But because most composition scholars are unlikely to have received formal training in linguistics, some may perceive such knowledge as unnecessary to effectively study or teach writing. Connors's and Crowley's accounts imply, however, that when we recognize and borrow from linguistics as a part of our (inter)disciplinary history, our understanding and treatment of students - especially our ability to appropriately approach and accommodate their writing practices - will grow. Further, as theoreticians of writing who understand our history as linked to that of linguistics, we can continue to learn from, build upon, and perhaps even contribute to conversations in which the two disciplines share mutual interests about the nature of language and language learning.

\footnotetext{
${ }^{11}$ Also see Martin Nystrand et al., "Where Did Composition Studies Come From? An Intellectual History." In this article, Nystrand et al. argue that composition's history can best be traced according to theoretical developments in literature and linguistics; they trace composition's development according to the primary theoretical frames (formalism, structuralism, and dialogism) that have influenced it, theoretical frames shared by linguistics and literature.
} 
What's more, when composition begins to consistently recognize linguistics as relevant to its history and its future, the discipline is more likely to acknowledge subfields of linguistics, including applied linguistics, sociolinguistics, and second-language acquisition, as equally relevant. Matsuda has drawn attention to composition's habitual sidelining of second-language studies, or Teaching English to Speakers of Other Languages (TESOL). In "Composition Studies and ESL Writing: A Disciplinary Division of Labor," Matsuda argues that in refusing to historicize TESOL as a part of composition studies, scholars "reinscribe" the view that the sole responsibility of teaching writing to ESL students falls upon professionals in another intellectual formation: second-language studies" (700). ${ }^{12}$ But because "ESL students in most cases are required to enroll in composition courses, and since many ESL writers also take professional writing courses," Matsuda contends, "ESL writing issues should be as much a concern for composition specialists as they are for second-language specialists" (715). The first step toward mutual understanding between disciplines (he is careful not to suggest that the disciplines merge), according to Matsuda, is understanding that TESOL and composition share a history that led to a "disciplinary division of labor" between 1941 and 1966. Once this history is integrated into our narratives, Matsuda argues, both disciplines can understand their work as mutually informative and potentially transformative on an institutional level (715).

Matsuda's microhistory demonstrates how an awareness of composition's historical relationship with linguistics and second-language studies can lead to an interdisciplinary revision of the "split," "decline," and "unifying" narrative that will

\footnotetext{
${ }^{12}$ A similar refusal of responsibility also exists between composition scholars and K-12 specialists, a disciplinary division I address below.
} 
benefit composition scholars seeking a deeper understanding of language and writing teachers hoping to better serve their students. However, Matsuda's historical account of TESOL also calls attention to the monolingual presumptions that ground our prevailing narratives: When we trace composition's disciplinarity according to its historical relationship to (or separation from) classical rhetoric and literature, the question of language is rarely raised as significant to this history. However, as John Trimbur points out in "Linguistic Memory and the Politics of U.S. English," the question of language should be raised when discussing the recent history of higher education in the U.S.; he writes that "the U.S. university has drastically curtailed the educational role of languages other than English - whether Greek and Latin in the old-time American pietistic colleges or German for those Americans who went to German universities to get PhDs" (583).

Once the question of language is raised in relation to composition's history whether in the context of the language used in "old-time" American colleges, international study, the study of modern languages, or non-native speakers and writers of English - our disciplinary past, and thus our sense of disciplinarity, becomes much more complex. As Bruce Horner and John Trimbur point out in "English Only and U.S. College Composition," disciplinary histories have taken for granted the monolingualism of composition studies, which they argue "replaced the bilingualism (in principle if not always in practice) of the classical curriculum" (595). Horner and Trimbur argue that the institutionalization of FYC led composition to privilege English as a "living language"; to marginalize the study of modern languages as an activity of reading (602-03); and ultimately to uphold a "tacit language policy of unidirectional English monolingualism" (594) that manifests itself in the contemporary discipline. Horner and Trimbur intend to 
"pose an alternative way of thinking about composition programs, the language of our students, and our own language practices that holds monolingualism itself to be a problem and a limitation of U.S. culture and that argues for the benefits of an actively multilingual language policy" (597).

I agree with Horner and Trimbur that "monolingualism itself" poses a problem but not just because of the institutionalization of FYC (and its monolingual bias) in universities during the nineteenth century. I argue, also, that composition's approach toward the writing of its history - our historiographic practice - has likely participated in the masking of "an actively multilingual" past that stretches far beyond the "bilingual" classical curriculum or the study of modern languages that Horner and Trimbur hope to recuperate. Matsuda's microhistory of TESOL and composition, as well as Jessica Enoch's and Damian Baca's histories, which I discussed in Chapter 3, hints at the importance of recognizing the immigration - and thus multilingual - history of the United States and the consequences this history must have had on teachers and students of writing from the nineteenth century on (see also Samantha NeCamp's research on the Moonlight Schools). Because composition studies is historicized as inevitably monolingual, and because acquisition of an international perspective is seen as a contemporary project, the discipline overlooks evidence of a multilingual past - a past that could further enrich our disciplinary links to linguistics and TESOL, as well as to modern languages and classics.

Just as the above historical accounts document the disappearance of speech communications, linguistics, TESOL, and modern languages from composition's purview, the discipline has also lost sight of its connection to the field of education. This 
loss is notable especially since many of the mid-century scholarly conversations surrounding composition's development took its connection to education, at least at the secondary level, for granted. For example, in his 1959 address to the Conference on College Composition and Communication (CCCC), Kitzhaber attempts to resolve the problems associated with first-year composition (FYC) by focusing on the bridge between high school and college. He proposes that, instead of abolishing FYC, college writing professors should work collaboratively with high school teachers and administrators to provide appropriate preparatory work in language, literature, and rhetoric. Although proposals such as Kitzhaber's are made occasionally in our scholarship and at conferences such as CCCC, many in the discipline no longer see $\mathrm{K}-12$ education as composition's responsibility.

Some of our lack of contemporary attention to composition's connections with education can perhaps be explained by the academy's attitude toward pedagogy, as well as composition's desire to be perceived as a "legitimate" academic discipline. The history of composition's relation to education has been documented by scholars such as Mariolina Salvatori and Margaret Marshall. In Pedagogy: Disturbing History, Salvatori presents a documentary history of how pedagogy has been perceived and defined within the academy; she is particularly "interested in calling attention to some of the questionable rationales that historically have allowed English departments to look at teacher preparation with suspicion, derision, and condescension" (6). She believes that an "investigation of the historical precedents that foster dismissive attitudes toward pedagogy must begin with the recuperative gesture, one that aims at recapturing a version of pedagogy's past that will make such dismissals problematic and self-indicting" (7). By 
recuperating and revaluing education's reputation within contemporary English departments, Salvatori's history offers a clear lens through which composition can identify its past as intrinsically - and fruitfully - connected to the field of education. And with this revaluation, composition can learn from ongoing and overlapping educational research while also opening up mutually beneficial lines of communication between the disciplines.

In Response to Reform: Composition and the Professionalization of Teaching, Marshall provides a historical account of the rhetoric used to describe teacher professionalization, literacy, and writing instruction. Marshall argues that scholarteachers within contemporary composition studies continue to be marginalized because of this discursive history; she believes that "attending to the echoes of prior discourses and being conscious of the ways language and argument construct (and limit) our conceptions" is a primary step in subverting composition's historically "low" status within the academy (16-17). She demonstrates how compositionists might "reconceptualize what it means to prepare for and enter the profession, especially the relationship between scholarship and teaching. Such an examination also repositions those of us who have chosen to teach the literacy of written discourse as something other than powerless victims" (2-3). With Marshall and Salvatori, I agree that retracing composition's disciplinary history as one intertwined with the discipline of education benefits compositionists hoping to see themselves as agents or their discipline as legitimate. In addition, such a retracing encourages compositionists to value the field of education as an equally legitimate discipline. The field of education deserves our attention not only because of what we can give it, but because of what we can learn from 
it: among many other things, the discipline can inform our understanding of literacy, of student identity in the classroom, of effective pedagogical practice, and it can help us bridge gaps in our knowledge about writing pedagogy and practice in primary and secondary schools.

As I already discussed in Chapters 2 and 3, the discipline's contemporary negligence of composition's connections to the field of education may account for some of its negligence of the history of writing practices and pedagogy at normal schools, which were responsible for the education of the nation's K-12 teachers (see my discussion of Kathryn Fitzgerald, Beth Ann Rothermel, and Kenneth Lindblom et al. in Chapter 2), and at primary and secondary schools (see my discussion of Lucille Schultz's The Young Composers in Chapter 3). In addition, composition's negligence of its ties to education might also help explain how and why the history of writing instruction for vocational purposes and/or for adults has escaped our attention. David Gold, Susan Kates, and Karyn Hollis have emphasized the important role played by vocational schools in rhetorical education, especially for relatively powerless groups of people in the United States.

In one chapter of Rhetoric at the Margins, Gold documents the history of writing instruction at Texas Woman's University (TWU), which provided vocational training for white women at the turn of the century. Gold insists that TWU and institutions like it need to be examined in composition histories as sites of rhetorical education and action. He explains that

... for white women in Texas, gender-centered vocational education represented an important avenue of socioeconomic and political achievement.... Unlike many of their peers at elite private women's colleges in the East, students at TWU were consistently encouraged to 
write and speak in public forums, to take part in political discourse, and to think of themselves as rhetors. (68)

Whereas Gold's study focuses on a traditional university context, both Kates and Hollis historicize writing instruction at two separate schools established out of the workers' education movement in the U.S. during the 1920s. At Brookwood Labor College and the Bryn Mawr Summer School for Women, Kates and Hollis find, "educators promoted the study of rhetoric as a deeply democratic and socially responsive endeavor" (Kates 18), and students "used writing to remake their discursive selves, forging new and more powerful 'real world' identities in the process" (Hollis 37). These three historians - and Kates and Hollis in particular - illustrate how composition's prevailing narratives about its disciplinarity can mask activities and institutions that fail to fit within our discourse because they cannot clearly be defined according to academic disciplinary divisions. As a consequence, Kates' and Hollis' research challenges the rhetorical boundaries of the discursive sphere; the educational practices they document cannot easily be made intelligible within prevailing narratives of composition's disciplinarity. Together, Gold's, Kates', and Hollis' historical research highlights the rich connections that can continue to be developed between the fields of composition and education, while also gesturing toward research that is needed to more fully understand of composition's interdisciplinary past.

The histories I have discussed in this final section provide clear starting points from which we can approach the rehistoricization project I advocate throughout this chapter. We might also explore composition's interrelation with areas closely related to those I have already discussed here, including professional writing, journalism, creative writing, and media studies. While scholars such as Jeff Rice, Katherine Adams, and 
Alexandria Peary have offered starting points along these lines, their histories - like many of those I have already discussed - remain marginal in relation to scholarship that repeats our prevailing historical narratives. Until we engage in a systematic project that recognizes composition's past as a fundamentally interdisciplinary one, I argue that these important historical accounts will remain marginal and will thus immobilize our calls for an interdisciplinary future.

\section{Conclusion}

The rehistoricization project I envision does not mean a dismissal of composition's ties to literary studies or rhetoric; rather, this project would draw from these ties while acknowledging others. It would refuse arbitrary disciplinary boundaries and resist the pressure to "purify" composition through rhetorical processes of disciplinary exclusion and neglect. And perhaps most importantly, this project would construct itself as dialogic at its heart, mutually beneficial for composition as well as the disciplines it engages. This interdisciplinary rehistoricization would seek out points of connection as well as division - at what points do our disciplinary interests converge, where do they separate, and toward what ends? What can we give to, and what can we learn from, these overlapping disciplines? And finally, what can we take from composition's historical position as an interdiscipline? Beginning with these questions, composition can construct an interdisciplinary narrative of the past, which will in turn allow it to pursue a rich and interdisciplinary future. 


\section{CONCLUSION}

When I began this project, I was not aware of composition's extensive historical knowledge. I did not expect to find that composition has published more than 150 books and articles about the history of writing instruction in the United States. I was not yet familiar with the many voices that today echo and overlap with one another as I write the words that must conclude this project. In fact, I began this study familiar only with James Berlin's, Susan Miller's, Robert Connors', and Sharon Crowley's histories and the early conversations about historiography that seemed to have dwindled by the mid-90s. Given the decade that had elapsed since the publication of Crowley's 1998 history, I wondered why I kept hearing their voices, their versions of history, instead of others in contemporary scholarship. I did not know what else was out there, and once I began searching, I found much more than I expected (even today, I am sure my search is incomplete). I suspect the same is true of many compositionists, particularly those whose research interests are not historical.

Thus, the impetus for the project: If certain versions of our disciplinary history prevail in the disciplinary imaginary, even in spite of a growing body of scholarship challenging these narratives, what are the material and intellectual consequences for contemporary scholars, teachers, and students? In other words, how can we identify and analyze the effects of historiography? And once we have considered the consequences of our historiographic practices, how can we effectively revise disciplinary discourse so as 
to illuminate competing versions of history, encourage complexity in our narratives, harness new rhetorical strategies, and therefore enable different consequences? Although some, such as Lisa Mastrangelo and Melissa Ianetta, have recently critiqued specific versions of our history that deserve revision, I contend that our prevailing historical narratives will persist until we systematically analyze and critique disciplinary historiography. ${ }^{1}$ Metahistorical critique allows for this level of analysis, in that it provides a methodical approach with which to read and analyze how a textual corpus, having a shared rhetorical purpose, evolves over time and produces lasting consequences. While the process is imperfect in that reading and interpretation are ultimately subjective activities, my analysis of three prevailing historical narratives in this dissertation demonstrates the value of metahistorical critique for the discipline.

At its heart, metahistorical critique pushes composition scholars to question problematic versions of our history and evaluate the consequences of using these narratives, thus applying measured critique to both historical and non-historical scholarship. Take for example Kurt Spellmeyer's contribution to the Composition Studies in the New Millenium collection, "Education for Irrelevance?" In this essay, Spellmeyer proposes a new future for rhetoric and composition that would do away with its ties to literary studies because "[w]hen compositionists emulate English studies, we are emulating irrelevance, world evasion, and failure" (82). In order to take this stance, Spellmeyer grounds his argument on two prevailing historical narratives - the "decline and fall" and "split" narratives - both of which I challenged in Chapters 2 and 4 . He writes: "In some ideal sense, the curriculum as we know it reaches back to ancient

\footnotetext{
'See Mastrangelo's 'Lone Wolf or Leader of the Pack? Rethinking the Grand Narrative of Fred Newton Scott" (College English 2010) and lanetta's "Disciplinarity, Divorce, and the Displacement of Labor Issues: Rereading Histories of Composition and Literature" (CCC 2010).
} 
Greece, but it actually took shape about a hundred years ago with the decline of the liberal arts college and the rise of the modern university" $(85-86){ }^{2}$

For some, Spellmeyer's proposal might be compelling in that he argues that FYC should not occupy the center of the discipline but should instead occupy the center of the university curriculum by becoming interdisciplinary and reaching "across existing divisions of knowledge while addressing the most important issues our society now faces" (87). But because his proposal is grounded on an assumption that composition's history is inextricably bound to literary studies and is not already interdisciplinary, as I argue in Chapter 4 it is, Spellmeyer's conception of the future will likely be unconvincing for many. First, Spellmeyer's proposal disparages literature, one of the disciplinary allies composition might need to enact his vision. And second, Spellmeyer deliberately presents his argument as a radical solution that some might argue is not all that radical, in that many universities already see FYC as central to the university as a general education course (see Fosen) and many compositionists already see FYC as an appropriate venue in which to raise socio-political concerns. In fact, some might argue that this has always been FYC's role in educational contexts which generally fall outside the purview of prevailing historical narratives, such as HBCUs (see Jarratt, Zaluda, and Royster and Williams), normal schools (see Fitzgerald, Lindblom et al., and Rothermel), vocational colleges (see Kates and Gold), and other venues for adult education (see Hollis, Greer, and NeCamp).

In addition to highlighting how historical narratives are used for specific and consequential rhetorical purposes, metahistorical critique demonstrates the process

\footnotetext{
${ }^{2}$ Given the content of the remainder of the essay, I interpret Spellmeyer's nod toward the shift from the liberal arts to the modern university as equivalent to the decline of rhetoric and rise of literature.
} 
through which historical narratives work to demarcate the rhetorical boundaries of disciplinary discourse. For example, I argue in Chapter 3 that because prevailing narratives about first-year composition (FYC) locate the discipline's origins at Harvard in the late nineteenth century, scholarship outside the boundaries suggested by this origin point - outside institutions of higher education, outside the classroom, outside contexts of monolingual writing and writing instruction, and outside the U.S. - often remains marginal within composition studies. While the process of demarcation is inevitable in that the production of academic knowledge is made possible by the existence of discrete disciplines, the boundaries are flexible and ultimately depend upon the decisions made by those conducting new research as well as those in editorial and administrative power. Metahistorical critique calls attention to this flexibility, demanding that scholars, editors, and publishers employ and enable the production of scholarship that will challenge boundaries and open up new possibilities for future investigation and discovery.

Further, because it analyzes texts in relation to one another, metahistorical critique helps compositionists not only assess those narratives that dominate disciplinary discourse, but it also encourages scholars to understand and attribute value to prevailing narratives. In Chapter 2, for example, I raise questions about current-traditional rhetoric and pedagogy (CTRP) not only because I see problems associated with its continued currency in composition scholarship, but also because I want to illuminate the uses to which CTRP has been put in disciplinary discourse. While I interpret the discipline's continued use of CTRP as a relevant pedagogical category as ultimately disabling, I understand and appreciate that the contemporary discipline has found prevailing narratives about CTRP useful in establishing legitimacy. Maintaining a critical awareness 
about both the limits and possibilities of prevailing historical narratives is necessary for the future because such awareness allows compositionists to move forward with selfreflexivity about those motives that drive the writing of history and the values, beliefs, and practices represented therein. Through this critical awareness, we should expect our new or revised narratives to travel, and we will be better prepared to evaluate the consequences of these narratives.

Further, metahistorical critique allows composition historians and non-historians to harness powerful historiographic strategies that allow for an enduring unsettling and revision of our narratives. These strategies include a consistent opening up of questions about the past; the simultaneous consideration of multiple and diverse sources; and a demand that our readings and renderings of history are always portrayed with a rhetorical complexity that acknowledges the lived and negotiated interaction between historian and text. I include examples of historians engaging compelling strategies in each analysis chapter: In Chapter 2, I present Jane Greer's microhistorical account of socialist pedagogy at work in Plain English, a textbook for an adult-education correspondence course; her analysis refuses to settle the tensions that inhere within the textbook, between what Greer calls the textbook author's desire for liberatory pedagogy and concerns about mechanical correctness demanded by dominant culture. In Chapter 3, I discuss Scott Zaluda's examination of curricula and student writing in and outside of FYC at Howard University in order to demonstrate how consideration of a variety of materials, especially in contexts beyond FYC, can disrupt prevailing assumptions about writing practices and pedagogy. And I conclude Chapter 4 with a call for a systematic rehistoricization of 
composition as an interdiscipline; such a project will necessitate a historiographic approach that continually acknowledges the complexity of composition's past.

And finally, metahistorical critique reveals gaps in our historical knowledge, illuminates alternative interpretations of existing evidence, and outlines paths for new and necessary historical research. My analysis reveals several underdeveloped or blind spots within existing historical scholarship: histories of K-12 writing practices and pedagogies; histories of working-class, vocational, and adult education in writing; histories of multilingual writing and instruction in the U.S.; and international histories of composition. Recognition of these gaps in our knowledge underlines composition's disciplinary biases and points us toward new areas of research, which will surely demand the complication and revision of prevailing narratives while also identifying new questions that must be asked of composition's past.

The cumulative benefits of metahistorical critique ultimately carry over to the field's understanding of its present and future. With a more systematic acknowledgement of the historical complexity of writing pedagogy and practice, we will approach our reading, writing, and thinking of contemporary students and teachers with a deeper awareness of the challenges and rewards inherent to the teaching and learning of writing no matter the time or place. As I show in Chapter 2, composition's historicization and subsequent rehistoricization of Edward T. Channing demonstrates the multiple ways in which a pedagogue and administrator such as Channing can be read by contemporary scholars. When we refuse to foreclose questions about Channing by vilifying him as a key player in the "decline and fall" of classical rhetoric, we can consider alternative explanations - as Charles Paine and Elizabeth Larsen do - that account for the socio- 
historical and institutional context in which he worked. While Channing may have made choices that ultimately helped move composition to the margins of English studies at Harvard, interpreting him as a figure struggling to make sense of a rapidly changing world helps us identify with - instead of against - him and reminds us to proceed with caution as we make our own choices as scholars, teachers, and administrators in the present and future.

If we are to allow for other questions and narratives about the discipline to emerge, and if we intend to promote ethical ways of engaging with teachers, students, and the world, we must continually interrogate the prevailing narratives that shape the field, as well as our habits of thinking, reading, and writing about the history of writing instruction in the United States. In situating multiple histories in relation to one another through a cultural-rhetorical lens, this project enriches composition's understanding of the history of writing and rhetorical education in the United States, emphasizes gaps and inconsistencies in our current historical knowledge, contributes to conversations about the politics of historiography, and defines disciplinary historiography as a rhetorical practice that reflects and shapes the field's larger values and beliefs - a practice which ultimately yields significant theoretical and material consequences for the discipline and its agents. 


\section{REFERENCES}

"agent, ppl. $a$. and n." The Oxford English Dictionary. $2^{\text {nd }}$ ed. 1989. OED Online. Oxford University Press. Web. 1 September 2010.

Adams, Katherine H. A Group of Their Own: College Writing Courses and American Women Writers, 1880-1940. Albany: SUNY UP, 2001. Print.

---. A History of Professional Writing Instruction in American Colleges: Years of Acceptance, Growth, and Doubt. Dallas: Southern Methodist UP, 1993. Print. Applebee, Arthur. Tradition and Reform in the Teaching of English: A History. Urbana, IL: NCTE, 1974. Print.

Atwill, Janet. "Changing the Puzzle (Octalog II)." Rhetoric Review 16.1 (1997): 22-25. Print.

Baca, Damian.Mestiz@Scripts, Digital Migrations, and the Territories of Writing. Hampshire, UK: Palgrave, 2008. Print.

Ballif, Michelle. "What Is It That the Audience Wants? Or, Notes toward a Listening with a Transgendered Ear for (Mis)Understanding." JAC 19.1 (1999) 51-70. Print.

Bartholomae, David. Writing on the Margins: Essays in Composition and Teaching. Pittsburgh: U of Pittsburgh P, 2005. Print.

---. "Writing with Teachers." College Composition and Communication 46.1 (1995): 6271. Print. 
Bazerman, Charles. "The Case for Writing Studies as a Major Discipline." Rhetoric and Composition as Intellectual Work. Ed. Gary A. Olson. Carbondale, IL: Southern Illinois UP, 2002. Print.

Berlin, James. "Postmodernism, Politics, and Histories of Rhetoric." Pre/Text 11.3-4 (1990): 169-188. Print.

---. "Revisionary Histories of Rhetoric: Politics, Power, and Plurality." Writing Histories of Rhetoric. Victor Vitanza, ed. Carbondale, IL: Southern Illinois UP, 1994. Print.

--.. Rhetoric and Reality: Writing Instruction in American Colleges, 1900-1985.

Carbondale, IL: Southern Illinois UP, 1987. Print.

---. Rhetorics, Poetics, and Cultures: Refiguring College English Studies. Urbana, IL:

NCTE, 1996. Print.

--.. "Richard Whately and Current-Traditional Rhetoric." College English 42.1 (1980): 10-17. Print.

---. Writing Instruction in Nineteenth-Century American Colleges. Carbondale, IL: Southern Illinois UP, 1984. Print.

Bizzell, Patricia, ed. Feminist Historiography in Rhetoric. Spec. issue of Rhetoric Society Quarterly 32.1 (2002): 1-122. Print.

Bledstein, Burton. The Culture of Professionalism: The Middle Class and the Development of Higher Education in America. . New York: Norton, 1978. Print. Brereton, John C., ed. The Origins of Composition Studies in the American College, 1875-1925: A Documentary History. Pittsburgh: U of Pittsburgh P, 1995. Print. Brody, Miriam. Manly Writing: Gender, Rhetoric, and the Rise of Composition. Carbondale, IL: Southern Illinois UP, 1993. Print. 
Campbell, JoAnn. "Controlling Voices: The Legacy of English A at Radcliffe College 1883-1917." College Composition and Communication 43.4 (1992): 472-85.

Print.

---. "Women's Work, Worthy Work: Composition Instruction at Vassar College, 18971922." Constructing Rhetorical Education. Eds. Marie Secor and Davida Charney. Carbondale IL: Southern Illinois UP, 1992. 26-42. Print.

Canagarajah, Suresh. "The Place of World Englishes in Composition: Pluralization Continued." College Composition and Communication 57.4 (2006): 586-619. Print.

Carr, Jean Ferguson, Stephen L. Carr, and Lucille Schultz. Archives of Instruction: Nineteenth-Century Rhetorics, Readers, and Composition Books in the United States. Carbondale, IL: Southern Illinois UP, 2005. Print.

Clark, Gregory, and S. Michael Halloran. Introduction. Oratorical Culture in NineteenthCentury America: Transformations in the Theory and Practice of Rhetoric. Ed. Gregory Clark and S. Michael Halloran. Carbondale IL: Southern Illinois UP, 1993. Print.

Coffey, Daniel P. “A Discipline's Composition: A Citation Analysis of Composition Studies." Journal of Academic Librarianship 32.2 (2006): 155-65. Print.

Colomb, Gregory G. "Franchising the Future." College Composition and Communication 62.1 (2010): 11-30. Print.

Connors, Robert J. "The Abolition Debate in Composition: A Short History." Selected Essays of Robert J. Connors. Eds. Lisa Ede and Andrea Lunsford. Boston: Bedford, 2003. 279-294. Print. 
---. "Adversus Haerese: Robert J. Connors Responds to Roxanne Mountford." JAC 19 (1999). Web. 7 September 2008.

---. Composition-Rhetoric: Backgrounds, Theory, and Pedagogy. Pittsburgh: $\mathrm{U}$ of Pittsburgh P, 1997. Print.

---. "Current-Traditional Rhetoric: Thirty Years of Writing with a Purpose." Rhetoric Society Quarterly 11.4 (1981): 208-21. Print.

---. "English Composition as a Social Problem (Octalog)." Rhetoric Review 7.1 (1988): 67. Print.

---. "Overwork/Underpay: Labor and Status of Composition Teachers since 1880." Selected Essays of Robert J. Connors. Eds. Lisa Ede and Andrea Lunsford. Boston: Bedford, 2003. 181-198. Print.

---. "The Rhetoric of Mechanical Correctness." Only Connect: Uniting Reading and Writing. Ed. Thomas Newkirk. Portsmouth, NH: Boynton/Cook, 1986. 27-58. Print.

---. "Textbooks and the Evolution of the Discipline." Selected Essays of Robert J.

Connors. Eds. Lisa Ede and Andrea Lunsford. Boston: Bedford, 2003. 99-116. Print.

Conway, Kathryn M. "Woman Suffrage and the History of Rhetoric at the Seven Sisters Colleges, 1865-1919." Reclaiming Rhetorica: Women in the Rhetorical Tradition. Ed. Andrea Lunsford. Pittsburgh: U of Pittsburgh P, 1995. 203-26. Print. Crowley, Sharon. Composition in the University: Historical and Polemical Essays. Pittsburgh: U of Pittsburgh P, 1998. Print.

---. "The Current-Traditional Rhetoric: An Informal History." Rhetoric Society Quarterly 
16.4 (1986): 233-50. Print.

---. "Linguistics and Composition Instruction: 1950-1980." Written Communication 6.4 (1989): 480-505. Print.

---. The Methodical Memory: Invention in Current-Traditional Rhetoric. Carbondale IL: Southern Illinois UP, 1990. Print.

---. "Pedagogical Goals (Octalog)." Rhetoric Review 7.1 (1988): 7-8. Print.

“definition, n." The Oxford English Dictionary. $2^{\text {nd }}$ ed. 1989; online version March 2011. OED Online. Oxford University Press. Web. 15 March 2011.

DeGenaro, William. "William Rainey Harper and the Ideology of Service at Junior Colleges." Local Histories: Reading the Archives of Composition. Ed. Patricia Donahue and Gretchen Flesher Moon. Pittsburgh: Pittsburgh UP, 2007. 181-198. Print.

Donahue, Christiane. “'Internationalization' and Composition Studies: Reorienting the Discourse." College Composition and Communication 61.2 (2009): 212-243. Print.

Donahue, Patricia "Disciplinary Histories: A Meditation on Beginnings." Local Histories: Reading the Archives of Composition. Ed. Patricia Donahue and Gretchen Flesher Moon. Pittsburgh: Pittsburgh UP, 2007. 220-236. Print. Donahue, Patricia and Bianca Falbo. "(The Teaching of) Reading and Writing at Lafayette College." Local Histories: Reading the Archives of Composition. Ed. Patricia Donahue and Gretchen Flesher Moon. Pittsburgh: Pittsburgh UP, 2007. 38-57. Print.

Donahue, Patricia, and Gretchen Flesher Moon, eds. Local Histories: Reading the 
Archives of Composition. Pittsburgh: Pittsburgh UP, 2007. Print.

Douglas, Wallace. "Rhetoric for the Meritocracy: The Creation of Composition at Harvard." English in America: A Radical View of the Profession. Ed. Richard Ohmann. New York: Oxford UP, 1976. 97-132. Print.

Downs, Douglas, and Elizabeth Wardle. "Teaching About Writing, Righting Misconceptions: (Re)Envisioning 'First-Year Composition' as 'Introduction to Writing Studies." College Composition and Communication 58.4 (2007): 552-84. Print.

Ede, Lisa. Situating Composition: Composition Studies and the Politics of Location. Carbondale, IL: Southern Illinois UP, 2004. Print.

Elbow, Peter. "Being a Writer vs. Being an Academic: A Conflict in Goals" College Composition and Communication 46.1 (1995): 72-83. Print.

Enoch, Jessica. Refiguring Rhetorical Education: Women Teaching African American, Native American, and Chicano/a Students, 1865-1911. Carbondale IL: Southern Illinois UP, 2008. Print.

Fitzgerald, Kathryn R. "From Disciplining to Discipline: A Foucauldian Examination of the Formation of English as a School Subject." JAC 16.3 (1996): 435-54. Web. 12 July 2009.

--.. "A Rediscovered Tradition: European Pedagogy and Composition in NineteenthCentury Midwestern Normal Schools." College Composition and Communication 53.2 (2001): 224-50. Print.

Fleming, David. "Rhetoric Revival or Process Revolution? Revisiting the Emergence of Composition-Rhetoric as a Discipline." Renewing Rhetoric's Relation to 
Composition: Essays in Honor of Theresa Jarnagin Enos. Eds. Shane

Borrowman, Stuart Brown and Thomas Miller. New York: Routledge, 2009. 25-

52. Print.

Fogarty, Daniel. Roots for a New Rhetoric. $2^{\text {nd }}$ ed. New York: Russell and Russell, 1968. Print.

Fosen, Chris. "'University Courses, Not Department Courses': Composition and General Education." Composition Studies 34.1 (2006): 11-34. Print.

Foucault, Michel. The Archaeology of Knowledge. Trans. A. M. Sheridan Smith. New York: Pantheon Books, 1972. Print.

--- Discipline and Punish: The Birth of the Prison. 1977. Trans. Alan Sheridan. $2^{\text {nd }}$ ed. New York: Vintage, 1997. Print.

---. The History of Sexuality: An Introduction. 1978. Trans. Robert Hurley. $2^{\text {nd }}$ ed. Vol. 1. New York: Vintage, 1990. Print.

---. The Order of Things. Vintage Books Edition. New York: Random House, 1994. Print. Fox, Tom. "Proceeding with Caution: Composition in the 90s." College Composition and Communication 46.4 (1995): 566-78. Print.

Garbus, Julie. "Vida Scudder in the Classroom and in the Archives." Local Histories: Reading the Archives of Composition. Ed. Patricia Donahue and Gretchen Flesher Moon. Pittsburgh: Pittsburgh UP, 2007. 77-93. Print.

George, Diana, and John Trimbur. 'The 'Communication Battle,' or Whatever Happened to the 4th C? (Teaching College Composition and Communication)." College Composition and Communication 50.4 (1999): 682-98. Print.

Gere, Anne Ruggles. Intimate Practice: Literacy and Cultural Work in U.S. Women's 
Clubs, 1880-1920. Carbondale, IL: Southern Illinois UP, 1997. Print.

---. "Kitchen Tables and Rented Rooms: The Extracurriculum of Composition." College Composition and Communication 45.1 (1994): 75-92. Print.

Goggin, Maureen Daly. Authoring a Discipline: Scholarly Journals and the Post-World War II Emergence of Rhetoric and Composition. Mahwah, NJ: Lawrence Erlbaum Associates, 2000. Print.

Goggin, Maureen Daly, and Steve Beatty. “Accounting For 'Well-Worn Grooves': Composition as a Self-Reinforcing Mechanism." Inventing a Discipline: Rhetoric Scholarship in Honor of Richard E. Young. Ed. Maureen Daly Goggin. Urbana, IL: NCTE, 2000. 29-66. Print.

Gold, David. “Eve Did No Wrong': Effective Literacy at a Public College for Women.” College Composition and Communication 61.2 (2009): W177-196. Web. 3 August 2010.

---. Rhetoric at the Margins: Revising the History of Writing Instruction in American Colleges, 1873-1947. Carbondale, IL: Southern Illinois UP, 2008. Print. Graff, Gerald. Professing Literature: An Institutional History. Chicago: U of Chicago P, 1987. Print.

Graff, Richard, Arthur E. Walzer, and Janet M. Atwill, eds. The Viability of the Rhetorical Tradition. Albany, NY: SUNY P, 2005. Print.

Greer, Jane. "No Smiling Madonna': Marian Wharton and the Struggle to Construct a Critical Pedagogy for the Working Class, 1914-1917." College Composition and Communication 51.2 (1999): 248-71. Print.

Guillory, John. Cultural Capital: The Problem of Literary Canon Formation. Chicago: U 
of Chicago P, 1993. Print.

Gustafson, Sandra. Eloquence is Power: Oratory and Performance in Early America. Chapel Hill, NC: U of North Carolina P, 2000. Print.

Halloran, S. Michael. "From Rhetoric to Composition: The Teaching of Rhetoric in America to 1900." A Short History of Writing Instruction from Ancient Greece to Twentieth-Century America. Ed. James J. Murphy. Davis, CA: Hermagoras, 1990. 151-82. Print.

---. "Rhetoric in the American College Curriculum: The Decline of Public Discourse." Pre/Text 3.3 (1982): 245-69. Print.

---. "Rhetoric and the English Department." Rhetoric Society Quarterly 17.1 (1982): 310. Print.

Harkin, Patricia. "Child's Ballads: Narrating Histories of Composition and Literary Studies." Disciplining Composition: Alternative Histories, Critical Perspectives. Eds. David R. Shumway and Craig Dionne. Albany, NY: SUNY P, 2002. Print. Harris, Joseph. "After Dartmouth: Growth and Conflict in English." College English 53.6 (1991): 631-46. Print.

---. A Teaching Subject: Composition since 1966. Upper Saddle River, NJ: Simon \& Schuster, 1997. Print.

Hawhee, Debra. "Composition History and the Harbrace College Handbook." College Composition and Communication 50.3 (1999): 504-23. Print.

Hawk, Byron. A Counter-History of Composition: Toward Methodologies of Complexity. Pittsburgh: U of Pittsburgh P, 2007. Print.

Herbst, Jurgen. And Sadly Teach: Teacher Education and Professionalization in 
American Culture. Madison WI: U of Wisconsin P, 1989. Print.

Heyda, John. 'Fighting over Freshman English: CCCC's Early Years and the Turf Wars of the 1950s." College Composition and Communication 50.4 (1999): 663-81. Print.

Historiography and the Histories of Rhetorics I: Revisionary Histories. Spec. issue of Pre/Text 8.1-2 (1987): 5-154. Print.

Historiography and the Histories of Rhetorics II: Revisionary Histories and Ethics. Spec. issue of Pre/Text 11.3-4 (1990): 165-288. Print.

Hollis, Karyn. Liberating Voices: Writing at the Bryn Mawr Summer School for Women Workers. Carbondale, IL: Southern Illinois UP, 2004. Print.

Horner, Bruce. Terms of Work for Composition: A Materialist Critique. Albany: SUNY P, 2000. Print.

Horner, Bruce, and Min-Zhan Lu. "Working Rhetoric and Composition." College English 72.5 (2010): 470-94. Print.

Horner, Bruce, Min-Zhan Lu, Jacqueline Jones Royster, and John Trimbur. “Opinion: Language Difference in Writing: Toward a Translingual Approach." College English 73.3 (2011): 303-321. Print.

Horner, Bruce, and John Trimbur. "English Only and U.S. College Composition." College Composition and Communication 53.4 (2002): 594-630. Print.

Ianetta, Melissa. "Disciplinarity, Divorce, and the Displacement of Labor Issues: Rereading Histories of Composition and Literature." College Composition and Communication 62.1 (2010): 53-72. Print.

Jarratt, Susan. "Classics and Counterpublics in Nineteenth-Century Historically Black 
Colleges." College English 72.2 (2009): 134-59. Print.

Johnson, Nan. "My Ideological Stance (Octalog).” Rhetoric Review 7.1 (1988): 9-10.

Print.

Kates, Susan. Activist Rhetorics and American Higher Education, 1885-1937.

Carbondale IL: Southern Illinois UP, 2001. Print.

Kitzhaber, Albert R. "4C, Freshman English, and the Future." College Composition and Communication 14 (1963): 129-38. Print.

---. “Death - or Transfiguration?” College English 21.7 (1960): 367-373. Print.

---. Rhetoric in American Colleges, 1850-1900. Dallas: Southern Methodist UP, 1990.

Print.

Kopelson, Karen. "Sp(l)itting Images: Or Back to the Future of (Rhetoric And?)

Composition." College Composition and Communication 59.4 (2008): 750-80.

Print.

LaCapra, Dominick. "Intellectual History and Defining the Present as 'Postmodern." Innovation/Renovation:New Perspectives on the Humanities. Eds. Ihab Hassan and Sally Hassan. Madison, WI: U of Wisconsin P, 1983. 47-64. Print.

---. Rethinking Intellectual History: Texts, Contexts, Language. Ithaca, NY: Cornell University Press, 1983. Print.

Larsen, Elizabeth. "The Progress of Literacy: Edward Tyrrel Channing and the Separation of the Student Writer from the World." Rhetoric Review 11.1 (1992): 159-71. Print.

Lauer, Janice. "Philosophical Statement (Octalog)." Rhetoric Review 7.1 (1988): 25. Print. 
--.. "Storiography and Rhetoric and Composition (Octalog II)." Rhetoric Review 16.1 (1997): 30-32. Print.

Lerner, Neal. "The Institutionalization of Required English." Composition Studies 24.1-2 (1996): 44-60. Print.

Lindblom, Kenneth, William Banks, and Rise Quay. "Mid-Nineteenth-Century Writing Instruction at Illinois State University: Credentials, Correctness, and the Rise of a Teaching Class." Local Histories: Reading the Archives of Composition. Ed. Patricia Donahue and Gretchen Flesher Moon. Pittsburgh: Pittsburgh UP, 2007. 94-114. Print.

Mailloux, Stephen. Disciplinary Identities: Rhetorical Paths of English, Speech, and Composition. New York: MLA, 2006. Print.

Marshall, Margaret J. Response to Reform: Composition and the Professionalization of Teaching. Carbondale, IL: Southern Illinois UP, 2004. Print.

Mastrangelo, Lisa. "Lone Wolf or Leader of the Pack?: Rethinking the Grand Narrative of Fred Newton Scott." College English 72.3 (2010): 248-68. Print.

Matsuda, Paul Kei. "Composition Studies and ESL Writing: A Disciplinary Division of Labor." College Composition and Communication 50.4 (1999): 699-721. Print.

---. "Process and Post-Process: A Discursive History." Journal of Second Language Writing 12 (2003): 65-83. Print.

McHenry, Elizabeth, and Shirley Brice Heath. "The Literate and the Literary: African Americans as Writers and Readers, 1830-1940." Literacy: A Critical Sourcebook. Eds. Ellen Cushman, et al. Boston: Bedford-St. Martin's, 2001. 261-74. Print. Miller, Susan. "Composition as a Cultural Artifact: Rethinking History as Theory." 
Writing Theory and Critical Theory. Eds. John Clifford and John Schilb. New York: MLA, 1994. 19-32. Print.

---. "How Writers Evaluate Their Own Writing." College Composition and Communication 33.2 (1982): 176-183. Print.

---. Textual Carnivals: The Politics of Composition. Carbondale, IL: Southern Illinois UP, 1991. Print.

---. "Writing Studies as a Mode of Inquiry." Rhetoric and Composition as Intellectual Work. Ed. Gary A. Olson. Carbondale, IL: Southern Illinois UP, 2002. 41-54. Print.

Miller, Thomas P. The Evolution of College English: Literacy Studies from the Puritans to the Postmodern. Pittsburgh: U of Pittsburg P, 2010. Print.

---. The Formation of College English: Rhetoric and Belles Lettres in the British Cultural Provinces. Pittsburgh: U of Pittsburgh P, 1997. Print.

Mountford, Roxanne. “Feminization of Rhetoric?” JAC 19 (1999): 485-92. Web. 7 September 2008.

---. "Looking for Rhetoric Where It Has Not Been Found: Definitions, Border Disputes, Future Directions (Octalog II)." Rhetoric Review 16.1 (1997): 32-35. Print. Muckelbauer, John. "Returns of the Question." Enculturation 5.2 (2004). Web. 6 February 2010.

Murray, Donald M. "Teach Writing as a Process Not Product." Cross-Talk in Comp Theory: $A$ Reader. $2^{\text {nd }}$ ed. Ed. Victor Villanueva. Urbana, IL: NCTE, 2003. 3-6. Print. 
"narrative, n." OED Online. March 2010. Oxford University Press. Web. 1 September 2010.

NeCamp, Samantha. The Moonlight Schools: Adult Literacy Education in the Age of Americanization. Diss. U of Louisville, 2011. Print.

Neel, Jasper. "Reclaiming our Theoretical Heritage: A Big Fish Tale." Rhetoric and Composition as Intellectual Work. Ed. Gary A. Olson. Carbondale, IL: Southern Illinois UP, 2002. 3-11. Print.

Nelms, Gerald. "The Case for Oral Evidence in Composition Historiography." Written Communication 9.3 (1992): 356-84. Print.

North, Stephen M. The Making of Knowledge in Composition: Portrait of an Emerging Field. Upper Montclair, NJ: Boynton/Cook, 1987. Print.

Nystrand, Martin, Stuart Greene, and Jeffrey Wiemelt. "Where Did Composition Studies Come From? An Intellectual History." Written Communication 10.3 (1993): 267333. Print.

"Octalog: The Politics of Historiography." Rhetoric Review 7 (1988): 5-49. Print.

“Octalog II: The (Continuing) Politics of Historiography." Rhetoric Review 16 (1997): 22-44. Print

“Octalog III: The Politics of Historiography in 2010." Conference on College Composition and Communication. Louisville, KY. 18 March 2010. Unpublished panel presentation.

Ohmann, Richard. English in America: A Radical View of the Profession. Middletown, CT: Wesyelan University Press, 1996. Print.

Olson, Gary A. "The Death of Composition as an Intellectual Discipline." Rhetoric and 
Composition as Intellectual Work. Ed. Gary A. Olson. Carbondale, IL: Southern Illinois UP, 2002. 23-31. Print.

---., ed. Rhetoric and Composition as Intellectual Work. Carbondale, IL: Southern Illinois UP, 2002.

Paine, Charles. The Resistant Writer: Rhetoric as Immunity, 1850 to the Present. Albany, NY: SUNY P, 1999. Print.

“paradigm, n." OED Online. December 2009. Oxford University Press. Web. 1 September 2010.

Peary, Alexandria. "The Licensing of the Poetic in Nineteenth-Century CompositionRhetoric Textbooks." College Composition and Communication 61.2 (2009):

W149-176. Web. 3 August 2010.

Perl, Sondra. "The Composing Processes of Unskilled College Writers." Cross-Talk in Comp Theory: A Reader. $2^{\text {nd }}$ ed. Ed. Victor Villanueva. Urbana, IL: NCTE, 2003. 17-42. Print.

Phelps, Louise Wetherbee. Composition as a Human Science: Contributions to the SelfUnderstanding of a Discipline. New York: Oxford UP, 1988. Print.

Pullman, George. "Stepping Yet Again into the Same Current." Post-Process Theory: Beyond the Writing-Process Paradigm. Ed. Thomas Kent. Carbondale, IL: Southern Illinois UP, 1999. 16-29. Print.

Ratcliffe, Krista. "Rhetorical Listening: A Trope for Interpretive Invention and a 'Code of Cross-Cultural Conduct.'" College Composition and Communication 51.2 (1999): 195-224. Print.

Reynolds, Nedra, Bruce Herzberg, and Patricia Bizzell. The Bedford Bibliography for 
Teachers of Writing. $6^{\text {th }}$ ed. Boston: Bedford, 2003. Web. 1 March 2011.

Rice, Jeff. "The 1963 Composition Revolution Will Not Be Televised, Computed, or Demonstrated by Any Other Means of Technology." Composition Studies 33.1 (2005): 55-74. Print.

Roemer, Marjorie, Lucille M. Schultz, and Russel K. Durst. "Reframing the Great Debate on First-Year Writing." College Composition and Communication 50.3 (1999): 377-392. Print.

Rothermel, Beth Ann. “'Our Life's Work': Rhetorical Preparation and Teacher Training at a Massachusetts State Normal School, 1839-1929." Local Histories: Reading the Archives of Composition. Ed. Patricia Donahue and Gretchen Flesher Moon. Pittsburgh: Pittsburgh UP, 2007. 134-158. Print.

---. "A Sphere of Noble Action: Gender, Rhetoric, and Influence at a Nineteenth-Century Massachusetts State Normal School.” Rhetoric Society Quarterly 33.1 (2003): 3564. Print.

Royster, Jacqueline Jones, and Jean C. Williams. "History in the Spaces Left: African American Presence and Narrative of Composition Studies." College Composition and Communication 50.4 (1999): 563-84. Print.

Russell, David R. Writing in the Academic Disciplines, 1870-1990: A Curricular History. Carbondale, IL: Southern Illinois UP, 1991. Print.

---. Writing in the Academic Disciplines, 1870-2000: A Curricular History. 2nd ed. Carbondale, IL: Southern Illinois UP, 2002. Print.

Salvatori, Mariolina Rizzi. Pedagogy: Disturbing History, 1819-1929. Pittsburgh: U of Pittsburgh P, 1998. Print. 
Schilb, John. "The History of Rhetoric and the Rhetoric of History." Pre/Text: The First Decade. Ed. Victor J. Vitanza. Pittsburgh: U of Pittsburgh P, 1993. 237-262. Print.

Scholes, Robert. The Rise and Fall of English: Reconstructing English as a Discipline. New Haven, CT: Yale UP, 1998. Print.

Schultz, Lucille. The Young Composers: Composition's Beginnings in NineteenthCentury Schools. Carbondale, IL: Southern Illinois UP, 1999. Print.

Selfe, Cynthia. "The Movements of Air, the Breath of Meaning: Aurality and Multimodal Composing." College Composition and Communication 60.4 (2009): 616-663. Print.

Shumway, David R., and Craig Dionne. Introduction. Disciplining Composition: Alternative Histories, Critical Perspectives. Eds. David R. Shumway and Craig Dionne. Albany, NY: SUNY P, 2002. 1-18. Print.

Simmons, Sue Carter. "Radcliffe Responses to Harvard Rhetoric: 'An Absurdly Stiff Way of Thinking." Nineteenth-Century Women Learn to Write. Ed. Catherine Hobbs. Charlottesville VA: UP of Virginia, 1995. 264-92. Print.

Spellmeyer, Kurt. "Education for Irrelevance? Or, Joining Our Colleagues in Lit Crit on the Sidelines of the Information Age." Composition Studies in the New Millennium: Rereading the Past, Rewriting the Future. Eds. Lynn Z. Bloom, Donald A. Daiker and Edward M. White. Carbondale, IL: Southern Illinois UP, 2003. 79-87. Print.

Stewart, Donald C. "Harvard's Influence on English Studies: Perceptions from Three Universities in the Early Twentieth Century." College Composition and 
Communication 43.4 (1992): 455-71. Print.

Strain, Margaret M. “Toward a Hermeneutic Model of Composition History: Robert Carlsen's 'the State of the Profession 1961-1962"' JAC 13.1 (1993): 217-40. Print.

Strickland, Donna. "Taking Dictation: The Emergence of Writing Programs and the Cultural Contradictions of Composition Teaching." College English 63.4 (2001): 457-79. Print.

Swearingen, Jan. "The Institutionalization of Rhetoric and the Inscription of Gender (Octalog)." Rhetoric Review 7.1 (1988): 10. Print.

Trachsel, Mary. Institutionalizing Literacy: The Historical Role of College Entrance Examinations in English. Carbondale IL: Southern Illinois UP, 1992. Print. Trimbur, John. "The Dartmouth Conference and the Geohistory of the Native Speaker." College English 71.2 (2008): 142-69. Print.

---. "Linguistic Memory and the Politics of U.S. English." College English 68.6 (2006): 575-88. Print.

Tuman, Myron. "From Astor Place to Kenyon Road: The NCTE and the Origins of English Studies.” College English 48.4 (1986): 339-49. Print.

Varnum, Robin. Fencing with Words: A History of Writing Instruction at Amherst College During the Era of Theodore Baird, 1938-1966. Urbana, IL: NCTE, 1996. Print.

Vitanza, Victor J. "“Notes' Towards Historiographies of Rhetorics: or, Rhetorics of the Histories of Rhetorics: Traditional, Revisionary, and Sub/Versive." Pre/Text 8.1-2 (1987): 63-126. Print. 
---., ed. Writing Histories of Rhetoric. Carbondale, IL: Southern Illinois UP, 1994. Print.

Weidner, Heidemarie Z. “A Chair 'Perpetually Filled by a Female Professor': Rhetoric and Composition Instruction at Nineteenth-Century Butler University.” Local Histories: Reading the Archives of Composition. Ed. Patricia Donahue and Gretchen Flesher Moon. Pittsburgh: Pittsburgh UP, 2007. 59-76. Print.

Welsch, Kathleen A. "Thinking like That: The Ideal Nineteenth-Century Student Writer." Local Histories: Reading the Archives of Composition. Ed. Patricia Donahue and Gretchen Flesher Moon. Pittsburgh: Pittsburgh UP, 2007. 14-37. Print.

White, Hayden. The Content of the Form: Narrative Discourse and Historical Representation. Baltimore: Johns Hopkins UP, 1987. Print.

---. Metahistory: The Historical Imagination in Nineteenth-Century Europe. Baltimore: Johns Hopkins UP, 1973. Print.

--.. Tropics of Discourse: Essays in Cultural Criticism. Baltimore: Johns Hopkins UP, 1978. Print.

Williams, Bronwyn. "Seeking New Worlds: The Study of Writing beyond Our Classrooms." College Composition and Communication 62.1 (2010): 127-146. Print.

Wozniak, John Michael. English Composition in Eastern Colleges, 1850-1940. Washington, DC: UP of America, 1978. Print.

Yood, Jessica. "Writing the Discipline: A Generic History of English Studies." College English 65.5 (2003): 526-40. Print.

Young, Richard. "Paradigms and Problems: Needed Research in Rhetorical Invention." Research and Composing: Points of Departure. Ed. Charles R. Cooper and Lee 
Odell. Urbana, IL: NCTE, 1978. 29-47. Print.

You, Xiaoye. Writing in the Devil's Tongue: A History of English Composition in China. Carbondale, IL: Southern Illinois UP, 2010. Print.

Zaluda, Scott. "Lost Voices of the Harlem Renaissance: Writing Assigned at Howard University, 1919-31." College Composition and Communication 50.2 (1998): 232-57. Print. 


\section{APPENDIX A}

The following table provides an alphabetical list of the historical texts cited within this dissertation along with indications of how I categorized each (as a macro- or microhistory), as well as indications of whether and how each used (repeated, challenged, rejected) the prevailing narratives discussed in Chapters 2 (CTRP), 3 (FYC), and 4 (DISC). For obvious reasons, I was not able to discuss every text in relation to every narrative in my analysis. However, I hope that this list will help make my method of reading visible and enable others to productively critique my categorizations, and/or to engage additional research in the future.

If a text's category is listed as "N/A," I mean that the text refers to composition's history and carries implications for historiographic practice, but did not clearly fit into one of the two available categories: For example, in Mestiz@Scripts, Damian Baca analyzes contemporary writing and visual rhetorical practices - suggesting that the book might not be categorized as a history at all - but at the same time, Baca argues that his analysis of present practices "must be comprehended historically: they are texts that speak to the Mesoamerican past while simultaneously addressing the colonial present" (2). Other texts, such as Patricia Donahue's "Disciplinary History" and Susan Miller's "Composition as a Cultural Artifact" take a meta-analytical view of disciplinary history, taking stock of contemporary practices. Some texts, such as Joseph Harris' A Teaching Subject and James Berlin's Rhetorics, Poetics, and Cultures are grounded in and narrate history but ultimately make a proposal for the future. And still others, such as Daniel 
Coffey's "A Discipline's Composition," account for composition's history but were composed for an audience outside composition. If "N/A" is listed in place of narratives, this means that I did not find evidence of the author working with any of the narratives central to my analysis. For a chronological listing of the same set of histories as well as analysis of their citation/reception, see Appendix B.

\begin{tabular}{|c|c|c|c|c|c|c|c|}
\hline \multirow{2}{*}{$\begin{array}{c}\text { PUB } \\
\text { DATE }\end{array}$} & \multirow{2}{*}{ AUTHOR } & \multirow{2}{*}{$\begin{array}{l}\text { TITLE } \\
\text { (Short) }\end{array}$} & \multicolumn{2}{|c|}{ CATEGORY } & \multicolumn{3}{|c|}{ NARRATIVES } \\
\hline & & & Macro & Micro & CTRP & FYC & DISC \\
\hline 1993 & Adams, $\mathrm{K}$. & A Group of Their Own & & $\mathrm{X}$ & \multicolumn{3}{|c|}{ N/A } \\
\hline 2001 & Adams, $\mathrm{K}$. & A History of Professional & & $\mathrm{X}$ & & & $\mathrm{X}$ \\
\hline 2008 & Baca, D. & Mestiz@Scripts, Digital & \multicolumn{2}{|c|}{ N/A } & \multicolumn{3}{|c|}{ N/A } \\
\hline 1987 & Berlin, J. & Rhetoric and Reality & $\mathrm{X}$ & & $\mathrm{X}$ & $\mathrm{X}$ & $\mathrm{X}$ \\
\hline 1996 &.--- & Rhetorics, Poetics... & \multicolumn{2}{|c|}{ N/A } & $\mathrm{X}$ & $\mathrm{X}$ & $\mathrm{X}$ \\
\hline 1980 & --.. & "Richard Whately" & & $\mathrm{X}$ & $\mathrm{X}$ & & \\
\hline 1984 & $\cdots$ & Writing Instruction & $\mathrm{X}$ & & $\mathrm{X}$ & $\mathrm{X}$ & $\mathrm{X}$ \\
\hline 1995 & Brereton, $\mathrm{J}$. & The Origins of Composition & $\mathrm{X}$ & & $\mathrm{X}$ & $\mathrm{X}$ & $\mathrm{X}$ \\
\hline 1993 & Brody, M. & Manly Writing & & $\mathrm{X}$ & $\mathrm{X}$ & & \\
\hline 1992 & Campbell, J. & "Controlling Voices" & & $\mathrm{X}$ & $\mathrm{X}$ & $\mathrm{X}$ & \\
\hline 1992 & Campbell, J. & "Women's Work" & & $\mathrm{X}$ & $\mathrm{X}$ & $\mathrm{X}$ & $\mathrm{X}$ \\
\hline
\end{tabular}




\begin{tabular}{|c|c|c|c|c|c|c|c|}
\hline \multirow{2}{*}{$\begin{array}{c}\text { PUB } \\
\text { DATE }\end{array}$} & \multirow{2}{*}{ AUTHOR } & \multirow{2}{*}{$\begin{array}{l}\text { TITLE } \\
\text { (Short) } \\
\end{array}$} & \multicolumn{2}{|c|}{ CATEGORY } & \multicolumn{3}{|c|}{ NARRATIVES } \\
\hline & & & Macro & Micro & CTRP & FYC & DISC \\
\hline 1993 & $\begin{array}{l}\text { Clark, G. \& } \\
\text { Halloran, S. }\end{array}$ & $\begin{array}{l}\text { "Introduction" (Oratorical Culture } \\
\text { in Nineteenth) }\end{array}$ & $\mathrm{X}$ & & $\mathrm{X}$ & & $\mathrm{x}$ \\
\hline 2006 & Coffey, D. & "A Discipline's Comp." & \multicolumn{2}{|c|}{$\mathrm{N} / \mathrm{A}$} & $\mathrm{X}$ & & $\mathrm{X}$ \\
\hline 1997 & Connors, $\mathrm{R}$. & Composition-Rhetoric & $\mathrm{X}$ & & $\mathrm{x}$ & $\mathrm{X}$ & $\mathrm{X}$ \\
\hline 1995 & Conway, $\mathrm{K}$. & "Woman Suffrage" & & $\mathrm{X}$ & & & $\mathrm{x}$ \\
\hline 1998 & Crowley, S. & Composition ... University & $\mathrm{X}$ & & $\mathrm{x}$ & $\mathrm{X}$ & $\mathrm{X}$ \\
\hline 1986 & -- & "The Current-Traditional" & $\mathrm{X}$ & & $\mathrm{x}$ & & \\
\hline 1989 &.-- & "Linguistics and Comp." & & $\mathrm{X}$ & $\mathrm{X}$ & $\mathrm{x}$ & $\mathrm{X}$ \\
\hline 1990 & $--\cdot$ & The Methodical Memory & $\mathrm{X}$ & & $\mathrm{x}$ & $\mathrm{X}$ & $\mathrm{x}$ \\
\hline 2007 & DeGenaro, W. & "William Rainey Harper" & & $\mathrm{X}$ & & $\mathrm{X}$ & $\mathrm{x}$ \\
\hline 2007 & Donahue, $\mathrm{P}$. & "Disciplinary Histories" & \multicolumn{2}{|c|}{ N/A } & $\mathrm{X}$ & $\mathrm{X}$ & $\mathrm{x}$ \\
\hline 2007 & $\begin{array}{l}\text { Donahue, P. \& } \\
\text { Falbo, B. }\end{array}$ & "(The Teaching of)" & & $\mathrm{X}$ & & & $\mathrm{X}$ \\
\hline 1976 & Douglas, W. & "Rhetoric ... Meritocracy" & & $\mathrm{x}$ & $\mathrm{X}$ & & $\mathrm{x}$ \\
\hline 2008 & Enoch, J. & Refiguring Rhetorical Ed. & & $\mathrm{X}$ & $\mathrm{X}$ & & $\mathrm{X}$ \\
\hline
\end{tabular}




\begin{tabular}{|c|c|c|c|c|c|c|c|}
\hline \multirow{2}{*}{$\begin{array}{c}\text { PUB } \\
\text { DATE }\end{array}$} & \multirow{2}{*}{ AUTHOR } & \multirow{2}{*}{$\begin{array}{l}\text { TITLE } \\
\text { (Short) }\end{array}$} & \multicolumn{2}{|c|}{ CATEGORY } & \multicolumn{3}{|c|}{ NARRATIVES } \\
\hline & & & Macro & Micro & CTRP & FYC & DISC \\
\hline 1996 & Fitzgerald, $\mathrm{K}$. & "From Disciplining" & & $\mathrm{X}$ & & & $\mathrm{X}$ \\
\hline 2001 &.-- & "A Rediscovered Tradition" & & $\mathrm{X}$ & $\mathrm{X}$ & & $\mathrm{X}$ \\
\hline 2006 & Fosen, C. & "University Courses, Not" & \multicolumn{2}{|c|}{$\mathrm{N} / \mathrm{A}$} & $\mathrm{X}$ & $\mathrm{X}$ & \\
\hline 2007 & Garbus, J. & "Vida Scudder" & & $\mathrm{X}$ & & $\mathrm{X}$ & $\mathrm{X}$ \\
\hline 1999 & $\begin{array}{l}\text { George, D. \& } \\
\text { Trimbur, J. }\end{array}$ & "Communication Battle"" & & $\mathrm{X}$ & & $\mathrm{X}$ & $\mathrm{X}$ \\
\hline 1997 & Gere, A. & Intimate Practices & & $\mathrm{X}$ & & & $\mathrm{X}$ \\
\hline 1994 & $--\cdot$. & "Kitchen Tables ... Rented" & \multicolumn{2}{|c|}{ N/A } & & $\mathrm{X}$ & $\mathrm{x}$ \\
\hline 2000 & Goggin, $M$. & Authoring a Discipline & $\mathrm{X}$ & & & $\mathrm{X}$ & $\mathrm{X}$ \\
\hline 2000 & $\begin{array}{l}\text { Goggin, M. \& } \\
\text { Beatty, S. }\end{array}$ & "Accounting for Well-“ & & $\mathrm{X}$ & & $\mathrm{X}$ & \\
\hline 2009 & Gold, D. & “"Eve Did No Wrong"” & & $\mathrm{X}$ & $\mathrm{X}$ & $\mathrm{X}$ & $\mathrm{X}$ \\
\hline 2008 &.--- & Rhetoric at the Margins & & $\mathrm{X}$ & $\mathrm{X}$ & $\mathrm{x}$ & $\mathrm{x}$ \\
\hline 1999 & Greer, J. & "No Smiling Madonna" & & $\mathrm{X}$ & $\mathrm{X}$ & & \\
\hline 1982 & Halloran, S. & "Rhetoric in American" & $\mathrm{X}$ & & $\mathrm{X}$ & & $\mathrm{X}$ \\
\hline
\end{tabular}




\begin{tabular}{|c|c|c|c|c|c|c|c|}
\hline \multirow{2}{*}{$\begin{array}{c}\text { PUB } \\
\text { DATE }\end{array}$} & \multirow{2}{*}{ AUTHOR } & \multirow{2}{*}{$\begin{array}{l}\text { TITLE } \\
\text { (Short) }\end{array}$} & \multicolumn{2}{|c|}{ CATEGORY } & \multicolumn{3}{|c|}{ NARRATIVES } \\
\hline & & & Macro & Micro & CTRP & FYC & DISC \\
\hline 1987 &.-- & "Rhetoric and the English" & $\mathrm{X}$ & & $\mathrm{X}$ & & $\mathrm{X}$ \\
\hline 2002 & Harkin, P. & "Child's Ballads" & & $\mathrm{x}$ & & & $\mathrm{X}$ \\
\hline 1997 & Harris, J. & A Teaching Subject & \multicolumn{2}{|c|}{ N/A } & & $\mathrm{X}$ & \\
\hline 1999 & Hawhee, D. & "Composition History" & & $\mathrm{x}$ & $\mathrm{X}$ & $\mathrm{X}$ & \\
\hline 2007 & Hawk, B. & A Counter-History & & $\mathrm{X}$ & $\mathrm{X}$ & $\mathrm{X}$ & $\mathrm{X}$ \\
\hline 1999 & Heyda, J. & "Fighting over Freshman" & & $\mathrm{x}$ & & $\mathrm{X}$ & $\mathrm{X}$ \\
\hline 2004 & Hollis, $\mathrm{K}$. & Liberating Voices & & $\mathrm{x}$ & $\mathrm{X}$ & & $\mathrm{X}$ \\
\hline 2002 & $\begin{array}{l}\text { Horner, B. \& } \\
\text { Trimbur, J. }\end{array}$ & "English Only and U.S." & & $\mathrm{X}$ & & $\mathrm{X}$ & $\mathrm{X}$ \\
\hline 2009 & Jarratt, $\mathrm{S}$. & "Classics and Counter..." & & $\mathrm{X}$ & & $\mathrm{X}$ & $\mathrm{X}$ \\
\hline 2001 & Kates, $\mathbf{S}$. & Activist Rhetorics & & $\mathrm{X}$ & $\mathrm{X}$ & & $\mathrm{X}$ \\
\hline $\begin{array}{l}1954 \\
(1990) \\
\end{array}$ & Kitzhaber, A. & Rhetoric in American & $\mathrm{X}$ & & $\mathrm{X}$ & $\mathrm{X}$ & $\mathrm{X}$ \\
\hline 1992 & Larsen, E. & "The Progress of Literacy" & & $\mathrm{X}$ & $\mathrm{X}$ & & $\mathrm{X}$ \\
\hline 1996 & Lerner, N. & "The Institutionalization" & & $\mathrm{X}$ & & $\mathrm{X}$ & \\
\hline
\end{tabular}




\begin{tabular}{|c|c|c|c|c|c|c|c|}
\hline \multirow{2}{*}{$\begin{array}{c}\text { PUB } \\
\text { DATE }\end{array}$} & \multirow{2}{*}{ AUTHOR } & \multirow{2}{*}{$\begin{array}{l}\text { TITLE } \\
\text { (Short) }\end{array}$} & \multicolumn{2}{|c|}{ CATEGORY } & \multicolumn{3}{|c|}{ NARRATIVES } \\
\hline & & & Macro & Micro & CTRP & FYC & DISC \\
\hline 2007 & $\begin{array}{l}\text { Lindblom, } \mathrm{K} \text {. } \\
\text { (et al.) }\end{array}$ & "Mid-Nineteenth-Century" & & $\mathrm{X}$ & $\mathrm{X}$ & & \\
\hline 2006 & Mailloux, S. & Disciplinary Identities & $\mathrm{X}$ & & & & $\mathrm{X}$ \\
\hline 2004 & Marshall, M. & Response to Reform & $\mathrm{X}$ & & & $\mathrm{X}$ & $\mathrm{X}$ \\
\hline 2010 & Mastrangelo, L. & "Lone Wolf or Leader..." & & $\mathrm{X}$ & $\mathrm{X}$ & & \\
\hline 1999 & Matsuda, P. & "Composition Studies" & & $\mathrm{X}$ & & & $\mathrm{X}$ \\
\hline 2003 & $\cdots$ & "Process and Post-Process" & $\mathrm{X}$ & & $\mathrm{X}$ & & \\
\hline $\begin{array}{l}1994 \\
(2001)\end{array}$ & $\begin{array}{l}\text { McHenry, E. \& } \\
\text { Heath, S. }\end{array}$ & "The Literate ... Literary" & & $\mathrm{X}$ & & & $\mathrm{X}$ \\
\hline 1994 & Miller, S. & "Composition as a Cultural" & & & $\mathrm{x}$ & & $\mathrm{X}$ \\
\hline 1991 & --.. & Textual Carnivals & $\mathrm{X}$ & & $\mathrm{x}$ & $\mathrm{x}$ & $\mathrm{X}$ \\
\hline 2010 & Miller, $\mathrm{T}$. & The Evolution of College & $\mathrm{X}$ & & $\mathrm{x}$ & & $\mathrm{X}$ \\
\hline 1997 & $\cdots$ & The Formation of College & $\mathrm{X}$ & & $\mathrm{X}$ & & $\mathrm{X}$ \\
\hline 1992 & Nelms, G. & "The Case for Oral" & & $\mathrm{X}$ & $\mathrm{X}$ & & \\
\hline 1987 & North, S. & The Making of Knowledge & $\mathrm{X}$ & & & & $\mathrm{x}$ \\
\hline
\end{tabular}




\begin{tabular}{|c|c|c|c|c|c|c|c|}
\hline \multirow{2}{*}{$\begin{array}{c}\text { PUB } \\
\text { DATE }\end{array}$} & \multirow{2}{*}{ AUTHOR } & \multirow{2}{*}{$\begin{array}{l}\text { TITLE } \\
\text { (Short) }\end{array}$} & \multicolumn{2}{|c|}{ CATEGORY } & \multicolumn{3}{|c|}{ NARRATIVES } \\
\hline & & & Macro & Micro & CTRP & FYC & DISC \\
\hline 1993 & Nystrand, M. & "Where Did Composition" & $\mathrm{X}$ & & & & $\mathrm{x}$ \\
\hline 1999 & Paine, C. & The Resistant Writer & & $\mathrm{X}$ & $\mathrm{x}$ & $\mathrm{X}$ & \\
\hline 2010 & Peary, A. & "The Licensing ... Poetic" & & $\mathrm{X}$ & $\mathrm{X}$ & $\mathrm{X}$ & $\mathrm{X}$ \\
\hline 1988 & Phelps, L. & Composition as a Human & $\mathrm{X}$ & & $\mathrm{X}$ & & $\mathrm{X}$ \\
\hline 2005 & Rice, J. & "The 1963 Composition" & & $\mathrm{X}$ & & & $\mathrm{X}$ \\
\hline 1999 & $\begin{array}{l}\text { Roemer, M. } \\
\text { (et al.) }\end{array}$ & "Reframing the Great" & $\mathrm{X}$ & & $\mathrm{X}$ & $\mathrm{X}$ & $\mathrm{X}$ \\
\hline 2007 & Rothermel, B. & "Our Life's Work" & & $\mathrm{x}$ & $\mathrm{X}$ & & $\mathrm{x}$ \\
\hline 2003 & ---. & "A Sphere of Noble Action" & & $\mathrm{X}$ & $\mathrm{X}$ & & $\mathrm{X}$ \\
\hline 1999 & $\begin{array}{l}\text { Royster, J. \& } \\
\text { Williams, J. }\end{array}$ & "History in the Spaces Left" & & $\mathrm{X}$ & $\mathrm{x}$ & $\mathrm{x}$ & \\
\hline $\begin{array}{l}1991 \\
(2002)\end{array}$ & Russell, D. & Writing in the Academic & $\mathrm{X}$ & & & $\mathrm{X}$ & $\mathrm{X}$ \\
\hline 1996 & Salvatori, $M$ & Pedagogy & $\mathrm{X}$ & & & & $\mathrm{x}$ \\
\hline 1999 & Schultz, L. & The Young Composers & $\mathrm{X}$ & & $\mathrm{x}$ & $\mathrm{X}$ & $\mathrm{X}$ \\
\hline 1995 & Simmons, $\mathrm{S}$. & "Radcliffe Responses" & & $\mathrm{X}$ & $\mathrm{X}$ & $\mathrm{X}$ & \\
\hline
\end{tabular}




\begin{tabular}{|l|l|l|c|c|c|c|c|}
\hline \multicolumn{1}{|c|}{ PUB } \\
DATE
\end{tabular}




\section{APPENDIX B}

The following table provides a chronological list of the historical texts I cited within this dissertation. For each text, I have included quasi-quantitative data to establish citation patterns and to substantiate my claims that certain historians have been more influential than others in narrating the discipline's past. I call this data quasi-quantitative because it is not comprehensive: Half of it comes from the Arts and Humanities Citation Index $(\mathrm{AHCI})$, and the other half of it comes from my own tracking of citations through each text included in this list (Times Cited in Histories).

Neither of these methods of citation tracking and analysis are error-free: $\mathrm{AHCI}$ is limited in that it only tracks a text's citation in journal articles, and it is limited even further in that it does not search all possible journals (for example, it does not find citations for texts published in two important journals for the discipline: $J A C$ and Composition Studies). Additionally, common names such as "Miller" and "Harris" turn up thousands of results (even when restricted by first-name initials), making it difficult to ensure the accuracy of my account. Further, my tracing of citations through the histories cited in the dissertation is also incomplete because of my own fallibility as a reader. What's more, I could have gathered additional data - for example, I might have collected institutional or faculty surveys or analyzed course syllabi - to better understand the 


\section{APPENDIX B}

The following table provides a chronological list of the historical texts I cited within this dissertation. For each text, I have included quasi-quantitative data to establish citation patterns and to substantiate my claims that certain historians have been more influential than others in narrating the discipline's past. I call this data quasi-quantitative because it is not comprehensive: Half of it comes from the Arts and Humanities Citation Index $(\mathrm{AHCI})$, and the other half of it comes from my own tracking of citations through each text included in this list (Times Cited in Histories).

Neither of these methods of citation tracking and analysis are error-free: AHCI is limited in that it only tracks a text's citation in journal articles, and it is limited even further in that it does not search all possible journals (for example, it does not find citations for texts published in two important journals for the discipline: $J A C$ and Composition Studies). Additionally, common names such as "Miller" and "Harris" turn up thousands of results (even when restricted by first-name initials), making it difficult to ensure the accuracy of my account. Further, my tracing of citations through the histories cited in the dissertation is also incomplete because of my own fallibility as a reader. What's more, I could have gathered additional data - for example, I might have collected institutional or faculty surveys or analyzed course syllabi - to better understand the 
prominence as disciplinary historians, I have listed the cumulative totals of all references to Berlin, Connors, and Crowley at the beginning of the table. These numbers include all texts authored by these historians, not all of which were cited within my dissertation (this is especially true of Connors because many of his early articles were folded into Composition-Rhetoric).

\begin{tabular}{|c|c|c|c|c|}
\hline $\begin{array}{c}\text { PUB } \\
\text { DATE }\end{array}$ & AUTHOR & $\begin{array}{l}\text { TITLE } \\
\text { (Short) }\end{array}$ & AHCI & $\begin{array}{c}\text { Times Cited } \\
\text { in Histories } \\
(+),(-)=(\text { total })\end{array}$ \\
\hline$N / A$ & Berlin, J. & $A L L$ & 187 & $(+) 25,(-) 19=44$ \\
\hline$N / A$ & Connors, $\mathrm{R}$. & $A L L$ & 245 & $(+) 20,(-) 15=35$ \\
\hline$N / A$ & Crowley, S. & $A L L$ & 163 & $(+) 13,(-) 7=20$ \\
\hline $\begin{array}{l}1954 \\
(1990)\end{array}$ & Kitzhaber, A. & Rhetoric in American & 31 & $(+) 13,(-) 13=26$ \\
\hline 1976 & Douglas, W. & "Rhetoric ... Meritocracy" & 1 & $(+) 4,(-) 0=4$ \\
\hline 1978 & Wozniak, J. & English Composition & 7 & $(+) 4,(-) 1=5$ \\
\hline 1980 & Berlin, J. & "Richard Whately" & 2 & $(+) 1, \quad(-) 0=1$ \\
\hline 1982 & Halloran, $\mathrm{S}$. & "Rhetoric in American" & 18 & -- \\
\hline 1984 & Berlin, J. & Writing Instruction & 80 & $(+) 9, \quad(-) 5=14$ \\
\hline 1986 & Crowley, $\mathrm{S}$. & "The Current-Traditional" & 2 & -- \\
\hline 1986 & Tuman, $\mathrm{M}$. & "From Astor Place" & 0 & --- \\
\hline 1987 & Berlin, J. & Rhetoric and Reality & 128 & $(+) 11,(-) 11=22$ \\
\hline 1987 & Halloran, $\mathrm{S}$. & "Rhetoric and the English" & 1 & $(+) 2, \quad(-) 1=3$ \\
\hline 1987 & North, S. & The Making of Knowledge & 104 & $(+) 0,(-) 3=3$ \\
\hline 1988 & Phelps, L. & Composition as a Human & 36 & --- \\
\hline 1989 & Crowley, S. & "Linguistics and Comp." & 5 & --- \\
\hline
\end{tabular}




\begin{tabular}{|c|c|c|c|c|}
\hline $\begin{array}{c}\text { PUB } \\
\text { DATE }\end{array}$ & AUTHOR & $\begin{array}{l}\text { TITLE } \\
\text { (Short) }\end{array}$ & AHCI & $\begin{array}{c}\text { Times Cited } \\
\text { in Histories } \\
(+),(-)=(\text { total })\end{array}$ \\
\hline 1990 & Crowley, S. & The Methodical Memory & 31 & $(+) 6,(-) 2=8$ \\
\hline 1991 & Miller, S. & Textual Carnivals & 86 & $(+) 13,(-) 3=16$ \\
\hline $\begin{array}{l}1991 \\
(2002)\end{array}$ & Russell, D. & Writing in the Academic & $\begin{array}{l}60(22) \\
=82\end{array}$ & $(+) 6, \quad(-) 4=10$ \\
\hline $\begin{array}{l}1991 \\
(2001)\end{array}$ & $\begin{array}{l}\text { Halloran, S. } \\
\text { (Wright, E.) }\end{array}$ & "From Rhetoric to Comp." & $\begin{array}{l}10(0) \\
=10\end{array}$ & $(+) 5,(-) 3=8$ \\
\hline 1992 & Campbell, J. & $\begin{array}{l}\text { "Controlling Voices" and } \\
\text { "Women's Work" }\end{array}$ & 1 & $(+) 7,(-) 3=10$ \\
\hline 1992 & Larsen, E. & "The Progress of Literacy" & 0 & -- \\
\hline 1992 & Nelms, G. & "The Case for Oral" & 1 & -- \\
\hline 1992 & Traschel, M. & Institutionalizing Literacy & 7 & $(+) 2,(-) 0=0$ \\
\hline 1993 & Adams, $\mathrm{K}$. & A History of Professional & 4 & $(+) 2,(-) 0=0$ \\
\hline 1993 & Brody, M. & Manly Writing & 19 & $(+) 1,(-) 0=0$ \\
\hline 1993 & $\begin{array}{l}\text { Clark, G. \& } \\
\text { Halloran, S. }\end{array}$ & $\begin{array}{l}\text { "Introduction" (Oratorical } \\
\text { Culture in Nineteenth) }\end{array}$ & 29 & $(+) 3,(-) 2=5$ \\
\hline 1993 & Nystrand, M. & "Where Did Composition" & 44 & -- \\
\hline 1993 & Strain, M. & "Toward a Hermeneutic" & $J A C$ & --- \\
\hline $\begin{array}{l}1994 \\
(2001)\end{array}$ & $\begin{array}{l}\text { McHenry, E. \& } \\
\text { Heath, S. }\end{array}$ & "The Literate ... Literary" & 7 & -- \\
\hline 1994 & Gere, A. & "Kitchen Tables ... Rented" & 31 & $(+) 4, \quad(-) 0=4$ \\
\hline 1994 & Miller, S. & "Composition as a Cultural" & 1 & --- \\
\hline 1995 & Brereton, J. & The Origins of Composition & 14 & $(+) 9,(-) 3=12$ \\
\hline 1995 & Connors, $\mathrm{R}$. & "The New Abolitionism" & 7 & $(+) 11,(-) 0=11$ \\
\hline 1995 & Conway, $\mathrm{K}$. & "Woman Suffrage" & 4 & $(+) 5,(-) 0=5$ \\
\hline 1995 & Simmons, $\mathrm{S}$. & "Radcliffe Responses" & 0 & $(+) 3, \quad(-) 0=3$ \\
\hline 1996 & Berlin, J. & Rhetorics, Poetics... & 38 & -- \\
\hline
\end{tabular}




\begin{tabular}{|c|c|c|c|c|}
\hline $\begin{array}{c}\text { PUB } \\
\text { DATE }\end{array}$ & AUTHOR & $\begin{array}{l}\text { TITLE } \\
\text { (Short) }\end{array}$ & AHCI & $\begin{array}{c}\text { Times Cited } \\
\text { in Histories } \\
(+),(-)=(\text { total })\end{array}$ \\
\hline 1996 & Fitzgerald, $\mathrm{K}$. & "From Disciplining" & $J A C$ & -- \\
\hline 1996 & Lerner, $\mathrm{N}$. & "The Institutionalization" & $\begin{array}{c}\text { Comp } \\
\text { Studies } \\
\end{array}$ & --- \\
\hline 1996 & Varnum, R. & Fencing with Words & 12 & $(+) 2,(-) 1=3$ \\
\hline 1996 & Salvatori, M. & Pedagogy & 9 & $(+) 4,(-) 0=4$ \\
\hline 1997 & Connors, $\mathrm{R}$. & Composition-Rhetoric & 54 & $(+) 12,(-) 14=26$ \\
\hline 1997 & Gere, A. & Intimate Practices & 56 & $(+) 4,(-) 0=4$ \\
\hline 1997 & Harris, J. & A Teaching Subject & 47 & $(+) 1,(-) 0=1$ \\
\hline 1997 & Miller, T. & The Formation of College & 37 & --- \\
\hline 1998 & Crowley, S. & Composition ... University & 54 & $(+) 7,(-) 5=12$ \\
\hline 1998 & Zaluda, S. & "Lost Voices ... Harlem" & 1 & --- \\
\hline 1999 & $\begin{array}{l}\text { George, D. \& } \\
\text { Trimbur, J. }\end{array}$ & "“Communication Battle"” & 3 & --- \\
\hline 1999 & Greer, J. & "No Smiling Madonna" & 4 & $(+) 1,(-) 0=1$ \\
\hline 1999 & Hawhee, D. & "Composition History" & 6 & -- \\
\hline 1999 & Heyda, J. & "Fighting over Freshman" & 0 & $(+) 1, \quad(-) 0=1$ \\
\hline 1999 & Matsuda, $P$. & "Composition Studies" & 14 & -- \\
\hline 1999 & Paine, $\mathrm{C}$. & The Resistant Writer & 9 & $(+) 1,(-) 0=1$ \\
\hline 1999 & $\begin{array}{l}\text { Roemer, M. } \\
\text { (et al.) }\end{array}$ & "Reframing the Great" & 1 & --- \\
\hline 1999 & $\begin{array}{l}\text { Royster, J. \& } \\
\text { Williams, J. }\end{array}$ & "History in the Spaces Left" & 9 & $(+) 2,(-) 0=1$ \\
\hline 1999 & Schultz, L. & The Young Composers & 9 & $(+) 6,(-) 0=6$ \\
\hline 2000 & Goggin, $\mathrm{M}$. & Authoring a Discipline & 10 & --- \\
\hline 2000 & $\begin{array}{l}\text { Goggin, M. \& } \\
\text { Beatty, S. }\end{array}$ & "Accounting for Well-“ & 0 & -- \\
\hline
\end{tabular}




\begin{tabular}{|c|c|c|c|c|}
\hline $\begin{array}{c}\text { PUB } \\
\text { DATE }\end{array}$ & AUTHOR & $\begin{array}{l}\text { TITLE } \\
\text { (Short) }\end{array}$ & AHCI & $\begin{array}{c}\text { Times Cited } \\
\text { in Histories } \\
(+),(-)=(\text { total) }\end{array}$ \\
\hline 2001 & Adams, $\mathrm{K}$. & A Group of Their Own & 2 & -- \\
\hline 2001 & Fitzgerald, $\mathrm{K}$. & "A Rediscovered Tradition" & 3 & $(+) 4,(-) 1=5$ \\
\hline 2001 & Kates, S. & Activist Rhetorics & 18 & $(+) 6,(-) 0=6$ \\
\hline 2001 & Strickland, D. & "Taking Dictation" & 4 & --- \\
\hline $\begin{array}{l}2001 \\
(1991)\end{array}$ & $\begin{array}{l}\text { Wright, E. \& } \\
\text { Halloran, S. }\end{array}$ & $\begin{array}{l}\text { "From Rhetoric to Comp." } \\
\text { [see } 1991 \text { - Halloran, S.] }\end{array}$ & $\begin{array}{c}\text { [see } \\
\text { above] }\end{array}$ & -- \\
\hline 2002 & $\begin{array}{l}\text { Horner, B. \& } \\
\text { Trimbur, J. }\end{array}$ & "English Only and U.S." & 20 & --- \\
\hline $\begin{array}{l}2002 \\
(1991) \\
\end{array}$ & Russell, D. & $\begin{array}{l}\text { Writing in the Academic } \\
\text { [see } 1991 \text { - Russell, D.] }\end{array}$ & $\begin{array}{c}{[\text { see }} \\
\text { above] }\end{array}$ & -- \\
\hline 2002 & Harkin, $\mathrm{P}$. & "Child's Ballads" & 0 & -- \\
\hline 2003 & Rothermel, B. & "A Sphere of Noble Action" & 2 & $(+) 1, \quad(-) 0=1$ \\
\hline 2003 & Matsuda, $P$. & "Process and Post-Process" & 6 & --- \\
\hline 2004 & Hollis, $\mathrm{K}$. & Liberating Voices & 8 & $(+) 3,(-) 0=3$ \\
\hline 2004 & Marshall, M. & Response to Reform & 0 & --- \\
\hline 2005 & Carr, J. (et al.) & Archives of Instruction & 8 & $(+) 1,(-) 1=1$ \\
\hline 2005 & Rice, J. & "The 1963 Composition" & $\begin{array}{l}\text { Comp } \\
\text { Studies }\end{array}$ & --- \\
\hline 2006 & Coffey, D. & "A Discipline's Comp." & 0 & --- \\
\hline 2006 & Fosen, $\mathrm{C}$. & "University Courses, Not" & $\begin{array}{l}\text { Comp } \\
\text { Studies }\end{array}$ & --- \\
\hline 2006 & Mailloux, $\mathrm{S}$. & Disciplinary Identities & 11 & -- \\
\hline 2006 & Trimbur, J. & "Linguistic Memory" & 3 & -- \\
\hline 2007 & DeGenaro, W. & "William Rainey Harper" & 0 & --- \\
\hline 2007 & $\begin{array}{l}\text { Donahue, P. \& } \\
\text { Falbo, B. }\end{array}$ & "(The Teaching of )" & 0 & --- \\
\hline 2007 & $\begin{array}{l}\text { Donahue, P. \& } \\
\text { Moon, G. }\end{array}$ & Local Histories (ed. coll.) & 6 & --- \\
\hline
\end{tabular}




\begin{tabular}{|l|l|l|c|c|}
\hline \multicolumn{1}{|c|}{$\begin{array}{c}\text { PUB } \\
\text { DATE }\end{array}$} & \multicolumn{1}{|c|}{ AUTHOR } & \multicolumn{1}{c|}{$\begin{array}{c}\text { TITLE } \\
\text { (Short) }\end{array}$} & AHCI & $\begin{array}{c}\text { Times Cited } \\
\text { in Histories } \\
(+),(-)=(\text { total })\end{array}$ \\
\hline 2007 & Donahue, P. & "Disciplinary Histories" & 0 & $(+) 1,(-) 0=1$ \\
\hline 2007 & Garbus, J. & "Vida Scudder" & 1 & --- \\
\hline 2007 & Hawk, B. & A Counter-History & 4 & --- \\
\hline 2007 & $\begin{array}{l}\text { Lindblom, K. } \\
\text { (et al.) }\end{array}$ & "Mid-Nineteenth-Century" & 1 & --- \\
\hline 2007 & Rothermel, B. & "Our Life's Work" & 0 & --- \\
\hline 2007 & Weidner, H. & "A Chair 'Perpetually..."” & 1 & --- \\
\hline 2007 & Welsch, K. & "Thinking Like That" & 0 & --- \\
\hline 2008 & Baca, D. & Mestiz@ Scripts, Digital & 2 & --- \\
\hline 2008 & Enoch, J. & Refiguring Rhetorical Ed. & 8 & --- \\
\hline 2008 & Gold, D. & Rhetoric at the Margins & 4 & $(+) 3,(-) 0$ \\
\hline 2008 & Trimbur, J. & "The Dartmouth Conf." & 2 & --- \\
\hline 2009 & Gold, D. & “"Eve Did No Wrong"” & -- & --- \\
\hline 2009 & Jarratt, S. & "Classics and Counter..." & -- & --- \\
\hline 2010 & Mastrangelo, L. & "Lone Wolf or Leader..." & -- & --- \\
\hline 2010 & Miller, T. & The Evolution of College & -- & --- \\
\hline 2010 & Peary, A. & "The Licensing ... Poetic" & -- & --- \\
\hline
\end{tabular}




\section{CURRICULUM VITAE}

\section{Lisa R. Arnold}

Department of English

University of Louisville

Louisville, Kentucky

\section{Education:}

Ph.D., Rhetoric and Composition, May 2011

University of Louisville

Dissertation: Historiography, Disciplinarity, and the Future(s) of Composition

Committee: Karen Kopelson (chair), Bruce Horner, Carol Mattingly, Susan Ryan, John Schilb

M.F.A., Creative Writing, Nonfiction, May 2005

George Mason University

Thesis: My Father's Bible: One Daughter's Journey out of Christian Fundamentalism

Director: Alan Cheuse

B.A., English, May 2001

Saint Louis University

Minor in Communications, Certificates in Women's Studies and Creative and

Professional Writing

\section{Publications:}

"(Re)Working 'Writing' and the History of Composition." Response Essay. JAC 29.1-2 (2009): 259-65.

"Forum on the Profession." With Laura Brady, Maggie Christensen, Joanne Giordano, Holly Hassel, Ed Nagelhout, Nathalie Singh-Corcoran, and Julie Staggers. Special Issue on Contingent Faculty. College English 73.4 (2011): 409-427.

\section{Conference Presentations:}

"Historiography and the 'Work' of Rhetoric and Composition," Thomas R. Watson Conference: Working English in Rhetoric and Composition, Louisville, KY: October 14, 2010. 
"Questions of/about 'Belonging': Teaching, Tradition(s), and Histories of Rhetoric(s)," Rhetoric Society of America Conference, Minneapolis, MN: May 23, 2010.

"Uneducated, Disconnected, and 'Disposable': Complicating Composition's Portrayal of Its Practitioners," Conference on College Composition and Communication, Louisville, KY: March 20, 2010.

"An 'Ethics of Difficulty': (Re)Reading Judith Butler's Performative Prose as Feminist Practice," The Louisville Conference on Literature and Culture since 1900, Louisville, KY: February 20, 2010.

"Rhetoric or Reality? Toward Meta-Historical Critical Practice," Feminism(s) and Rhetoric(s) Conference, Michigan State University: October 9, 2009.

"Troubling the Discipline(s): Gender Trouble's 'Complex Historicity' and Feminist Theory," Reception Studies Society Conference on Reception Study, Purdue University: September 12, 2009.

"(Re)Designing (Our) Selves and Sequences: New Perspectives on First-Year Composition Course Development," with Laura Detmering, Vanessa Kraemer, Brice Nordquist, and Kenny Smith, College English Association Conference, Pittsburgh, PA: March 28, 2009.

"Disruptive and Disturbing: Rhetoric(s) of Decentering in Postcolonial Scholarship," Rhetoric Panel, South Central Modern Language Association Conference, San Antonio, TX: November 7, 2008.

"Reprogramming Dialogue: Freirian Collaboration in the $21^{\text {st }}$ Century," Thomas R. Watson Conference: The New Work of Composing, Louisville, KY: October 18, 2008.

"What It Be Like? A Rhetorical Analysis of Delpit and Smitherman in The Real Ebonics Debate," The Kentucky Philological Association Conference, Louisville, KY: March 7, 2008.

"Service Optional: An Adjunct's Guide to Increasing Civic Engagement within the Academy," Conference on College Composition and Communication, New York, NY: March 24, 2007.

\section{Teaching:}

College Writing Skills (basic writing): Fontbonne University

College Composition I (or equivalent): University of Louisville, Fontbonne University

St. Louis Community College-Meramec

College Composition II (or equivalent): University of Louisville, Fontbonne University,

St. Louis Community College-Meramec

Advanced (Honors) Composition: University of Louisville 
Introduction to Literature: Fontbonne University

Introduction to Creative Writing: University of Louisville, St. Louis Community CollegeMeramec

Writing about Literature: University of Louisville

Women in Literature: University of Louisville

\section{Awards, Grants, Honors:}

University Fellowship

University of Louisville: Fall 2007 - Spring 2011

Barbara Plattus Award for Excellence in Graduate Student Teaching

University of Louisville Composition Program: April 2010

Dr. M. Celeste Nichols Professional Development Award ( $\$ 100)$

Professionalization Grant, University of Louisville Women's Center: November 2009

CCCC Professional Equity Project Grant (\$500): March 2006

Thesis Completion Fellowship (Prose)

George Mason University: $2004-2005$

Outstanding Nonfiction Graduate Student of the Year Award

George Mason University: $2004-2005$

\section{Professional Activities:}

Rhetoric Society of America Graduate Student Steering Committee, Fall 2008 - 2011

Guest Lecturer on Historiography for Carol Mattingly's History of Rhetoric II (English 672) class, University of Louisville: August 31, 2010

Guest Lecturer on Judith Butler for Karen Hadley's Literary Theory (English 691) class, University of Louisville: March 11, 2010

Pedagogy Workshop Presentation (with Vanessa Kraemer) on the role of reading in the composition classroom, Composition Program, University of Louisville: February 17, 2010

Participant, History Matters workshop (with Richard Graff and Debra Hawhee), Rhetoric Society of America Summer Institute, Pennsylvania State University: June 26-28, 2009

Work-in-Progress Presenter: What Happens When the Music Stops? Silence and Resistance in Critical Pedagogy, Research Network Forum, Conference on College Composition and Communication, New Orleans, LA: April 1, 2008 


\section{Professional Affiliations:}

National Council of Teachers of Education

Conference on College Composition and Communication

Rhetoric Society of America

The Coalition of Women Scholars in the History of Rhetoric and Composition 